\title{
Estudos estruturais de cristais líquidos liotrópicos por métodos de espalhamento
}

\author{
Arnaldo Gomes de Oliveira Filho
}

Orientador: Prof. Dr. Cristiano Luis Pinto de Oliveira

Tese de doutorado apresentada ao Instituto de Física como requisito parcial para a obtenção do título de Doutor em Ciências

Banca examinadora:

Prof. Dr. Cristiano Luis Pinto de Oliveira (IFUSP)

Prof. Dr. André de Pinho Vieira (IFUSP)

Prof. Dr. Luiz Tadeu Fernandes Eleno (EEL-USP)

Prof. Dr. Emerson Rodrigo da Silva (UNIFESP)

Prof. Dr. Ítalo Marcos Nunes de Oliveira (UFAL) 
FICHA CATALOGRÁFICA

Preparada pelo Serviço de Biblioteca e Informação do Instituto de Física da Universidade de São Paulo

Oliveira Filho, Arnaldo Gomes de

Estudos estruturais de cristais líquidos liotrópicos por métodos de espalhamento. São Paulo, 2021.

Tese (Doutorado) - Universidade de São Paulo, Instituto de Física, Depto. de Física Experimental

Orientador: Prof. Dr. Cristiano Luís Pinto de Oliveira

Área de Concentração: Física

Unitermos: 1. Espalhamento de raios $X$ a baixos ângulos; 2. Modelos matemáticos; 3. Simulação; 4. Cristais líquidos; 5 . Mudança de fase.

USP/IF/SBI-028/2021 


\title{
Structure studies of lyotropic liquid crystals by scattering methods
}

\author{
Arnaldo Gomes de Oliveira Filho
}

Supervisor: Prof. Dr. Cristiano Luis Pinto de Oliveira

\begin{abstract}
Thesis submitted to the Physics Institute of the University of São Paulo in partial fulfillment of the requirements for the degree of Doctor of Science.
\end{abstract}

Examination board:

Prof. Dr. Cristiano Luis Pinto de Oliveira (IFUSP)

Prof. Dr. André de Pinho Vieira (IFUSP)

Prof. Dr. Luiz Tadeu Fernandes Eleno (EEL-USP)

Prof. Dr. Emerson Rodrigo da Silva (UNIFESP)

Prof. Dr. Ítalo Marcos Nunes de Oliveira (UFAL) 



\section{Agradecimentos}

São muitos os professores, amigos e colegas que de algum modo me acompanharam nesta jornada, dando seu apoio e sugestões, mostrando compreensão e paciência. A todos devo efusivos agradecimentos, certamente insuficientes nas linhas que se seguem.

Agradeço primeiramente aos que me acolheram para a confecção deste trabalho.

Ao professor Dr. Cristiano Luis Pinto de Oliveira (IF-USP), que me propôs esta empreitada, acreditou que eu poderia conduzi-la e pacientemente me orientou.

Ao professor Dr. Antônio Martins Figueiredo Neto (IF-USP), que me orientou e acompanhou na primeira fase desta tese, explicando sempre com sua habitual clareza os tópicos de que tratamos.

Ao professor Dr. Marcus Bastos Lacerda Santos (IF-UnB), cujas sugestões e orientações nas técnicas de DLS foram imprescindíveis.

To professor Dr. Erol Akpinar (Bolu Abant Izzet Baysal University, Turkey), who helped us enormously in the production of the samples and was always a good friend.

Ao Dr. Odair Gimenez Martins, técnico do GFCx, sempre prestativo, e caro amigo. Agradeço pela inestimável ajuda com os trabalhos em Física e pelas inúmeras conversas sobre Política e Geopolítica.

Ao Msc. Dennys Reis, companheiro de trabalho e discussões contínuas da Física e outros assuntos, de Política a Ciências, um amigo, cuja e honestidade intelectual nos obriga a manter o prumo.

Ao caro Társis Mendes Germano, não só pelas diversos apoios nos trabalhos em laboratório, como pelas impagáveis sugestões de cervejas, música e leituras.

Aos colegas de trabalho em laboratório, Daniel Espinosa, Igino G.V. Martins e Fernando Batalioto, que sempre deram aquela "mãozinha" nos momentos difíceis e foram compreensivos com as demandas desta tese.

Às caras colegas Ellen Binotto e Juliana Peçanha, que sempre resolveram as pendências administrativas do GFCx de maneira prestativa e afável.

Aos colegas, agora doutores, André Sehnem e Eduardo Sell Gonçalves, pelas diversas colaborações ao longo deste tempo, e pelas inúmeras e divertidas discussões. Não menos, também aos ora doutores Maximilia F. S. Degenhardt e Pedro L. Oseliero Filho, pelas diversas contribuições que tivemos nesta jornada em comum.

Ao caro Dr. Roman Spirin, por todas as discussões e colaborações nos trabalhos com DLS 
e SLS, e pelo companheirismo.

Ao Dr. Wagner Wlysses R. Araújo, por todas as discussões sobre Física e todos os papos neste percurso.

Ao Dr. Celso L. S. Risi, que me ensinou os princípios da técnica de DLS e com quem tive boas discussões sobre a física de cristais líquidos.

Aos colegas de grupo, com quem tive boas colaborações e conversas neste período, Aline Perez, Dr. Eraldo Sales, Luiz Henrique Silva, Luciene O. Machado, Cibele Castro, Ana Paula Q. Mello e à Dra. Zahra Lotfollahi, sempre gentil, e cujo português tem melhorado paulatinamente.

Devo muito ainda à torcida de vários amigos para o êxito deste processo, mas ainda mais a quem me deu o apoio cotidiano e, mais do que isso, aguentou minhas variações de humor e meu cansaço.

Agradeço à minha companheira, Lívia Leite, que me apoiou e me ajudou como pôde durante este trabalho, e teve mais paciência do que eu poderia pedir.

Ao meu amigo-irmão João Luis M. Assirati, que me incentivou e ajudou nas discussões técnicas e de Física, e há muito tempo me faz ter perspectivas diferentes sobre qualquer assunto.

Ao amigo Márcio P. B. Eichler, in memoriam, cujo incentivo me permitiu voltar a um doutoramento, e com quem muito aprendi sobre amizade.

Agradeço muito à minha mãe, Juracy Oliveira, por todo seu apoio, paciência, e torcida à distância. E à minha família, também pela torcida.

Ao Daniel Garoux e à Gabriela Bitencourt, queridos amigos, fraternos, companheiros e grandes debatedores. E à cara Eliane Arakaki e ao caro Leando Pasini, apesar dos poucos encontros, mas sempre felizes.

À turma da CEP, Caroline Sampaio, Fábio Torres, Maira Fanton, Henrique Toledo, Fabrizia Gallan, Daniela Jakubasco, Rinaldo Arruda, Zezé Vilhora, Helena Salgado, Rodrigo Y Castro, Fernando Franco, Ângela, Ingrid Andrade, Ricardo Bertrand, Maurício Torres, Ulisses Assis, Alexandre Arcanjo, Lissandro Massa, José Arbex Jr. e, não menos, o caro Pedrão Garcia, pelos papos, e pela torcida por mim e pelo país.

Agradeço também aos vários amigos e colegas deram seu apoio e carinho durante este tempo, Elisabeth Camargo, Vanessa Neves, Alvimar Floriano, Paula Toledo, Rodrigo Fresneda, Glauce Pereira, Roberta Masiero, Roberto Baginski, Maria Amélia, Márcia Schonts, Frank Ferrer Sene, Glauce Pereira, Raquel Simões e Lilian Grisolio.

Agradeço à Capes, ao CNPq, à FAPESP e ao INCT-FCx pelo apoio por intermédio do Grupo de Fluidos Complexos do IF-USP.

E ao Instituto de Física da Universidade de São Paulo. 


\section{Resumo}

Efetuamos neste trabalho modelagens e simulações computacionais do processo de espalhamento de raios X por sistemas liotrópicos, levando à caracterização detalhada de dados experimentais de SAXS. As estruturas micelares formadas em misturas de moléculas anfifílicas em água, que apresentam fases líquido cristalinas liotrópicas nemáticas, foram usadas como modelo de teste dos métodos computacionais, sobretudo pelas questões ainda pendentes sobre as dimensões estruturais dessas micelas. A ordem orientacional de longo alcance dessas fases nemáticas (discótica, calamítica ou biaxial) é usualmente explicada por diferentes modelos micelares. Em alguns desses modelos, micelas elipsoidais oblatas e prolatas explicam as fases nemáticas, em contraposição a modelos que sugerem que as micelas são intrinsecamente biaxiais e apenas sua mudança de ordem orientacional média caracteriza a fase. Preparamos então diversas misturas liotrópicas (com diferentes moléculas anfifílicas como principal surfactante) e usamos técnicas de microscopia óptica de luz polarizada, conoscopia laser e espalhamento de raios $\mathrm{X}$ a baixos ângulos (SAXS) para identificar, caracterizar e estudar as estruturas de suas fases nemáticas. Efetuamos também um estudo dos modos das flutuações do diretor nemático de algumas dessas misturas por espalhamento de luz dinâmico. Como resultado, abordagens inéditas na literatura foram obtidas, permitindo a determinação das dimensões micelares e detalhes de sua organização, bem como a confiabilidade e a pertinência das abordagens utilizadas.

Palavras-chave: espalhamento de raios $\mathrm{X}$ a baixos ângulos; modelos matemáticos; simulação; cristais líquidos; mudança de fase 



\begin{abstract}
In this work, advanced computational modeling and simulations for the small-angle scattering process of lyotropic systems are proposed, allowing for the detailed characterization of experimental SAXS data. The micellar structures formed by amphiphilic molecules in water, which present nematic lyotropic liquid crystalline phases, were used as a toy model for the computational methods, especially for the remaining questions about structural dimensions of these micelles. The long-range orientational order of nematic phases (discotic, calamitic or biaxial) is usually explained by different micellar models. In some of these models, oblate and prolate ellipsoidal micelles define the nematic phases, whereas other models suggest that micelles are intrinsically biaxial, hence only a change in their average orientational order would characterize the phase. We prepared a few lyotropic mixtures (with different amphiphilic molecules as the main surfactant) and used polarized light optical microscopy, laser conoscopy and small-angle X-ray scattering (SAXS) to identify, characterize and survey the structure of their nematic phases. We also studied the fluctuation modes of the nematic director of some of those mixtures by dynamic light scattering. As a result, new methodologies are proposed, enabling for the determination of micellar dimensions, details on its supramolecular organization as well as the reliability of the proposed models.
\end{abstract}

Keywords: small angle X-ray scattering; mathematical models; simulation; liquid crystals; phase transition 



\section{Sumário}

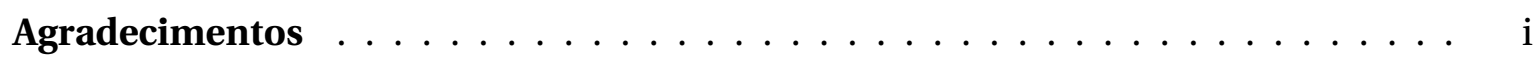

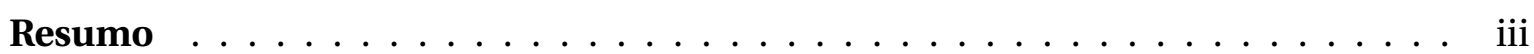

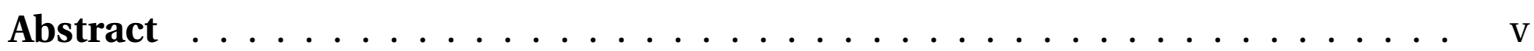

1 Introdução 1

2 Estudos das estruturas micelares por espalhamento de raios $\mathrm{X}$ a baixo ângulo 9

2.1 A experiência de espalhamento de raios $\mathrm{X} \ldots \ldots \ldots \ldots$

2.1.1 Intensidade da onda de raios X espalhada $\ldots \ldots \ldots \ldots$. . . . . . . 11

2.2 Obtenção de curvas a partir dos dados experimentais . . . . . . . . . . . . 14

2.3 Modelo para os perfis de espalhamento . . . . . . . . . . . . . 16

2.3.1 Implementação do programa de ajuste . . . . . . . . . . . . . 20

2.4 Parâmetro de ordem . . . . . . . . . . . . . . . . . . . . 22

2.4.1 Cálculo do parâmetro de ordem . . . . . . . . . . . . . . . 24

2.5 Simulação de SAXS por estruturas micelares . . . . . . . . . . . . . . . 26

2.5.1 Programas da simulação de espalhamento . . . . . . . . . . . . 27

2.5.1.1 Criação dos elipsoides coarse grained . . . . . . . . . . . . 28

2.5.1.2 Simulação de SAXS pelas estruturas criadas . . . . . . . . . . 29

2.5.1.3 O modelo core-shell . . . . . . . . . . . . . . . 30

3 Técnicas e procedimentos experimentais 33

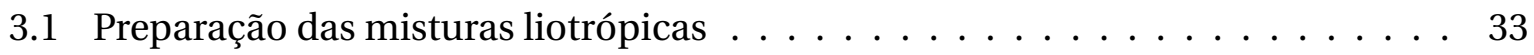

3.2 Microscopia óptica de luz polarizada $\ldots \ldots \ldots \ldots \ldots \ldots \ldots$

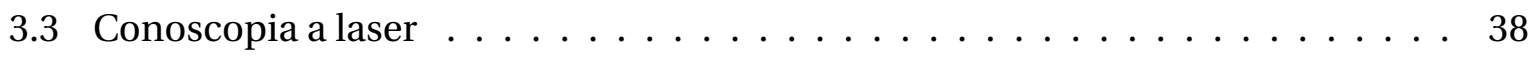

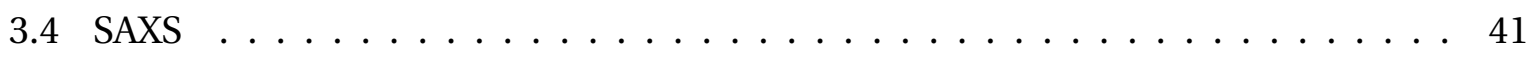

3.5 Espalhamento de luz dinâmico (DLS) . . . . . . . . . . . . . . . . 47

3.5.1 A técnica de espalhamento de luz dinâmico (DLS) . . . . . . . . . . . 47

3.5.2 Flutuações do diretor nemático . . . . . . . . . . . . . . . . . 49

3.5.2.1 A função de autocorrelação . . . . . . . . . . . . . . . . 52

3.5.3 Análise de resultados . . . . . . . . . . . . . . . . . . . . . 54

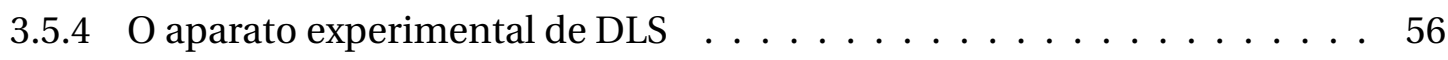


4 Resultados $\quad 59$

4.1 Modelagem de SAXS . . . . . . . . . . . . . . . . . . 59

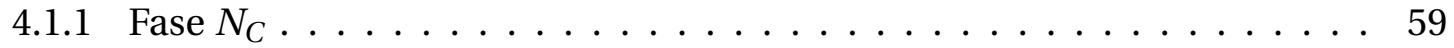

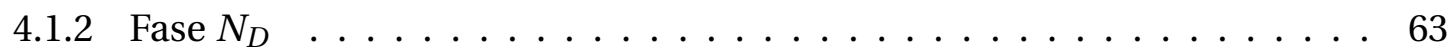

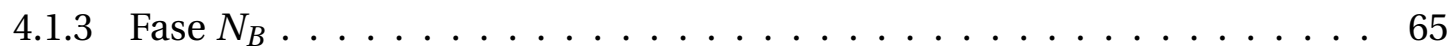

4.1.4 Parâmetros de ordem ． . . . . . . . . . . . . . . . . . 67

4.2 Simulações de SAXS por estruturas de tipo micelar . . . . . . . . . . . . . 69

4.2 .1 Estrutura cristalina e esfera . . . . . . . . . . . . . . . . . 70

4.2 .2 Micelas $2 \times 1 \times 2 \ldots \ldots \ldots \ldots \ldots \ldots$

4.2 .3 Micelas $4 \times 1 \times 4 \ldots \ldots \ldots \ldots \ldots \ldots \ldots \ldots$

4.2 .4 Micelas $4 \times 4 \times 4 \ldots \ldots \ldots \ldots \ldots \ldots \ldots$

$4.2 .4 .1 \quad$ Rede cúbica . . . . . . . . . . . . . . . . . 76

4.2.4.2 Rede cúbica com dispersões gaussianas . . . . . . . . . . . 78

4.2.5 Rede cúbica, $20 \times 1 \times 20$, com e sem dispersões _ . . . . . . . . . . . 82

4.2.6 Dispersões rotacionais de aglomerados verticais . . . . . . . . . . 85

4.3 Análise das fases de uma mistura liotrópica . . . . . . . . . . . . . . . . . 88

4.4 Medidas de $D L S \ldots \ldots \ldots \ldots \ldots \ldots$. . . . . . . . . . . . . . . . 95

5 Conclusões $\quad 99$

A Resultados experimentais complementares $\quad 101$

A.1 Medidas de SAXS . . . . . . . . . . . . . . . . . . . . . . 101

A.1.1 Micelas $20 \times 1 \times 1 \ldots \ldots \ldots \ldots 1 \ldots \ldots \ldots \ldots$

A.1.2 Rede cúbica . . . . . . . . . . . . . . . . . . . . . . 103

A.1.3 Rede cúbica de corpo centrado . . . . . . . . . . . . . . . . . . 106

A.1.4 Rede cúbica de corpo centrado com dispersões gaussianas . . . . . . . 111

A.1.5 Rede cúbica de corpo centrado com dispersões gaussianas . . . . . . . . 112

A.1.6 Camadas rotacionadas em torno do eixo $y$. . . . . . . . . . . . . . . . . 117

A.1.7 Camadas rotacionadas em torno do eixo $y$, com dispersões . . . . . . 122

$\begin{array}{ll}\text { Referências Bibliográficas } & 127\end{array}$ 


\section{Capítulo 1}

\section{Introdução}

Neste trabalho, abordamos o problema da determinação da disposição e das dimensões típicas de estruturas micelares em cristais líquidos liotrópicos em fases nemáticas [1, 2, 3] a partir de modelagem e simulação de espalhamento de raios X a baixos ângulos (SAXS, do inglês Small Angle X-ray Scattering) por essas estruturas. A técnica de SAXS é utilizada normalmente para a caracterização de sistemas de partículas da ordem de dez a algumas centenas de nanômetros e apresenta a vantagem de permitir a observação de sistemas em solução, sem alteração de sua composição ou condição física [4]. Em contrapartida, é uma técnica de baixa resolução e seus resultados representam médias orientacionais dos constituintes da amostra. Com o aperfeiçoamento das técnicas de análise e simulação de espalhamento de raios $\mathrm{X}$ e, correspondentemente, com o aumento do poder computacional, tornou-se possível passar a uma avaliação mais robusta dos padrões de espalhamento produzidos por esse método experimental [5, 6, 7]. As técnicas aqui desenvolvidas são relativamente gerais, podendo ser aplicadas a sistemas orientados similares ao sistema líquido cristalino que no serviu de base. Façamos então uma descrição desse sistema.

Estamos acostumados a certos estados da matéria condensada, como o sólido e o líquido, assim como às transições entre esses estados. Em particular, sólidos cristalinos se caracterizam pela organização espacial de longo alcance de suas unidades constituintes, ao passo que as que formam um líquido não possuem qualquer organização espacial de longo alcance, o que o caracteriza como isotrópico. Há substâncias que, no entanto, apresentam fases com ordem intermediária entre a sólida e a líquida, chamadas mesofases ou cristais líquidos [2, 8]. Essa classe de materiais é estudada no âmbito da Física da matéria mole (Soft Matter Physics), que lida uma ampla gama de materiais, tão comuns como géis, colas, esponjas, tintas, emulsões, polímeros etc., que apresentam comportamentos diversos dos estudados como sólidos ou líquidos [9].

Os cristais líquidos (CL) são classificados em dois tipos segundo a variável que induz sua transição de fase, definida pela organização de suas estruturas moleculares. São ditos termotrópicos quando suas transições de fase ocorrem em função essencialmente da temperatura 
e da pressão; suas unidades constituintes são moléculas. São chamados liotrópicos quando a concentração de seus componentes controla a fase, embora sejam também sensíveis a variações de temperatura. O presente trabalho tem foco em cristais líquidos liotrópicos e as descrições a seguir referem-se a essa classe [2]. No entanto, diversas abordagens teóricas e metodológicas são aplicáveis a ambas as classes, uma vez que descrevem a estrutura e organização de seus constituintes.

Moléculas surfactantes como o laurato de potássio (KL: $\mathrm{C}_{12} \mathrm{H}_{23} \mathrm{KO}_{2}$ ) têm uma "cabeça" polar, hidrofílica, e uma "cauda" apolar, hidrofóbica, sendo assim chamadas de "anfifílicas”. Em baixa concentração em um solvente (por exemplo, em água), essas moléculas tendem a migrar para as bordas e para a superfície do recipiente, com a parte hidrofóbica para fora. A partir de uma concentração molecular crítica (CMC) das moléculas anfifílicas [10, 11, 12], num solvente como água, por exemplo, ocorre sua associação, por autoorganização, formando-se agregados complexos, como estruturas lamelares, cilíndricas, hexagonais, micelares e outras [2]. Na figura 1.1, são dados como exemplos representações de uma estrutura micelar (a), e lamelar (b), ambas em corte. Em particular, no presente trabalho, estamos interessados na formação de estruturas micelares. Dependendo da geometria, da concentração e das interações das moléculas anfifílicas, pode-se ter a formação de micelas esferoides ou com formas anisotrópicas.

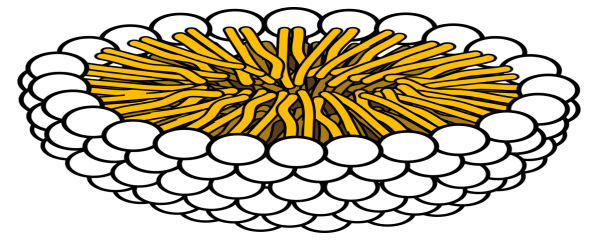

(a)

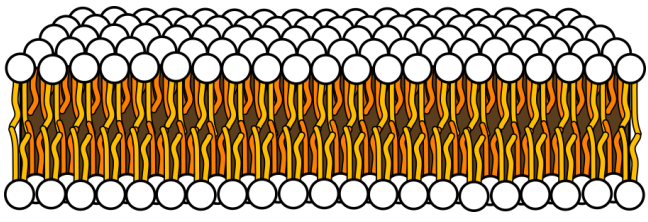

(b)

Figura 1.1. Representação de agregados formados a partir de moléculas anfifílicas. (a) Recorte de uma estrutura micelar. A dimensão típica da micela (diâmetro médio, $\phi$ ) é da ordem de $\phi \lesssim$ $10 \mathrm{~nm}$. (b) Recorte de uma estrutura lamelar. A aproximação da parte hidrofílica das moléculas reduz ou mesmo impede a presença do solvente na região interior do agregado. Não obstante, as ligações não são suficientemente rígidas para impedir a mobilidade das moléculas. (Figuras adaptadas das originais de Mariana Ruiz Villarreal (2007), distribuída por Wikimedia Commons.)

A figura 1.2 mostra a representação de um modelo micelar ideal em formato elipsoidal com dois tipos de simetria, prolata (1.2b) e oblata (1.2a, em formato de disco) . Estes possíveis formatos, em que há assimetria em apenas um dos eixos do elipsoide, foi proposto $[13,14]$ considerando que, se um campo magnético $\mathbf{H}$ é aplicado à mistura liotrópica, o eixo maior das cadeias parafínicas (não perfluorinadas) de moléculas anfifílicas tendem a se alinhar perpendicularmente a $\mathbf{H}$. 
(a)

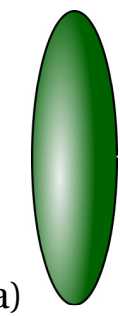

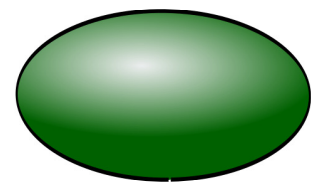

(b)

Figura 1.2. Representação geométrica de micelas em formato elipsoide de tipo cilíndrico (a) e de tipo discótico (b).

É importante ressaltar que micelas não são rígidas e há algum trânsito das moléculas nas micelas - o "tempo de residência" típico das moléculas no agregado micelar é da ordem de $10^{-4} \mathrm{~s}$ [11]. Os modelos micelares, incluindo os elipsoidais, são aproximações de um formato médio esperado. Nas palavras de Wojtowicz ${ }^{1}$ (em tradução livre), Micelas não são entidades compostas de números fixos de moléculas, tendo uma forma geométrica fixa. Elas devem ser consideradas como de natureza estatística, em equilíbrio com as moléculas anfifílicas ao redor, e flutuando constantemente em tamanho e forma em resposta à temperatura.

Em liotrópicos, na fase micelar, as micelas interagem para a formação de ordens orientacionais de longo alcance em alguma direção (embora possa haver ordem de curto alcance em outras direções). Essa organização também pode ser classificada segundo o grau de simetria da disposição das micelas: se há quiralidade (ordem colestérica); e se não há ordem posicional, porém orientacional de longo alcance (ordem nemática), como mostrado na figura 1.3; ou o caso isotrópico, em que não há qualquer ordem. Define-se o diretor nemático,

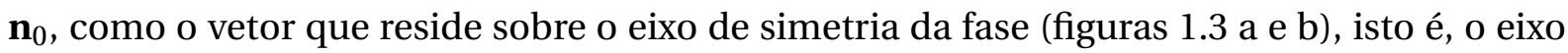
que indica a orientação média das micelas. A medida do grau de ordem de um sistema é dada pelo parâmetro de ordem, com o que se podem descrever também as transições de fase do sistema (seção 2.4).

Há três fases nemáticas de cristais líquidos liotrópicos identificadas, duas de caráter uniaxial e uma biaxial, segundo suas propriedades ópticas, magnéticas, estruturais e hidrodinâmicas [2], denominadas nemática discótica, nemática calamítica e nemática biaxial. O caso nemático terá especial relevância no presente trabalho, tanto na investigação das possíveis coexistências de fases, na medida de flutuações do diretor nemático, quanto nos estudos de padrões de espalhamento de raios X a baixo ângulo (SAXS). Para uma dada estequiometria de uma mistura liotrópica, as diferentes fases nemáticas mudam em função da temperatura. Estudos baseados em ressonância magnética nuclear (RMN) propunham que as duas fases nemáticas então observadas estivessem relacionadas a dois formatos micelares [14] -

\footnotetext{
${ }^{1}$ In [8], cap. 18.
} 


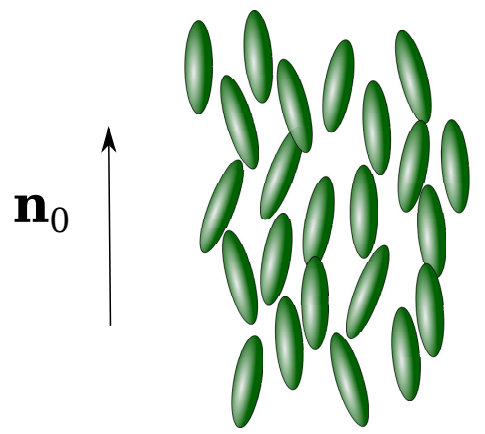

(a)

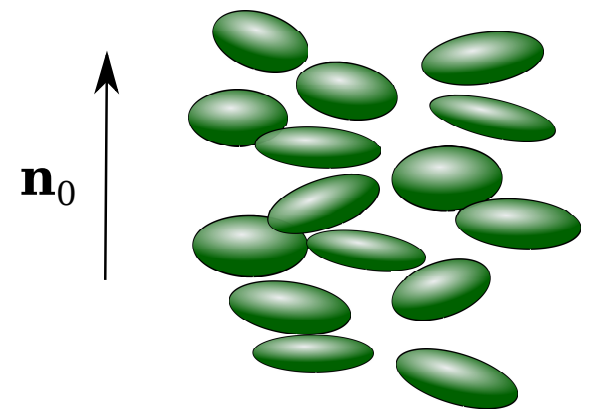

(b)

Figura 1.3. Representação esquemática das ordens nemáticas, em acordo com o modelos de micelas uniaxiais. A figura (a) representa a fase calamítica $\left(N_{C}\right)$ e a figura (b) representa a fase discótica $\left(N_{D}\right)$. O diretor nemático $\mathbf{n}_{0}$ está representado em cada caso.

aproximadamente elipsoidais oblongos ou oblatos, então chamadas liomesofase de tipo I e de tipo II, respectivamente [15]. Atualmente, a fase de tipo I é chamada nemática calamítica (figura 1.2a) e denotada $N_{C}$; a fase de tipo II é então chamada nemática discótica (figura 1.2b) e denotada por $N_{D}$. Com a verificação de que, com a adição de um surfactante extra, há uma fase biaxial $\left(N_{B}\right)$ [16], emergiu a pergunta de quais seriam as estruturas micelares nessa fase - se uma coexistência das anteriores ou de uma nova.

As fases $N_{C}$ e $N_{D}$ possuem simetria uniaxial, para o que um único diretor, $\mathbf{n}_{0}$, basta para caracterizar seu alinhamento. Misturas com anfifílicos de cadeias carbônicas não perfluoradas tendem a se alinhar conforme a aplicação de um campo magnético externo [2, 17]. Na fase $N_{C}$, a anisotropia de susceptibilidade magnética, $\chi^{A}$, é positiva, o que faz que $\mathbf{n}_{0}$ se alinhe na direção do campo; na fase $N_{D}, \chi^{A}<0$, o que induz o alinhamento de $\mathbf{n}_{0}$ perpendicularmente ao campo magnético aplicado [17,2]. No caso de simetria biaxial, da fase $N_{B}$, os três eixos de simetria ortogonais levam à definição de três diretores, $\mathbf{l}, \mathbf{m}$ e n; havendo três índices de refração diferentes, há duas birrefringências não-nulas, mensuráveis. A fase $N_{B}$ pode ser observada entre as fases $N_{C}$ e $N_{D}$, em função da temperatura, para uma mesma mistura. Ocorrem assim as transições de fase $N_{D}-N_{B}-N_{C}$ e $N_{C}-N_{B}-N_{D}$ em função da temperatura crescente, sendo todas reversíveis e de segunda ordem $[18,19,20]$.

O comprimento de correlação medido por técnica de espalhamento dinâmico de luz [21] é suficientemente grande (da ordem de dois diâmetros micelares) para que não se esperem modificações drásticas nas formas das micelas [18]. Figueiredo Neto et al. [1], baseado em análise das imagens dos padrões de espalhamento de raios $\mathrm{X}$ a baixo ângulo por liotrópicos nemáticos, elaborou um modelo de micelas intrinsecamente biaxiais. Foram calculados os comprimentos de correlação em função da largura a meia altura dos picos (máximos de intensidade) observados nas direções vertical e horizontal de medidas de SAXS. As posições dos picos horizontais mudam suavemente em função da temperatura, do que se inferiu que as variações das dimensões micelares são pequenas. Tais mudanças são no entanto consis- 
tentes com mudanças orientacionais nas transições das fases nemáticas [3]. Isso sugere que as micelas têm um formato intrinsecamente biaxial (Intrinsically Biaxial Micelles, IBM) e que as fases são dadas em função das orientações dessas micelas. Consideremos, por aproximação, que uma micela pode ser representada por elipsoide biaxial. Na fase $N_{D}$, as rotações dos elipsoides em torno do menor de seus eixos maiores promove um comportamento médio similar ao de um disco figura 1.4(a), enquanto que na fase $N_{C}$, as rotações das micelas em torno do maior de seus eixos maiores dão a elas em média o aspecto similar ao de um cilindro 1.4(c). Na fase biaxial, $N_{B}$, os elipsoides teriam orientações dos eixos maiores relativamente fixos em média em relação aos diretores nemáticos da fase, sem rotações.

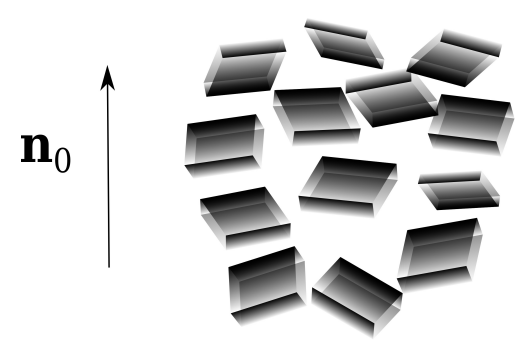

(a) $N_{D}$

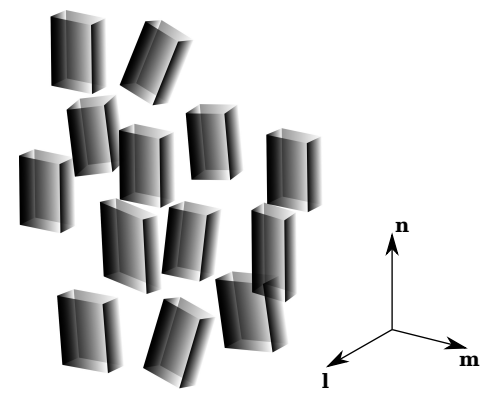

(b) $N_{B}$

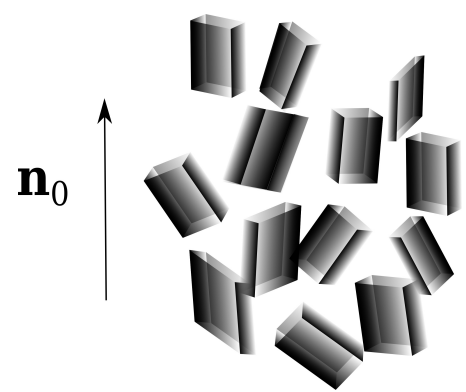

(c) $N_{C}$

Figura 1.4. Ordem nemática de cristal líquido, fases (a) $N_{D}$, (b) $N_{B}$ e (c) $N_{C}$, de acordo com o modelo

IBM, e respectivos vetores diretores nemáticos. O caso $N_{B}$ apresenta três diretores nemáticos

$(\mathbf{l}, \mathbf{m}, \mathbf{n})$, enquanto os casos uniaxiais, $N_{C}$ e $N_{D}$, possuem apenas o diretor $\mathbf{n}_{0}$. As micelas têm aqui uma representação de paralelepípedo (brick-like) apenas como ilustração do modelo.

O comportamento termodinâmico do sistema micelar descrito pelo modelo IBM está de acordo com as previsões teóricas das transições de fase, que são de segunda ordem, por argumentos de simetria [22, 23]. Modelos mais genéricos de Mecânica Estatística com micelas discóticas e cilíndricas, em que não se limita a teoria de Landau por simetria [24], conseguem reproduzir satisfatoriamente alguns diagramas de fase (ainda que não se tenha observado coexistência de fases nemáticas, não se descarta em definitivo a coexistência de tipos micelares distintos na fase biaxial) [25, 26, 27].

Para o estudo dessas estruturas a partir das técnicas de espalhamento de raios $\mathrm{X}$ a baixo ângulo, desenvolvemos um modelo que se ajusta às curvas experimentais levando em consideração a ordem pseudolamelar das estruturas micelares e outros efeitos. Enquanto em trabalhos anteriores [1,3] efetuavam-se apenas a análise da posição e da largura dos picos, o presente modelo explica a forma dos picos de espalhamento a baixo ângulo pelos fatores de forma e estrutura dos arranjos micelares, de modo a se extrair parâmetros que descrevam as relações de curto e longo alcance nas diversas direções dos nemáticos em suas diferentes fases. 
Usamos também técnicas de simulação dos padrões de espalhamento para o caso dos liotrópicos nemáticos. Há relativamente pouco tempo, foram desenvolvidos algoritmos eficientes de simulação de padrões bidimensionais de espalhamento de raios X por partículas modeladas por "contas" esféricas (spherical beads) [28], ou seja, modelos de tipo coarsegraining. Em particular, essas técnicas foram ampliadas para sistemas ordenados [29]. Nós nos propusemos a criar um modelo geométrico coarse grained das estruturas micelares e efetuar simulações de SAXS, com o intuito de usar os dados quantitativos dos ajustes dos dados experimentais como parâmetros de construção desse modelo. Desenvolvemos, assim, uma série de programas de computador que definem as estruturas das micelas e, ainda, de aglomerados de micelas, e usamos os algoritmos de simulação de SAXS para recriar padrões de imagens de espalhamento (seção 2.5).

Estudamos também no presente trabalho as fases nemáticas de um cristal líquido liotrópico, motivados por trabalho recente de Amaral et al. [30], que, baseando-se em trabalho de Quist [31], sugeriram haver uma região de coexistência de fases nemáticas uniaxiais $\left(N_{C}+N_{D}\right)$ no diagrama de fases de uma mistura liotrópica de sódio dodecil sulfato (SDS) - 1decanol (DeOH) - água pesada $\left(\mathrm{D}_{2} \mathrm{O}\right)$. A existência de tais domínios não é prevista por teorias de campo médio do tipo de Landau, considerando argumentos de simetria, que consideram transições de fase nemática para nemática como de segunda ordem. Outros resultados experimentais com misturas liotrópicas com diferentes anfifílicos, em que foi medido o parâmetro de ordem (tensor dielétrico) na vizinhança da transição de fase nemático-nemático, não foram identificada tal coexistência. A partir de uma discussão com a autora, profa. Dra. Lia Amaral [30], preparamos a mistura supracitada em concentrações correspondentes às da região em que se afirma a coexistência $N_{C}+N_{D}$ em [30]. Três técnicas foram utilizadas: microscopia óptica de luz polarizada (seção 3.2), conoscopia a laser (seção 3.3) e espalhamento de raios X a baixo ângulo (Small Angle X-ray Scattering - SAXS, capítulo 2 e seção 3.4); combinadas, as técnicas nos permitem identificar cada fase com segurança.

Investigamos, além disso, o comportamento dinâmico de um sistema liotrópico, isto é, as flutuações do diretor nemático de um sistema nas fases $N_{C}$ e $N_{D}$ com a técnica de espalhamento dinâmico de luz (DLS). Esta fase do trabalho se iniciou em colaboração com o Dr. Celso L.S. Risi, à época, aluno de doutoramento no Grupo de Fluidos Complexos do IF-USP. O trabalho teve como objetivo avaliar eventuais variações das difusões dos modos de flutuação do diretor nemático com diferentes concentrações da dopagem das amostras por ferrofluido. Apresentaremos aqui algumas características dessa técnica de investigação (seção 3.5) e resultados preliminares.

No capítulo 2.1, explicamos os fundamentos da técnica de espelhamento de raios $\mathrm{X}$ a baixo ângulo, como os dados são tratados, o modelo de ajuste proposto e apresentamos os princípios da simulação de estruturas micelares aqui desenvolvidos. No capítulo 3 mostramos as demais técnicas experimentais empregadas neste trabalho e descrevemos os equipamentos utilizados. O capítulo 4 apresenta os resultados das medidas experimentais, da 
modelagem e das simulações.

Os resultados resultados relativos à caracterização de fases dos liotrópicos desenvolvidos no início do trabalho, apresentados na seção 4.3, levaram à publicação do artigo [32]. 


\section{Capítulo 2}

\section{Estudos das estruturas micelares por espalhamento de raios $X$ a baixo ângulo}

Tratamos neste capítulo das principais técnicas usadas no presente trabalho para caracterizar estruturas micelares, baseadas em espalhamento de raios $\mathrm{X}$ a baixo ângulo (Small Angle X-ray Scattering, SAXS). As técnicas de SAXS tornam-se imprescindíveis para a pesquisa sobre as estruturas nanoscópicas de sistemas como as misturas de liotrópicos, porque permitem a investigação desses sistemas sem que se afete seu comportamento dinâmico, em contraste com outras técnicas que exigem secamento ou cristalização das misturas. Apresentamos a seguir os procedimentos para medidas e tratamento dos dados experimentais de SAXS, o modelo para ajuste das curvas obtidas pelo tratamento e as simulações computacionais elaboradas para o cálculo de espalhamento de raios X por estruturas geométricas similares a micelas.

\subsection{A experiência de espalhamento de raios $\mathrm{X}$}

A experiência de espalhamento de raios X por uma amostra tem como resultado a formação de uma imagem num anteparo (tela), cujo padrão é uma representação bidimensional da intensidade medida da onda espalhada em cada ponto desse anteparo. As diferentes intensidades no anteparo são consequência da sobreposição da interferência de fases dessa onda espalhada. Consideremos o aparato experimental para a medida do processo de espalhamento (figura 2.1). Primeiramente, há uma fonte de raios X monocromática; no caso de nossas experiências, foram utilizadas fontes de tubo com alvo de cobre, com $\lambda\left(K_{\alpha, \mathrm{Cu}}\right) \approx 1.5419 \AA$ (mas poderiam ser usadas outros tipos de fonte, como de anodo rotativo ou síncrotron).

Um espelho especial multicamada, com formato correspondente a um corte de um pa- 


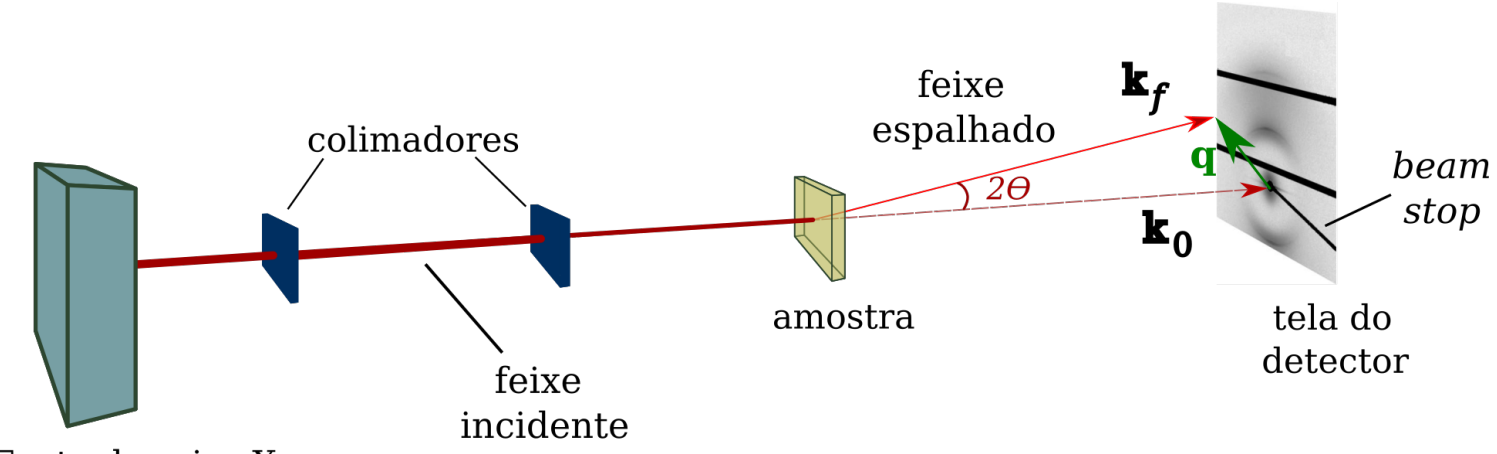

Fonte de raios $\mathrm{X}$ monocromática

Figura 2.1. Esquema de espalhamento de raios $\mathrm{X}$ a baixos ângulos por uma amostra. A fonte gera uma onda direcionada para a amostra por um espelho multicamada no formato de seção de paraboloide. O espelho também seleciona um comprimento de onda específico. Colimadores sem espalhamento (scaterless) garantem que o feixe tenha um perfil restrito a uma seção quadrada pequena. A tela do detector é formada por uma matriz de diodos fotossensíveis.

raboloide $^{1}$, direciona os fótons gerados para a amostra e efetua uma colimação parcial. Dois conjuntos de fendas completam o processo de colimação, do que resulta um feixe aproximadamente quadrado, de cerca de $1 \mathrm{~mm}$ de lado. A parte central do feixe tende a ser mais intensa, pois, em geral, as amostras tendem a espalhar pouco. Ao atingir a amostra, o feixe é espalhado e atinge uma tela com algum material sensível aos raios $\mathrm{X}$. Tradicionalmente, o registro de espalhamento era efetuado [34] em telas fluorescentes de sulfeto de zinco com traços de níquel ou por filmes fotográficos de brometo de prata; correntemente, usamos um detector formado por matrizes de diodos fotossensíveis ligados a circuitos contadores eletrônicos. A intensidade registrada em cada ponto da tela é, portanto, resultante da contagem do número de fótons incidentes em cada diodo durante o período de medida. Uma representação por cores ou tons de cinza das intensidades registradas (isto é, a associação dos valores computados a cores) forma um padrão reconhecível como uma imagem bidimensional do espalhamento (ver figuras 2.2a, 2.3a e na seção 4.1). Em geral, usa-se uma gradação logarítmica de cores ou tons para destacar os contrastes da imagem.

A posição de cada ponto na tela é usualmente definida pelo vetor de espalhamento $\mathbf{q}=$ $\mathbf{k}_{f}-\mathbf{k}_{0}$, em que $\mathbf{k}_{f}$ e $\mathbf{k}_{0}$ são os vetores número de onda, respectivamente, das ondas espalhada e incidente (figura 2.1). O ângulo formado entre a trajetória incidente e a espalhada é definido como $2 \theta$.

Para a interpretação dos dados experimentais de SAXS, usa-se comumente a boa aproximação de Rayleigh-Gans-Debye (RGD) [35, 7], que supõe que o feixe incidente não é distorcido pelo meio de modo significativo: uma onda plana incidente se propaga através da partícula homogeneamente, ou seja, a magnitude do campo é a mesma em todos os pontos da partícula. Assumimos também que a maior parte dos fótons passam pela amostra sem

\footnotetext{
${ }^{1}$ As fontes usadas nas experiências conduzidas neste trabalho, da empresa Xenocs, têm espelhos com cortes de paraboloides ou, por aproximação, cortes de elipsoides de revolução [33].
} 
serem desviados e que uns poucos são espalhados uma única vez, de modo que espalhamentos de ordens mais altas são desprezáveis, e consideramos que o processo de espalhamento é quase elástico, isto é, que os dos vetores de onda incidente, $\mathbf{k}_{0}$, e do vetor da onda espalhada, $\mathbf{k}_{f}$, são aproximadamente iguais, $\left|\mathbf{k}_{0}\right| \approx\left|\mathbf{k}_{f}\right|=k$.

Quando a direção de espalhamento difere pouco da direção do feixe incidente, as ondas espalhada e incidente encontram-se praticamente em fase, o que promove uma interferência construtiva e, portanto, uma intensidade maior nas proximidades do ponto de incidência normal (point of normal incidence, ou p.o.n.i.) do feixe na tela do detector. A diferença de fases aumenta com o ângulo $2 \theta$ e, com ele, reduz-se a intensidade medida, em função de interferência destrutiva. Para partículas de dimensão aproximada $d$, a diferença de fases tende a zero quando $2 \theta \approx \lambda / d$, o que indica que o método pode ser usado para avaliação das dimensões das partículas [4].

Isso justifica o uso de SAXS para o estudo de partículas da ordem de algumas dezenas de nanômetros, pois radiações com comprimento típico como $\lambda_{K \alpha}(\mathrm{Cu})$ implicará ângulos de espalhamento da ordem de $1^{\circ}$. A tabela (2.1) apresenta alguns valores de referência, a título de exemplo, que correspondem às distâncias de medidas usadas no equipamento Xeuss do GFCx-IF-USP (descrito no capítulo 3).

\begin{tabular}{cccc}
\hline \hline$L(\mathrm{~m})$ & $2 \theta\left(^{\circ}\right)$ & $q\left(\AA^{-1}\right)$ & $d(\mathrm{~nm})$ \\
\hline \hline 0.12 & $1.22-38.77$ & $0.08692-2.70536$ & $0.12-3.61$ \\
0.45 & $0.33-12.09$ & $0.02318-0.85830$ & $0.37-13.55$ \\
0.83 & $0.18-6.62$ & $0.01257-0.47088$ & $0.67-25.00$ \\
1.20 & $0.12-4.59$ & $0.00869-0.32654$ & $0.96-36.14$ \\
2.50 & $0.06-2.21$ & $0.00417-0.15703$ & $2.00-75.29$ \\
3.80 & $0.04-1.45$ & $0.00275-0.10334$ & $3.04-114.44$ \\
5.10 & $0.03-1.08$ & $0.00205-0.07701$ & $4.08-153.59$ \\
6.46 & $0.02-0.85$ & $0.00161-0.06080$ & $5.17-194.54$ \\
\hline \hline
\end{tabular}

Tabela 2.1. Valores típicos do vetor de espalhamento $(q)$ e das dimensões das partículas medidas (d), calculados para um aparato experimental com feixe gerado a partir de um alvo de cobre e um detector Pilatus 300k. As distâncias $L$ da amostra ao detector são típicas usadas no laboratório do GFCx-IF-USP.

\subsubsection{Intensidade da onda de raios $X$ espalhada}

Supõe-se uma onda incidente de raios X, 


$$
E\left(\mathbf{r}_{j}\right)=E_{e} f_{j} e^{-l \mathbf{r}_{j} \cdot \mathbf{k}_{0}}
$$

em que $E_{e}$ é a amplitude de espalhamento de um elétron (espalhamento Thomson), $f_{j}$ é o fator de espalhamento do ponto $j, \mathbf{r}_{j}$ é a posição do $j$-ésimo centro espalhador em relação a uma dada origem arbitrária, $\mathbf{k}_{0}=2 \pi / \lambda \mathbf{e}_{0}$ é o vetor número de onda ( $\lambda$ é o comprimento de onda do feixe monocromático) e $\mathbf{e}_{0}=\mathbf{k}_{0} /\left|\mathbf{k}_{0}\right|$ é o versor da onda incidente. A onda espalhada tem número de onda $\mathbf{k}_{f}=2 \pi / \lambda \mathbf{e}_{f}$ e, considerando-se um espalhamento elástico, isto é, $\left|\mathbf{k}_{0}\right| \approx\left|\mathbf{k}_{f}\right|=k$, o vetor de espalhamento, $\mathbf{q}=\mathbf{k}_{f}-\mathbf{k}_{0}$, tem módulo

$$
\begin{gathered}
q=|\mathbf{q}|=\left|\mathbf{k}_{f}-\mathbf{k}_{0}\right| \Rightarrow q^{2}=k^{2}+k^{2}-2 k^{2} \cos 2 \theta=4 k^{2} \operatorname{sen}^{2} \theta \\
\therefore \quad q=2 k \operatorname{sen} \theta=\frac{4 \pi}{\lambda} \operatorname{sen} \theta
\end{gathered}
$$

Ao se comparar a equação (2.2) à lei de Bragg $(2 d \operatorname{sen} \theta=n \lambda)$, tem-se $d_{\text {Bragg }}=2 \pi / q$ (com $n=1$ ), ou seja, as dimensões típicas medidas são inversamente proporcionais a $q$.

A amplitude $E_{j}(\mathbf{q})$ de espalhamento pelo centro $j$ é [4]

$$
E_{j}(\mathbf{q})=E_{e} f_{j} e^{-l \mathbf{r}_{j} \cdot \mathbf{q}}
$$

A intensidade espalhada por $N$ centros é $I(\mathbf{q})=|E(\mathbf{q})|^{2}$, então,

$$
I(\mathbf{q})=\sum_{i=1}^{N} \sum_{j=1}^{N} E_{i} E_{j}^{*}=E_{e}^{2} \sum_{i=1}^{N} \sum_{j=1}^{N} f_{i} f_{j} \exp \left[-i \mathbf{q} \cdot\left(\mathbf{r}_{i}-\mathbf{r}_{j}\right)\right] .
$$

Nesta soma, permanece apenas o termo correspondente à função par, logo

$$
I(\mathbf{q})=E_{e}^{2} \sum_{i=1}^{N} \sum_{j=1}^{N} f_{i} f_{j} \cos \left[-\mathbf{q} \cdot \mathbf{R}_{i j}\right]
$$

em que $\mathbf{R}_{i j}=\mathbf{r}_{i}-\mathbf{r}_{j}$ é o vetor entre os centros $i$ e $j$.

A equação 2.5 pode ser reescrita para o caso de uma distribuição contínua de espalhadores, considerando-se que os centros espalhadores (unidades que compõem o sistema) são pequenos e em grande número. Assim, dada uma densidade de espalhamento contínua $\rho(\mathbf{r})=\bar{\rho}+\Delta \rho(\mathbf{r})$, escrita em termos de sua média $\bar{\rho}$ e das flutuações $\Delta \rho(\mathbf{r})$, a amplitude de espalhamento é

$$
E(\mathbf{q})=\int_{V} \Delta \rho(\mathbf{r}) e^{-i \mathbf{q} \cdot \mathbf{r}} d \mathbf{r},
$$

uma vez que $\int_{V} \bar{\rho} e^{-i \mathbf{q} \cdot \mathbf{r}} d \mathbf{r}$ tem um pico centrado em $\mathbf{q}=0$, de tal forma que apenas as contribuições da equação 2.6 são relevantes para $\mathbf{q} \neq 0$. 
O detector mede a intensidade da onda espalhada, $I_{S}(\mathbf{q})=|E(\mathbf{q})|^{2}$ e, portanto,

$$
I(\mathbf{q})=E_{e}^{2} \int_{V} \int_{V} \Delta \rho\left(\mathbf{r}_{1}\right) \Delta \rho\left(\mathbf{r}_{2}\right) \exp \left[-i \mathbf{q} \cdot\left(\mathbf{r}_{1}-\mathbf{r}_{2}\right)\right] d \mathbf{r}_{1} d \mathbf{r}_{2},
$$

em que as somas foram substituídas por integrais de volume.

\section{Função de correlação}

É conveniente definir-se a função de correlação de dois pontos [36],

$$
\gamma(\mathbf{r})=\frac{1}{V} \int_{V} \Delta \rho\left(\mathbf{r}^{\prime}\right) \Delta \rho\left(\mathbf{r}^{\prime}+\mathbf{r}\right) d \mathbf{r}^{\prime}
$$

A intensidade pode então ser reescrita como

$$
I(\mathbf{q})=\int_{V} \gamma(\mathbf{r}) e^{-i \mathbf{q} \cdot \mathbf{r}} d \mathbf{r}
$$

ou seja, a intensidade de espalhamento pode ser interpretada como a transformada de Fourier da função de correlação da densidade de espalhamento. Como se pode esperar,

$$
\gamma(\mathbf{r})= \begin{cases}\left\langle\Delta \rho^{2}\right\rangle, & r \rightarrow 0 \\ \langle\Delta \rho\rangle^{2}, & r \rightarrow \infty\end{cases}
$$

pelo que se define a função de correlação normalizada,

$$
\gamma_{0}(\mathbf{r})=\frac{\gamma(\mathbf{r})-\langle\Delta \rho\rangle^{2}}{\left\langle\Delta \rho^{2}\right\rangle-\langle\Delta \rho\rangle^{2}}
$$

que varia entre $\gamma(0)=1$ e $\gamma(r \rightarrow \infty)=0$. Escrevendo mais uma vez a intensidade (2.7), agora em termos de (2.11), tem-se

$$
I(\mathbf{q})=\left(\left\langle\Delta \rho^{2}\right\rangle-\langle\Delta \rho\rangle^{2}\right) \int_{V} \gamma_{0}(\mathbf{r}) e^{-l \mathbf{q} \cdot \mathbf{r}} d \mathbf{r}+\langle\Delta \rho\rangle^{2} \delta(\mathbf{q}),
$$

em que, novamente, se evidencia que apenas as flutuações de densidade eletrônica produzem um sinal mensurável, ao passo que a densidade média dos centros espalhadores (segundo termo à direita) gera apenas um sinal em $q=0(\delta(\mathbf{q})$ é a "função" delta de Dirac) [7].

Vale dizer que a medida de espalhamento é efetuada ao longo de um dado tempo de exposição do detector ao processo de espalhamento, para que haja estatística suficiente. A imagem assim formada é um histograma da frequência $f(x, z)$ de fótons incidentes num dado intervalo de tempo nas coordenadas $(x, z)$ da tela, relativas ao centro do feixe, de modo 
que $q \propto \sqrt{x^{2}+z^{2}}$. A intensidade medida é, portanto, uma média da intensidade no ensemble (considerando-se ergodicidade do sistema) sobre as flutuações das partículas, com o que, evidentemente, perde-se informação sobre as flutuações rápidas (em comparação com o tempo da medida) das configurações do sistema.

No caso de orientações igualmente distribuídas das partículas, efetua-se a média orientacional da função $\gamma_{0}(\mathbf{r})$, de modo que ela passa a depender somente do módulo de $r$. Tomando-se também a média sobre as direções do fator de fase, $\left\langle e^{-i \mathbf{q} \cdot \mathbf{r}}\right\rangle=\operatorname{sen}(q r) /(q r)$, resultado clássico de Debye [37, 7],

$$
I(q)=\left\langle|E(\mathbf{q})|^{2}\right\rangle=4 \pi\left(\left\langle\Delta \rho^{2}\right\rangle-\langle\Delta \rho\rangle^{2}\right) \int_{0}^{\infty} \gamma_{0}(r) r^{2} \frac{\operatorname{sen}(q r)}{q r} d r
$$

de modo que a função a intensidade passa a depender apenas da magnitude de $q=|\mathbf{q}|$.

Como o campo espalhado é a transformada de Fourier das flutuações de densidade (eq. 2.6), o padrão de espalhamento, que corresponde às intensidades medidas pelo detector, é uma imagem no espaço recíproco. Poder-se-ia, em tese, calcular a função de correlação pela transformada inversa de Fourier de $I(q)$, mas isso não é possível na prática, em geral, uma vez que se tem a medida da intensidade em um intervalo limitado e que se trata de uma transformada dupla. Além disso, em função das médias no ensemble e nas orientações espaciais, obtém-se apenas uma informação unidimensional sobre o sistema.

\subsection{Obtenção de curvas a partir dos dados experimentais}

Um procedimento usual para o tratamento de imagens obtidas por SAXS é a caracterização da curva de intensidade em função de q ou, no caso de sistemas isotrópicos ou de partículas orientadas aleatoriamente, em função de $q=|\mathbf{q}|$, pois a imagem produzida tem simetria azimutal. A figura 2.2a é um exemplo de espalhamento de raios $\mathrm{X}^{2}$ por um liotrópico na fase $N_{C}$, alinhado em relação ao aparato experimental de modo que a maior dimensão de suas micelas é paralela ao feixe incidente. Nesses casos, a intensidade do espalhamento no detector é apenas função do módulo do vetor de espalhamento $(q)$.

Para melhorar a estatística de contagem dos fótons, é comum efetuar-se uma integração azimutal, no plano do detector, para um dado $q$, cujo resultado é apresentado na figura 2.2b. Por comparação da equação $2.2 \mathrm{com}$ a lei de Bragg, vê-se que as dimensões típicas dos espalhadores, $d$, relacionam-se com o o vetor de espalhamento por $q \sim 2 \pi / d$; os picos na figura $2.2 \mathrm{~b}$ correspondem então ao resultado da interferência construtiva das fases de espalhamento por estruturas de dimensão típica $d$.

O espalhamento por sistemas com algum grau de orientação tem perfis diferentes em função de $q$ em cada direção, ou seja, é função de q. Um exemplo é apresentado na figura

\footnotetext{
${ }^{2}$ A explicação sobre a obtenção das imagens de espalhamento encontra-se na seção 3.4.
} 
2.3a, de um liotrópico à base de alcanoatos (KC14/KC15) também em fase $N_{C}$, mas com sua maior dimensão alinhada perpendicularmente ao feixe, na direção horizontal. Pode-se obter informação relativa a cada direção ao se efetuar integrações parciais do domínio, em setores circulares, como indicado na figura. O resultado na parte b da figura 2.3. Essa abordagem permite de pronto indicar os picos característicos da amostra alinhada, à moda dos procedimentos cristalográficos. Uma análise quantitativa desses resultados sugere a modelagem das curvas, como faremos na seção 2.3. O procedimento para tratamento dos dados SAXS é descrito na seção 3.4 .

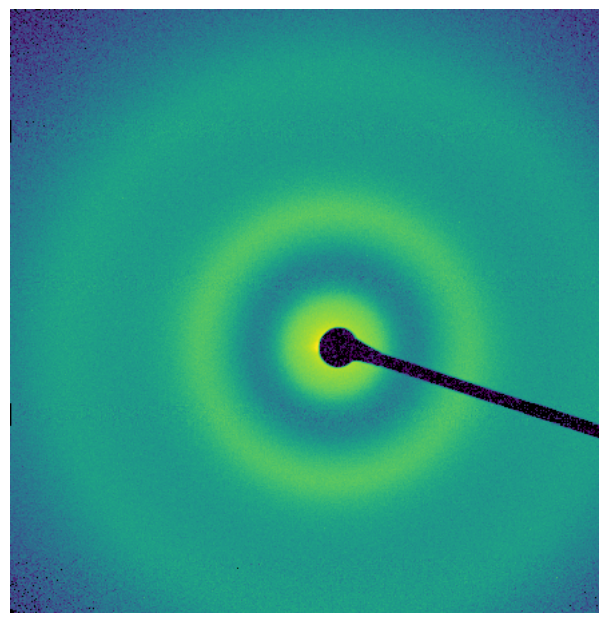

(a) Espalhamento.

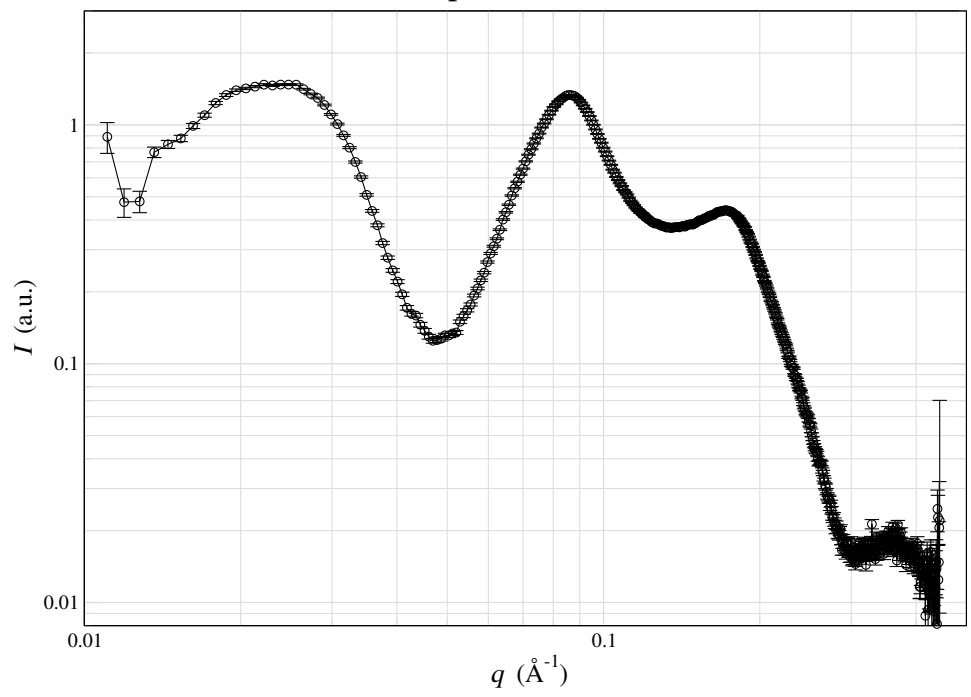

(b) Integração azimutal da imagem (a).

Figura 2.2. Exemplo de espalhamento de uma mistura de $\mathrm{KC1} 14$ / $\mathrm{KC15} / \mathrm{Rb}_{2} \mathrm{SO}_{4} /$ 1-decanol / $\mathrm{H}_{2} \mathrm{O}$ na fase $N_{C}$. Em função do alinhamento do eixo maior das micelas na direção do feixe, dada a geometria do aparato experimental, a imagem obtida neste caso é simétrica. 


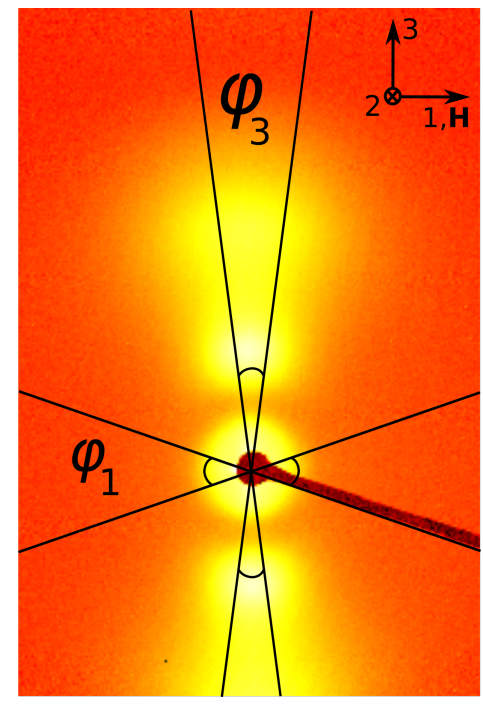

(a) Espalhamento.

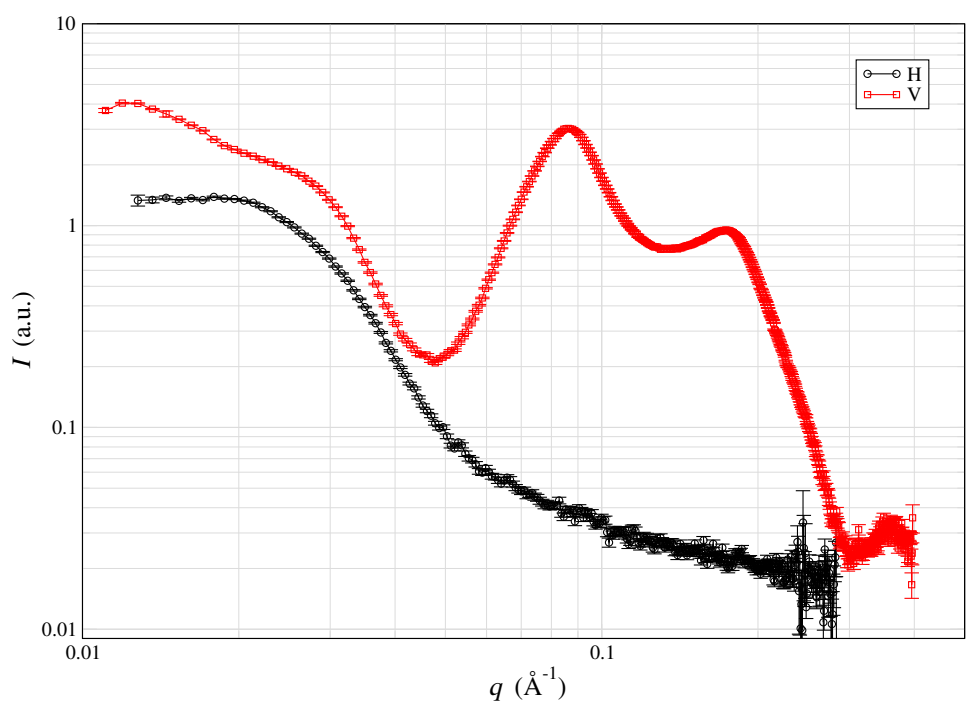

(b) Integrações azimutais de (a) por setores.

Figura 2.3. Exemplo de espalhamento de uma mistura de $\mathrm{KC} 14$ / $\mathrm{KC} 15$ / $\mathrm{Rb}_{2} \mathrm{SO}_{4}$ / 1-decanol / $\mathrm{H}_{2} \mathrm{O}$ na fase $N_{C}$ e dos "cortes" da imagem em setores circulares para tratamento dos dados. Em função do alinhamento do eixo maior das micelas na direção perpendicular ao feixe, dada a geometria do aparato experimental, a imagem obtida neste caso é anisotrópica. O alinhamento da amostra é definido nas direções 1 e 3 . Os "cortes" (linhas escuras) representam os setores em que são efetuadas as integrações numéricas (médias) sobre um arco (ângulo azimutal, no plano da figura), indicado pelo ângulos $\varphi_{1,3}$, para um dado valor fixo do vetor de espalhamento, q. Em (b), são apresentadas as curvas de intensidade em função do módulo do vetor de espalhamento, $I(q) \times q$, obtidas pela referida média dos arcos de (a).

\subsection{Modelo para os perfis de espalhamento}

O modelo ora proposto para ajuste às curvas obtidas por integração de setores, como na figura 2.3, supõe que as estruturas micelares podem ter sua forma representada por elipsoides de revolução (figura 1.2), os quais sofrem um processo de "empacotamento" que revela padrões estruturais (figuras 1.2 e 1.4). Seria natural assumir inicialmente que tais elipsoides tenham seus três eixos maiores distintos, porém as imagens obtidas por SAXS são consequência da composição dos fatores de forma e de estrutura das micelas. São ainda resultado de uma média ao longo do tempo de medida. Em suma, trata-se de uma técnica que revela estruturas microscópicas de sistemas em solução, porém com baixa resolução. Assim, sugerimos que a intensidade espalhada é função do fator de forma de um elipsoide de revolução (core-shell, representando as diferentes densidades eletrônicas entre a cauda e a cabeça polar dos surfactantes) e de fatores de estrutura que consideram o empacotamento, polidispersidade e, em certa medida, exclusão de volume. 
Fator de forma de elipsoide de tipo core-shell. Consideramos um elipsoide de revolução core-shell, com "raio" $R_{c}$, excentricidade $\epsilon$ e espessura de camada $T$, e passaremos a designar as regiões do core, da shell ou ambas conjuntamente pelos índices $c, s$ e $c s$ respectivamente. seu fator de forma é dado por [7]

$$
P_{m i c}\left(q, R_{c}, T, \epsilon\right)=\int_{0}^{\pi / 2} F_{c s}\left[q, r\left(R_{c}, \epsilon, \alpha\right)\right]^{2} \operatorname{sen} \alpha d \alpha
$$

em que $r\left(R_{c}, \epsilon, \alpha\right)=R_{c} \sqrt{\operatorname{sen}^{2} \alpha+\epsilon \cos ^{2} \alpha} \mathrm{e}$

$$
F_{c s}\left[q, r\left(R_{c}, \epsilon, \alpha\right)\right]=\frac{\Delta \rho_{s}\left(V_{c}+V_{S}\right) F_{0}\left(q, R_{c}+T\right)+\left(\Delta \rho_{c}-\Delta \rho_{s}\right) V_{c} F_{0}\left(q, R_{c}\right)}{\Delta \rho_{c} V_{c}+\Delta \rho_{s} V_{s}}
$$

é a amplitude de espalhamento core-shell, sendo $\Delta \rho_{c}$ e $\Delta \rho_{s}$, as diferenças de densidade eletrônica para o meio, e $V_{c}$ e $V_{s}$ os volumes das regiões de core e de shell da micela, respectivamente. $\mathrm{O}$ fator $F_{0}\left(q, R_{c}\right)$ é a clássica amplitude do fator de forma de uma esfera homogênea, calculada por Lord Rayleigh em 1911, dado por

$$
F_{0}(q, R)=\frac{3[\operatorname{sen}(q R)-q R \cos (q R)]}{(q R)^{3}} .
$$

A intensidade do fator de forma é então

$$
I_{m i c}(q)=\int_{0}^{\infty} P_{m i c}\left(q, R_{c}, T, \epsilon\right) D\left(R_{c}, \bar{R}_{c}, \sigma_{c}\right) d R_{c}
$$

em que foi inserida uma função de distribuição radial, $D\left(R_{c}, \bar{R}_{c}, \sigma_{c}\right)$, dependente de $R_{c}$, do raio médio $\bar{R}_{c}$ e do desvio padrão da distribuição, $\sigma_{c}$. Usamos a função de Schulz-Zimm [7] para representar essa distribuição,

$$
D\left(R_{c}, \bar{R}_{c}, \sigma_{c}\right)=\left(\frac{z+1}{\bar{R}}\right)^{z+1} \frac{R^{z}}{\Gamma(z+1)} \exp \left[-(z+1) \frac{R}{\bar{R}}\right],
$$

em que $z+1=\bar{R}^{2} / \sigma^{2}$ e $\Gamma(z)$ é a usual função gama.

Fator de estrutura lamelar do arranjo micelar. A presença de picos nas figuras anisotrópicas de espalhamento de liotrópicos sugerem um arranjo espacial periódico, como estruturas lamelares ou pseudo lamelares [1]. Assim, o arranjo micelar pode ser descrito pelo fator de estrutura lamelar sugerido por Förster [38],

$$
S_{L A M}(q)=1+\beta(q) G(q)\left[Z_{0}(q)-1\right] .
$$


Nesta expressão, o arranjo estrutural do sistema é dado pelo fator de rede

$$
Z_{0}(q)=\frac{(2 \pi)^{d-1} c}{n v_{d} \Omega_{d} q^{d-1}} \sum_{\{h k l\}} m_{h k l} f_{h k l}^{2} L_{h k l}(q),
$$

em que $c$ é um fator de escala, $d$ é a dimensão da célula unitária, $n$ é o número de partículas por célula unitária, $\Omega_{d}$ é o ângulo sólido $d$-dimensional, $q$ é o vetor de espalhamento, $m_{h k l}$ é a multiplicidade dos picos, $f_{h k l}$ é um fator de simetria e $L_{h k l}(q)$ é uma função do pico normalizada. No caso presente, em que se considera uma estrutura lamelar com periodicidade $a$, a equação 2.20 é bastante simplificada, pois $d=1, m_{h 00}=1, f_{h 00}=1, \Omega_{d}=1, n=1, v_{d}=a$. Usamos a função pico [39]

$$
L_{h k}(q)=\frac{2}{\pi \delta} \prod_{n=0}^{\infty}\left[1+\frac{\gamma^{2}}{(n+v / 2)} \frac{4\left(q-q_{h k l}\right)}{\pi^{2} \delta^{2}}\right]^{-1}
$$

em que $q_{h k l}$ é a posição dos picos e

$$
\gamma_{v}=\sqrt{\pi} \frac{\Gamma[v / 2]}{\Gamma(v / 2)}, \int_{-\infty}^{\infty} L_{h k l}(q) d q=1
$$

Essa função tem a vantagem de tender à gaussiana quando $v \rightarrow \infty$ e à lorentziana quando $v \rightarrow 0$. O parâmetro $\delta$ está relacionado ao tamanho dos domínios micelares, pela equação de Debye-Scherrer, $D=2 \pi / \delta$.

O fator $G(q)$ em 2.19 é o fator de Debye-Waller para desordem térmica,

$$
G(q)=\exp \left(-\sigma_{a}^{2} \bar{a}^{2} q^{2}\right)
$$

cujo deslocamento médio quadrático é $\sigma_{a}^{2}$, relacionado ao parâmetro de Caillè, $\eta=8 \sigma_{a}^{2}$, ligado às flutuações de bicamadas [40].

O termo $\beta(q)$, relativo à polidispersidade, também pode ser representado por uma gaussiana [39],

$$
\beta(q) \approx \exp \left(-\sigma_{R} R^{2} q^{2}\right)
$$

Compensação para uma estrutura pseudolamelar. Foi incluído no modelo um fator de forma simples de esferas duras, que compensa o fato de que a estrutura observada não é exatamente lamelar, reduzindo a intensidade medida. Esse termo é dado por [7]

$$
S_{H S}(q)=\frac{1}{1+24 \eta G\left(2 R_{H S} q\right) /\left(2 R_{H S} q\right)},
$$


em que $R_{h s}$ são os raios das esferas duras e

$$
\begin{aligned}
G(x) & =\frac{\alpha(\operatorname{sen} x-\cos x)}{x^{2}}+\frac{\beta\left(2 x \operatorname{sen} x+\left(2-x^{2}\right) \cos x-2\right)}{x^{3}} \\
& +\frac{\gamma\left\{-x^{4} \cos x+4\left[\left(3 x^{2}-6\right) \cos x+\left(x^{3}-6 x\right)\right]\right\}}{x^{5}},
\end{aligned}
$$

com

$$
\alpha=\frac{(1+2 \eta)^{2}}{(1-\eta)^{4}}, \quad \beta=\frac{(1+2 \eta)^{2}}{(1-\eta)^{4}}, \quad \gamma=\frac{\eta \alpha}{2}
$$

sendo $\eta$ a fração de volume das esferas.

Agregados de ferrofluido. Introduzimos ainda um termo referente à ascensão da curva em baixos valores de $q$. Medidas experimentais de SAXS de liotrópicos nos mostram que essa parte da curva está relacionada à concentração de ferrofluido usado na dopagem das amostras, e desaparece numa mistura pura. Nos casos em que o efeito desses agregados de ferrofluido se manifesta, podemos usar a intensidade do fator de forma de um elipsoide triaxial,

$$
P_{A G}(q, a, b, c)=\frac{2}{\pi} \int_{0}^{\pi / 2} \int_{0}^{\pi / 2} F_{0}[q, r(a, b, c)]^{2} \operatorname{sen} \alpha d \alpha d \beta,
$$

em que $F_{0}[q, r(a, b, c)]$ é o fator de forma de uma esfera de raio $r$ (eq. 2.16), $a, b$ e $c$ são os semieixos maiores do elipsoide $\mathrm{e}$

$$
r=\left[\left(a^{2} \operatorname{sen}^{2}+b^{2} \cos ^{2} \beta\right) \operatorname{sen}^{2} \alpha+c^{2} \cos ^{2} \alpha\right]^{1 / 2} .
$$

O fator de estrutura correspondente a $P_{\text {elt }}$ é então

$$
S_{A G}(q)=1+S_{c a} P_{A G}(q, a, b, c),
$$

com o devido fator de escala para o agregado, $S_{c a}$.

Expressão final do modelo. A expressão para ajuste do modelo aos dados é então dada por

$$
I(q)=C_{0} \times I_{m i c}(q) \times S_{L A M}(q) \times S_{H S} \times S_{A G}(q)+B_{0}
$$

em que $C_{0}$ é um fator de escala constante e $B_{0}$ é uma constante correspondente a espalhamento de fundo (background).

A figura 2.4 mostra um exemplo da aplicação do modelo a uma amostra com KC14 / KC15 (alcanoatos de potássio) como principais surfactantes. As curvas correspondentes a 
cada um dos termos da equação 2.30 são apresentadas explicitamente. A curva íngreme à esquerda, $S_{A G G}$, corresponde ao efeito dos agregados de ferrofluido, ausente nas curvas em que a dopagem é baixa, como é o caso das amostras da seção 4.1.

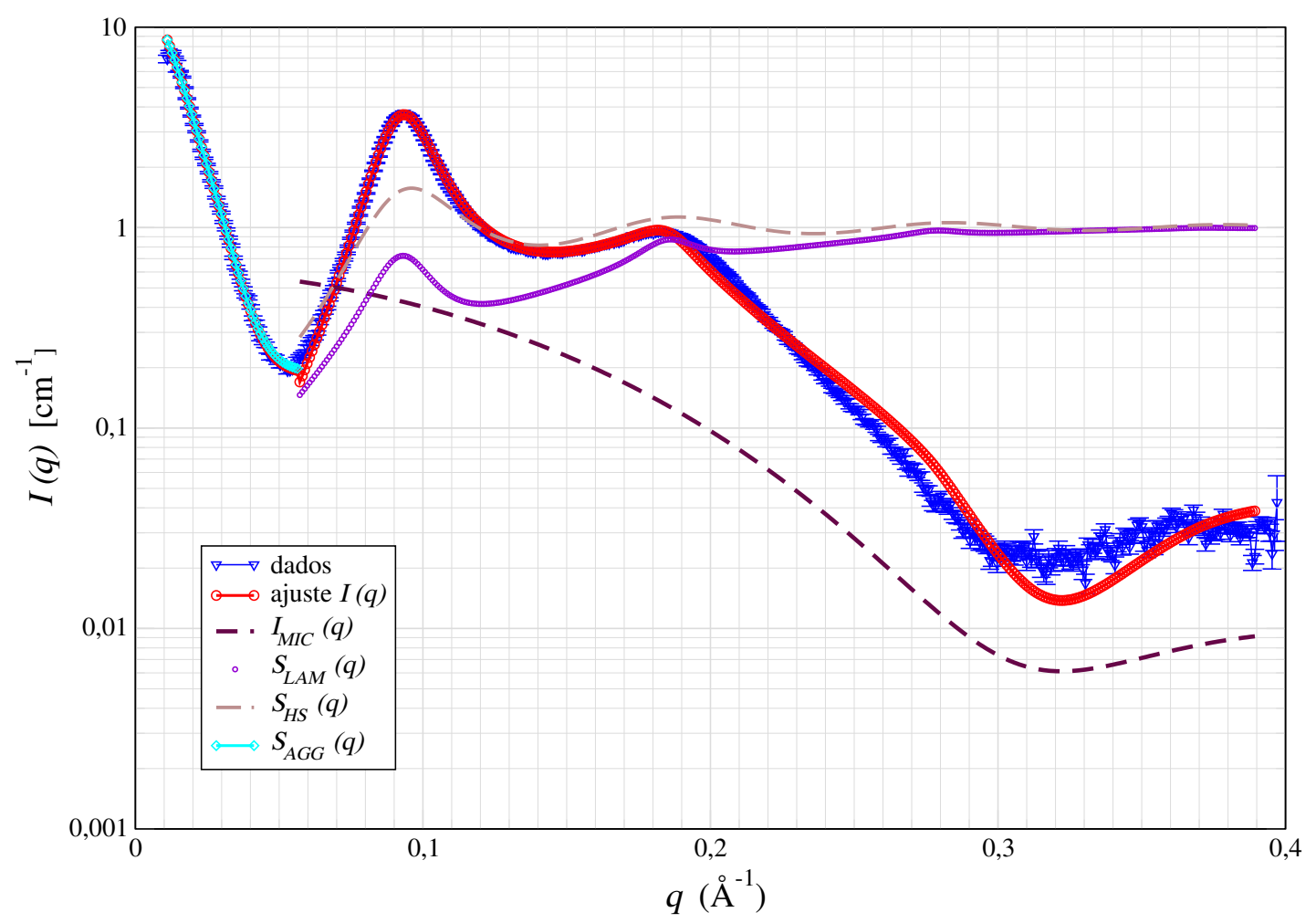

Figura 2.4. Exemplo de implementação do modelo da equação 2.30 a uma medida de SAXS de amostra de $\mathrm{KC1} 4 / \mathrm{KC15} / \mathrm{Rb}_{2} \mathrm{SO}_{4} / 1$-decanol $/ \mathrm{H}_{2} \mathrm{O}$ na fase $N_{B}$ com campo $H$ paralelo à direção do feixe de raios X. Cada curva ajustada corresponde a um dos termos da referida equação.

\subsubsection{Implementação do programa de ajuste}

A complexidade do modelo apresentado exigiu a implementação de um programa de computador específico. O programa foi inicialmente criado em linguagem Python, em que usamos a função de ajuste curve_fit da biblioteca Python SciPy, versão 1.1. Em função do grande número de parâmetros do modelo é necessário o controle dos intervalos de ajuste de cada parâmetro, o que é permitido pela curve_fit com a escolha do método TRF (Trust Region Reflective). A constante interação para controle intervalos de ajustes nos levou à implementação de um programa auxiliar com janelas, a que denominamos graffitt, apresentado na figura 2.5. O sistema interativo por janela foi implementado com uso da biblioteca Tk (Python-Tk). O programa permite não só visualizar os dados experimentais e o ajuste, bem como definir facilmente quais parâmetros podem ser modificados pelo ajuste ou a qual intervalo ficam restritos. 


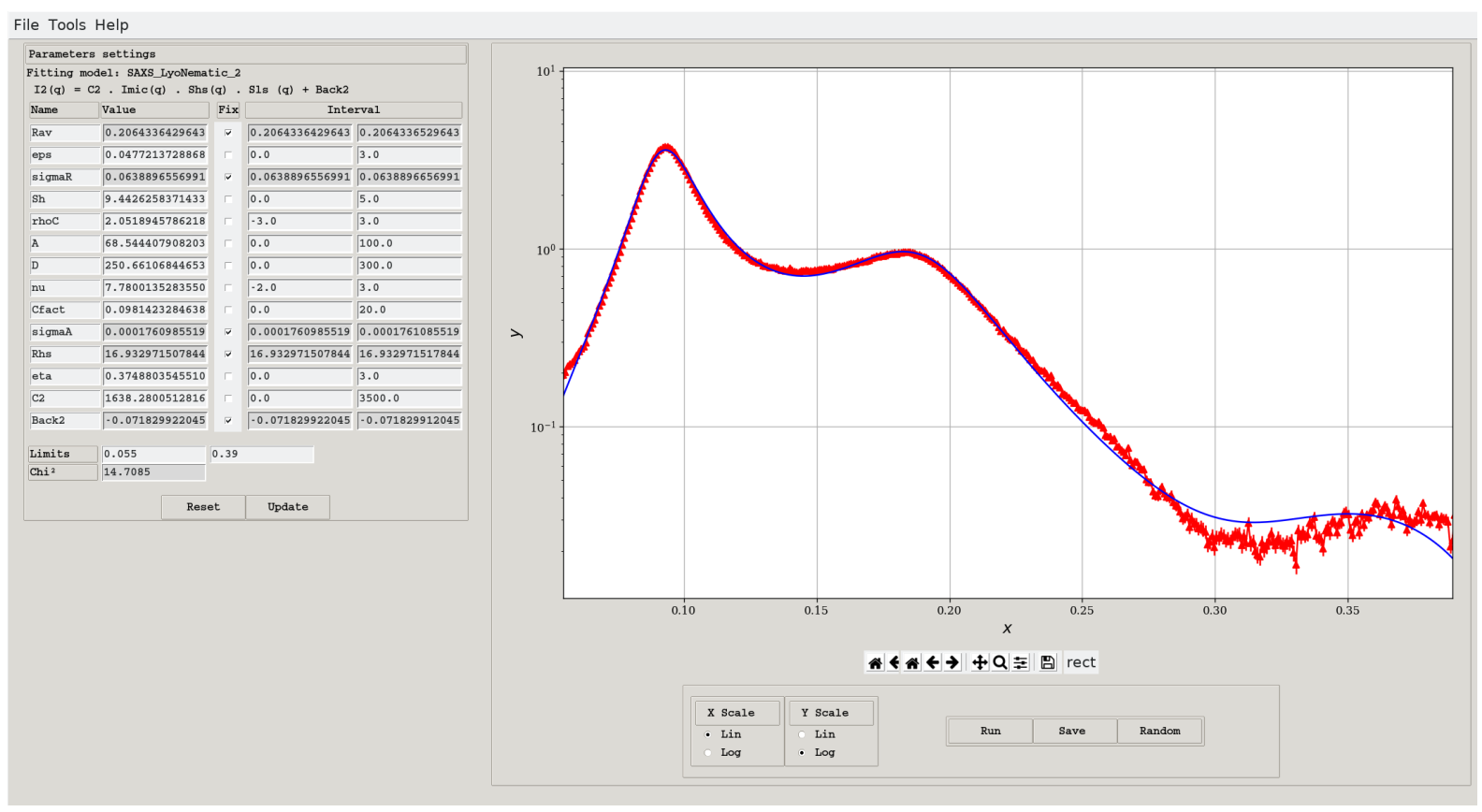

Figura 2.5. Imagem do programa graffitt.

A alta demanda de processamento para o ajuste, haja vista o grande número de funções e integrações numéricas necessárias ao cálculo da intensidade de espalhamento (eq. 2.30), também nos levou a implementar a parte específica do modelo em linguagem C. A linguagem Python depende de um interpretador, o que torna o processamento dezenas de vezes mais lento em relação a linguagens compiladas, a despeito de seus recursos de mais alto nível. Assim, o programa graffitt lê arquivos de dados e de parâmetros e faz a interação com usuário, controlando intervalos de interação. Para o ajuste, o algoritmo TRF é executado em Python, que por sua vez "chama" o módulo escrito em C. O programa pode rodar diferentes modelos, bastando para tanto que haja um módulo escrito em Python para executá-lo ou que chame outros módulos compilados com a devido protocolo de transformação de tipos (por exemplo, Python possui estruturas de dados mais complexas do que $\mathrm{C}$, o que exige uso de bibliotecas de comunicação apropriadas).

A implementação do módulo em C também fez uso de multithreading, isto é, de processamento paralelo. Como os cálculos dos valores da função $I(q)$ podem ser feitos independentemente para cada valor de $q$, a função subdivide o intervalo de ajuste de acordo com o número de núcleos de processamento disponíveis. Ainda assim, alguns ajustes podem tomar alguns minutos.

Com os resultados dos ajustes desse modelos, podemos usar valores típicos para inserir nas simulações de padrões de espalhamento bidimensionais, explicadas na seção 2.5a seguir. 


\subsection{Parâmetro de ordem}

Em sistemas que sofrem transição de fase, além das propriedades termodinâmicas usuais, a redução da simetria pode exigir mais um parâmetro para a descrição do processo [41]. Tal parâmetro, chamado parâmetro de ordem, é uma grandeza mensurável do grau de ordem. Normalmente, ele é definido de modo que seu valor tende a zero no sistema desordenado (isotrópico) e tende a 1 num sistema totalmente ordenado.

A teoria de Landau [42] para transições de fase de segunda ordem descreve a densidade de energia livre, $f(T)$, em função da temperatura, $T$, do sistema próximo à transição de fase como uma série de potências em termos dos invariantes do parâmetro de ordem. Por exemplo, no caso de um material ferromagnético uniaxial, sem campo magnético externo, a transição de fase isotrópica para a fase magnetizada pode ser descrita em função da magnetização $m$, por $[2,8]$

$$
f(m, T)=f_{0}(T)+\frac{1}{2} A(T) m^{2}+\frac{1}{4} C(T) m^{4}
$$

em que $f_{0}(T), A(T)$ e $C(T)$ são funções suaves de $T$. Supondo-se que próximo à temperatura crítica (que denotaremos $T_{C}^{*}$ ) o coeficiente $C(T)$ varia lentamente em comparação com $A(T)$, fazemos $C$ constante e maior do que zero. Os mínimos de $f(T)$ nas diferentes fases exigem que $A(T)$ seja positivo acima de $T_{C}$ e negativo abaixo de $T_{C}$, do que $A(T)=a\left(T-T_{C}^{*}\right)$, com $a>0$ é uma constante [8] e, assim,

$$
f(m, T) \approx f_{0}(T)+\frac{1}{2} a\left(T-T_{C}^{*}\right) m^{2}+\frac{1}{4} m^{4} .
$$

Consideremos agora a natureza do parâmetro de ordem em sistemas com orientação espacial. No caso de partículas alongadas, do tipo bastão, que se orientam numa direção (por exemplo, o modelo de Maier-Saupe [43]), tomemos o ângulo ( $\beta$ ) que o eixo maior de cada partícula (ou "bastão") faz com o eixo que define a orientação média das partículas $\left(\mathbf{n}_{0}\right)$. Poderíamos tomar a média dos $\beta$ como medida da orientação do sistema; como as direções de $\beta$ não são relevantes para a medida da ordem, pode-se considerar a projeção, $\cos \beta$, em $\mathbf{n}_{0}$; como tais sistemas não apresentam polaridade, usamos $\cos ^{2} \beta$. Ou melhor, em se tratando de uma avaliação sobre a orientação de todas as partículas, toma-se a média $\left\langle\cos ^{2} \beta\right\rangle$; no caso em que as partículas estão totalmente desorientadas, $\left\langle\cos ^{2} \beta\right\rangle=1 / 3$. Em função da normalização do parâmetro, escolhe-se tradicionalmente a média do polinômio de Legendre de ordem $2, P_{2}(\cos \beta)$,

$$
S=\left\langle P_{S}(\cos \beta)\right\rangle=\frac{1}{2}\left(3\left\langle\cos ^{2} \beta\right\rangle-1\right),
$$

que é igual a 1 para um sistema totalmente ordenado e 0 para um sistema isotrópico [8].

Fases nemáticas de sistemas líquido cristalinos são caracterizadas por um tensor de se- 
gunda ordem, de traço nulo, com dois autovalores diferentes na fase uniaxial e três na biaxial. Por exemplo, tomemos a susceptibilidade magnética [8], no caso uniaxial,

$$
\overleftrightarrow{\chi}=\left(\begin{array}{ccc}
\chi_{\perp} & 0 & 0 \\
0 & \chi_{\perp} & 0 \\
0 & 0 & \chi_{\|}
\end{array}\right)
$$

em que $\chi_{\|}$e $\chi_{\perp}$ são os autovalores correspondentes à susceptibilidade nas direções paralela e perpendicular ao eixo de simetria, respectivamente, sendo $\hat{z} \| \mathbf{n}_{0}$. Interessa-nos a parte anisotrópica de $\overleftrightarrow{\chi}, \chi_{\alpha \beta}^{A}=\chi_{\alpha \beta}-(1 / 3) \chi_{\gamma \gamma} \delta_{\alpha \beta}$ ( $\chi_{\gamma \gamma}$ é o traço do tensor e $\delta_{\alpha \beta}$ é o símbolo de Kronecker), tal que

$$
\overleftrightarrow{\chi}^{A}=\frac{2}{3} \Delta \chi\left(\begin{array}{ccc}
-1 / 2 & 0 & 0 \\
0 & -1 / 2 & 0 \\
0 & 0 & 1
\end{array}\right)
$$

com $\Delta \chi=\chi_{\|}-\chi_{\perp}$. No caso do modelo de partículas na forma de bastões, as equações $2.32 \mathrm{e}$ 2.34 levam ao parâmetro de ordem ${ }^{3}$

$$
Q_{\alpha \beta}=\left\langle P_{2}(\cos \beta)\right\rangle\left(\begin{array}{ccc}
-1 / 2 & 0 & 0 \\
0 & -1 / 2 & 0 \\
0 & 0 & 1
\end{array}\right)
$$

A teoria de Landau foi estendida para o caso de transições de fase de primeira ordem de nemáticos por de Gennes [44]. Considerando o termo de ordem cúbica em 2.31, $B Q^{3}$ ( $B$ constante), consegue-se uma descrição da transição de fase de primeira ordem. Chega-se então a $[45,8]$

$$
f(S, T)=f_{0}(T)+\frac{3}{4} a\left(T-T_{C}^{*}\right) S^{2}+\frac{1}{4} B S^{3}+\frac{9}{16} C S^{4},
$$

sendo $T_{C}^{*}$, neste caso, a temperatura em que a energia livre passa de um mínimo a um máximo.

Na seção 2.4.1 mostraremos o procedimento para a implementação do cálculo do parâmetro de ordem a partir de imagens de SAXS. Os resultados são apresentados na seção 4.1.

\footnotetext{
${ }^{3} \mathrm{~A}$ rigor, mostra-se que $\Delta \chi=(\Delta \chi)_{\max }\left\langle P_{2}(\cos \beta)\right\rangle$, considerando-se as médias orientacionais da susceptibilidade de cada partícula, e se define $Q_{\alpha \beta}=(3 / 2) \chi_{\alpha \beta} /(\Delta \chi)_{\text {max }}$, em que $(\Delta \chi)_{\text {max }}$ é a máxima anisotropia diamagnética [8].
} 


\subsubsection{Cálculo do parâmetro de ordem}

Calculamos os parâmetros de ordem $\bar{P}_{2}$ e $\bar{P}_{4}$ baseados no artigo de Deutsch [46], que obteve expressões analíticas para esses parâmetros relacionadas à medida da intensidade de SAXS. Dado o ângulo $\beta$ entre a direção de orientação de cada partícula de um meio líquido cristalino (em particular, nemático) e o diretor $\mathbf{n}_{0}$, o parâmetro de ordem orientacional

$$
\bar{P}_{n}=\int_{0}^{\pi / 2} P_{n}(\cos \beta) f(\beta) d(\cos \beta),
$$

em que $P_{n}(x)$ é o polinômio de Legendre de ordem $n$, depende da definição da função de distribuição orientacional $f(\beta)$.

Partículas estruturadas em pequenos aglomerados, cujas orientações ficam correlacionadas, porém com distribuições orientacionais $f(\beta)$, têm um padrão de espalhamento [47]

$$
I(\varphi)=\int_{\varphi}^{\pi / 2} f(\beta) \sec ^{2} \varphi\left(\operatorname{tg}^{2} \beta-\operatorname{tg}^{2} \varphi\right)(\operatorname{sen} \beta) d \beta,
$$

em que $\varphi$ é o ângulo azimutal definido como 0 num dos picos (maior intensidade de espalhamento). A expressão 2.38 representa os arcos típicos dos padrões de espalhamento por cristais líquidos, como efeito de um "borramento" (smearing) dos picos (pontos de Bragg) do caso de alinhamento perfeito.

O problema é estimar-se $f(\beta)$, o que pode ser feito supondo-se um modelo para essa distribuição. Outra estimativa para $f(\beta)$, como aproximação empírica, é usar a própria $I(q)$ [48, 49]. Deutsch, no entanto, efetua a inversão analítica dessa expressão e usa o resultado para o cálculo dos polinômios de Legendre $P_{2 n}(\cos \beta)$, chegando a [46]

$$
\bar{P}_{2}=1-N^{-1} \frac{3}{2} \int_{0}^{\pi / 2} I(\varphi)\left\{\operatorname{sen}^{2} \varphi+(\operatorname{sen} \varphi)\left(\cos ^{2} \varphi\right) \ln \left[\frac{(1+\operatorname{sen} \varphi)}{\cos \varphi}\right]\right\} d \varphi
$$

$\mathrm{e}$

$$
\begin{aligned}
\bar{P}_{4} & =1-N^{-1} \int_{0}^{\pi / 2} I(\varphi) \times \\
& \times\left\{\operatorname{sen}^{2} \varphi\left(\frac{105}{16} \cos ^{2} \varphi+\frac{15}{24}\right)+(\operatorname{sen} \varphi) \ln \left[\frac{(1+\operatorname{sen} \varphi)}{\cos \varphi}\right]\left(\frac{105}{16} \cos ^{4} \varphi-\frac{15}{4} \cos ^{2} \varphi\right)\right\} d \varphi,
\end{aligned}
$$

cuja normalização é dada por

$$
N=\int_{0}^{\pi / 2} I(\varphi) d \varphi
$$

Para o cálculo dos parâmetros de ordem, foi feita a integração radial das imagens em um anel que engloba os picos do espalhamento (figura 2.6), de modo a obter-se $I(\varphi)$. O intervalo de integração em $q$ foi definido pelo exame da curva de $I(q)$ integrada, tomando-se a meia 
altura do pico. A implementação do cálculo de 2.39 e 2.40 foi executada por programas que usam as bibliotecas Python PyFAI e FabIO (ver seção 3.4). Foi então ajustada uma função ao resultado da integração, dada por

$$
I_{O P}(\varphi)=C_{1} L\left(\varphi ; \varphi_{1}, v, \delta_{1}\right)+C_{2} L\left(\varphi ; \varphi_{2}, v, \delta_{2}\right)+B_{0}
$$

em que foram usadas duas vezes a função pico da equação 2.21, para os pontos centrais $\varphi_{1}$ e $\varphi_{2}$, com larguras $\delta_{1}$ e $\delta_{2}$; os coeficientes $C_{1}$ e $C_{2}$ são constantes e $B_{0}$ é uma constante representando o fundo (background). Os cálculos dos parâmetros de ordem foram efetuados sobre as curvas ajustadas $I_{O P}(\varphi)$, como uma rotina dentro do próprio programa de ajuste. O cálculo também foi efetuado diretamente sobre os dados puros, sem ajuste, para comparação. Uma vez que o cálculo de $\bar{P}_{2}$ e $\bar{P}_{4}$ é efetuado em apenas meio pico (do alto do pico, $\varphi=0$, até $90^{\circ}$ ), o programa efetuou o cálculo sobre os quatro quadrantes e então obtivemos como resultado a média dos quatro valores calculados e os respectivos erros. Os resultados da integração radial dos picos e dos cálculos dos parâmetros de ordem são mostrados na seção 4.1.

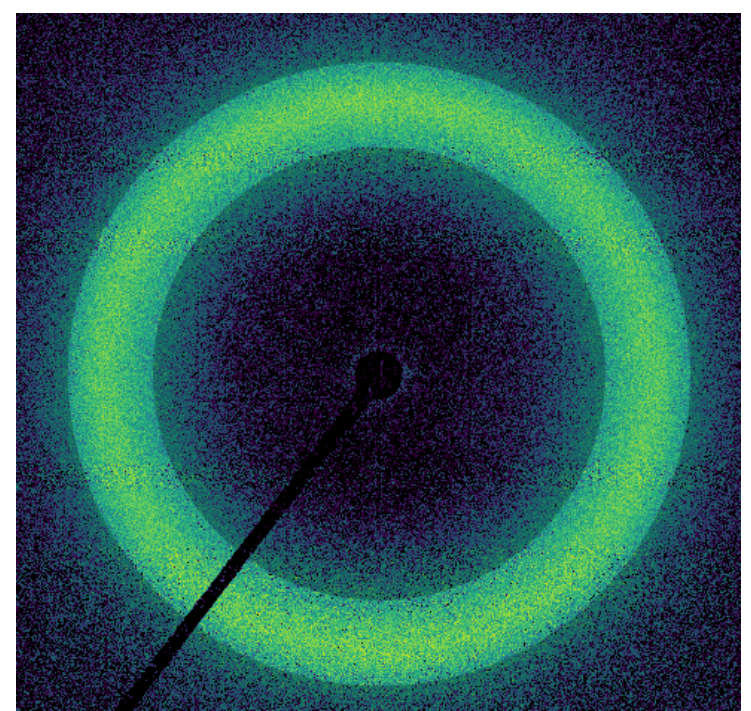

(a) $H_{\|}$

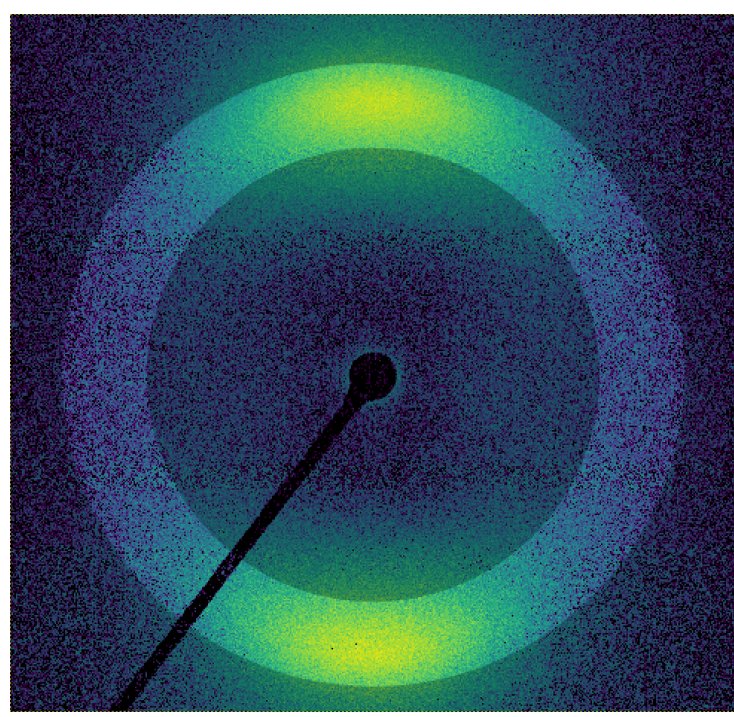

(b) $H_{\perp}$

Figura 2.6. Exemplo de regiões definidas para a obtenção de $I(\varphi)$ pelo cálculo da integração radial das imagens. As imagens acima são da fase $N_{C}$ do liotrópico obtido pela mistura DTAB / $\mathrm{KBr} / 1$ undecanol / $\mathrm{H}_{2} \mathrm{O}$. A figura (a) corresponde à medida da amostra com campo $H$ paralelo à direção do feixe e a figura (b), com campo perpendicular à amostra. 


\subsection{Simulação de SAXS por estruturas micelares}

As técnicas desenvolvidas nesta seção constituem um dos principais objetivos do presente trabalho. A motivação é encontrar uma representação geométrica das estruturas micelares que reproduza razoavelmente os padrões de espalhamento por raios X medidos experimentalmente. A proposta é criar conjuntos de pontos em $\mathbb{R}^{3}$ que se assemelhem a estruturas que aproximadamente representem as micelas. Aceitamos a hipótese de que essas estruturas são similares a elipsoides uniaxiais ou biaxiais e definimos aleatoriamente pontos no interior dos volumes definidos por esses elipsoides, formando uma representação coarsegrained das micelas (figura 2.7).

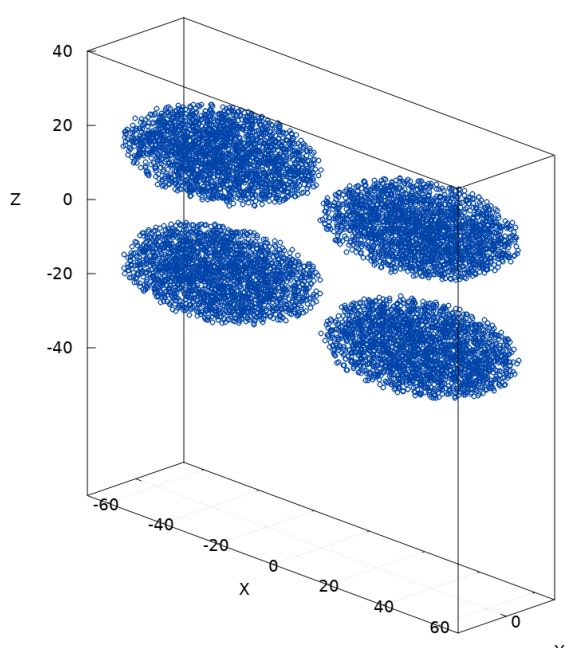

Figura 2.7. Exemplo de representação de estruturas micelares por conjuntos de pontos sorteados (coarse-graining).

A equação de intensidade de espalhamento 2.5 é uma soma dupla sobre todos os $N$ pontos espalhadores,

$$
I(\mathbf{q})=E_{e}^{2} \sum_{i=1}^{N} \sum_{j=1}^{N} f_{i}(\mathbf{q}) f_{j}(\mathbf{q}) \cos \left[-i \mathbf{q} \cdot \mathbf{R}_{i j}\right]
$$

o que implica que o cálculo de $I(\mathbf{q})$ (ou seu processamento) é da ordem $\mathscr{O}\left(n^{2}\right)$ para cada $\mathbf{q}$. Um cálculo do padrão de espalhamento sobre uma "tela" de um hipotético detector de $L \times L$ pontos, por um conjunto de $m$ micelas com $N$ pontos espalhadores cada uma, demandaria $\mathscr{O}\left(L^{2} \times m^{2} \times N^{2}\right)$ operações. Por exemplo, se $m=4$ micelas com $N=5000$ pontos espalhadores (ou beads) cada, uma simulação para uma imagem de $L \times L=500^{2}$ pontos demandaria $\mathscr{O}\left(10^{14}\right)$ operações. Para computadores cujo desempenho é da ordem de 100 Gigaflop $^{4}$, a tarefa tomaria $\mathscr{O}\left(10^{3}\right)$ s, o que é um tempo razoável para testes. Uma vez que o número real

\footnotetext{
${ }^{4}$ Flop é a abreviatura de floating point operation, que se refere ao número de operações de ponto flutuante efetuados por segundo, uma das medidas de velocidade de computadores.
} 
de espalhadores numa micela é muito maior ${ }^{5}$, assim como o número de micelas é da ordem de $10^{16}$ por $\mathrm{mm}^{3}$ (volume típico de espalhamento) ${ }^{6}$, há que se tentar cálculos aproximados e amostragens para que se consigam padrões similares aos experimentais.

Alguns autores tentaram abordar o problema de cálculo de padrões bidimensionais de espalhamento utilizando a estratégia de elementos finitos [50, 51]. No entanto, estes autores sugeriram que seria impossível aplicar tal procedimento ao caso de sistemas compostos por unidades esféricas. Em trabalho recente, Alves, Pedersen e Oliveira [29] sugeriram uma simplificação do cálculo, na qual se substituem as somas sobre todos os produtos escalares por uma única soma ponderada sobre histogramas dos produtos $\mathbf{q} \cdot \mathbf{R}_{i j} \mathrm{em}$ cada direção. Trata-se de um tipo de construção da imagem por amostragem nas diversas direções de q.

Dado o versor $\mathbf{e}_{\mathbf{q}}$, definido na direção de um dado $\mathbf{q}$, constrói-se o histograma de todos os produtos $\mathbf{e}_{\mathbf{q}} \cdot \mathbf{R}_{i j}$, a que chamaremos $h_{\mathbf{q}}\left[\left(\mathbf{e}_{\mathbf{q}} \cdot \mathbf{R}_{i j}\right)_{k}\right]$, sendo $k$ um dos intervalos (bins) do histograma, que contém a contagem das projeções dos $\mathbf{R}_{i j}$ na direção q. A equação 2.5 pode então ser reescrita como

$$
I(\mathbf{q})=\left|E_{e} f_{i}\right|^{2}\left\{N+2 \sum_{k=1}^{n_{b i n s, \mathbf{q}}} h_{\mathbf{q}}\left[\left(\mathbf{e}_{\mathbf{q}} \cdot \mathbf{R}_{i j}\right)_{k}\right] \cos \left[|\mathbf{q}|\left(\mathbf{e}_{\mathbf{q}} \cdot \mathbf{R}_{i j}\right)_{k}\right]\right\},
$$

em que $n_{b i n s, q}$ é o número de intervalos do histograma, e os cálculos dos cossenos podem ser agora efetuados sobre os $q$ numa dada direção. Assim, efetua-se o procedimento proporcional a $n^{2}$ uma só vez em cada direção, de modo que o cálculo para o intervalo de $q$ se transforma em uma soma simples. A resolução do padrão passa a depender das direções $\mathbf{e}_{\mathbf{q}}$ escolhidas, isto é, do passo angular definido para os cálculos. Esse procedimento pode reduzir o tempo de cálculo em até $\mathscr{O}\left(10^{3}\right)$, dependendo da qualidade do padrão de espalhamento.

Há ainda outro procedimento de amostragem utilizado em redes maiores. Trata-se de criar blocos de pontos tomados por amostragem entre todos as beads e efetuar os cálculos independentemente sobre cada um desses blocos. Ou seja, dadas $m$ elipsoides com $N$ pontos cada, suponhamos que queiramos criar $b$ blocos independentes. Tomamos então $n_{B}=m N / b$ pontos aleatoriamente do total para formar o primeiro bloco, outros $n_{B}$ pontos para o segundo e assim sucessivamente, até que todos os pontos pertençam aos blocos. Os cálculos são efetuados por blocos e os resultados, somados ao final. Como a complexidade é $\mathscr{O}\left(n_{B}^{2}\right)$, o tempo de simulação cai $\operatorname{com} b^{2}$, com a pena de perda de estatística.

\subsubsection{Programas da simulação de espalhamento}

Vários programas em linguagem C foram criados para a implementação das simulações descritas acima, havendo dois principais, um para criação dos elipsoides e um para o cálculo da

\footnotetext{
${ }^{5}$ Como estimativa, 100 moléculas por micela $\times 130$ elétrons por molécula $=13000$ elétrons por micela.

${ }^{6}$ Para uma micela cujo eixo maior tenha $50 \AA$ e a camada de solvente tenha cerca de $60 \AA$, o número de micelas é $m=\left(1 \mathrm{~mm}^{3}\right) /\left(60 \times 10^{-7}\right)^{3} \mathrm{~mm}^{3} \approx 5 \times 10^{15}$.
} 
imagem de espalhamento.

\subsubsection{Criação dos elipsoides coarse grained}

O primeiro programa gera um conjunto de coordenadas pseudoaleatórias em $\mathbb{R}^{3}$, com distribuição de densidade constante, que correspondem às posições de pontos espalhadores (beads) no interior do volume elipsoidais. Passaremos a chamar a esse conjunto de coordenadas definidos no volume elipsoidal todo, por associação, também de micelas. Definem-se previamente parâmetros para as dimensões das micelas (os tamanhos de seus eixos maiores), espessura da shell (modelo core-shell), espessura da camada de solvente (para definir as distâncias entre micelas vizinhas), número de elétrons na cauda e na cabeça da molécula de surfactante (para uma estimativa das densidades eletrônicas na definição de um modelo core-shell, ver seção 2.5.1.3), número de beads por micela, número de micelas e outros para a disposição das micelas.

Como é apresentado na seção 4.2, dos resultados, não somente o formato das micelas, como a configuração de sua disposição espacial tem implicação direta no padrão de espalhamento. Assim, partimos de uma configuração do tipo cúbica simples (figura 2.8) para a disposição das micelas e efetuamos diversas modificações em suas posições, procurando reproduzir o que entendemos como uma configurações típicas do caso nemático.

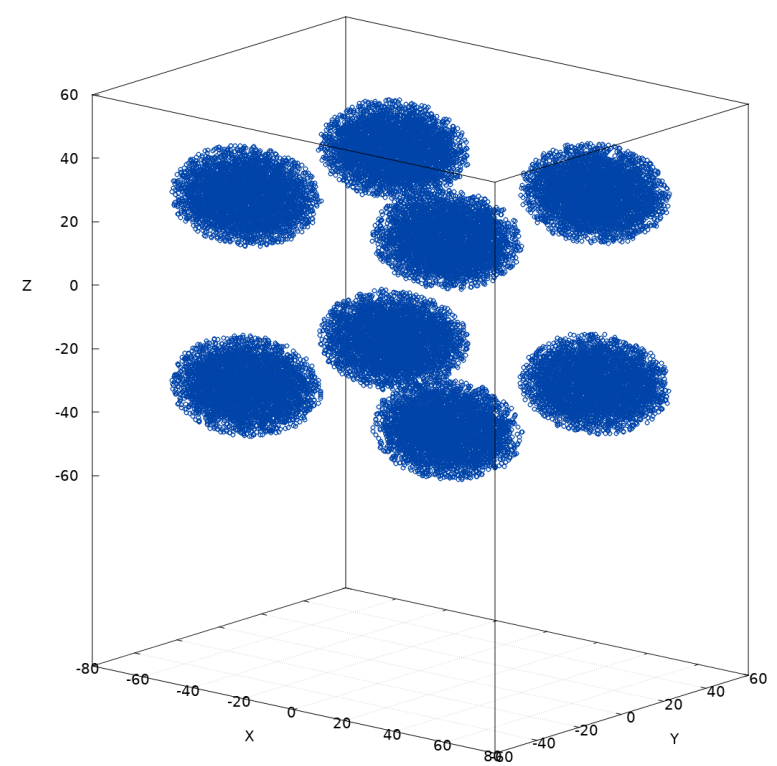

Figura 2.8. Exemplo de representação de estruturas micelares core-shell por conjuntos de pontos sorteados (coarse-graining) em configuração cúbica simples.

Para a montagem do sistema geométrico, são geradas coordenadas arbitrárias a partir de números pseudoaleatórios normalizados para o volume definido pelas dimensões micelares, dadas como parâmetros. No caso do modelo core-shell, a proporção de beads entre 
core é shell definida pela estimativa de densidades eletrônicas em cada região (seção 2.5.1.3). São então calculadas as posições dos centros das micelas, de acordo com suas dimensões e a espessura da camada de solvente, e as coordenadas são transladadas.

Após testes com micelas biaxiais (modelo IBM) e uniaxiais, verificamos que padrões de espalhamento para um pequeno número de micelas na disposição cúbica tende a criar padrões quadrados, que não representam os observados experimentalmente, embora os picos das imagens coincidam com as referentes dimensões da estrutura. Implementamos no programa de geração de micelas uma função que efetua deslocamentos com probabilidade gaussiana em cada direção espacial, quebrando assim a rigidez da ordem espacial, ainda que as micelas preservem sua ordem orientacional. Além disso, criamos funções que executam rotações rígidas ou aleatórias com distribuição gaussiana dos eixos de cada micela, permitindo quebrar ou reduzir a ordem orientacional. Escolhemos a transformação de Tait-Bryan como matriz de rotação, que mantém relação mais evidente com os eixos do laboratório (ver, por exemplo, [52]). Normalmente, efetuamos pequenas rotações para verificação da influência dessas modificações no padrão de espalhamento. A cada modificação na posição das micelas, é efetuada verificação de que não há sobreposição de seus volumes. Novas posições são aceitas somente quando não há “colisão”.

Implementamos também uma função que efetua o deslocamento de uma camada de micelas, de modo a criar uma disposição inicial cúbica de corpo centrado, a partir da qual podem ser efetuados outros deslocamentos. Esse arranjo simula maior compactação do sistema, ainda que preservando as distâncias definidas pela camada de solvente. Outros deslocamentos também foram efetuados a partir desta configuração inicial.

Foram ainda implementados programas auxiliares que efetuam translações e rotações em todo o conjunto de micelas, de modo a tentar alternativas à rigidez da configuração cúbica e compensar os efeitos de tamanho finito da rede (finite size effects). Nas figuras das seções A.1.6 e A.1.7 são mostradas disposições de grupos de micelas rotacionadas conjuntamente. Tomemos, por exemplo, um conjunto de $4 \times 4 \times 4$ micelas, que podemos considerar como quatro camadas ao longo do eixo $y$ de 16 micelas no plano $x z$. É primeiramente gerado um grupo de $4 \times 4=16$ micelas dispostas em rede no plano $x z$. Efetua-se rotação rígida de, digamos, $30^{\circ}$ em cada micela em torno do eixo $y$ e, então, outra rotação de $-30^{\circ} \mathrm{em}$ todo o conjunto das 16 micelas. Com isto, a orientação das micelas é preservada, mas a disposição em rede ganha um aspecto diagonal. Repete-se o mesmo procedimento com passos angulares $20^{\circ}$, para os outros grupos de 16 micelas, de modo que a disposição das quatro redes quadradas tem seu efeito reduzido no padrão da imagem.

\subsubsection{Simulação de SAXS pelas estruturas criadas}

Definida uma configuração das micelas, passamos à simulação do espalhamento por raios X. O programa tem como funções principais as de cálculo dos histogramas e de espalhamento. 
Após ler as coordenadas dos conjuntos de pontos gerados no programa anterior, o primeiro passo é separar os pontos em blocos, se for o caso. Os parâmetros necessários à simulação são o passo angular, o número de pontos $q_{i}$ em cada direção radial sobre a "tela", e parâmetros físicos para normalização dos dados, como o comprimento de onda, as dimensões dos pixels, a distância entre a amostra e o detector, um fator relativo à amplitude de espalhamento de um ponto (fator $A_{e}$ na equação 2.43) e o raio de uma bead, tomada como esférica.

A partir dos blocos formados, o processamento é separado em intervalos angulares para multithreading, caso haja vários núcleos disponíveis. Cada processador então efetua o cálculo do histograma e do espalhamento. Cada histograma foi montado dinamicamente, porque seria inviável armazenar o grande número de produtos escalares para decidir a posteriori como seriam definidos seus intervalos. Assim, são armazenados alguns milhares de produtos a serem inseridos num histograma, que tem seus intervalos recalculados se o intervalo de valores se altera.

Ao final, os resultados definidos em coordenadas polares foram projetados para coordenadas cartesianas de uma tela por interpolação linear.

Os programas foram compilados com gcc nas versões 8.3 e 10.2, com optimização -O3 e rodados em plataforma GNU/Linux.

\subsubsection{O modelo core-shell}

Um modelo core-shell ${ }^{7}$ é uma representação de uma partícula em que há distinção entre uma região central, o core (núcleo), e sua região (ou regiões) mais externa(s), a shell (casca). As estruturas micelares em análise possuem justamente duas regiões distintas, em direta correspondência ao modelo core-shell: um volume central que engloba as caudas das moléculas anfifílicas, e uma região superficial, que compreende as cabeças polares dessas moléculas. Como as densidades eletrônicas são fundamentais para o estudo de espalhamento por raios $\mathrm{X}$ e as duas regiões se distinguem nesse aspecto, faz sentido que apliquemos tal modelo às micelas.

Uma micela possui número de agregação da ordem de $10^{2}$. Uma típica molécula anfifílica, com uma cadeia de 12 carbonos deve ter 12(6+2)=96 elétrons (dos átomos de carbono e de hidrogênio) em sua cauda, isto é, algo também da ordem de $10^{2}$ elétrons. Há portanto $\mathscr{O}\left(10^{4}\right)$ elétrons apenas no núcleo da micela. Uma simulação computacional com números dessa ordem por micela pode tornar-se inviável. Assim, definimos o número total conveniente de centros espalhadores (beads) por micela, $N$, e cuidamos de manter a proporção das densidades eletrônicas ao definir o número de centros espalhadores em cada região, $N_{c}$ no core e $N_{s}$ na shell.

Pode-se adotar como aproximação uma densidade média no core, pois as regiões de

\footnotetext{
${ }^{7}$ Usaremos a já consagrada expressão em língua inglesa.
} 
hidrocarbonetos encontram-se em estado líquido à temperatura ambiente ([11], p. 536). Usaremos a mesma aproximação para a shell. O objetivo aqui é a obtenção de uma razão aproximada entre o número de centros espalhadores no core e na shell para a execução das simulações.

Definimos a diferença de densidade eletrônica em relação ao meio num volume $V$ como a relação $\delta \rho=\delta n_{e} / V$, sendo $n_{e}$ o número total de elétrons em $V$ em relação à média do meio. A relação entre as densidades eletrônicas da shell e do core é

$$
\rho_{r e l}=\frac{\delta \rho_{s}}{\delta \rho_{c}}=\frac{\delta n_{e, s} / V_{s}}{\delta n_{e, c} / V_{c}}=\frac{\delta n_{e, s}}{\delta n_{e, c}} \frac{V_{c}}{V_{s}}
$$

sendo o índice $s$ referente à shell e $c$, ao core. O número de elétrons na micela é $\delta n=\delta n_{c}+\delta n_{s}$ e, usando a relação 2.44 ,

$$
\begin{aligned}
\delta n_{e, s} & =\delta n-\delta n_{e, c}=\rho_{r e l} \frac{V_{s}}{V_{c}} \delta n_{e, c}, \\
\therefore \delta n_{e, c} & =\delta n\left(1+\rho_{r e l} \frac{V_{s}}{V_{c}}\right)^{-1} .
\end{aligned}
$$

Dados o número de agregação $(M)$, o número de elétrons na cauda da molécula anfifílica em relação ao meio $\left(\delta n_{t}\right)$, e o número de elétrons na cabeça polar da molécula em relação ao meio $\left(\delta n_{h}\right), \delta n_{e, c}=M \delta n_{t}$, e $\delta n_{e, s}=M \delta n_{h}$, logo

$$
\rho_{\text {rel }}==\frac{M \delta n_{h} / V_{s}}{M \delta n_{t} / V_{c}}=\frac{\delta n_{h}}{\delta n_{t}} \frac{V_{c}}{V_{s}}
$$

Para a simulação, consideramos os números de centros espalhadores proporcionais às densidades eletrônicas. Podemos então usar a equação 2.46 e reescrever 2.45 como

$$
N_{c}=N\left(1+\frac{\delta n_{h}}{\delta n_{t}} \frac{V_{c}}{V_{s}} \frac{V_{s}}{V_{c}}\right)^{-1}=N\left(1+\frac{\delta n_{h}}{\delta n_{t}}\right)^{-1}
$$

em que substituímos o número relativo de elétrons no core pelo respectivo número de centros espalhadores nesse volume, $N_{C}$, e $N$ é o número total de centros espalhadores (definidos no início de cada simulação). Obtêm-se assim os números de centros espalhadores,

$$
\begin{aligned}
& N_{c}=\frac{\delta n_{t}}{\delta n_{h}+\delta n_{t}} N, \\
& N_{s}=\frac{n_{h}}{\delta n_{h}+\delta n_{t}} N .
\end{aligned}
$$

Se fizermos a aproximação de que a densidade eletrônica do meio (solvente) é nula, basta a contagem do número de elétrons na cauda e na cabeça da molécula anfifílica. O contraste deve ser considerado para comparações com valores numéricos mais exatos, no entanto. 


\section{Capítulo 3}

\section{Técnicas e procedimentos experimentais}

São aqui apresentados os procedimentos experimentais usados na preparação das amostras e as técnicas de medidas relevantes para sua caracterização.

\subsection{Preparação das misturas liotrópicas}

As amostras liotrópicas usadas no presente trabalho têm, de modo geral, em sua composição: um surfactante principal (laurato de potássio, $\mathrm{KL}$ : $\mathrm{C}_{12} \mathrm{H}_{23} \mathrm{KO}_{2}$; dodecil sulfato de sódio, SDS: $\mathrm{C}_{12} \mathrm{H}_{25} \mathrm{NaO}_{4}$ S; brometo de dodecil trimetilamônio, DTMABr ou DTAB: $\mathrm{C}_{15} \mathrm{H}_{34} \mathrm{BrN}$ ); um surfactante secundário, como 1-decanol $\left(\mathrm{C}_{10} \mathrm{H}_{22} \mathrm{O}\right)$ ou dodecanol $\left(\mathrm{C}_{12} \mathrm{H}_{26} \mathrm{O}\right)$, necessário para a formação da fase biaxial [16, 2]; água pura; em alguns casos, um sal como $\mathrm{KBr}$ ou $\mathrm{NaBr}$, que tende a estabilizar as misturas e ampliar o intervalo de temperaturas da fase biaxial [53]. As representações da estrutura química e de modelo atômico das moléculas do surfactante principal de cada mistura são apresentadas na figura 3.1. Em particular, os resultados da dinâmica do diretor nemático por DLS foram obtidos a partir do laurato de potássio (figura 3.1a) e os resultados para o diagrama de fases da referência [32] foram obtidos a partir da mistura baseada em SDS (figura 3.1b). Os resultados para o DTMABr (figura 3.1c) de SAXS foram obtidos em um intervalo maior de q, possível em função de equipamento Xeuss 2.0 (Xenocs), que pôde ser configurado para distâncias de até 2,5 m entre amostra e detector (Pilatus 300k), portanto alcançando $q \approx 0,04 \AA^{-1}$ com fonte de cobre ${ }^{1}$, o que corresponde a informações sobre de diâmetro típico de até $\phi \approx 75 \mathrm{~nm}$.

Para a preparação de uma mistura, é feito o cálculo da estequiometria em massa, e os componentes da mistura são pesados em balança de precisão (até décimos de miligramas). A mistura, colocada em tubo de ensaio, é agitada em vórtice por dois ou três minutos, em velocidade variável, e então submetida a centrifugação, em geral por $30 \mathrm{~min}$ a $4000 \mathrm{rpm}$. O processo de vórtice e centrifugação é repetido duas ou três vezes, até a total homogeneização da amostra. Algumas amostras mais sensíveis à precipitação com a temperatura podem

\footnotetext{
${ }^{1}$ Equação 2.2, calculando-se o ângulo máximo de espalhamento, e usando-se $\lambda\left(K_{\alpha}\right)$ do cobre.
} 
exigir tempos mais curtos de centrifugação, com velocidades menores; é o caso da mistura usada com SDS, que foi centrifugada sempre por menos de 15 min a, no máximo, $1500 \mathrm{rpm}$.

$\mathrm{K}^{+}$<smiles></smiles>

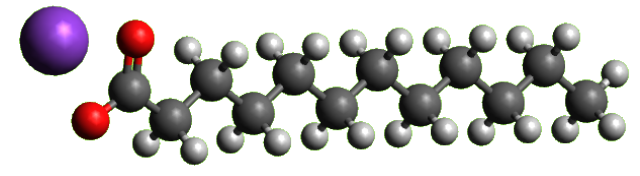

(a) Laurato de potássio (KL: $\mathrm{C}_{12} \mathrm{H}_{23} \mathrm{KO}_{2}$ ). CMC: $2.512 \times 10^{-2} \mathrm{M}$ [54], CMC: $2.5 \times 10^{-3} \mathrm{dm}^{3} / \mathrm{L}$ [55].

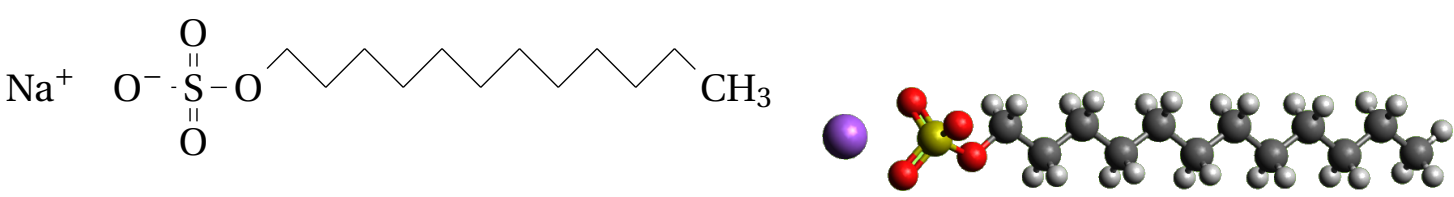

(b) Dodecil sulfato de sódio (SDS: $\mathrm{C}_{12} \mathrm{H}_{25} \mathrm{NaO}_{4} \mathrm{~S}$ ). CMC: $8.3 \times 10^{-3} \mathrm{~mol} / \mathrm{dm}^{3}$.

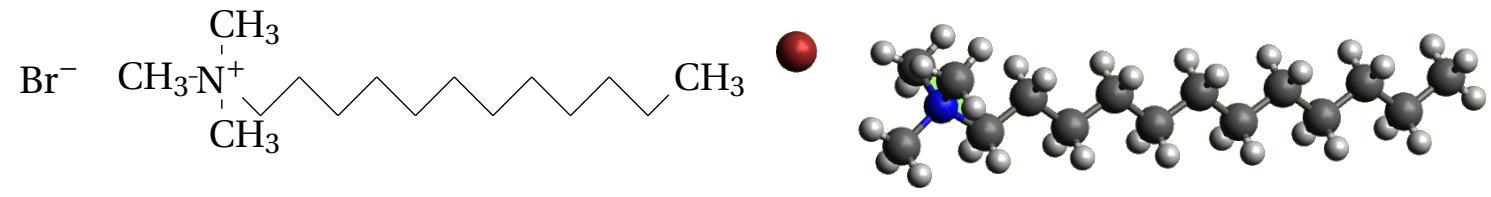

(c) Brometo de dodecil trimetilamônio (DTMABr: $\mathrm{C}_{15} \mathrm{H}_{34} \mathrm{BrN}$ ). CMC: $2.03 \times 10^{-2} \mathrm{~mol} / \mathrm{dm}^{3}$.

Figura 3.1. Representações da estrutura química e do modelo atômico das principais moléculas surfactantes usadas nas misturas estudadas neste trabalho.

As estequiometrias das misturas, apresentadas na tabela 3.1, foram definidas pelo professor doutor Erol Akpinar, a partir de trabalhos em colaboração com o Grupo de Fluidos Complexos - IF-USP, nos quais foram estudados os intervalos das fases nemáticas em função de diferentes surfactantes, comprimentos de cadeias carbônicas do segundo surfactante, presença de sal, etc $[56,57,58]$.

Após a homogeneização, é normalmente efetuada a dopagem da amostra com ferrofluido $[2,59]$. A presença de nanopartículas magnéticas reduz em muito o tempo de alinhamento do sistema na presença de um campo magnético. A ação específica das partículas sobre o alinhamento da amostra, isto é, a causa do acoplamento entre campo e diretor ainda é motivo de dúvida. Pode-se especular sobre um acoplamento magnético entre o campo local dos grãos e o acoplamento mecânico. Façamos então uma avaliação aproximada da interação magnética, considerando partículas de dimensão característica $\phi$, com concentração em volume $\eta$ na suspensão. O número de grãos é $n=\eta V_{F} / V_{P}=6 \eta V_{F} /\left(\pi \phi^{3}\right)$, em que $V_{F}$ é o volume de ferrofluido adicionado (total pipetado), $\eta$ é a porcentagem volumétrica de grãos magnéticos e $V_{P}=\frac{4}{3} \pi\left(\frac{\phi}{2}\right)^{3}$ é o volume de cada grão (aproximado como uma esfera de diâmetro $\phi$ ). A concentração final de partículas por volume de amostra é $c=n / V_{S}$, em que 


\begin{tabular}{ll|c|c|c}
\hline \hline & Surfactante principal & \multirow{2}{*}{ Surfactante 2 } & Meio & Sal \\
\cline { 2 - 5 } & & & & \\
\hline \hline & KL (\% mol/mol) & 1 -decanol & $\mathrm{H}_{2} \mathrm{O}$ & - \\
\hline$\left(N_{D}\right)$ & 2.98 & 1.23 & 95.79 & \\
\hline$\left(N_{C}\right)$ & 3.23 & 1.22 & 95.55 & \\
\hline \hline & SDS (g) & 1 -decanol & $\mathrm{D}_{2} \mathrm{O}$ & - \\
\hline & 0.289 & 0.0532 & $\left.{ }^{*}\right)$ & \\
\hline \hline & DTAB $(\mathrm{g})$ & $\mathrm{DDeOH}$ & $\mathrm{H}_{2} \mathrm{O}$ & $\mathrm{NaBr}$ \\
\hline & 0.5428 & 0.1223 & 0.5930 & 0.0115 \\
\hline \hline
\end{tabular}

Tabela 3.1. Composição e respectivas estequiometrias para cada amostra usada no presente trabalho. $\left({ }^{*}\right) \mathrm{O}$ caso da mistura com SDS teve os valores de $\mathrm{D}_{2} \mathrm{O}$ modificados para o mapeamento do diagrama de fases, sendo os valores para cada mistura: 0.6020, 0.6228, 0.6436, 0.6644, 0.6768 .

$V_{S}$ é o volume da amostra. Considerando que os grãos estejam distribuídos uniformemente numa rede cúbica, o volume aproximado por grão é de aproximadamente $c^{-1}$, logo a aresta do cubo da rede é

$$
\ell=V_{G}^{1 / 3}=c^{-1 / 3}=\left(\frac{V_{S}}{n}\right)^{\frac{1}{3}}=\left(\frac{\pi}{6} \frac{V_{S}}{\eta V_{F}}\right)^{\frac{1}{3}} \phi .
$$

Foram utilizados ferrofluidos comerciais, que apresentam de $2 \%$ a $4 \%$ de concentração de nanopartículas em volume, para dopagens de cerca de $1 \mu \mathrm{L}$ por grama de amostra, correspondendo a cerca de $10^{13}$ partículas por $\mathrm{mL}$. Em alguns casos, foram feitas dopagens mais fracas, resultando em cerca de $10^{12}$ partículas por mL, ou mesmo não foram efetuadas dopagens, a título de comparação (concentrações mais altas de ferrofluido na presença de campos magnéticos podem acarretar formação de aglomerados da ordem de poucos micrômetros, que podem prejudicar o alinhamento por ação mecânica).

Usando valores típicos em 3.1, tem se $\ell \approx 500 \mathrm{~nm}$. A energia de interação magnética dipolo-dipolo é dada por

$$
U\left(\mathbf{r}, \mathbf{m}_{1}, \mathbf{m}_{2}\right)=-\frac{\mu_{0}}{4 \pi}\left[3 \frac{\left(\mathbf{m}_{1} \cdot \mathbf{r}\right)\left(\mathbf{m}_{2} \cdot \mathbf{r}\right)}{r^{5}}-\frac{\left(\mathbf{m}_{1} \cdot \mathbf{m}_{2}\right)}{r^{3}}\right],
$$

em que r é a distância entre os dipolos 1 e 2, $\mathbf{m}_{1,2}$ é o momento de dipolo magnético de cada partícula e $\mu_{0}=4 \pi \times 10^{-7} \mathrm{~N} / \mathrm{A}^{2}$ é a permeabilidade do vácuo. Pode-se considerar como valor típico da energia de interação

$$
U \sim \frac{\mu_{0}}{4 \pi} \frac{m^{2}}{r^{3}}
$$

A relevância da interação dipolo-dipolo pode ser estimada pela relação $\lambda$ entre $U$ e a 
energia térmica,

$$
\lambda=\frac{U}{k_{B} T} \sim \frac{\mu_{0}}{4 \pi} \frac{m^{2}}{r^{3} k_{B} T}
$$

em que $m=|\mathbf{m}|, k_{B}=1.38 \times 10^{-23} \mathrm{~J} . \mathrm{K}^{-1}$ é a constante de Boltzmann e $T=300 \mathrm{~K}$ é a temperatura ambiente. Para um grão de ferrofluido de magnetita, o momento $m$ pode ser estimado como a saturação da magnetização $(\sigma)$ de uma esfera $\operatorname{com} \phi=10 \mathrm{~nm}$ de diâmetro. A magnetização de saturação da magnetita é $\sigma \approx 90 \mathrm{~A} \cdot \mathrm{m}^{2} \cdot \mathrm{kg}^{-1}$, o volume de um grão é $V_{P}=\frac{\pi}{6} \phi^{3} \approx 524$ $\mathrm{nm}^{3}$ e a densidade de magnetita é $\rho=5.2 \mathrm{~g} . \mathrm{cm}^{-3}$, portanto $m=\sigma V \rho \approx 2.5 \times 10^{-19}$ A.m ${ }^{2}$. Usando o valor de referência $r \approx 500 \mathrm{~nm}$, então

$$
\lambda=\frac{U}{k_{B} T} \sim \frac{\left(4 \pi \times 10^{-7}\right)}{4 \pi} \frac{\left(2.5 \times 10^{-19}\right)^{2}}{\left(5 \times 10^{-7}\right)^{3}\left(1.38 \times 10^{-23}\right)(300)} \approx 10^{-5} .
$$

Considerando ainda duas partículas a distância bastante próxima uma da outra, com $r \approx \phi=10 \mathrm{~nm}$, a razão acima é $\lambda \approx 1,5$, portanto o acoplamento de dipolos é desprezável.

A influência do acoplamento entre campo e diretor nemático é, então, provavelmente, de caráter mecânico. De fato, pode-se comparar a energia elástica de um grão quando alinhado paralela ou perpendicularmente a $\mathbf{n}_{0}$. Tome-se a constante elástica de Frank média de um cristal líquido nemático (ver eq. 3.9, seção 3.5.2), $\bar{K}=\left(K_{1}+K_{2}+K_{3}\right) / 3$, cujo valor é da ordem de $10^{-6}$ dyn [60, 24]; dado que a dimensão típica das partículas é da ordem de $\phi \sim 10 \mathrm{~nm}$ $=10^{-6} \mathrm{~cm}$, a energia necessária para mudar a orientação do eixo alinhado a $\mathbf{n}_{0}$ é da ordem de $\bar{K} \phi \sim 10^{-12}$ erg $=10^{-19} \mathrm{~J}$, ao passo que $k_{B} T \sim 10^{-14} \mathrm{erg}=10^{-21} \mathrm{~J}$, ou seja, $\bar{K} \phi / k_{B} T>>1$. Logo o acoplamento mecânico entre as partículas anisométricas e o diretor nemático é o fator relevante para a orientação do sistema dopado (nemáticos transmitem torque, [24]) e submetido a campo magnético fraco [2].

O processo de dopagem é efetuado com microseringa, colocando-se a gota na superfície da amostra liotrópica; para menores concentrações, dilui-se a mistura de ferrofluido em água pura e então se efetua a dopagem com a microseringa. Passa-se então a nova agitação por vórtice e centrifugação, até que se atinja homogeneidade. Neste caso, em função da densidade das nanopartículas magnéticas, o processo de centrifugação deve ser feito a menores velocidades (cerca de 1500 rpm), para que não haja depósito ou se favoreça agregação.

A amostra deve ser utilizada em poucos dias após o preparo, em função de eventual deposição de partículas de ferrofluido ou de evaporação da água, o que altera sua estequiometria e, por conseguinte, a definição de suas fases. Uma vez pronta a amostra, o mapeamento das fases da mistura é efetuado pelas técnicas descritas nas seções 3.2, 3.3 e 3.4 a seguir. 


\subsection{Microscopia óptica de luz polarizada}

A microscopia óptica de luz polarizada (MOLP) é utilizada para identificar as texturas das amostras. Um microslide é preenchido com a amostra por capilaridade, selado com resina dental (endurecida com UV) e então colocado entre dois polarizadores cruzados perpendicularmente, fazendo um ângulo de $45^{\circ}$ em relação a seus eixos. No caso presente, foi usado um microslide de $100 \mu \mathrm{m}$ de espessura, $1 \mathrm{~mm}$ de largura e $50 \mathrm{~mm}$ de comprimento. Foram usados dois ímãs permanentes para a aplicação de um campo magnético constante de aproximadamente 300 Oe no plano da mesa do microscópio (um Leitz-Orhtoplan-Pol, figura 3.2) para o alinhamento da amostra, o que tomava algumas horas. A temperatura do conjunto foi controlada por um dispositivo Instec HS1. Cada amostra foi observada por até alguns poucos dias (evitando-se eventual evaporação de seus componentes).
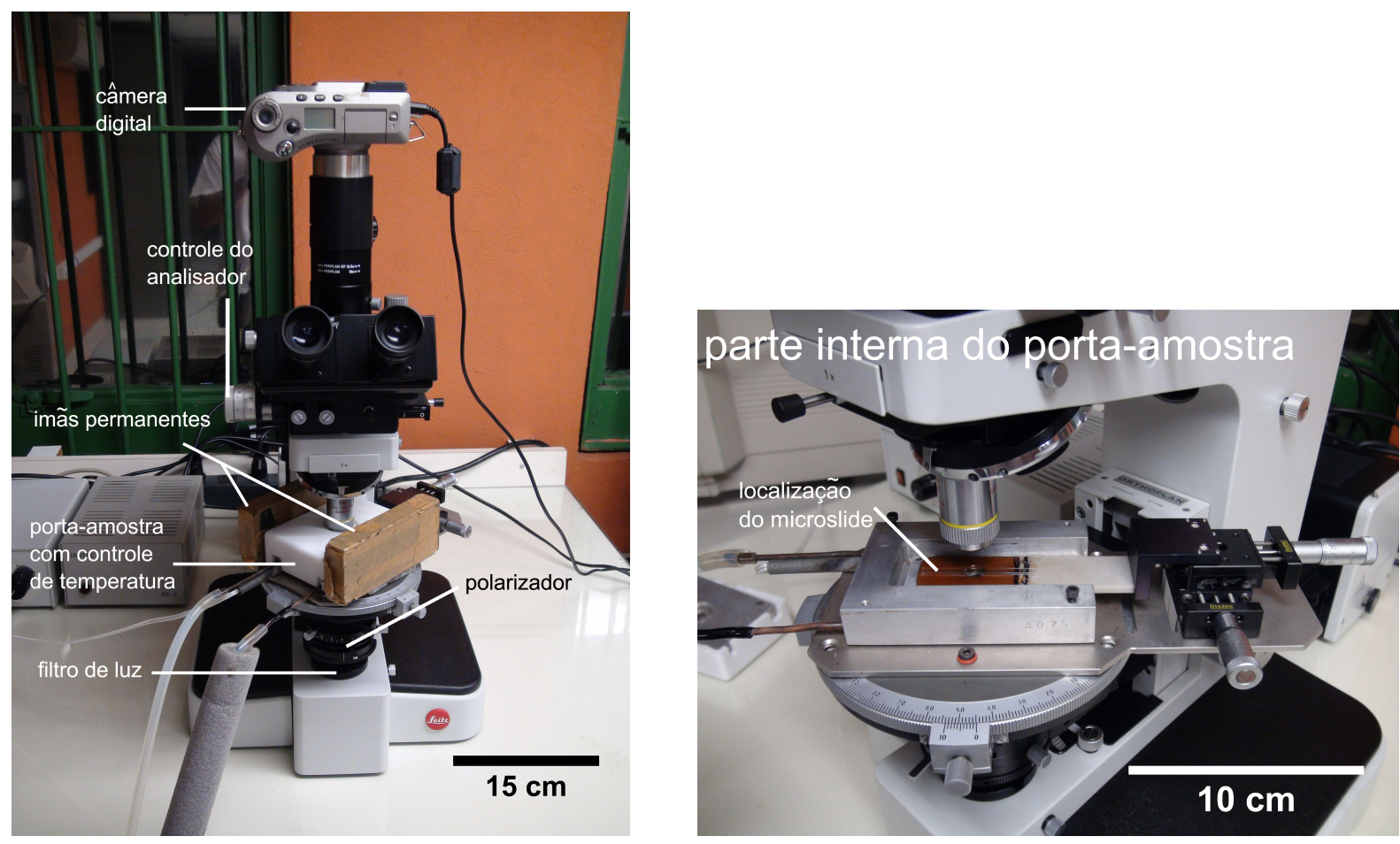

Figura 3.2. Fotografia do aparato usado para a microscopia óptica de luz polarizada. Acima, uma visão geral; abaixo, detalhe do aparato. Figura retirada de [61].

Numa fase isotrópica, da desorientação das micelas resulta uma textura totalmente escura, uma vez que os polarizadores estão cruzados entre si. Na fase discótica $\left(N_{D}\right)$, o diretor nemático alinha-se perpendicularmente à direção do campo magnético; neste caso, em função da posição dos ímãs, o alinhamento tende a ser homeotrópico, implicando também uma textura escura. Em ambos os casos, se a amostra for rotacionada em relação aos polarizadores, a textura continua escura, a menos que o diretor nemático $\mathbf{n}_{0}$ (que aponta na direção da propagação da luz) não esteja bem alinhado. Pode-se diferenciar estes casos de duas formas; primeiro, observando-se as bordas do microslide. No caso isotrópico, as bordas 
continuam escuras; na fase $N_{D}$, há uma tendência de ancoramento das moléculas na parede lateral, logo a textura aparece mais clara nessa região [2]. Como as fases nemáticas são sensíveis ao campo magnético, principalmente com a adição de ferrofluido, faz-se o seguinte teste: retiram-se os ímãs laterais e coloca-se um pequeno ímã (mas forte, de neodímio, cujo campo em sua proximidade pode alcançar $1 \mathrm{kOe}$ ) acima da amostra, de modo que o campo $H$ passa a ser quase paralelo à direção de propagação da luz. Isso altera a direção de $\mathbf{n}_{0}, \mathbf{e}$ veem-se regiões claras e escuras, alternadamente (figura 4.25, em resultados experimentais). Ao se restituírem os ímãs às posições anteriores, retirando-se o ímã pequeno, o diretor volta a se alinhar e a textura torna-se escura novamente. No caso da fase $N_{C}$, o alinhamento é planar e a textura é homogênea, mas relativamente clara. A fase $N_{B}$ tem aparência similar à $N_{C}$ e, em geral, é difícil distingui-las por textura. Já a fase lamelar é clara e não facilmente alterável pela mudança de ímãs, por ter estrutura mais rígida em relação à fase nemática.

\subsection{Conoscopia a laser}

A segunda técnica utilizada para a identificação das fases foi a conoscopia laser [62, 63], que permite a medida das diferenças dos índices de birrefringência da amostra, por sua vez relacionadas ao parâmetro de ordem (tensor dielétrico), identificando-se claramente cada fase nemática. Na técnica de conoscopia laser, um feixe laser (HeNe, $\lambda=632,8 \mathrm{~nm}$ ) é expandido e focalizado por uma lente objetiva para ser direcionado à amostra, colocada em uma célula construída com dois vidros ópticos planos paralelos, com pequeno espaçamento $(\approx 1 \mathrm{~mm}$, correspondente ao caminho óptico na amostra). A luz monocromática e coerente do laser, ao ser aplicada ao conjunto formado por polarizador, lente convergente, amostra e analisador, forma um padrão de interferência típico para cada fase [20], que pode ser visualizado em um anteparo, figura 3.3. ${ }^{2}$

A técnica é baseada na interferência no infinito de duas ondas que atravessam um meio anisotrópico (no caso, a amostra), figura 3.4. Sendo o meio anisotrópico, dada uma onda incidente (com ângulo de incidência $i$ ), haverá duas ondas refratadas, com polarizações ortogonais - uma onda ordinária, com índice de refração $n^{\prime}$ (correspondentemente, ângulo de refração $r^{\prime}$ ), e uma onda extraordinária, com índice de refração $n^{\prime \prime}$ (ângulo de refração $r^{\prime \prime}$ ). O cálculo da diferença nos caminhos das ondas na interface entre o CL e o ar, isto é, na emergência das ondas, leva ao valor das birrefringências principais, $\Delta n=n_{2}-n_{1}$ e $\delta n=n_{3}-n_{2}$, em que $n_{1}, n_{2}$ e $n_{3}$ são os índices correspondentes aos eixos do elipsoide dos índices de refração. A figura 3.5 mostra padrões típicos de interferência produzidos por um liotrópico nas diferentes fases nemáticas; a partir das franjas escuras obtêm-se as diferenças dos índices de refração $\Delta n$ e $\delta n$.

\footnotetext{
${ }^{2}$ Esses padrões são analisados, por exemplo, em [63], cap. 14. Em [20], os padrões são estudados no caso de cristais líquidos liotrópicos.
} 

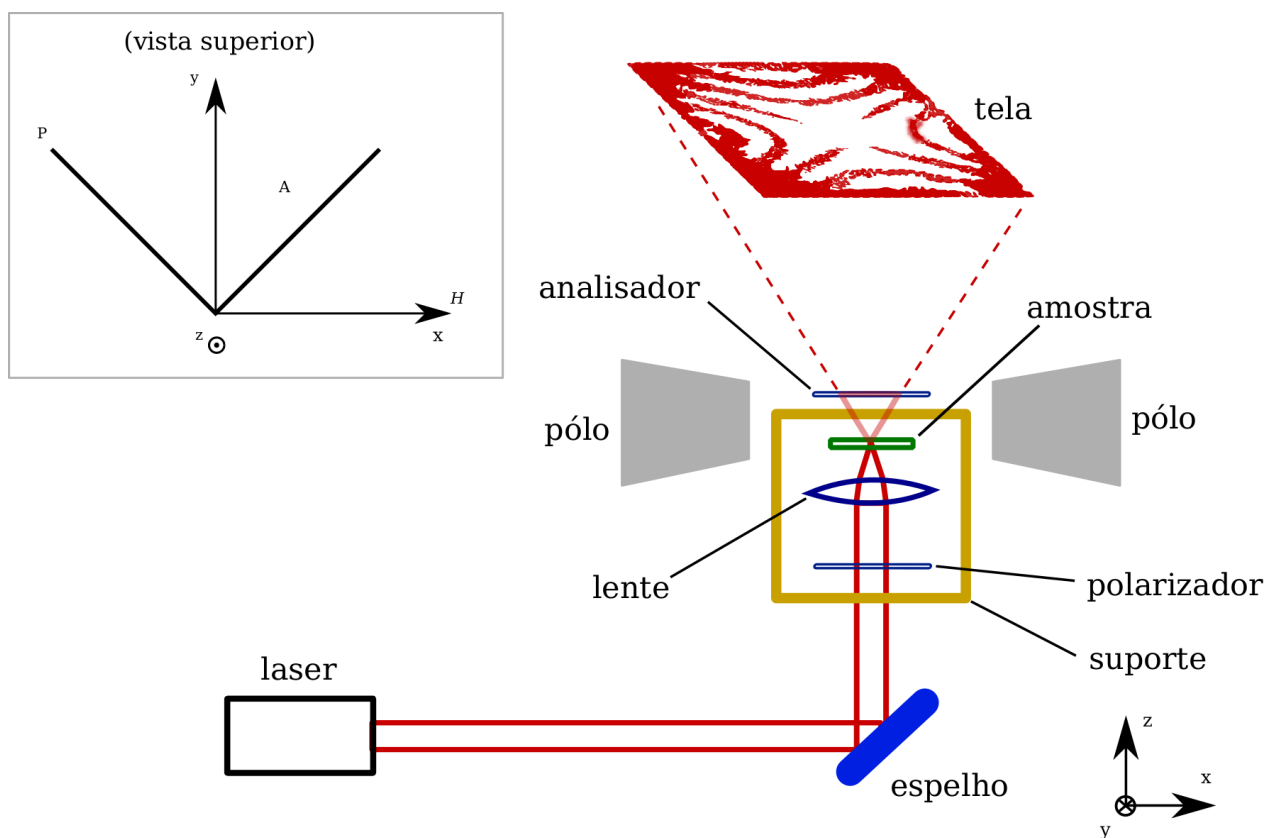

Figura 3.3. Esquema simplificado do sistema de conoscopia (à direita), indicando a fonte laser, o sistema de polarizador $(P)$, lente (objetiva de microscópio) e analisador $(A)$, o suporte da amostra com controle de temperatura, os polos do eletroímã e o padrão de interferência. À esquerda, em vista superior do aparato, o diagrama mostra as posições dos polarizadores em relação ao sistema de eixos: o campo magnético $\mathbf{H}$ encontra-se na direção do eixo $x$, a amostra e a figura de interferência (tela) estão no plano $x y$; a direção do polarizador é perpendicular à do analisador, $\mathrm{e}$ ambos fazem ângulo de $45^{\circ}$ com o campo magnético.

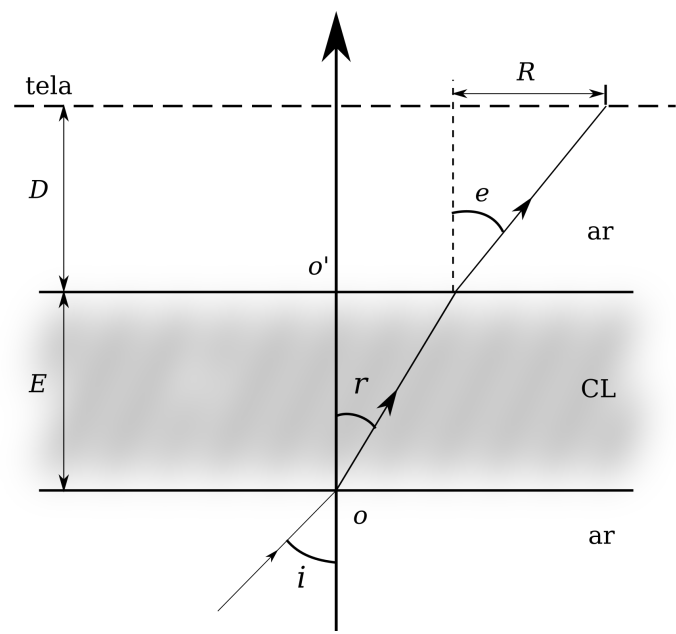

Figura 3.4. Representação do processo de refração de um feixe de luz ao passar pela amostra de cristal líquido (CL, área hachurada). $E$ é a espessura da amostra, $D$ é a distância entre a amostra e o anteparo (tela), $i$ é o ângulo de incidência, $r$ é o ângulo de refração, $e$ é o ângulo de emergência da luz. 


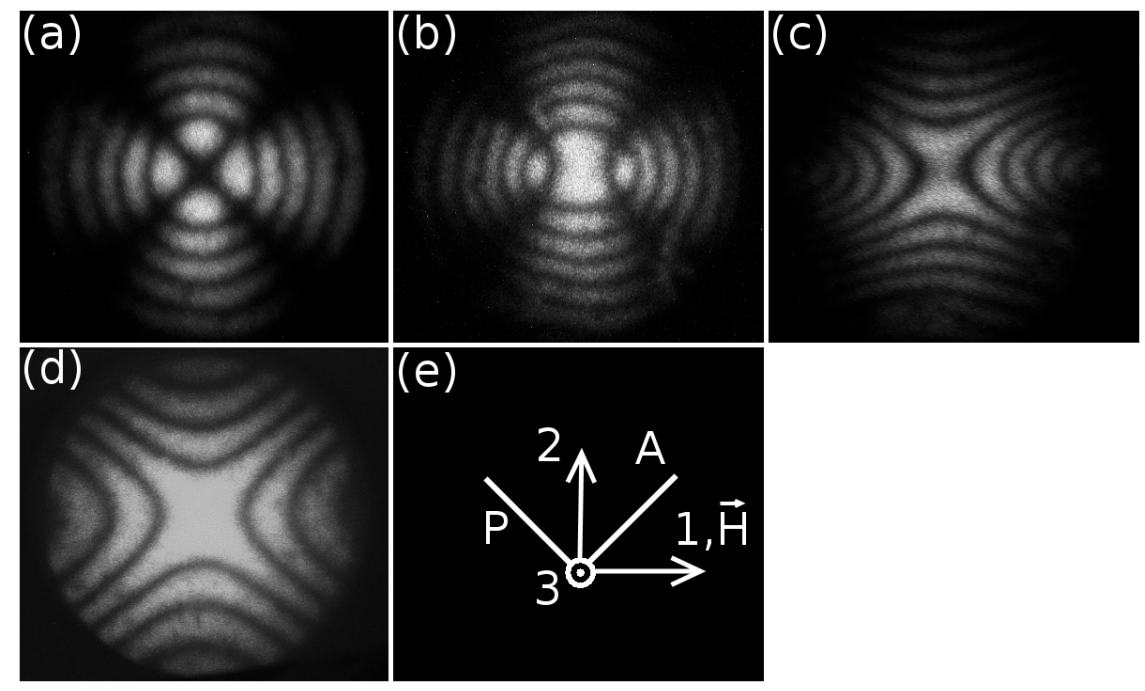

Figura 3.5. Padrões típicos observados em conoscopia. (a) $N_{D}$; (b) $N_{B}$ próximo à transição $N_{D}$ para $N_{B}$; (c) $N_{B}$; (d) $N_{C}$; (e) geometria do experimento: $\mathrm{P}=$ polarizador, $\mathrm{A}=$ analisador, $\vec{H}=$ campo magnético. Figura retirada de [64].

A partir dos ângulos de refração do padrão de interferência produzido, podem-se medir as birrefringências principais $\Delta n$ e $\delta n$ em função da temperatura $T$ (tome-se a figura 3.6 como exemplo) e daí obter o parâmetro de ordem, cujas componentes diagonais são [2]

$$
\begin{aligned}
& \epsilon_{11}=\frac{4\langle n\rangle}{3}\left(\Delta n+\frac{\delta n}{2}\right), \\
& \epsilon_{22}=-\frac{2\langle n\rangle}{3}(\Delta n-\delta n), \\
& \epsilon_{33}=-\frac{4\langle n\rangle}{3}\left(\frac{\Delta n}{2}+\delta n\right),
\end{aligned}
$$

em que $\langle n\rangle$ é o índice de refração médio da mistura.

Observa-se que é necessário o alinhamento prévio do cristal líquido, para o que o aparato de conoscopia deve ser montado de modo que a célula de vidros ópticos situe-se no interior de um campo magnético (H) homogêneo e estático. Esse processo de alinhamento normalmente é efetuado na fase $N_{D}$, e nesse caso a amostra deve ser rotacionada em cerca de $\pm 45^{\circ}$ a cerca de cada $5 \mathrm{~min}$, para que se quebre a degenerescência do alinhamento (na fase $N_{D}$, o alinhamento "natural" do diretor nemático em cada ponto pode ocorrer em qualquer direção do plano perpendicular à direção do campo magnético aplicado). A temperatura $(T)$ da amostra é controlada com boa precisão, pois pode-se prejudicar o alinhamento por instabilidade térmica, e a fase também depende de $T$. A lente convergente, uma objetiva de 
microscópio, garante uma forte convergência do feixe luminoso no centro da amostra (estreita cintura de feixe, beam waist), de modo que se intensifique o efeito das refrações sobre as componentes do campo (E) da onda incidente.

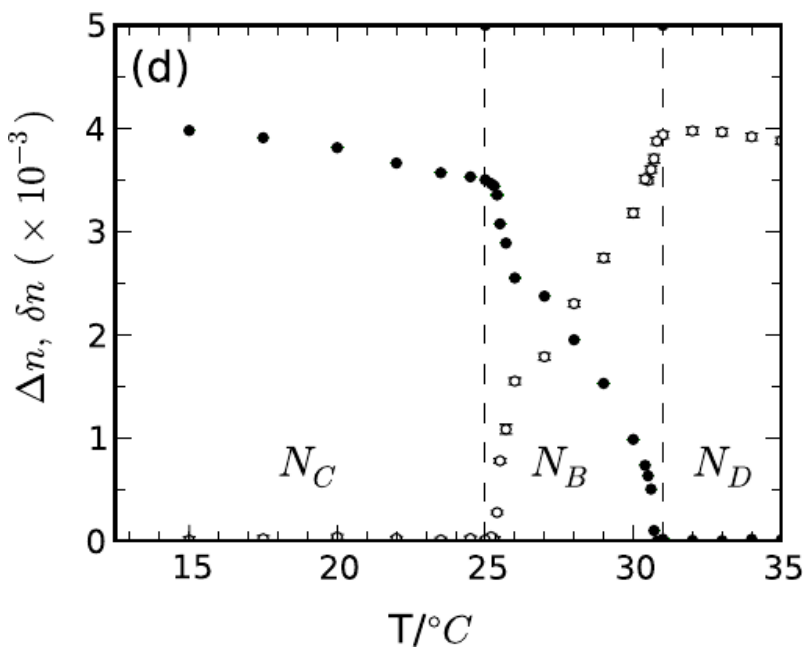

Figura 3.6. Gráfico de birrefringências $\Delta n=n_{2}-n_{1}$ e $\delta n=n_{3}-n_{2}\left(n_{1}, n_{2}\right.$ e $n_{3}$ são os índices de refração em cada direção) em função da temperatura $T$ para a mistura $\mathrm{KL} / \mathrm{K}_{2} \mathrm{SO}_{4} / \mathrm{UndeOH} / \mathrm{H}_{2} \mathrm{O}$. Extraído de [53], fig. 2.

\subsection{SAXS}

No espalhamento de raios-X a baixo ângulo, um feixe de raios $\mathrm{X}$ é colimado, passa pela amostra e é espalhado, de modo que o padrão de espalhamento é projetado na tela de um detector (esquema da figura 2.1). O detector registra em cada ponto a intensidade $I$ do feixe espalhado. É então efetuada a integração azimutal do padrão (seção 2.2), de modo a obter-se uma curva de $I$ em função do módulo do vetor de espalhamento, $q=4 \pi \operatorname{sen}(\theta) / \lambda$ (equação 2.2), sendo $2 \theta$ o ângulo de espalhamento. $O$ ângulo para as integrações azimutais depende da fase do liotrópico, uma vez que o padrão pode tornar-se anisotrópico. Neste caso, a integração pode reduzir-se a um ângulo de cerca de $10^{\circ}$ em torno da direção horizontal (eixo 1, ou $x$ ) ou da direção vertical (eixo 3, ou $z$ ), resultando duas curvas de intensidade $I_{1,3}(q)$. $\mathrm{O}$ tempo de exposição de cada medida variou tipicamente de $600 \mathrm{~s} \mathrm{a} 1800 \mathrm{~s}$, dependendo das condições de alinhamento das amostras in loco.

O presente trabalho foi realizado em dois sistemas Xeuss para SAXS/WAXS, da empresa Xenocs. Ambas as máquinas estão localizadas no IF-USP sob responsabilidade do GFCXIF-USP (figura 3.7). As medidas efetuada neste trabalho usaram fontes e detectores com as mesmas especificações. A diferença se deu em relação à distância entre amostra e detector, que pode ser maior - portanto, permite medidas a ângulos (ou q) menores - numa das máquinas. 


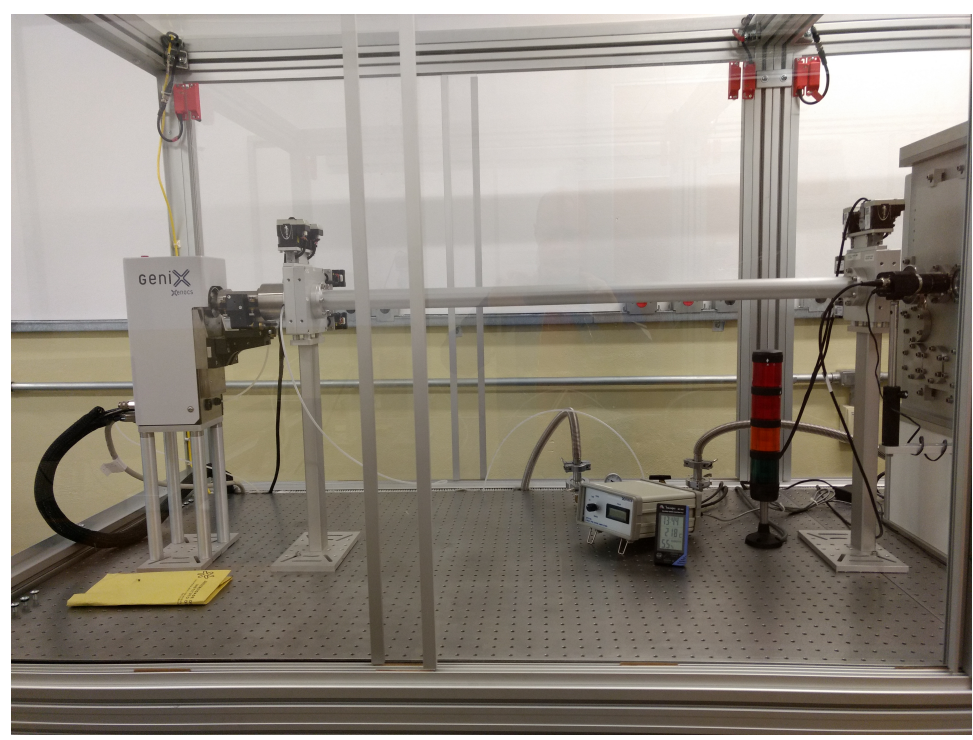

(a) Xeuss 1 .

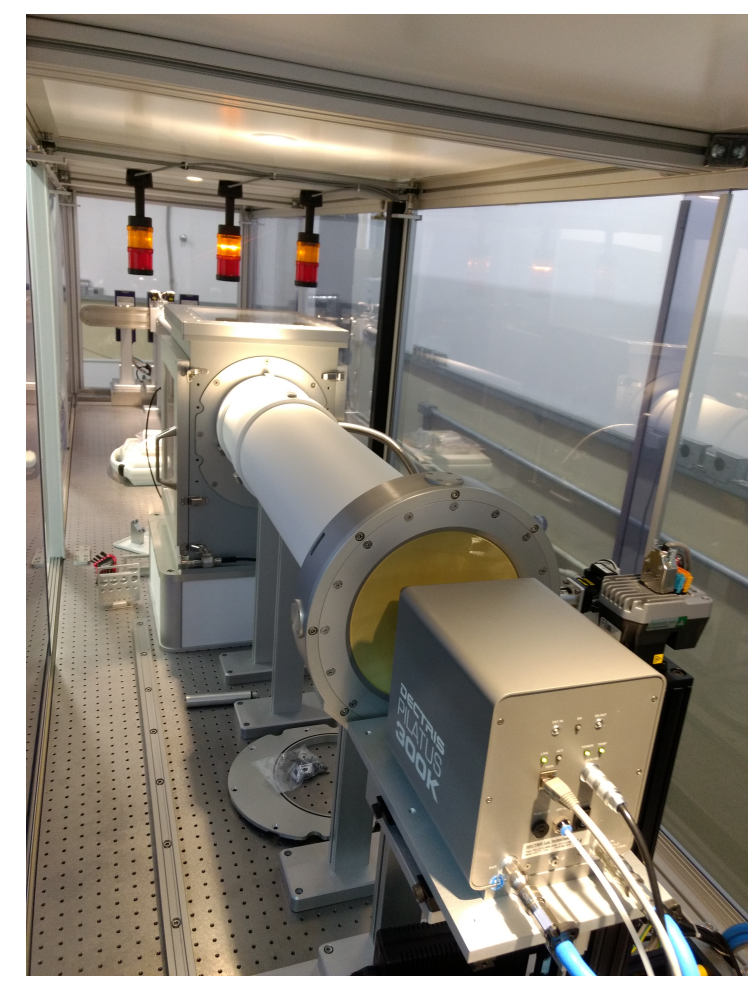

(b) Xeuss 2.

Figura 3.7. Imagens dos equipamentos Xeuss 1 (a) e Xeuss 2 (b). Na figura (a), vê-se a fonte de raios $\mathrm{X}$ à esquerda, o caminho de vácuo em tubo até a câmara, com os blocos quadrados contendo as fendas para colimação. Na mesa óptica, encontram-se um termômetro para controle da temperatura e umidade ambiente, o contador de fótons ligados ao pin diode, colocado no centro do beam stop, e atrás, o conjunto de válvulas e mangueiras de controle de vácuo. A figura (b) é uma vista em perspectiva do equipamento Xeuss 2 . Ao fundo, no alto à esquerda, encontram-se as fontes de raios X; ao centro é vista a câmara para colocação das amostras e o tubo em vácuo com janela de kápton, por onde passa o feixe espalhado; à direita, abaixo, encontra-se o detector Pilatus 300K. 
Os equipamentos têm fontes GeniX com anodo de cobre, que produzem feixes com comprimento de onda $\lambda=1,54189 \AA$, espelho Xenocs FOX para monocromatização e dois conjuntos de fendas para colimação, produzindo um feixe de $0,8 \times 0,8 \mathrm{~mm}^{2}$ ou de $1 \times 1 \mathrm{~mm}^{2}$ de seção transversal. A maior parte do percurso do feixe ocorre em vácuo, para que se evite seu espalhamento pelo ar. As medidas de SAXS no caso presente foram efetuadas com as amostras em ar, ou seja, o trajeto em vácuo é interrompido para colocação das amostras, que devem ser rotacionadas periodicamente para o alinhamento (figura 3.9). As janelas de abertura para o caminho do feixe são seladas com folhas de kápton. O feixe espalhado foi medido por um detector Pilatus $300 \mathrm{~K}$ Dectris, que possui uma matriz de $487 \times 619$ pontos, de $172 \mu \mathrm{m} \times 172 \mu \mathrm{m}$ cada ponto, formada por três conjuntos de retangulares de diodos fotossensíveis. Cada diodo é ligado a um contador eletrônico e a matriz de contagens correspondente é registrada em um computador.

A montagem dos conjuntos retangulares não é contígua, de modo que há duas faixas escuras, sem contagens, no meio da imagem. O procedimento usual para que se desconsiderem os pontos dessa região no processo de integração é a definição de uma "máscara", isto é, um arquivo com uma matriz (em um de seus possíveis formatos, formada por 0s e 1s) que indica quais pontos devem ou não ser considerados nos cálculos. Como alternativa, no presente trabalho, as medidas foram efetuadas duas vezes, sendo que na segunda o detector foi deslocado na vertical em relação à primeira. De todo modo, a "máscara" não é normalmente dispensável. Como a maior parte dos fótons passa pela amostra, o centro do feixe tem alta intensidade, o que requer seu bloqueio, normalmente para poupar o detector e evitar reflexões. O bloqueador do centro do feixe é chamado beam stop, e pode ser visto nas figuras 3.8a e b como um círculo na ponta de uma haste. Assim, a máscara é necessária para "cobrir” os pontos da sombra do beam stop.

As amostras foram inseridas com micropipetas em capilares cilíndricos de borossilicato de 1,5 cm de diâmetro, então selados e colocados verticalmente num porta amostras. A temperatura do sistema foi mantida durante as medidas por um banho térmico Julabo F25ME, cuja precisão é de $0,03^{\circ} \mathrm{C}$. As medidas referentes às amostras com base em SDS foram realizadas com distâncias entre amostra e detector a aproximadamente 0,80 m numa das máquinas e as medidas das amostras de DTAB tiveram essa distância fixa em 0,94 m.

Para o alinhamento das amostras, foram usados dois ímãs de neodímio, cujo campo, horizontal, perpendicular à direção do feixe, tinha intensidade $H \approx 1 \mathrm{kOe}$ (figura 3.9). Pelo sistema de coordenadas adotado em laboratório, o feixe se encontra na direção do eixo $y$, o capilar com a amostra é colocado na vertical ( $z$ ) e o campo magnético é definido na direção $x$. Na fase $N_{C}$, o diretor nemático $\mathbf{n}$ tende a se alinhar com o campo magnético, enquanto que na fase $N_{D}$ o diretor se alinha perpendicularmente a ele, em qualquer direção do plano $y z$. Efetuando-se rotações periódicas (a cada 2 ou $3 \mathrm{~min}$ ) da amostra de $90^{\circ} \mathrm{em}$ torno do eixo $z$ do capilar na fase $N_{D}$, a degenerescência do diretor no plano $y z$ é quebrada e $\mathbf{n}$ se alinha progressivamente ao eixo $z$. 


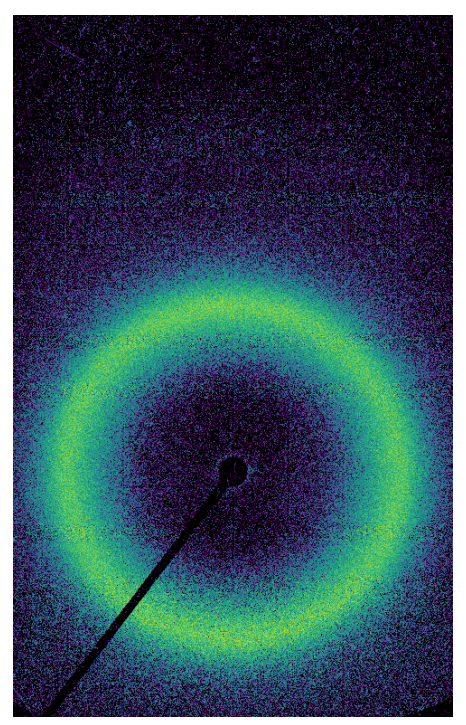

(a)

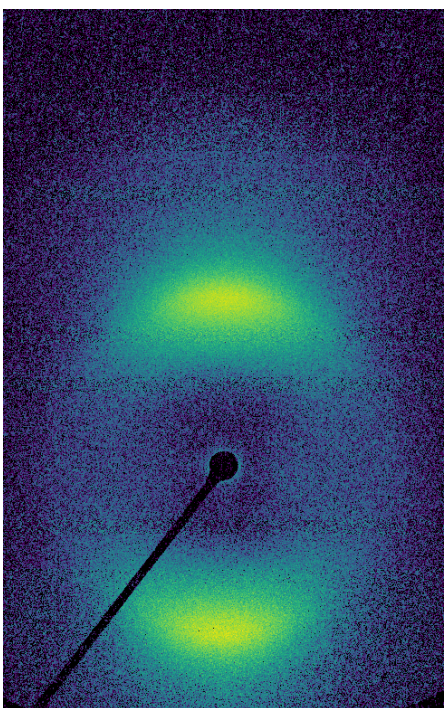

(b)

Figura 3.8. Exemplos de padrões de imagem espalhamento a baixo ângulo em que há sombra causada pelo beam stop (haste com círculo na ponta). Uma "máscara" se faz necessária para eliminar os pontos sem contagem de fótons durante o processo de integração.

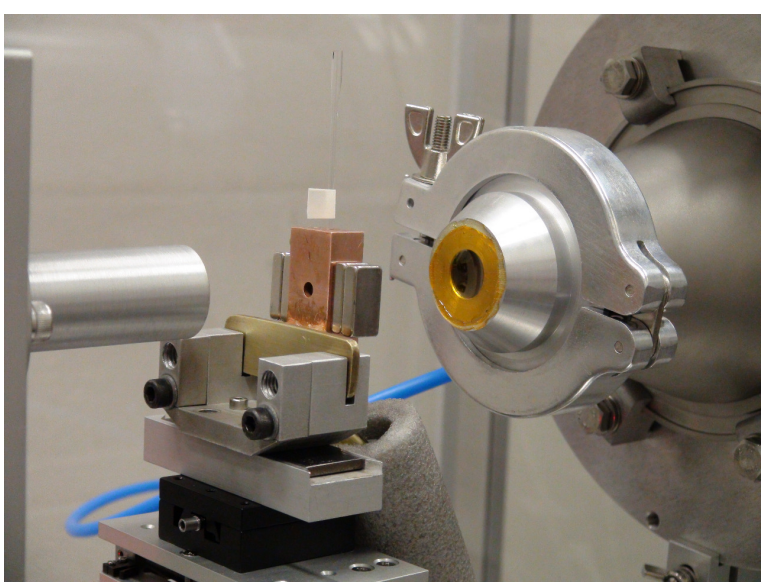

(a) Vista anterior.

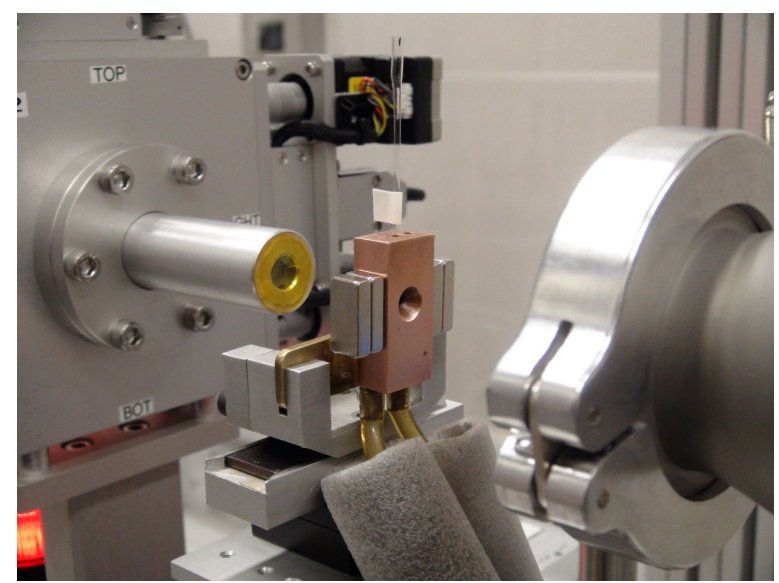

(b) Vista posterior.

Figura 3.9. Imagens do suporte em latão para o capilar de borossilicato, usado no alinhamento e nas medidas de SAXS dos liotrópicos. Veem-se as duplas de ímãs de neodímio nas laterais do suporte (pequenos blocos retangulares). $\mathrm{O}$ furo posterior (figura $\mathrm{b}$ ) tem maior ângulo de abertura para que não se bloqueie o feixe espalhado. O suporte conta com um circuito para circulação de líquido que passa por um banho térmico, para controle da temperatura da amostra. As medidas foram feitas "em ar", isto é, o caminho de vácuo do feixe é interrompido para a colocação da amostra, que deve ser alinhada periodicamente. A "bandeira" branca colada ao capilar é a marcação do posicionamento da amostra para rotação periódica em torno do eixo $z$ no processo de alinhamento. 
Quando a amostra está alinhada, o diretor $\mathbf{n}$ deve apontar na direção do eixo $x$ na fase $N_{C}$, na direção de $z$ na fase $N_{D}$ e os diretores $\mathbf{l}, \mathbf{m}$ e $\mathbf{n}$ devem apontar nas direções de $x, y$ e $z$ na fase $N_{B}$. O processo de alinhamento pode durar de cerca de uma hora a várias horas, dependendo do liotrópico. As medidas ditas "com campo $H$ perpendicular ao feixe" se referem à posição na qual foi feito o alinhamento da amostra, mantendo-se o campo presente; para a medida "com campo $H$ paralelo ao feixe", os ímãs são retirados e a amostra é rotacionada de $90^{\circ} \mathrm{em}$ torno de seu eixo $z$. Em geral, um bom alinhamento é conseguido iniciando-se pela fase $N_{D}$; as demais medidas são efetuadas variando-se a temperatura até se alcancem as fases $N_{B}$ e $N_{C}$.

Acompanhamos o processo de alinhamento fazendo medidas rápidas de 1 ou $2 \mathrm{~min}$, em que se pode verificar que as imagens, principalmente na fase $N_{D}$ tendem a ganhar definição e se estabilizar de modo que os picos mais intensos permanecem na vertical. As medidas que correspondem ao campo paralelo ao feixe eram obtidas retirando-se os ímãs e rotacionando a amostra $90^{\circ}$ em torno de $z$. Esse procedimento garante uma boa medida por ao menos 15 min, que é o tempo típico de uma medida, mas pode variar com a amostra. Como liotrópicos normalmente apresentam razoável espalhamento, o processo de desalinhamento não afeta de modo significativo a medida.

Para a obtenção dos perfis de intensidade de espalhamento da amostra, $I_{\text {sample }}(q)$, como descrito na seção 2.2, é necessário que sejam efetuadas medidas complementares. Uma vez que o padrão de interferência resultante no detector é função das diferenças de densidade eletrônicas locais (eq. 2.7), a intensidade medida é também função do espalhamento do meio em que as partículas se encontram e do porta amostras (como um capilar), denominada intensidade de background ("fundo"). Assim, além da medida da amostra propriamente, é também necessário repetir a medida apenas com o meio líquido, frequentemente, água, em porta amostras similar, para que sua intensidade $I_{b a c k}(q)$ seja subtraída de $I_{\text {sample }}(q)$. No caso de amostra em água dopada com ferrofluido e alinhada, a intensidade do background é obtida pela medida de água com a mesma dopagem de ferrofluido e também alinhada.

São também efetuadas medidas de calibração. Para normalização da intensidade para escala absoluta, repete-se a medida apenas com água e com o correspondente capilar vazio, para que seu espalhamento seja descontado. Também é efetuada medida de uma substância cujos picos são conhecidos, como o behenato de prata, para definição da distância amostradetector. É também efetuada a correção de valores na vizinhança do beam stop (chamada shadow correction) pela medida de um padrão, como carbono vítreo, que tem alto espalhamento, praticamente constante a baixo ângulo. Pode-se ainda descontar a medida de ruído do sistema, em que o detector faz medida durante algum tempo com o feixe totalmente bloqueado.

Idealmente, as medidas de uma amostra e de seu background devem ser efetuadas no mesmo capilar, para que imperfeições de sua geometria sejam apropriadamente desconta- 
das. No entanto, o uso de capilares descartáveis, em função do processo de alinhamento e pela dificuldade de remoção da amostra do capilar, torna esse procedimento inviável. Isso pode ser compensado com uma escolha adequada de capilares.

O cálculo da intensidade final, que incorpora as medidas acima ponderadas pelo tempo e pela transmitância, é dado por [7,65]

$$
I(q)=\left\{\left[\frac{I_{\text {sample }}(q)}{\Phi_{s} T_{s} t_{s}}-\frac{I_{\text {back }}(q)}{\Phi_{b} T_{b} t_{b}}-\frac{I_{\text {noise }}(q)}{t_{\text {noise }}\left(\Phi_{s} T_{s}-\Phi_{b} T_{b}\right)}\right] \frac{1}{I_{\text {shadow }}(q)}\right\} \frac{d \Sigma / d \Omega_{\text {water }, 20^{\circ} \mathrm{C}}}{I(0)_{\text {water }, 20^{\circ} \mathrm{C}}}
$$

em que $I(q)$ é a intensidade final, $I_{\text {sample }}(q)$ é a medida experimental da intensidade de espalhamento da amostra, $I_{b a c k}(q)$ é a medida do background, $I_{\text {noise }}(q)$ é a medida de ruído, $I_{\text {shadow }}(q)$ é a medida de intensidade da shadow correction, $I(0)_{\text {water }, 20^{\circ} \mathrm{C}}$ é a medida de intensidade do espalhamento da água a $20^{\circ} \mathrm{C}, d \Sigma / d \Omega_{\text {water, } 20^{\circ} \mathrm{C}}=0.01632 \mathrm{~cm}^{-1}$ é a seção de choque diferencial teórica da água a $20^{\circ} \mathrm{C}$. Os termos indicados por $T$ são as respectivas taxas de transmissão de cada amostra (registradas pelo equipamento), os termos $\Phi$ são a intensidade do feixe incidente e $t$ indica os tempos de exposição. É tomada uma medida do feixe transmitido antes e depois de cada medida da amostra, sem o beam stop, e efetuada a média dos dois valores, pelo que se tem a contagem de fótons $N_{s, b}=\Phi_{s, b} \times T_{s, b} \times t_{s, b}$. O desvio padrão $\sigma_{I}$ relativo a $I(q)$ da expressão 3.7 é obtido pela usual propagação de erros,

$$
\begin{aligned}
& \sigma_{I}(q)=\left[\frac{\sigma_{0}^{2}(q)}{I_{\text {shadow }}^{2}(q)}+\left(\frac{I_{\text {sample }}(q)}{\Phi_{s} T_{s} t_{s}}\right)^{2} \frac{\sigma_{\text {shadow }}^{2}}{I_{\text {shadow }}^{2}(q)}\right]^{\frac{1}{2}}, \\
& \sigma_{o}(q)=\sigma_{\text {sample }}^{2}(q)+\sigma_{\text {back }}^{2}(q)+\sigma_{\text {noise }}^{2}(q)\left(\frac{1}{\Phi_{s} T_{s}}-\frac{1}{\Phi_{b} T_{b}}\right)^{2},
\end{aligned}
$$

na qual as varianças $\sigma_{s, b, n}^{2}$ são tomadas como a própria contagem de pontos $\left(\sigma_{s, b, n}^{2}(q)=\right.$ $\left.I_{s, b, n}(q)\right)$.

Para a implementação dos cálculos de tratamento dos dados de SAXS, foram criados, em colaboração com o Msc. Dennys Reis, técnico do GFCX-IF-USP, um conjunto de programas em Python, usando as bibliotecas Python PyFAI [66], para integração azimutal, e FabIO [67] para manipulação de imagens de raios X. Os programas leem os arquivos correspondentes às medidas dos calibrantes, do background e da amostra e efetuam as devidas subtrações de background e normalizações. O primeiro passo é a determinação do p.o.n.i. e da distância entre amostra e detector, calculados com o programa pyFAI-calib, parte do pacote PyFAI, com o uso da medida do calibrante cujos picos são conhecidos (no caso presente, behenato de prata para SAXS). Em seguida, os scripts Python executam as funções de extração dos dados dos arquivos gerados na medida (formato EDF, European Data Format) com as funções da biblioteca FabIO, efetuam as integrações azimutais (função integrateld) ou radiais (fun- 
ção integrate_radial) de cada medida (amostra, background, água, ruído) com as funções da biblioteca PyFAI, descontados pontos definidos pela máscara, e registram a curva $I(q)$ resultante em cada setor (intervalos em $\varphi$ ) ou anel (intervalos em $q$ ) circular de acordo com a equação 3.7.

\subsection{Espalhamento de luz dinâmico (DLS)}

É interessante também caracterizar o comportamento dinâmico das estruturas micelares, o que pode ser observado a partir de medidas das flutuações locais do diretor nemático. $\mathrm{O}$ diretor se alinha de acordo com a orientação média das micelas nas fases nemáticas, mas pequenas variações locais do alinhamento implicam mudanças do tensor dielétrico ou, correspondentemente, no índice de refração. Como antes, o alinhamento do diretor caracteriza cada uma das fases, $N_{D}, N_{B}$ ou $N_{C}$; os modos típicos dessas flutuações em cada fase vão corresponder a variações perceptíveis da seção de choque de espalhamento, mensuráveis pela técnica de espalhamento de luz dinâmico (DLS).

Como explicado na seção 3.1, é prática usual a dopagem das amostras de liotrópicos com pequena quantidade de ferrofluido. A presença de nanopartículas magnéticas no meio aumenta a anisotropia de susceptibilidade magnética e facilitando o alinhamento da amostra. Propusemo-nos então a estudar a eventual interferência da presença dessas nanopartículas magnéticas na difusão dos modos de flutuação do diretor nemático pela técnica de DLS. Esse estudo poderia fornecer alguma informação sobre as viscosidades dos modos e sobre as constantes elásticas da energia de Frank, como descritas a seguir.

\subsubsection{A técnica de espalhamento de luz dinâmico (DLS)}

A técnica de espalhamento de luz dinâmico (Dynamic Light Scattering, DLS ) permite a avaliação de tempos de resposta típicos da amostra a partir da análise da autocorrelação da luz espalhada. A partir dos tempos de correlação, podem-se calcular coeficientes de difusividade do sistema. O uso mais comum da técnica de DLS é a estimativa de tamanho de partículas em suspensão num meio. Partículas com maior raio hidrodinâmico movem-se mais lentamente num meio viscoso, logo é possível obter informações sobre suas dimensões a partir do tempo típico da autocorrelação medida.

Em termos gerais, se uma partícula possui polarizabilidade anisotrópica, a incidência de luz induz um momento de dipolo que varia com o tempo, tanto pelas rotações e vibrações da partícula quanto por sua a translação; esta última promove variação da fase do campo espalhado. A superposição das amplitudes espalhadas pelas partículas no volume iluminado, modulada pelo movimento dessas partículas, forma o padrão de interferência a ser medido. A intensidade espalhada é então proporcional às flutuações locais do tensor dielétrico ${ }^{3}$. A

\footnotetext{
${ }^{3}$ Nesta seção, seguiremos essencialmente a descrição do clássico livro de Berne e Pecora [68].
} 
técnica de DLS consiste em direcionar um feixe de laser polarizado para a amostra e medirse a luz espalhada em um ângulo específico por um detector (em nosso caso, uma célula fotoelétrica), conforme esquematizado na figura 3.10. A luz espalhada também passa por um polarizador (analisador). O processo de espalhamento aqui tratado é do tipo Rayleigh (usamos nas experiências um laser verde, de comprimento de onda $\lambda=532 \mathrm{~nm}$ ).

No caso de materiais líquido cristalinos, flutuações locais do diretor nemático implicam também flutuações locais do tensor dielétrico. Neste caso, as medidas de DLS registram os tempos típicos dos modos de flutuação do diretor. A disposição dos polarizadores selecionará o modo (splay, bend ou twist) a ser medido pelo detector, segundo descrito na seção 3.5.2.

O vetor de espalhamento é $\mathbf{q}=\mathbf{k}_{f}-\mathbf{k}_{i}$. Admite-se a aproximação $\left|\mathbf{k}_{f}\right| \approx\left|\mathbf{k}_{i}\right|=k=2 \pi n / \lambda$ (condição de Bragg), em que $n$ é o índice de refração da amostra e $\lambda$ é o comprimento de onda do laser. Pela equação 2.2, novamente, $q=(4 \pi n / \lambda) \operatorname{sen}(\theta)$.

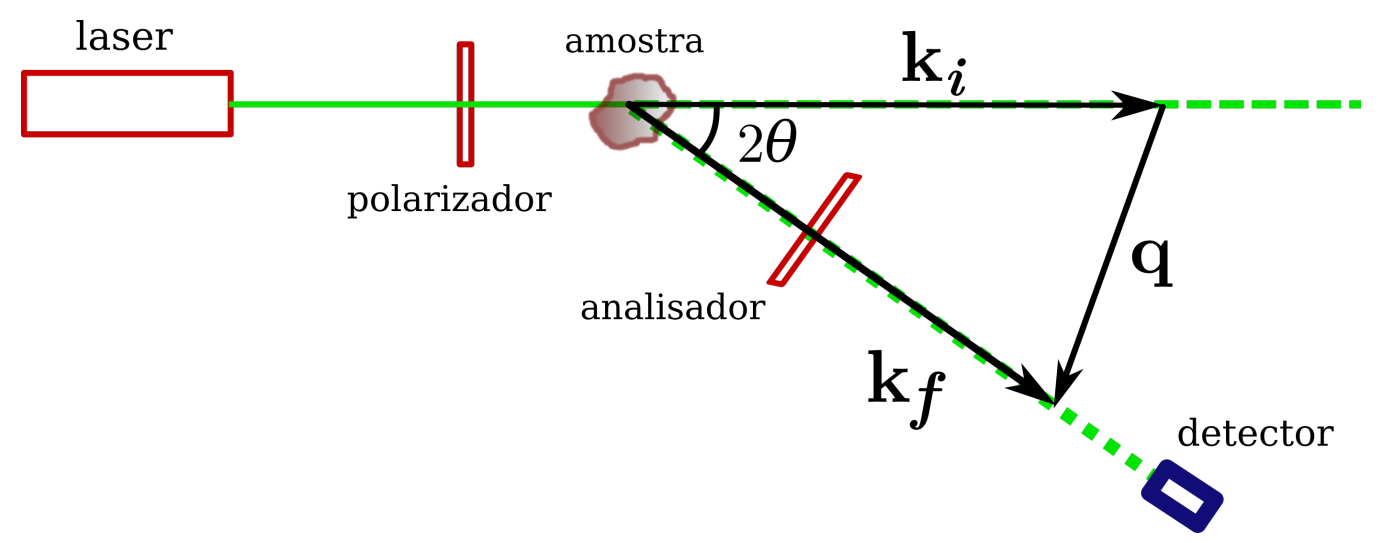

Figura 3.10. Esquema genérico de espalhamento de luz para análise da técnica de DLS. O laser emite um feixe que é espalhado pela amostra. O detector encontra-se em posição tal que recebe a luz espalhada em ângulo $2 \theta$, indicada pelo vetor de onda $\mathbf{k}_{f}$, em relação à direção do feixe incidente, indicada pelo vetor de onda $\mathbf{k}_{i}$. O vetor de espalhamento é $\mathbf{q}=\mathbf{k}_{f}-\mathbf{k}_{i}$. Pela lei dos cossenos, mostra-se que $q=(4 \pi n / \lambda) \operatorname{sen}(\theta / 2)$, em que $n$ é o índice de refração da amostra e $\lambda$ é o comprimento de onda do laser.

O detector é composto por uma fibra óptica conectada a um par de células fotoelétricas, por seu turno ligadas a um correlacionador controlado por um software específico em um computador (figura 3.11). O correlacionador efetua eletronicamente a autocorrelação dos fótons contados pelas fotocélulas e o software armazena esses dados. Obtêm-se então conjuntos de pontos que correspondem a essas funções de autocorrelação - tipicamente uma função exponencial decrescente ou uma soma delas (ver seção 3.5.2.1). O ajuste de exponenciais à função de autocorrelação fornece a frequência típica de difusão que corresponde às oscilações (splay, bend ou twist), como descrito na seção 3.5.3 a seguir. 


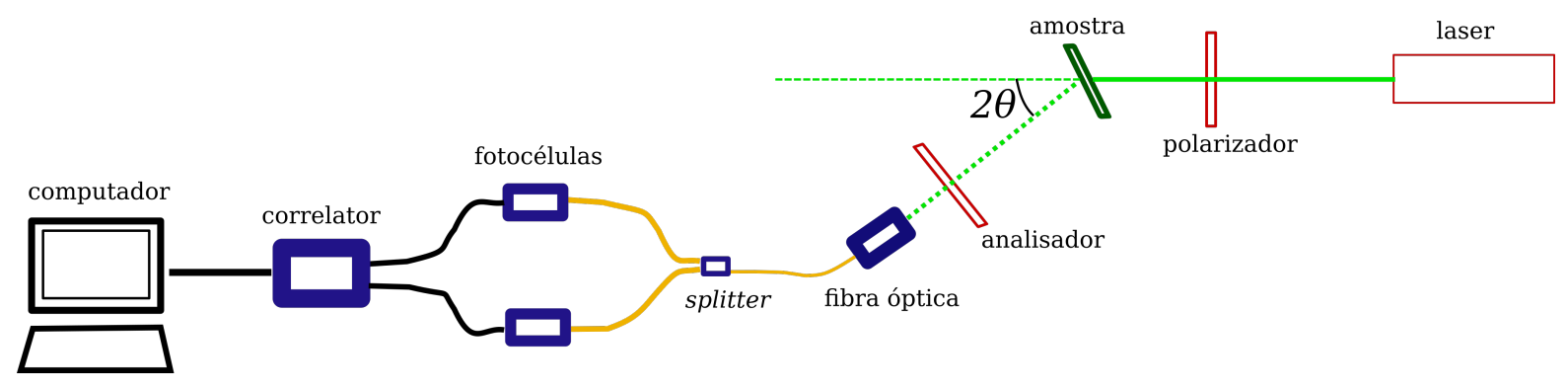

Figura 3.1 1. Diagrama geral do aparato para detecção por espalhamento dinâmico de luz, continuação da figura 3.10 .

\subsubsection{Flutuações do diretor nemático}

Variações térmicas levam a mudanças orientacionais que correspondem, em longo alcance, a flutuações do diretor nemático. Tais flutuações apresentam modos normais e podem ser estudadas por experimentos de espalhamento de luz ([24, 69]). Fazemos aqui uma breve descrição das flutuações, como justificativa para o uso da técnica.

Tomemos primeiramente algumas definições dos modos normais do diretor nemático a partir da fase de cristal líquido uniaxial. As flutuações $\delta \mathbf{n}(\mathbf{r}, t)=\mathbf{n}(\mathbf{r}, t)-\mathbf{n}_{0}$ (n $\mathbf{n}_{0}$ é a orientação de equilíbrio do diretor) podem ser analisadas a partir da energia elástica de Frank $[8,70]$,

$$
\mathscr{F}=\frac{1}{2} \int\left\{K_{1}(\nabla \cdot \mathbf{n})^{2}+K_{2}(\mathbf{n} \cdot \nabla \times \mathbf{n})^{2}+K_{3}(\mathbf{n} \times \nabla \times \mathbf{n})^{2}\right\} d \vec{r}
$$

em que cada termo está relacionado a um tipo de flutuação: $K_{1}(\nabla \cdot \mathbf{n})^{2}$ representa flutuações denominadas splay, $K_{2}(\mathbf{n} \cdot \nabla \times \mathbf{n})^{2}$ representa flutuações de tipo twist, e $K_{3}(\mathbf{n} \times \nabla \times \mathbf{n})^{2}$, flutuações bend (ver figura 3.12). $K_{1}, K_{2}$ e $K_{3}$ são as constantes elásticas dos modos.

Ainda, é conveniente analisar a flutuação $\delta \mathbf{n}$ em dois modos normais, $\delta n_{1} \mathbf{e} \delta n_{2}$, segundo o plano definido pelo diretor $\mathbf{n}_{0}$ e o vetor de espalhamento q. Assim [24, 70],

$$
\mathbf{n}=\mathbf{n}_{0}+\delta n_{1} \mathbf{e}_{1}+\delta n_{2} \mathbf{e}_{2}
$$

em que $\mathbf{e}_{1}$ é um versor paralelo ao plano $\left(\mathbf{n}_{0}, \mathbf{q}\right)$ e $\mathbf{e}_{2}$ é perpendicular a esse plano. Neste caso, o modo $\delta n_{1}$ corresponde a uma combinação das flutuações splay e bend, e $\delta n_{2}$ está ligado às flutuações twist e bend. Na figura 3.12, vê-se uma representação de cada um dos tipos de flutuações do diretor nemático ao longo do vetor de espalhamento.

Com o uso de técnicas de medidas de correlação de fótons espalhados (ver seção 3.5), podem-se medir as taxas de relaxação das flutuações do diretor para cada modo $\alpha=1,2$. A amplitude espalhada é função das componentes de Fourier $n_{1}(q)$ e $n_{2}(q)$ da flutuação $\delta \mathbf{n}(\mathbf{r}, t)$. Para cada modo, há uma força restauradora, dada por [70] 


\section{$111 / 11111_{\dot{q}}$}

(a) splay

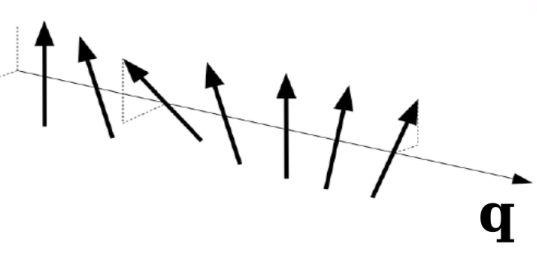

(b) twist

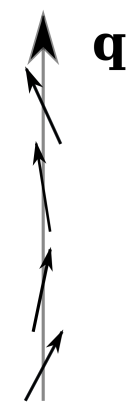

(c) bend

Figura 3.12. Representação das flutuações do tipo splay (a), twist (b) e (c) bend ao longo do vetor de espalhamento.

$$
K_{\alpha}(q)=K_{\alpha} q_{\perp}^{2}+K_{3} q_{\|}^{2}
$$

em que $q_{\perp}$ e $q_{\|}$são, respectivamente, as componentes perpendicular e paralela do vetor de espalhamento q. Considerando-se um modelo viscoelástico de relaxação das flutuações dos modos do diretor, $n_{1}$ e $n_{2}$, tem-se

$$
\frac{\partial n_{\alpha}}{\partial t}(q)=-\Gamma_{\alpha} n_{\alpha}(q)
$$

na qual $\Gamma_{\alpha}$ representa uma frequência típica do modo. Por sua vez [70],

$$
\Gamma_{\alpha}=\frac{K_{\alpha} q_{\perp}^{2}+K_{3} q_{\|}^{2}}{\eta_{\alpha}(q)}, \quad i=1,2
$$

e $\eta_{\alpha}$ é a viscosidade efetiva do $\alpha$-ésimo modo, dependente dos coeficientes de Leslie [24]. O modo $\alpha=1$ está ligado às flutuações splay e bend, ao passo que $\alpha=2$ refere-se aos modos twist e bend. Na geometria simétrica, o arranjo experimental auxilia na separação dos modos, de modo que, quando $\mathbf{q} \perp \mathbf{n}_{0}$,

$$
\Gamma_{\text {twist }}=\frac{K_{2}}{\eta_{\text {twist }}} q^{2} \equiv D_{\text {twist }} q^{2}
$$

em que $\eta_{\text {twist }}$ é a viscosidade do modo twist e $D_{\text {twist }}$ é a difusividade desse modo.

De maneira semelhante, pela preparação dos arranjos experimentais de espalhamento de luz selecionam-se outros modos, ou combinações deles, especialmente pela disposição dos polarizadores. Neste caso, as regras de seleção dos modos são obtidas a partir da seção de choque diferencial [70] 


$$
\frac{d \sigma}{d \Omega}=\left(\frac{\Delta \epsilon \omega^{2}}{4 \pi c^{2}}\right)^{2} \sum_{\alpha=1}^{2}\left\langle\left|n_{\alpha}(\mathbf{q})\right|^{2}\right\rangle\left(i_{\|} f_{\alpha}+i_{\alpha} f_{\|}\right)^{2},
$$

em que o símbolo “|l” define a direção paralela ao diretor nemático, $\Delta \epsilon=\epsilon_{\|}-\epsilon_{\perp}$ é a anisotropia da constante dielétrica do meio, $\omega$ é a frequência angular, $c$ é a velocidade da luz, $i_{\|}$e $f_{\|}$ são as componentes das polarizações paralelas a $\mathbf{n}_{0}$, e $i_{\alpha}$ e $f_{\alpha}$ são as componentes relativas a $\hat{e}_{1}$ e $\vec{e}_{2}$. O termo $\left\langle\left|n_{\alpha}(\mathbf{q})\right|^{2}\right\rangle$ representa a média térmica das componentes de Fourier $n_{1} \mathrm{e}$ $n_{2}$, e é dado por [70]

$$
\left\langle\left|n_{\alpha}(\mathbf{q})\right|^{2}\right\rangle=\frac{V k_{B} T}{\left(K_{\alpha} q_{\perp}^{2}+K_{3} q_{\|}^{2}\right)},
$$

em que $V$ é o volume da amostra, $T$ é a temperatura e $k_{B}$ é a constante de Boltzmann. A equação 3.15 é usada então para o cálculo de cada configuração do sistema (direção do diretor, plano de espalhamento, orientação dos polarizadores), de modo a se obter a regra de seleção de cada caso.

Observemos, por exemplo, no caso em que a polarização da luz incidente e da espalhada estão no plano apresentado na figura 3.13, com a polarização de incidência vertical e a polarização da onda espalhada no plano da figura. Na figura, está definida a geometria simétrica, fundamental para a simplificação dos cálculos (caso contrário, teríamos de considerar refrações extras da luz na cubeta). Como $\mathbf{q} \perp \mathbf{n}$, a componente $q_{\|}$, paralela ao diretor, é nula e, portanto, não há flutuação de tipo bend. Pela geometria, tem-se $i_{\|}=0, f_{\|}=\cos (\theta / 2), i_{1}=0$, $i_{2}=1, f_{1}=\operatorname{sen}(\theta / 2), f_{2}=0$; usando-se agora a equação 3.15 , apenas o termo $i_{2} \cdot f_{\|}=\cos (\theta / 2)$ permanece, correspondendo à flutuação twist. Os demais casos das regras de seleção são apresentados na tabela 3.2 .

Tabela 3.2. Regras de seleção para os modos de flutuação do diretor nemático em geometria simétrica. A letra "V" indica incidência de luz polarizada verticalmente (em relação ao plano de espalhamento), "H” indica horizontal. Os casos em que a polarização de incidência e de espalhamento coincidem, o caso é dito "polarizado”; será “despolarizado” quando não estão paralelas.

\begin{tabular}{ccccc}
\hline & \multicolumn{2}{c}{ Polarizado } & \multicolumn{2}{c}{ Despolarizado } \\
\hline \hline & VV & HH & VH & HV \\
\hline \hline Homeotrópico & splay & twist & twist & twist \\
\hline Planar, $\mathbf{n}_{0} \perp \mathbf{q}$ & - & bend & bend & bend \\
\hline Planar, $\mathbf{n}_{0} \| \mathbf{q}$ & - & - & splay-twist & splay-twist \\
\hline
\end{tabular}

Caso a medida de espalhamento detecte mais de um modo, podem-se identificar na função de autocorrelação dois tempos de relaxação característicos, obtidos pelo ajuste de duas exponenciais, como no exemplo da figura 4.34 da seção 4.4 adiante. 
A figura 3.13 apresenta um esquema do espalhamento na chamada geometria simétrica, em que o vetor de onda $\mathbf{k}_{i}$, correspondente à onda incidente, e o vetor $\mathbf{k}_{i}$, correspondente à onda espalhada, são dispostos simetricamente em relação ao diretor nemático, $\mathbf{n}_{0}$, por sua vez perpendicular às paredes da célula que contém a mistura liotrópica. Essa disposição é obtida rotacionando-se concomitantemente a célula sobre a qual incide a onda de um ângulo $\theta$ e o detector, também de um ângulo $\theta$. Como resultado dessa disposição, compensamse as refrações intermediárias, que exigiriam correções do espalhamento pelo índice de refração em cada trecho. Outra disposição também conveniente, usada no experimento com espalhamento estático, a cubeta é cilíndrica, mas o diretor é orientado verticalmente; como a cubeta é colocada em um líquido cujo índice de refração é similar ao do vidro (index matching), as correções refrativas são novamente dispensadas.

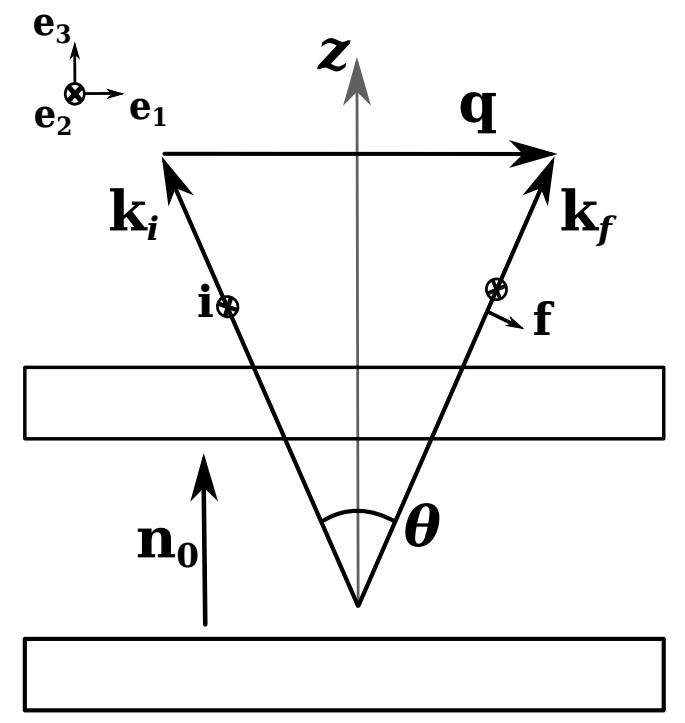

Figura 3.13. Diagrama da geometria simétrica de espalhamento de luz em uma amostra orientada. São apresentadas as orientações do diretor nemático, $\mathbf{n}_{0}$, do vetor de espalhamento, $\mathbf{q}$, dos vetores de onda de incidência, $\mathbf{k}_{f}$, e de transmissão, $\mathbf{k}_{f}, \theta$ é o ângulo de espalhamento e as orientações dadas pelos versores $\mathbf{e}_{i}, i=1,2,3$. Os vetores $\mathbf{i}$ e $\mathbf{f}$ indicam, respectivamente, as direções de polarização dos feixes incidente e transmitido (definidos, no aparato experimental, por polarizadores - v. fig. 3.10). Esta figura exemplifica o caso homeotrópico.

\subsubsection{A função de autocorrelação}

Os coeficientes de difusividade de uma partícula ou de modos de flutuação do diretor nemático são conseguidos a partir da função de autocorrelação dos fótons espalhados, que mede os tempos típicos de variação do tensor dielétrico do meio. Em geral, a função de autocorrelação é uma medida da persistência de uma variável, como variações espaciais do parâmetro de ordem, o que a faz útil para análise de transições de fase [41]. Seguimos aqui a abordagem do clássico livro de Berne \& Pecora [68]. 


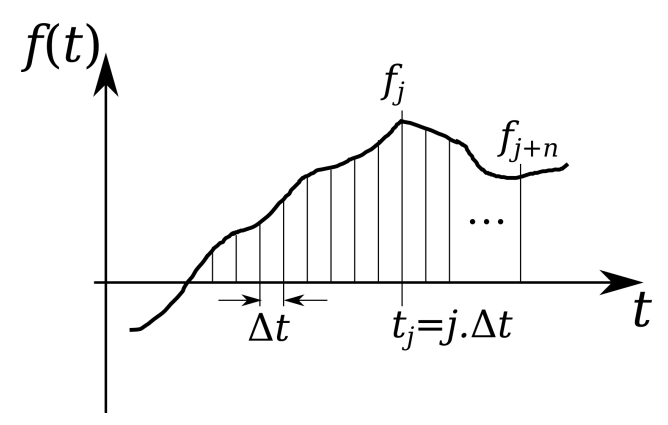

(a)

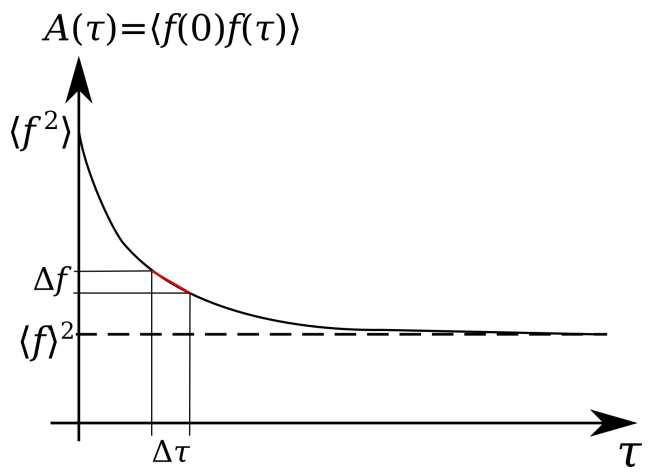

(b)

Figura 3.14. Exemplo de propriedade física $f(t)$, que varia com o tempo. Em (a), seu domínio é recortado em intervalos $\Delta t$ e os valores médios de $f_{j}=f\left(t_{j}\right)$ são comparados em intervalos distintos $t_{j}$ e $t_{j}+\tau=t_{j}+n \cdot \Delta t$, isto é, compara-se $f_{j}$ a $f_{j+n}$ pela média $\left\langle f_{j} \cdot f_{j+n}\right\rangle$. Em (b), a forma típica da função de autocorrelação $A(\tau)$, com seus valores para $\tau=0$ e $\tau \rightarrow \infty$, e a análise de seu decaimento num intervalo $\Delta \tau$.

Seja uma propriedade física $f(t)$, que flutua com o tempo $t$ (figura 3.14). Consideremos que certo intervalo de tempos, $\left[t_{0}, T\right]$, seja recortado em intervalos $N$ iguais, tais que $\Delta t=$ $\left(T-t_{0}\right) / N$, sendo $j$-ésimo instante dado por, $t_{j}=t_{0}+j \cdot \Delta t$, para $j=0,1,2, \ldots, N$. Se é $f(t)$ é uma variável aleatória com o tempo, dado um intervalo $\tau=n \cdot \Delta t(n=1,2, \ldots, N)$, é suposto que $f\left(t_{0}+\tau\right) \neq f\left(t_{0}\right)$. Se o intervalo de comparação $\tau$ é pequeno, $f\left(t_{0}+\tau\right) \approx f\left(t_{0}\right)$, ao passo que a relação entre $f(t)$ e $f\left(t_{0}+\tau\right)$ é mais tênue conforme $\tau$ aumenta. Define-se então a função de autocorrelação,

$$
A(\tau) \equiv\left\langle f\left(t_{0}\right) \cdot f\left(t_{0}+\tau\right)\right\rangle=\langle f(0) \cdot f(\tau)\rangle
$$

em que $\langle f(0) \cdot f(\tau)\rangle=\lim _{T \rightarrow \infty} \frac{1}{T} \int_{0}^{T} f(t) \cdot f(t+\tau) d t$. No caso de intervalos discretos,

$$
\begin{aligned}
& A(\tau)=\frac{1}{N}[f(0) f(\tau)+f(\Delta t) f(\Delta t+\tau)+ \\
& \quad+f(2 \Delta t) f(2 \Delta t+\tau)+\ldots+f((N-1) \Delta t) f(T)]
\end{aligned}
$$

isto é,

$$
A(\tau)=\langle f(0) f(\tau)\rangle \approx \lim _{N \rightarrow \infty} \frac{1}{N} \sum_{j=1}^{N} f_{j} \cdot f_{j+n} \quad(\tau=n \cdot \Delta t) .
$$


Para $\tau=0$, como $f(t) \in \mathbb{R}$,

$$
\begin{aligned}
A(0)=\langle f(0) f(0)\rangle & \approx \frac{1}{N} \sum_{j=1}^{N} f_{j} \cdot f_{j}=\frac{1}{N} \sum_{j=1}^{N} f_{j}^{2} \\
& \geq \sum_{j=1}^{N} f_{j} \cdot f_{j+1} \Rightarrow\left\langle f^{2}(0)\right\rangle \geq\langle f(0) f(\tau)\rangle .
\end{aligned}
$$

Portanto, se $f(t)$ não é constante, decai com $\tau$, iniciando em $A(0)=\left\langle f^{2}(0)\right\rangle$; para $\tau$ grande, sendo $f(t)$ descorrelacionada, $\lim _{\tau \rightarrow \infty}\langle f(0) f(\tau)\rangle=\langle f(0)\rangle\langle f(\tau)\rangle=\langle f(\tau)\rangle^{2}$, como se vê na figura 3.14(b). Considerando-se, tipicamente, que a taxa de decaimento de $A(\tau)$ é proporcional a seu valor, $\dot{A}(\tau)=-\Gamma A(\tau) \Rightarrow A(\tau)=B+A_{0} e^{-\Gamma \tau}$. De acordo com o gráfico acima,

$$
A(\tau)=\langle f\rangle^{2}+\left(\left\langle f^{2}\right\rangle-\langle f\rangle^{2}\right) e^{-\Gamma \tau}
$$

em que $\Gamma=\frac{1}{\tau_{0}}$, e $\tau_{0}$ é o tempo típico de relaxação de $f(t)$.

Nas experiências de DLS que efetuamos, o correlacionador define um intervalo de tempo (uma "janela") de contagem de fótons $\Delta t$ típica de poucos nanossegundos. O número de fótons contados nesse intervalo é multiplicado pelos valores dos demais intervalos, e são efetuadas as médias para os $\Delta t$ espaçados por $\tau$. Por uma questão técnica de redução da autocorrelação eletrônica, que pode introduzir fortes ruídos no sistema, a medida é efetuada em dois canais separados e os produtos para as médias das correlações são efetuadas entre os canais, o que se chama correlacionamento cruzado (cross correlation).

\subsubsection{Análise de resultados}

A análise dos dados consiste, primeiro, em ajuste das curvas de autocorrelação obtidas em um dado ângulo de espalhamento, para uma dada configuração dos polarizadores (que determina o regime de oscilação medido). A seguir, as medidas são efetuadas para outros ângulos de espalhamento, ainda com a mesma configuração de polarizadores, com a finalidade de melhorar a avaliação da medida de difusividade do(s) modo(s).

O aparato experimental mede a intensidade da luz, $I(\mathbf{q}, t)$, espalhada em função do tempo $t$, para um dado ângulo de espalhamento $2 \theta$, relacionado ao vetor de espalhamento q (equação 2.2). A função de correlação é, então,

$$
A(\tau)=\langle I(0) \cdot I(\tau)\rangle=\lim _{T \rightarrow \infty} \frac{1}{T} \int_{0}^{T} I(\mathbf{q}, t) I(\mathbf{q}, t+\tau) d t,
$$

em que $\tau \ll T$ é o intervalo de tempo de comparação do sistema. Definem-se as funções de 
autocorrelação normalizada do campo espalhado,

$$
g^{(1)}(q, \tau) \equiv \frac{\left\langle E(\mathbf{q}, 0) E^{*}(\mathbf{q}, \tau)\right\rangle}{\langle I(\mathbf{q})\rangle}
$$

e da intensidade de espalhamento,

$$
g^{(2)}(q, \tau) \equiv \frac{\langle I(\mathbf{q}, 0) I(\mathbf{q}, \tau)\rangle}{\langle I(\mathbf{q})\rangle^{2}}
$$

Considerando então os valores médios $\langle E(\mathbf{q}, t)\rangle,\langle I(\mathbf{q}, t)\rangle=\left\langle|E(\mathbf{q}, t)|^{2}\right\rangle$, e $\langle I(\mathbf{q}, 0) I(\mathbf{q}, \tau)\rangle=$ $\left\langle|E(\mathbf{q}, t)|^{2}\right\rangle$, mostra-se que [7]

$$
g^{(2)}(q, \tau) \equiv 1+\beta\left[g^{(1)}(q, \tau)\right]^{2}
$$

chamada relação de Siegert, que explicita as propriedades de fatorização da função de correlação de variáveis gaussianas. O fator $\beta$ representa o grau de coerência espacial da luz espalhada sobre o detector.

Tipicamente, a função de autocorrelação $g^{(1)}$ é bem representada por uma exponencial decrescente, $c . e^{-\Gamma t}$. Pela equação de Siegert, eq. 3.25, pode-se escrever a função de autocorrelação das intensidades como

$$
A(\tau)=B+C \exp (-2 \Gamma \tau)
$$

em que $\tau$ é o tempo de correlação e $\Gamma$ corresponde à taxa de relaxação do modo (isto é, o inverso de um tempo típico $\tau_{0}$ de relaxação, $\Gamma=1 / \tau_{0}$ ), definido na equação 3.13. As constantes $A, B$ e $\Gamma$ são determinadas por ajuste da exponencial 3.26 a dados medidos experimentalmente. Tipicamente, a constante $B$, que define a linha de base da função exponencial, tem valor aproximado de 1 e $C \leq 1$ (em geral, experimentalmente, tem valores entre 0,6 e 0,9) e caracteriza a amplitude da função (em relação ao valor dado por $B$ ).

O modelo da equação 3.26 representa o caso em que a medida de $I(q, \mathrm{t})$ é resultante apenas ou em grande maior da luz espalhada pela amostra $\left(I_{\text {espalhada }} \gg I_{\text {local }}\right)$, chamado método homódino. Neste caso, $C$ tem valores próximos de 1 . Há também o chamado método heteródino, em que parte da luz laser não espalhada é misturada à espalhada no detector e, nesse caso, o campo total no detector é a sobreposição do campo espalhado e do campo local. Nesse caso, a intensidade terá um termo cruzado proporcional a $g^{(1)}(q, \tau)$; se a intensidade do campo local é alta, o termo homódino pode ser desprezado e a função de correlação é obtida diretamente de $g^{(1)}(q, \tau)$. O tratamento do caso heteródino é simplificado, principalmente se o sinal medido é proveniente de efeitos com tempo de correlação distintos, o que implica ajuste de somas de exponenciais simples (no caso homódino, as somas são elevadas ao quadrado); experimentalmente, no entanto, o regime heteródino não é facilmente 
implementado. Pode ocorrer, ainda, que haja interferência do sinal local meramente pelas características geométricas do sistema, como um "vazamento" para o detector, o que implica o regime heteródino sem o esperado controle. Normalmente, isso implica a redução da amplitude $C$, tornando a medida mais difícil. Nesses casos, em que parte da luz local se sobrepõe à espalhada no meio, a determinação sobre a natureza homódina ou heteródina da medida se dá pela avaliação da relação $C / B$, usando-se um "ábaco", como descrito em [71]. Conduzimos os experimentos deste trabalho pelo método homódino, mas foram feitas correções nos ajustes conforme identificamos um ou outro regime de medida pelos critérios acima.

O software que recebe dados do correlacionador possui dois canais, fornecendo, assim, a cada medida, dois conjuntos de curvas de autocorrelação. Para selecionar os trechos relevantes das funções de autocorrelação, isto é, os intervalos que tipificam o tempo de autocorrelação (descartando os intervalos correspondentes a tempos de nanossegundos, ou de segundos), desenvolvemos um software em linguagem Python que permite efetuar a média das curvas obtidas pelos diferentes canais do correlacionador (ou em várias sequências de medidas), selecionar o intervalo relevante para o ajuste e efetuar automaticamente o ajuste de uma ou duas exponenciais. O programa permite também a escolha de ajuste para os casos de espalhamento homódino ou heteródino.

Após a obtenção das frequências típicas para cada ângulo de espalhamento (ou, analogamente, para o vetor de espalhamento, $\vec{q}$ ), ajusta-se a reta $\Gamma_{i}=D_{i} q^{2}$ ( $i$ indica o modo, ver equação 3.14) aos pontos do gráfico de $\Gamma_{i} \times q^{2}$, do que se obtém a difusividade do modo definido pela disposição dos polarizadores. A caracterização dos modos de flutuação do diretor se dá enfim pelo cálculo das viscosidades de cada modo a partir das difusividades obtidas.

\subsubsection{O aparato experimental de DLS}

A figura 3.15 mostra o equipamento do GFCX-IF-USP usado nas medidas de DLS aqui apresentadas. O aparato foi inicialmente montado em colaboração com o professor Dr. Ítalo M. N. de Oliveira, da Universidade Federal de Alagoas - UFAL, e o Dr. Celso L. S. Risi (IF-USP). Recentemente, foram efetuados aprimoramentos ao equipamento, em colaboração com o Dr. Roman Spirin (IF-USP), sob supervisão do prof. Dr. Cristiano L. P. Oliveira (IF-USP), em que foi acrescentada uma cuba com sistema de controle de temperatura e casamento de índice de refração (index matching), e automatização do goniômetro para uso também em espalhamento estático de luz (SLS). As medidas aqui apresentadas foram ainda anteriores às últimas modificações, portanto sem utilização do sistema de index matching.

O equipamento possui um laser de marca Coherent, modelo Verdi V6, que produz um feixe monocromático verde, de comprimento de onda $\lambda=532 \mathrm{~nm}$, com cerca de $60 \mathrm{~m}$ de 


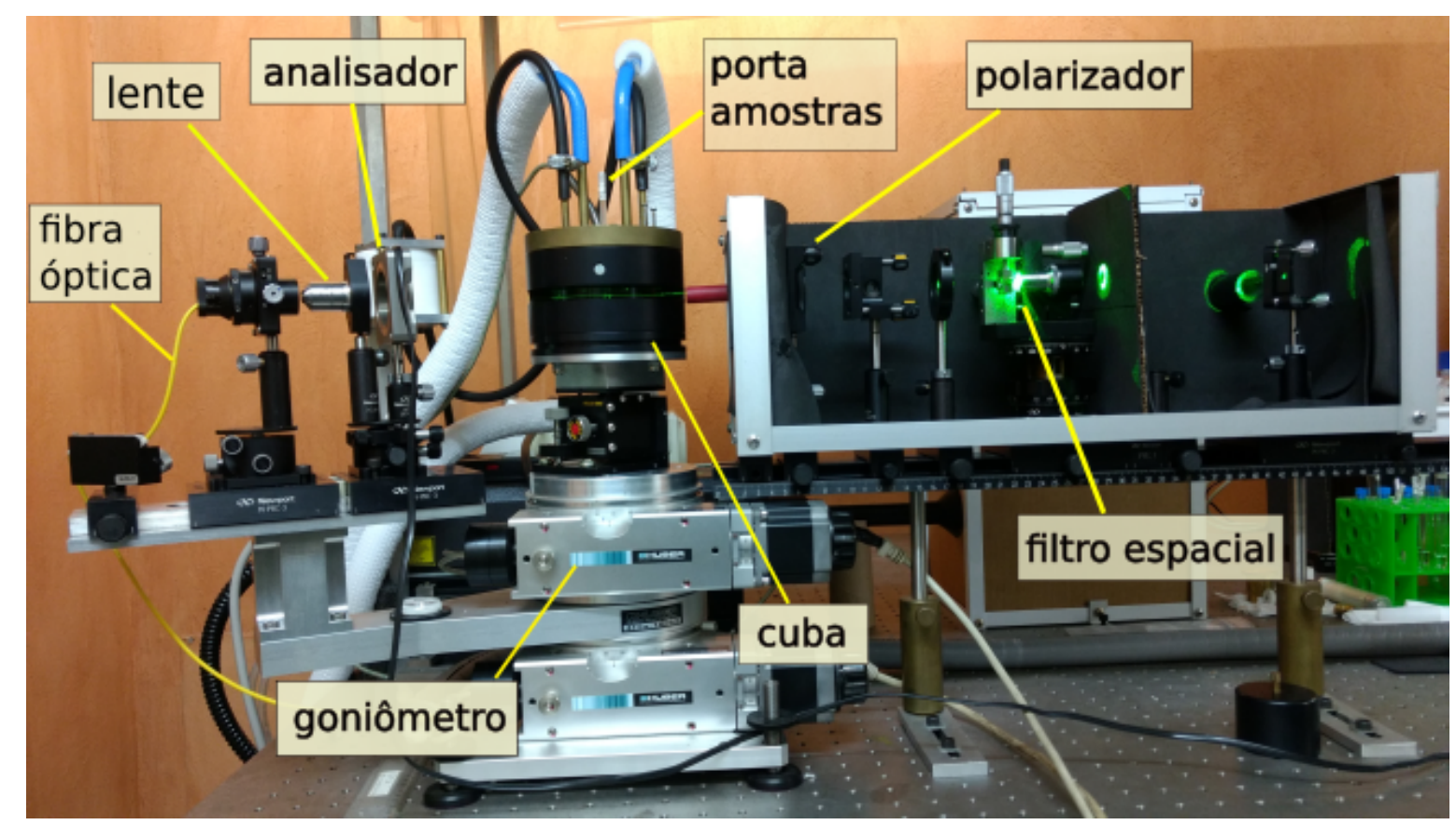

Figura 3.15. Equipamento do GFCx-IF-USP usado nas medidas de DLS. As legendas apontam os principais componentes do aparato. Uma lente objetiva pequena é colocada na entrada da fibra óptica. Esta é separada por um divisor (splitter), por sua vez conectado às fotomultiplicadoras e, daí, ao correlacionador (não mostrados).

comprimento de coerência. O diâmetro médio do feixe é 1,5 $\mathrm{mm}$. A potência do laser foi fixada entre $0,3 \mathrm{~W}$ e $1 \mathrm{~W}$, tomando-se em conta a redução da intensidade do feixe pelo filtro espacial. O sistema conta com um sistema de espelhos que eleva o feixe até a altura do goniômetro, mais espelhos auxiliares para direcionar o feixe à amostra. O feixe produzido pelo equipamento laser tem polarização vertical, que pode ser mantida ou rotacionada pelo conjunto de espelhos. A seguir, o feixe passa por um filtro espacial, composto por uma lente objetiva e um pin hole posicionado no foco da lente; o filtro garante maior circularidade do feixe e que ele tenha um perfil gaussiano (como pressupõe a aproximação gaussiana, de que as diferentes regiões do volume de espalhamento são estatisticamente independentes). $\mathrm{O}$ perfil gaussiano foi verificado por uma câmera CCD. Foi ainda usada uma íris e uma lente convergente, cujo foco se dá na posição da amostra. O porta amostras é colocado sobre um goniômetro, de marca Hubber, modelo 415, que possui precisão angular de 0,01 ${ }^{\circ}$. A luz espalhada é captada por um conjunto de analisador, lente e fibra óptica. A fibra está ligada a um divisor de feixes Schäfter \& Kirchhof, modelo FBS-532-Y-50/50-APC-100/100, que então se acopla a duas fotomultiplicadoras por duas fibras ópticas. As intensidades dos feixes são iguais após o divisor. As fotomultiplicadoras se conectam então ao correlacionador, todos da marca Correlator Inc., modelo Flex02-01D. O correlacionador se conecta via porta USB a um computador e o sinal correlacionado é analisado por um software fornecido pela empresa Correlator Inc. O ajuste de exponenciais às curvas de autocorrelação experimentais foi 
efetuado com um programa escrito por nós em Python, que usa a função de ajuste curve_fit da biblioteca SciPy. A característica principal do programa é permitir a definição manual do intervalo de ajuste relevante, por inspeção visual, em função de eventuais ruídos do sistema. As curvas são ajustadas automaticamente a cada seleção de intervalo, o que permite estudar o comportamento da superposição de exponenciais quando há aparente sobreposição de sinais e avaliar os ajustes nos regimes homódino e heteródino. 


\section{Capítulo 4}

\section{Resultados}

São aqui apresentados os resultados das medidas de caraterização de fases dos liotrópicos por microscopia de luz polarizada, concoscopia laser e SAXS; alguns resultados sobre dinâmica de flutuação do diretor nemático medidos por DLS; curvas de SAXS da mistura liotrópica DTAB (ou DTMABr) / $\mathrm{KBr} /$ 1-undecanol / $\mathrm{H}_{2} \mathrm{O}$, ajustada pelo modelo da seção 2.3; e resultados das simulações computacionais de espalhamento por estruturas similares a micelas.

\subsection{Modelagem de SAXS}

As figuras seguintes mostram resultados representativos do tratamento das imagens dos padrões de SAXS dos liotrópicos e as curvas resultantes das médias efetuadas por sobre cortes em cada imagem (figura 2.3). As curvas experimentais abaixo são acompanhadas dos resultados dos ajustes do modelo apresentado na seção 2.3. A tabela 4.1 identifica os parâmetros do modelo. As incertezas são normalmente calculadas a partir da matriz de covariâncias, mas nem sempre o método de ajuste obteve uma matriz válida. Ainda que a integração azimutal possa ser efetuada em toda a circunferência nos casos isotrópicos, ela também foi efetuada em setores, demonstrando a coincidência dos resultados em torno das duas direções, vertical e horizontal.

\subsubsection{Fase $N_{C}$}

Na fase $N_{C}$, os padrões de espalhamento na direção perpendicular e paralela ao campo $\mathbf{H}$ são bastante distintas, uma vez que as micelas tendem a se alinhar com o campo. Tanto na descrição das estruturas micelares pelo modelo IBM quanto pelo modelo de micelas prolatas, o padrão na direção paralela a $H$ é isotrópico (figura 4.1), enquanto o padrão na direção perpendicular a $H$ (figura 4.2) é anisotrópico. 


\begin{tabular}{|c|c|c|c|c|}
\hline Intensidade & Termo & Parâmetro & Significado & Referência (eq.) \\
\hline \multirow{5}{*}{$I_{m i c}(q)$} & \multirow{2}{*}{$D\left(R_{c}, \bar{R}_{c}, \sigma_{c}\right)$} & $\overline{\bar{R}}$ & raio médio da micela & \multirow{3}{*}{2.18} \\
\hline & & $\sigma_{R}$ & polidispersidade & \\
\hline & $r\left(R_{c}, \epsilon, \alpha\right)$ & $\epsilon$ & excentricidade & \\
\hline & \multirow{2}{*}{$F_{c s}\left[q, r\left(R_{c}, \epsilon, \alpha\right)\right]$} & $T$ & espessura da shell & \multirow{2}{*}{2.15} \\
\hline & & $\rho_{C}$ & densidade eletrônica (core) & \\
\hline \multirow{5}{*}{$S(q)$} & $Z_{0}(q)$ & $A$ & periodicidade lamelar & 2.20 \\
\hline & $D=2 \pi / \delta$ & $D$ & tamanho do domínio & 2.21 \\
\hline & $L_{h k}(q)$ & $v$ & forma do pico & 2.21 \\
\hline & $Z_{0}(q)$ & $c_{z}$ & fator de correção & 2.20 \\
\hline & $G(q)$ & $\sigma_{A}$ & deslocamento D-W & 2.23 \\
\hline \multirow{2}{*}{$S_{H S}(q)$} & & $R_{H S}$ & raio de esferas duras & \multirow{2}{*}{2.25} \\
\hline & & $\eta$ & fração de volume & \\
\hline \multirow{2}{*}{$I(q)$} & & $C_{2}$ & fator de escala & \multirow{2}{*}{2.30} \\
\hline & & $B_{0}$ & background & \\
\hline
\end{tabular}

Tabela 4.1. Parâmetros usados no modelo de ajuste.

As diferenças entre os resultados das integrações em torno da direção horizontal e vertical podem ser consequência dos diferentes intervalos de integração em cada direção. As distâncias típicas entre os centros das micelas, no entanto, são as mesmas nos dois casos (parâmetro $A$ do fator de estrutura $S(q)$ ), pois trata-se da mesma periodicidade. Consideremos então as integrações em torno da direção vertical, que alcançam maior $q$. Comparando-se o caso $H_{\|}$e $H_{\perp}$, observamos alguma diferença significativa no valor da dimensão dos domínios micelares $(D)$, que podem ser função dos erros dos ajustes. Os demais valores são compatíveis com resultados encontrados na literatura [1, 2, 14, 3, 72]. 


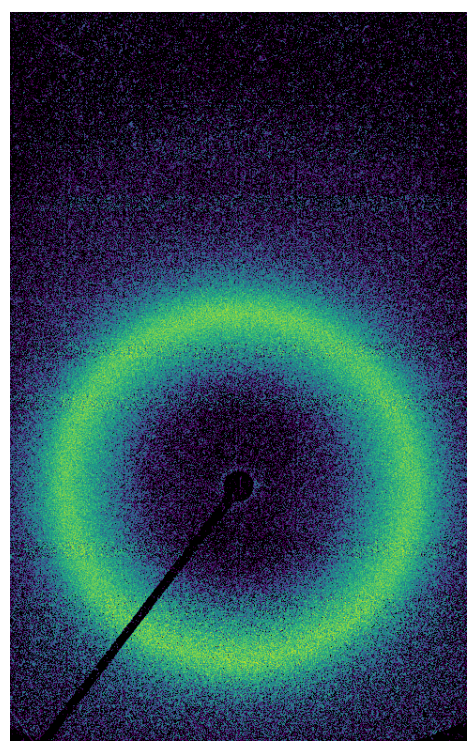

(a) Espalhamento.

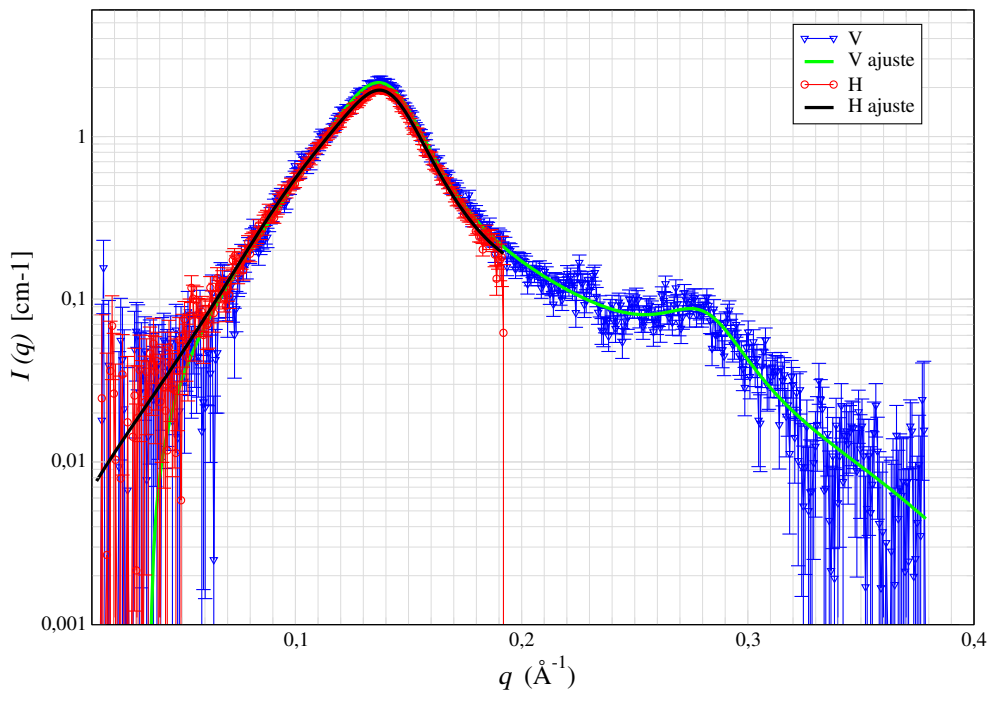

(b) Integrações em torno da horizontal $(\bigcirc)$ e da vertical $(\nabla)$.

Figura 4.1. Mistura liotrópica de $\mathrm{DTAB} / \mathrm{KBr} / 1$-undecanol / $\mathrm{H}_{2} \mathrm{O}$ na fase $N_{C}$. A imagem (a) corresponde ao efeito de um campo magnético $\mathbf{H}$ paralelo ao feixe na amostra. $\mathrm{O}$ tempo de exposição da medida foi de $1200 \mathrm{~s}$. As curvas (b) correspondem à integração azimutal de $15^{\circ} \mathrm{em}$ torno da vertical e de $40^{\circ}$ em torno da horizontal.

\begin{tabular}{cr}
\hline \hline \multicolumn{2}{c}{ DTMABr, $N_{C}, H_{\|}$, horizontal } \\
\hline \hline $\bar{R}$ & 12.9905 \\
\hline$\epsilon$ & 2.4316 \\
\hline$\sigma_{R}$ & 7.0526 \\
\hline$T$ & 1.5002 \\
\hline$\rho_{C}$ & -0.2000 \\
\hline \hline$A$ & 44.8309 \\
\hline$D$ & 142.1970 \\
\hline$v$ & -0.1622 \\
\hline$c_{z}$ & 0.1151 \\
\hline$\sigma_{A}$ & 0.0031 \\
\hline \hline$R_{H S}$ & 27.5235 \\
\hline$\eta$ & 0.1829 \\
\hline \hline$C_{2}$ & 1277.3857 \\
\hline$B_{0}$ & -0.0080 \\
\hline
\end{tabular}

\begin{tabular}{cr}
\hline \hline \multicolumn{2}{c}{ DTMABr, $N_{C}, H_{\|}$, vertical } \\
\hline \hline $\bar{R}$ & 7.9471 \\
\hline$\epsilon$ & 1.3206 \\
\hline$\sigma_{R}$ & 2.3903 \\
\hline$T$ & 4.5000 \\
\hline$\rho_{C}$ & -0.2000 \\
\hline \hline$A$ & 44.5922 \\
\hline$D$ & 229.4896 \\
\hline$v$ & 1.0000 \\
\hline$c_{z}$ & 0.2591 \\
\hline$\sigma_{A}$ & 0.0336 \\
\hline \hline$R_{H S}$ & 22.1540 \\
\hline$\eta$ & 0.2056 \\
\hline \hline$C_{2}$ & 78.8550 \\
\hline$B_{0}$ & -0.0284 \\
\hline
\end{tabular}

Tabela 4.2. Resultados dos ajustes (eq. 2.30) às curvas experimentais da figura 4.1. Liotrópico em fase $N_{C}$, campo $H$ paralelo ao feixe. 


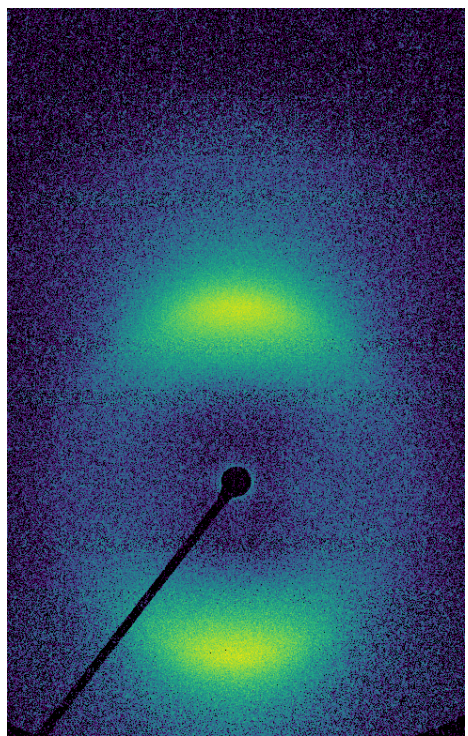

(a) Espalhamento.

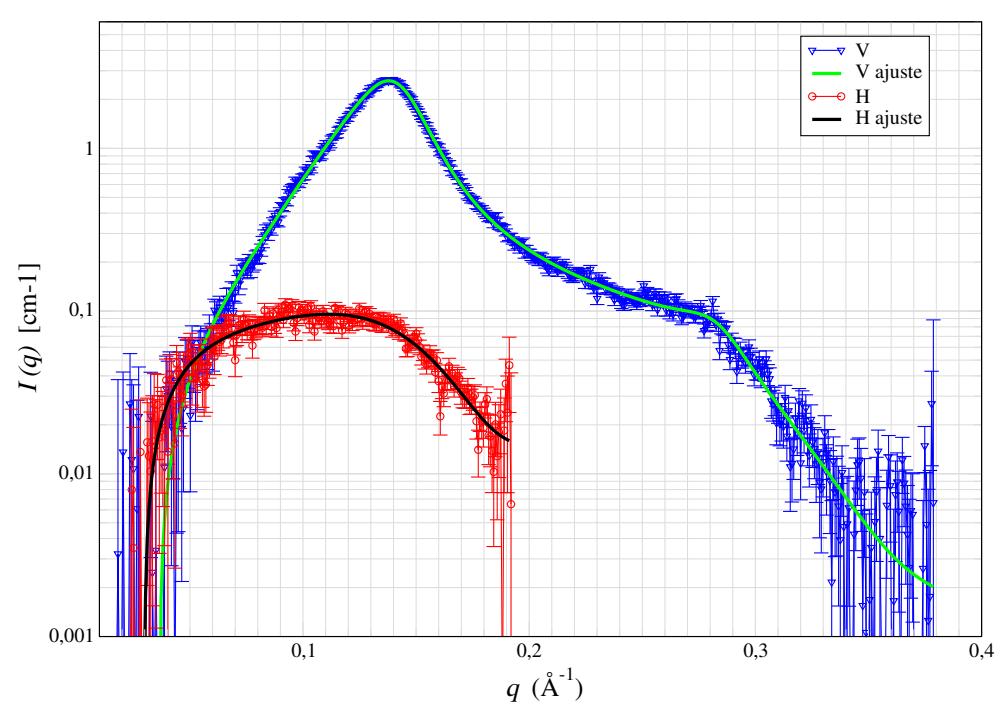

(b) Integrações em torno da horizontal $(\bigcirc)$ e da vertical $(\nabla)$.

Figura 4.2. Mistura liotrópica de DTAB / $\mathrm{KBr} / 1$-undecanol / $\mathrm{H}_{2} \mathrm{O}$ na fase $N_{C}$. A imagem corresponde ao efeito de um campo magnético $\mathbf{H}$ perpendicular ao feixe na amostra. O tempo de exposição da medida foi de $3600 \mathrm{~s}$. As curvas correspondem a integrações azimutais de $15^{\circ} \mathrm{em}$ torno das direções horizontal e vertical.

\begin{tabular}{cr}
\hline \hline \multicolumn{2}{c}{ DTMABr, $N_{C}, H_{\perp}$, horizontal } \\
\hline \hline $\bar{R}$ & 15.3857 \\
\hline$\epsilon$ & 2.8475 \\
\hline$\sigma_{R}$ & 5.1338 \\
\hline$T$ & 2.1453 \\
\hline$\rho_{C}$ & -0.2000 \\
\hline \hline$A$ & 44.9603 \\
\hline$D$ & 55.8211 \\
\hline$v$ & 0.5715 \\
\hline$c_{z}$ & 1.2425 \\
\hline$\sigma_{A}$ & 0.0054 \\
\hline \hline$R_{H S}$ & 13.2055 \\
\hline$\eta$ & 0.2894 \\
\hline$C_{2}$ & 1303.1222 \\
\hline \hline$B_{0}$ & -0.4213 \\
\hline
\end{tabular}

\begin{tabular}{cr}
\hline \hline \multicolumn{2}{c}{ DTMABr, $N_{C}, H_{\perp}$, vertical } \\
\hline \hline $\bar{R}$ & 7.7271 \\
\hline$\epsilon$ & 0.5000 \\
\hline$\sigma_{R}$ & 1.8147 \\
\hline$T$ & 1.5000 \\
\hline$\rho_{C}$ & -0.2000 \\
\hline \hline$A$ & 44.3634 \\
\hline$D$ & 181.1703 \\
\hline$v$ & 0.1016 \\
\hline$c_{z}$ & 7.5479 \\
\hline$\sigma_{A}$ & 0.1214 \\
\hline \hline$R_{H S}$ & 22.4545 \\
\hline$\eta$ & 0.2163 \\
\hline$C_{2}$ & 16.8067 \\
\hline \hline$B_{0}$ & -0.0600 \\
\hline
\end{tabular}

Tabela 4.3. Resultados dos ajustes (eq. 2.30) às curvas experimentais da figura 4.2. Liotrópico em fase $N_{C}$, campo $H$ perpendicular ao feixe. 


\subsubsection{Fase $N_{D}$}

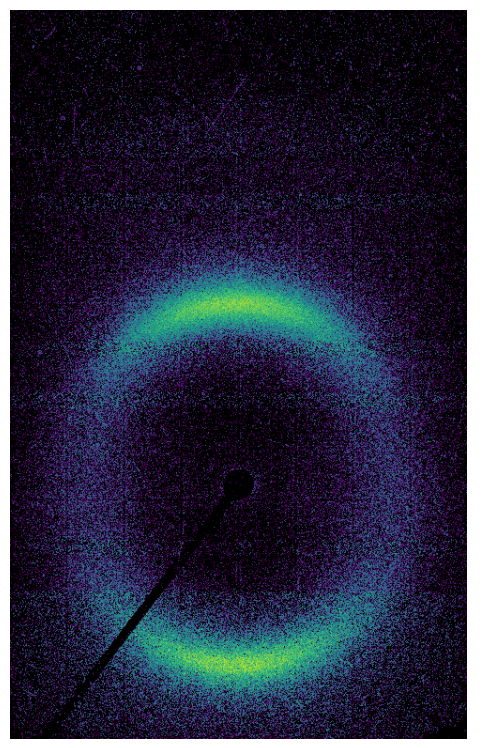

(a) Espalhamento.

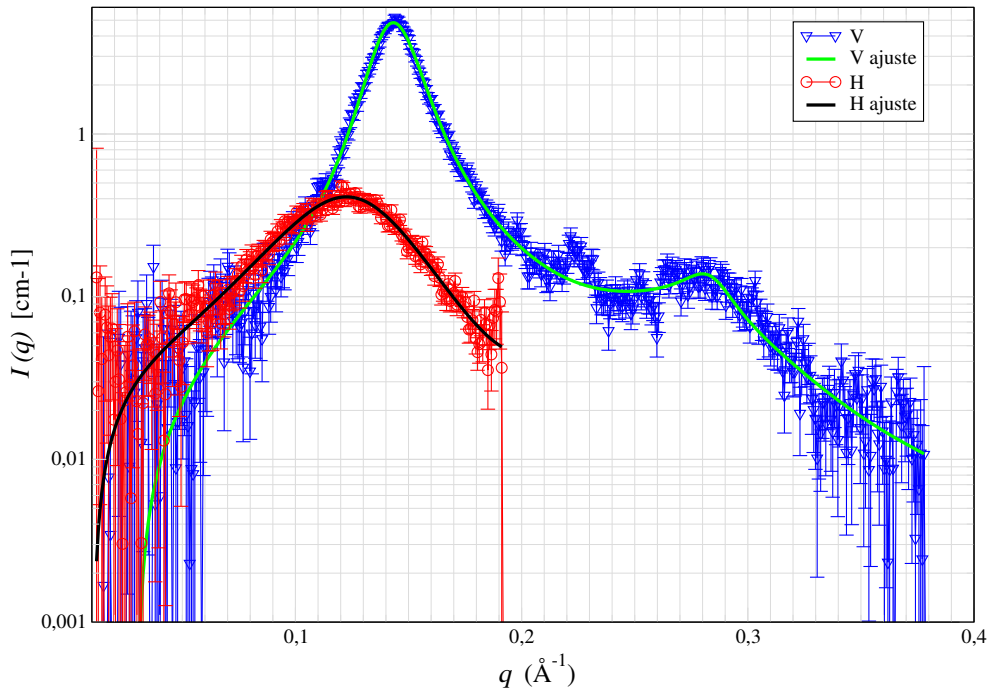

(b) Integrações em torno da horizontal $(\bigcirc)$ e da vertical $(\nabla)$.

Figura 4.3. Mistura liotrópica de DTAB / $\mathrm{KBr} / 1$-undecanol / $\mathrm{H}_{2} \mathrm{O}$ na fase $N_{D}$. . As imagens corresponde ao efeito de um campo magnético $\mathbf{H}$ paralelo ao feixe na amostra. $\mathrm{O}$ tempo de exposição da medida foi de $600 \mathrm{~s}$. A curva corresponde à integrações azimutais em setores de $15^{\circ} \mathrm{em}$ torno das direções horizontal e vertical.

\begin{tabular}{cr}
\hline \hline \multicolumn{2}{c}{ DTMABr, $N_{D}, H_{\|}$, horizontal } \\
\hline \hline $\bar{R}$ & 20.4161 \\
\hline$\epsilon$ & 1.6914 \\
\hline$\sigma_{R}$ & 7.3727 \\
\hline$T$ & 1.9124 \\
\hline$\rho_{C}$ & -0.2000 \\
\hline \hline$A$ & 50.2647 \\
\hline$D$ & 88.8354 \\
\hline$v$ & 0.0130 \\
\hline$c_{z}$ & 1.3408 \\
\hline$\sigma_{A}$ & 0.0006 \\
\hline \hline$R_{H S}$ & 14.1212 \\
\hline$\eta$ & 0.2240 \\
\hline \hline$C_{2}$ & 1237.8423 \\
\hline$B_{0}$ & -0.1887 \\
\hline
\end{tabular}

\begin{tabular}{cr}
\hline \hline \multicolumn{2}{c}{ DTMABr, $N_{D}, H_{\|}$, vertical } \\
\hline \hline $\bar{R}$ & 9.7068 \\
\hline$\epsilon$ & 2.0612 \\
\hline$\sigma_{R}$ & 3.5886 \\
\hline$T$ & 6.0000 \\
\hline$\rho_{C}$ & -0.2000 \\
\hline \hline$A$ & 44.3634 \\
\hline$D$ & 367.8663 \\
\hline$v$ & 1.0000 \\
\hline$c_{z}$ & 0.2325 \\
\hline$\sigma_{A}$ & 0.0471 \\
\hline \hline$R_{H S}$ & 22.3854 \\
\hline$\eta$ & 0.4269 \\
\hline \hline$C_{2}$ & 159.5475 \\
\hline$B_{0}$ & -0.0122 \\
\hline
\end{tabular}

Tabela 4.4. Resultados dos ajustes (eq. 2.30) às curvas experimentais da figura 4.3. Liotrópico em fase $N_{D}$, campo $H$ paralelo ao feixe. 


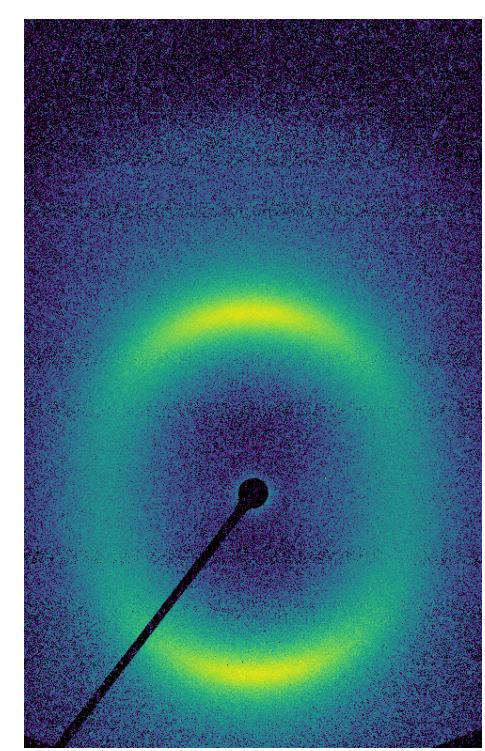

(a) Espalhamento.

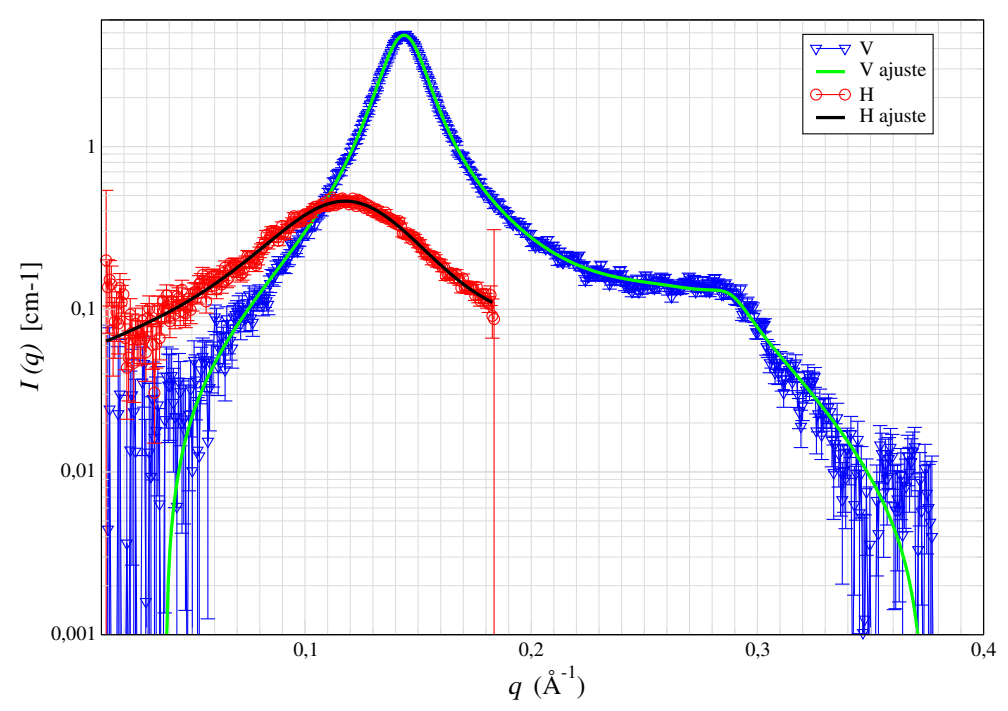

(b) Integrações em torno da horizontal $(\bigcirc)$ e da vertical $(\nabla)$.

Figura 4.4. Mistura liotrópica de $\mathrm{DTAB} / \mathrm{KBr} / 1$-undecanol $/ \mathrm{H}_{2} \mathrm{O}$ na fase $N_{D}$. As imagem corresponde ao efeito de um campo magnético $\mathbf{H}$ perpendicular ao feixe na amostra. O tempo de exposição da medida foi de $3600 \mathrm{~s}$. A curva corresponde à integração azimutal de $15^{\circ} \mathrm{em}$ torno da vertical e de $40^{\circ}$ em torno da horizontal.

\begin{tabular}{cr}
\hline \hline DTMABr, $N_{D}, H_{\perp}$, horizontal \\
\hline \hline $\bar{R}$ & 14.2446 \\
\hline$\epsilon$ & 2.7930 \\
\hline$\sigma_{R}$ & 5.7129 \\
\hline$T$ & 2.1368 \\
\hline$\rho_{C}$ & -0.2000 \\
\hline \hline$A$ & 54.6961 \\
\hline$D$ & 80.0371 \\
\hline$v$ & 0.0831 \\
\hline$c_{z}$ & 0.0856 \\
\hline$\sigma_{A}$ & 0.0000 \\
\hline \hline$R_{H S}$ & 21.0685 \\
\hline$\eta$ & 0.2120 \\
\hline \hline$C_{2}$ & 1301.7448 \\
\hline$B_{0}$ & 0.0018 \\
\hline
\end{tabular}

\begin{tabular}{cr}
\hline \hline \multicolumn{2}{c}{ DTMABr, $N_{D}, H_{\perp}$, vertical } \\
\hline \hline $\bar{R}$ & 10.7304 \\
\hline$\epsilon$ & 2.5000 \\
\hline$\sigma_{R}$ & 4.1322 \\
\hline$T$ & 4.5000 \\
\hline$\rho_{C}$ & -0.2000 \\
\hline \hline$A$ & 43.5147 \\
\hline$D$ & 407.5236 \\
\hline$v$ & 1.0000 \\
\hline$c_{z}$ & 0.7452 \\
\hline$\sigma_{A}$ & 0.0926 \\
\hline \hline$R_{H S}$ & 22.3484 \\
\hline$\eta$ & 0.3906 \\
\hline \hline$C_{2}$ & 63.3381 \\
\hline$B_{0}$ & -0.0287 \\
\hline
\end{tabular}

Tabela 4.5. Resultados dos ajustes (eq. 2.30) às curvas experimentais da figura 4.4. Liotrópico em fase $N_{D}$, campo $H$ perpendicular ao feixe. 


\subsubsection{Fase $N_{B}$}

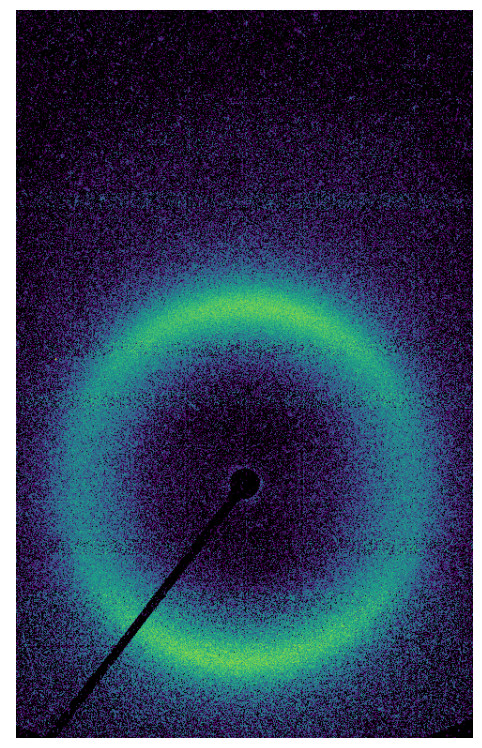

(a) Espalhamento.

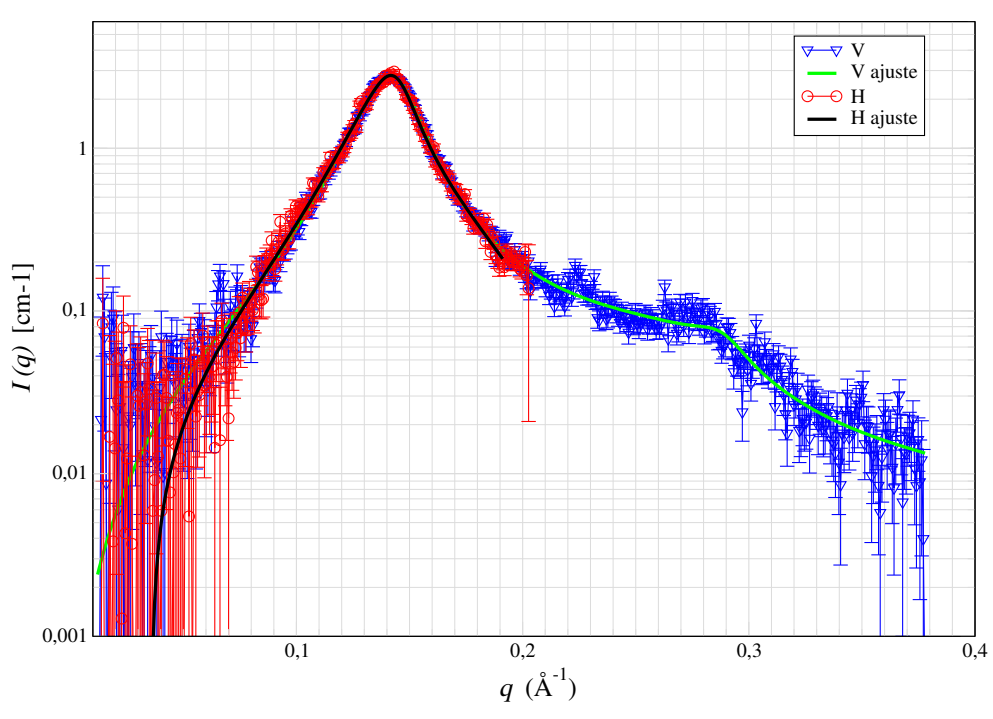

(b) Integrações em torno da horizontal $(\bigcirc)$ e da vertical $(\nabla)$.

Figura 4.5. Mistura liotrópica de $\mathrm{DTAB} / \mathrm{KBr} / 1$-undecanol / $\mathrm{H}_{2} \mathrm{O}$ na fase $N_{B}$. As imagem corresponde ao efeito de um campo magnético $\mathbf{H}$ paralelo ao feixe na amostra. O tempo de exposição da medida foi de $1200 \mathrm{~s}$. As curvas correspondem à integração azimutal de $15^{\circ}(\mathrm{V}) \mathrm{e} 40^{\circ}(\mathrm{H})$.

\begin{tabular}{cr}
\hline \hline DTMABr, $N_{B}, H_{\|}$, horizontal \\
\hline \hline $\bar{R}$ & 8.3900 \\
\hline$\epsilon$ & 0.7838 \\
\hline$\sigma_{R}$ & 0.8374 \\
\hline$T$ & 2.9801 \\
\hline$\rho_{C}$ & -0.2000 \\
\hline \hline$A$ & 43.5717 \\
\hline$D$ & 112.8305 \\
\hline$v$ & -1.4606 \\
\hline$c_{z}$ & 0.3293 \\
\hline$\sigma_{A}$ & 0.0484 \\
\hline \hline$R_{H S}$ & 23.1063 \\
\hline$\eta$ & 0.3633 \\
\hline \hline$C_{2}$ & 140.2529 \\
\hline$B_{0}$ & -0.0161 \\
\hline
\end{tabular}

\begin{tabular}{cr}
\hline \hline \multicolumn{2}{c}{ DTMABr, $N_{B}, H_{\|}$, vertical } \\
\hline \hline $\bar{R}$ & 8.1664 \\
\hline$\epsilon$ & 1.1031 \\
\hline$\sigma_{R}$ & 3.5514 \\
\hline$T$ & 7.0756 \\
\hline$\rho_{C}$ & -0.2000 \\
\hline \hline$A$ & 43.5249 \\
\hline$D$ & 283.2891 \\
\hline$v$ & 0.5115 \\
\hline$c_{z}$ & 0.3525 \\
\hline$\sigma_{A}$ & 0.0542 \\
\hline \hline$R_{H S}$ & 22.6555 \\
\hline$\eta$ & 0.3471 \\
\hline \hline$C_{2}$ & 46.6801 \\
\hline$B_{0}$ & 0.0005 \\
\hline
\end{tabular}

Tabela 4.6. Resultados dos ajustes (eq. 2.30) às curvas experimentais da figura 4.5. Liotrópico em fase $N_{B}$, campo $H$ paralelo ao feixe. 


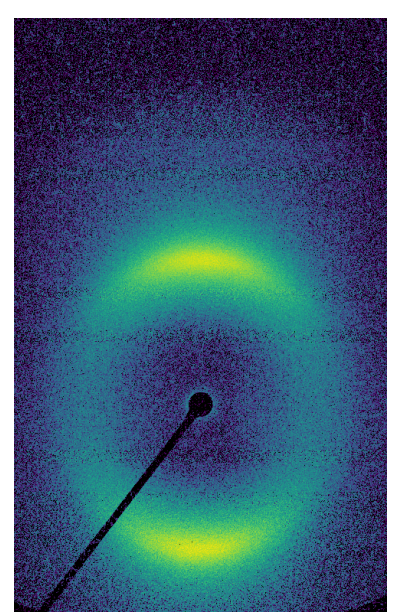

(a) Espalhamento.

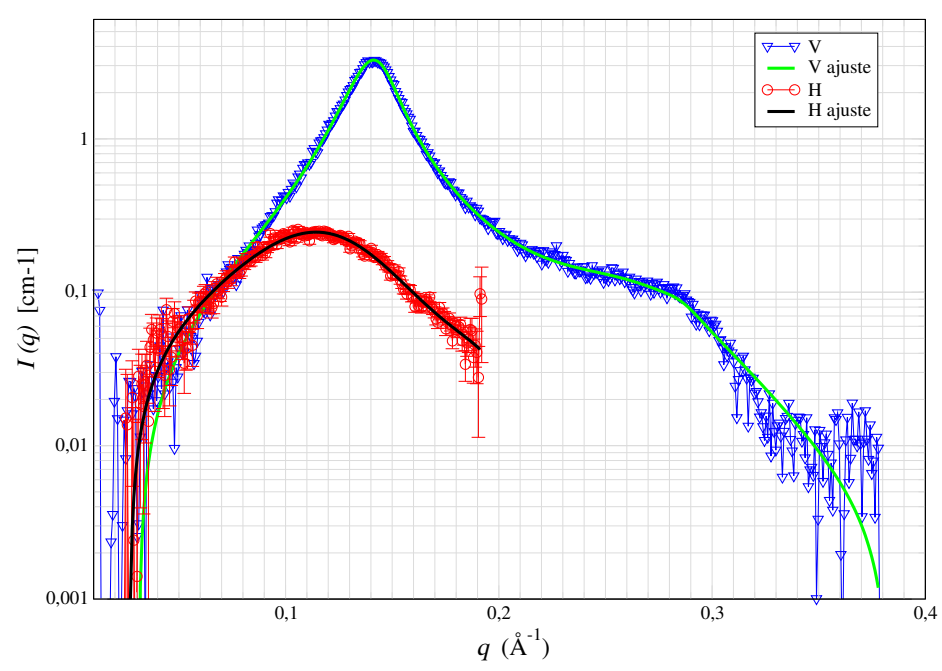

(b) Integrações em torno da horizontal $(\bigcirc)$ e da vertical $(\nabla)$.

Figura 4.6. Mistura liotrópica de $\mathrm{DTAB} / \mathrm{KBr} / 1$-undecanol / $\mathrm{H}_{2} \mathrm{O}$ na fase $N_{B}$. A imagem corresponde ao efeito de um campo magnético $\mathbf{H}$ perpendicular ao feixe na amostra. $\mathrm{O}$ tempo de exposição da medida foi de $3600 \mathrm{~s}$. As curvas correspondem a integrações azimutais de $15^{\circ} \mathrm{e} 40^{\circ}$ em torno das direções vertical e horizontal, respectivamente, conforme a legenda.

\begin{tabular}{cr}
\hline \hline \multicolumn{2}{c}{ DTMABr, $N_{B}, H_{\perp}$, horizontal } \\
\hline \hline $\bar{R}$ & 14.5209 \\
\hline$\epsilon$ & 2.8058 \\
\hline$\sigma_{R}$ & 5.2062 \\
\hline$T$ & 2.2053 \\
\hline$\rho_{C}$ & -0.2000 \\
\hline \hline$A$ & 52.4701 \\
\hline$D$ & 62.4648 \\
\hline$v$ & 0.0131 \\
\hline$c_{z}$ & 0.4323 \\
\hline$\sigma_{A}$ & 0.0002 \\
\hline \hline$R_{H S}$ & 14.6064 \\
\hline$\eta$ & 0.2431 \\
\hline \hline$C_{2}$ & 1307.9478 \\
\hline$B_{0}$ & -0.2965 \\
\hline
\end{tabular}

\begin{tabular}{cr}
\hline \hline \multicolumn{2}{c}{ DTMABr, $N_{B}, H_{\perp}$, vertical } \\
\hline \hline $\bar{R}$ & 10.2700 \\
\hline$\epsilon$ & 2.5000 \\
\hline$\sigma_{R}$ & 3.5648 \\
\hline$T$ & 4.3000 \\
\hline$\rho_{C}$ & -0.2000 \\
\hline \hline$A$ & 43.8710 \\
\hline$D$ & 388.8914 \\
\hline$v$ & 1.0000 \\
\hline$c_{z}$ & 0.5537 \\
\hline$\sigma_{A}$ & 0.1087 \\
\hline \hline$R_{H S}$ & 22.8503 \\
\hline$\eta$ & 0.3766 \\
\hline \hline$C_{2}$ & 49.9479 \\
\hline$B_{0}$ & -0.0235 \\
\hline
\end{tabular}

Tabela 4.7. Resultados dos ajustes (eq. 2.30) às curvas experimentais da figura 4.6. Liotrópico em fase $N_{B}$, campo $H$ perpendicular ao feixe. 


\subsubsection{Parâmetros de ordem}

Utilizando a metodologia descrita na seção 2.4.1, calculamos os parâmetros de ordem das fases indicadas nas figuras anteriores. Os resultados são mostrados na Tabela 4.8. As colunas "ajuste" e são resultado dos ajustes mostrados nas figuras 4.7 (caso $N_{C}$ ), 4.8 (caso $N_{D}$ ) e 4.9 (caso $N_{B}$ ). A metodologia fornece um ótimo ajuste aos dados experimentais bem como valores dos parâmetros de ordem $\bar{P}_{2}$ (eq. 2.39) e $\bar{P}_{4}$ (eq. 2.40) para cada configuração. As colunas indicadas como "direto" correspondem aos valores calculados diretamente dos dados, com propagação de erros direta, da integração numérica por método dos trapézios; os resultados obtidos de ambas as formas são compatíveis.

Tabela 4.8. Resultado dos cálculos dos parâmetros de ordem. Os valores das colunas marcadas como "ajuste" foram obtidas pela integração de curvas ajustadas; os valores das colunas "direto" foram obtidas pela integração direta dos dados.

\begin{tabular}{cccccc}
\hline \multicolumn{5}{c}{} & \multicolumn{2}{c}{$P_{2}$} & & $P_{4}$ \\
\hline \hline \multirow{2}{*}{$N_{B}$} & & ajuste & direto & ajuste & direto \\
\cline { 2 - 6 } & $H_{\|}$ & $0.44 \pm 0.01$ & $0.462 \pm 0.003$ & $0.09 \pm 0.02$ & $0.105 \pm 0.004$ \\
\hline \multirow{2}{*}{$N_{C}$} & $0.662 \pm 0.007$ & $0.666 \pm 0.003$ & $0.31 \pm 0.01$ & $0.293 \pm 0.002$ \\
\cline { 2 - 6 } & $H_{\|}$ & $0.45 \pm 0.03$ & $0.48 \pm 0.04$ & $0.21 \pm 0.02$ & $0.24 \pm 0.04$ \\
\hline \multirow{2}{*}{$N_{D}$} & $H_{\perp}$ & $0.708 \pm 0.006$ & $0.709 \pm 0.009$ & $0.38 \pm 0.01$ & $0.352 \pm 0.003$ \\
\cline { 2 - 6 } & $H_{\|}$ & $0.629 \pm 0.006$ & $0.615 \pm 0.001$ & $0.26 \pm 0.01$ & $0.228 \pm 0.002$ \\
\hline
\end{tabular}

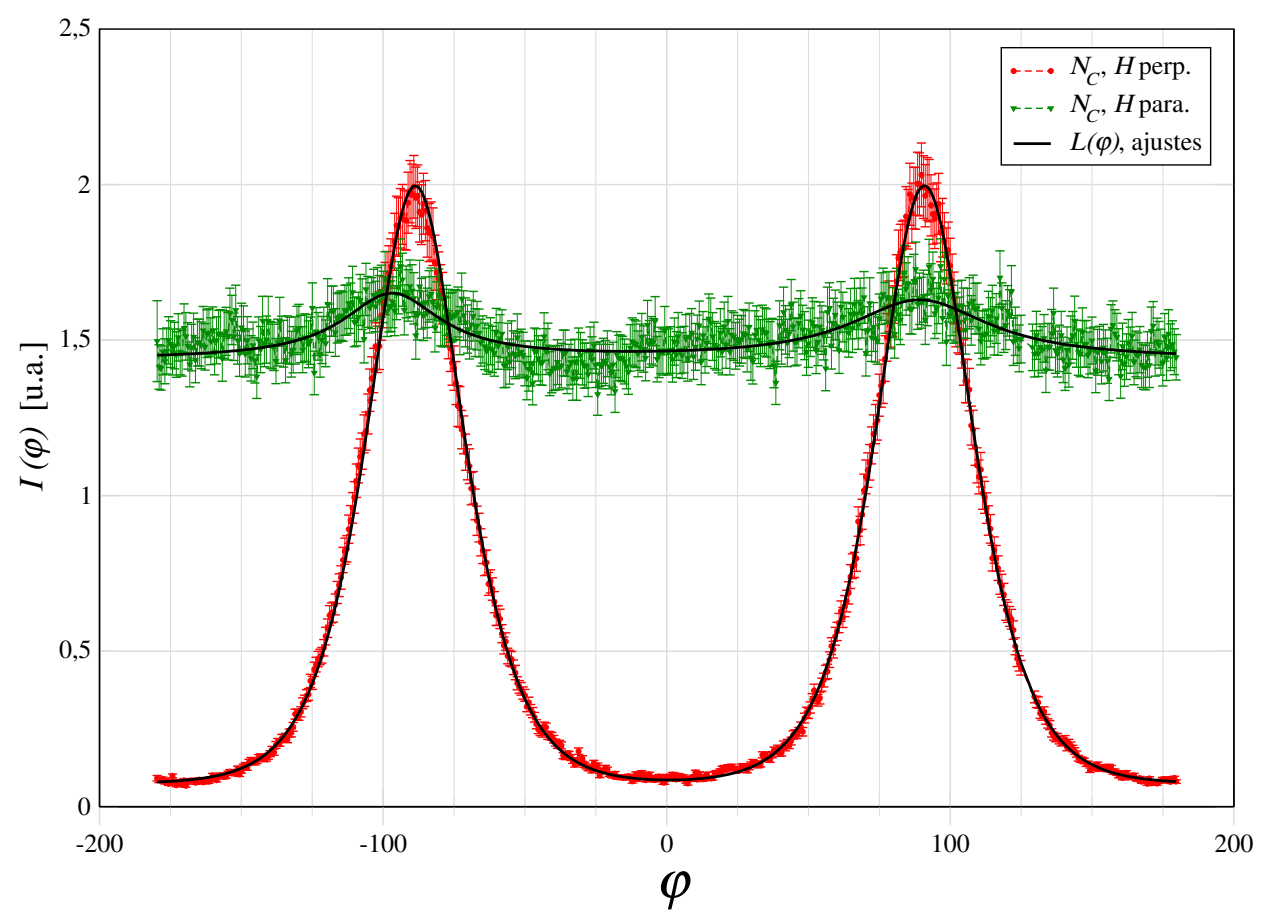

Figura 4.7. Resultado da integração radial das imagens 4.1a e 4.2a, com respectivos ajustes. Fase $N_{C}$, com campo $H$ na direção paralela e perpendicular ao feixe. 


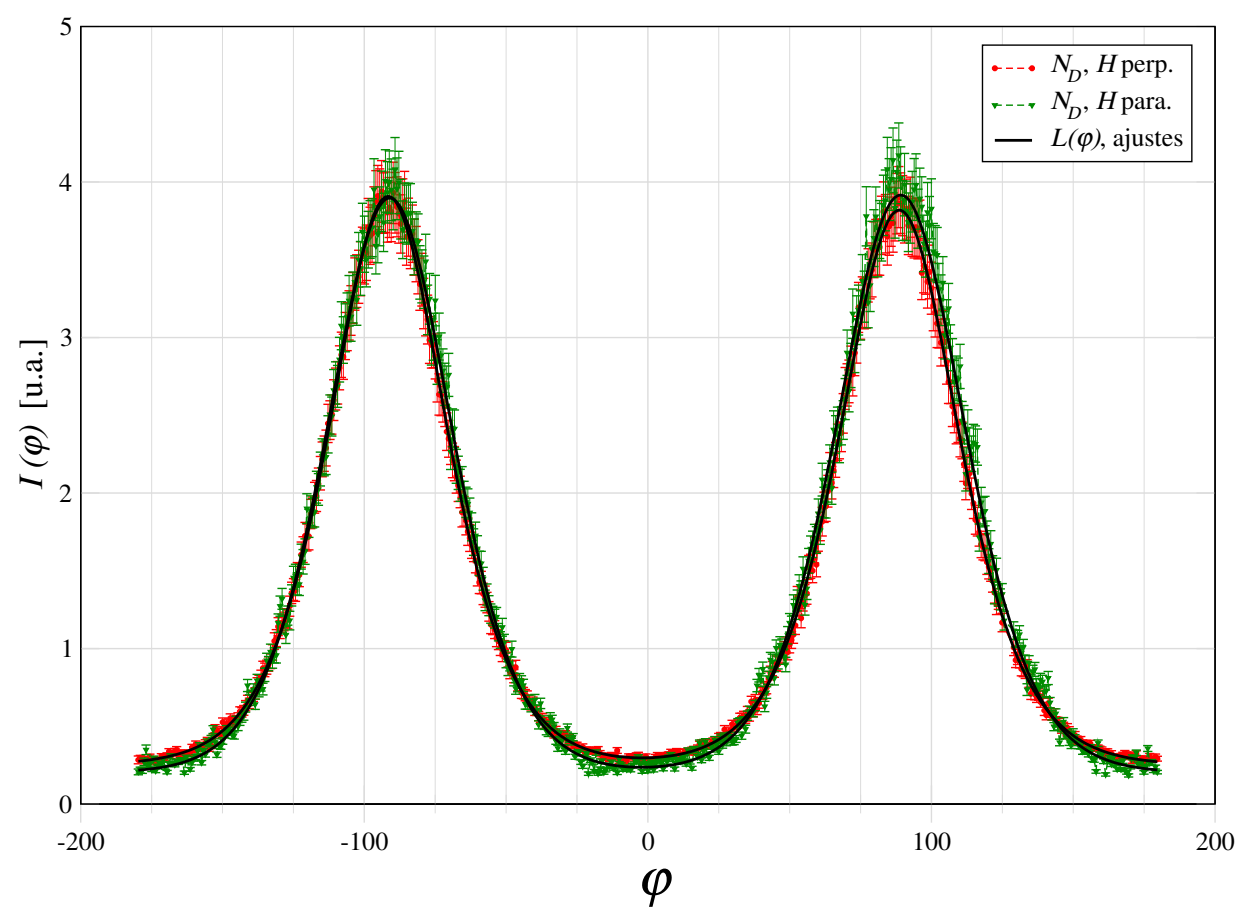

Figura 4.8. Resultado da integração radial das imagens 4.1a e 4.2a, com respectivos ajustes. Fase $N_{D}$, com campo $H$ na direção paralela e perpendicular ao feixe.

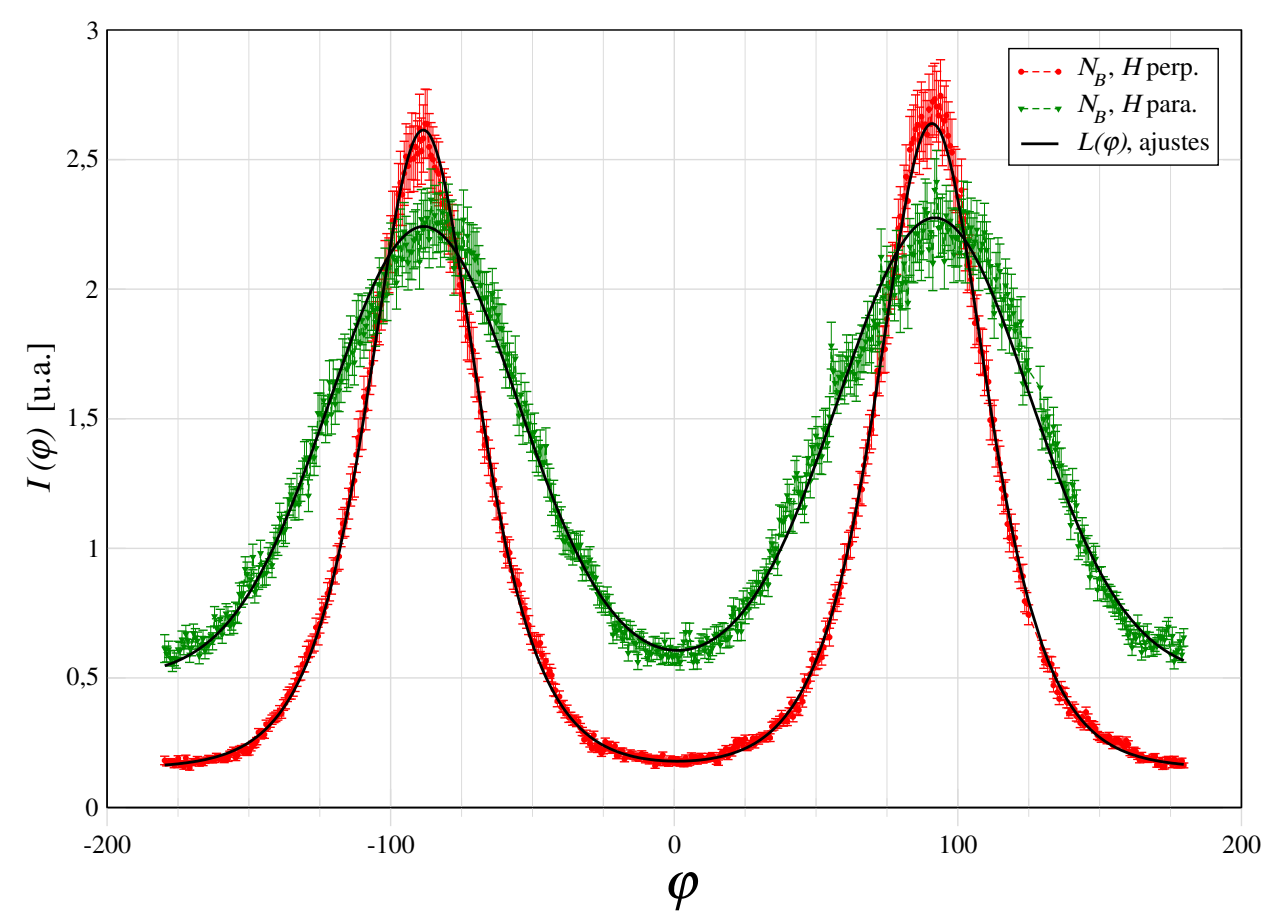

Figura 4.9. Resultado da integração radial das imagens 4.1a e 4.2a, com respectivos ajustes. Fase $N_{B}$, com campo $H$ na direção paralela e perpendicular ao feixe.

Em todos os casos, nas fases e direções em que se espera alinhamento da amostra $\left(N_{C}\right.$ com $H_{\perp}, N_{D}$ e $N_{B}$ em ambas as direções), os valores obtidos indicam uma qualidade de 
ordenamento razoável. Ainda quando a amostra é rotacionada, sem a presença dos ímãs, como no caso de $N_{D}$ e $N_{B}$ com $H_{\|}$, o alinhamento é razoavelmente preservado. Poderíamos esperar uma diferença mais significativa entre os valores de $\bar{P}_{2}$ na fases $N_{B}$ e $N_{C}$ com $H_{\|}$, já que a figura para $N_{C}$ é isotrópica nesse caso (figura 4.1a; curva em verde, com leves oscilações na figura 4.7); os valores de $\bar{P}_{4}$, no entanto, são bastante distintos nesses casos.

Estes resultados indicam que o modelo proposto consegue descrever satisfatoriamente os dados experimentais de SAXS (compare-se com os resultados e métodos para termotrópicos em [47], por exemplo). Estes são resultados iniciais, mas muito promissores, uma vez que fornecem indicações estruturais das dimensões das micelas e sua organização estrutural através do ajuste da curva inteira. Tal abordagem é nova e não existe na literatura. Os resultados indicam que as micelas podem ser compreendidas como elipsoides de revolução prolatos que se arranjam em estruturas pseudolamelares. Apesar de serem resultados preliminares, demonstram o potencial do modelo proposto.

\subsection{Simulações de SAXS por estruturas de tipo micelar}

Apresentamos abaixo resultados das simulações obtidos a partir dos procedimentos descritos na seção 2.5. A sequência de imagens e gráficos é representativa das tentativas de reprodução dos dados experimentais e mostram a influência das mudanças de configurações estruturais das micelas nos padrões de espalhamento. Resultados complementares encontram-se na seção A.1 do apêndice.

Como se trata de uma busca de padrões de espalhamento, decidimos observar as configurações que corresponderiam à fase $N_{C}$, pois suas imagens de SAXS experimentais apresentam diferenças mais evidentes quando confrontadas as disposições em que o campo magnético $H$ aplicado encontra-se em direção paralela ou perpendicular ao feixe incidente. Nessa fase, a imagem na configuração de campo $H$ paralelo à direção do feixe incidente é isotrópica, enquanto que a imagem correspondente à configuração de campo perpendicular é bastante anisotrópica (figuras 2.2a e 2.3a).

Nas simulações do modelo IBM em fase $N_{C}$, foram aplicadas rotações aleatórias em torno eixo maior de maior dimensão dos elipsoides. Assim, num elipsoide de $a \times b \times c=$ $45.0 \AA \times 35.0 \AA \times 20.0 \AA$, em que a direção de $a$ se alinha à de $y$, foram efetuadas rotações em torno do eixo $a$, esperando-se que a imagem represente picos correspondentes a $a$ na horizontal e a algum valor intermediário entre $b$ e $c$ na vertical. Os valores das dimensões das micelas foram baseados em valores médios encontrados na literatura da área $[2,11,12,72] \mathrm{e}$ definidas de modo a que alguns efeitos fossem observados.

Em todas as simulações abaixo, o feixe incidente encontra-se sempre na direção do eixo $y$, em consonância com o aparato experimental usado. O comprimento de onda foi definido como o do $K_{\alpha}$ do cobre $(\lambda=1.5419 \AA)$. A amplitude de espalhamento $E_{e}$ foi definida como 
1.0 e o raio de uma bead foi fixado em 0.001 Å para que seu fator de forma não interferisse na imagem.

A região escura das bordas não contém informação, pois as simulações foram efetuadas em simetria circular, segundo a descrição do método proposto. Os pontos escuros nas regiões circulares, principalmente a ângulos mais altos, são decorrentes de baixa estatística, ou seja, pequeno número de beads nas micelas. Isso ocorreu principalmente nos estudos em que o número de micelas foi bastante aumentado, para o que se reduziu o número de beads.

Os programas e simulações foram efetuados em um computador com um processador AMD Ryzen 7 3700x (64 bits, 3.7 GHz, 8 núcleos, 4 MB + 32 MB cache). Os tempos típicos de simulação variaram de alguns minutos a algumas horas, dependendo do número de pontos de espalhamento (beads), do número de subgrupos (blocos) de pontos e do número de pontos do padrão de espalhamento. Como exemplo, para um cálculo com $m=64$ micelas com $N=1000$ pontos cada em um único bloco $(b=1)$, numa "tela" de $L=250$ pontos de raio e 360 direções (passos de $1^{\circ}$ ), ou seja, algo de $\mathscr{O}\left(10^{14}\right)$ operações, o tempo de execução era de cerca de $10 \mathrm{~min}$.

\subsubsection{Estrutura cristalina e esfera}

As figuras 4.10 e 4.11 mostram as possibilidades do programa em comparação com resultados conhecidos para estruturas mais simples do que os liotrópicos. Para a montagem da rede cristalina, definiu-se uma "micela" de uma única conta (bead) e foram dispostas 8000 micelas em rede cúbica simples. Para a esfera, foi gerada uma única micela com 25000 e 50000 beads em cada uma das simulações.

Em ambos os casos, as imagens produzidas se aproximam das obtidas experimentalmente e os picos correspondem de fato aos tamanhos e distâncias estabelecidos no programa, pela relação $d=2 \pi / q$, em $d$ é um comprimento típico. No caso da esfera, as curvas (figura 4.11c) se convergem para os resultados teóricos (equação 2.16) com aumento do número de beads, o que mostra a consistência do processo em casos padrão, mas com grande número de pontos espalhadores. 


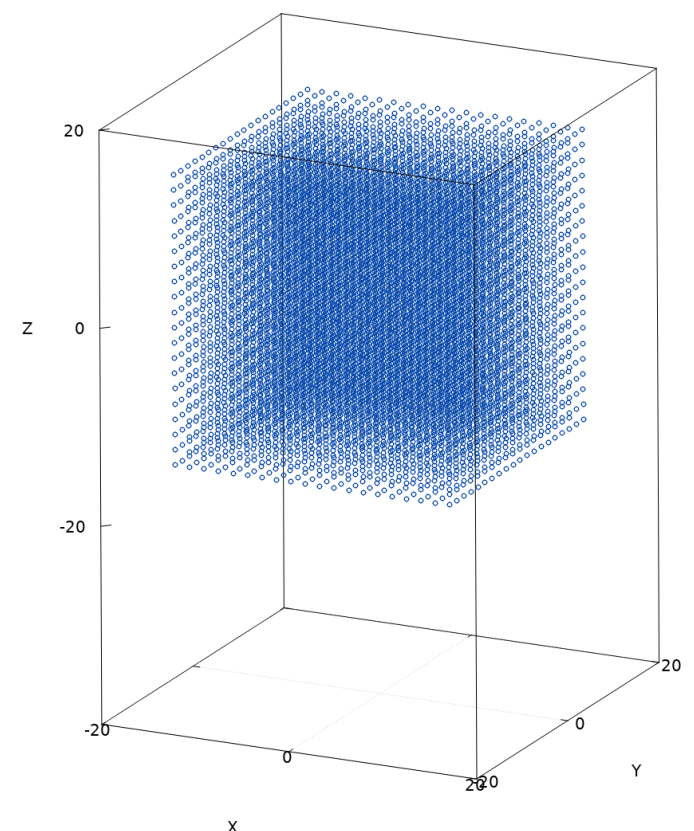

(a) Rede cristalina.

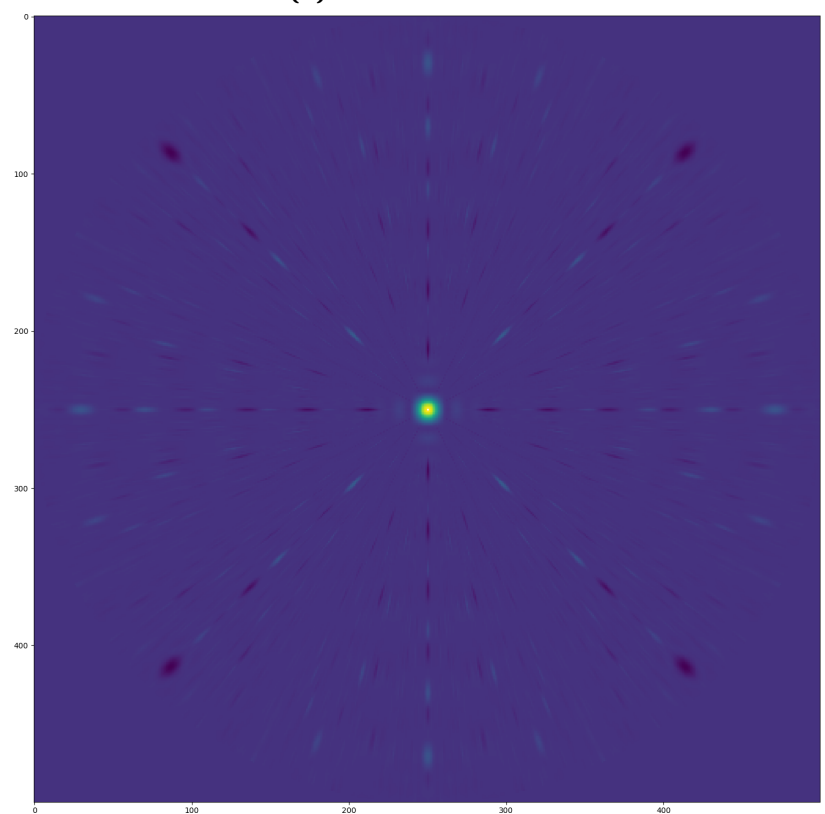

(b) Espalhamento

Figura 4.10. Simulação de SAXS de um conjunto de $20 \times 20 \times 20$ pontos de espalhamento (8000 no total), em rede cúbica. A distância entre os pontos da rede é de $4.6257 \AA$ em cada direção (três vezes o comprimento de onda do $K_{\alpha}$ do cobre). A distância entre amostra e detector é de $0.050 \mathrm{~m}$. 


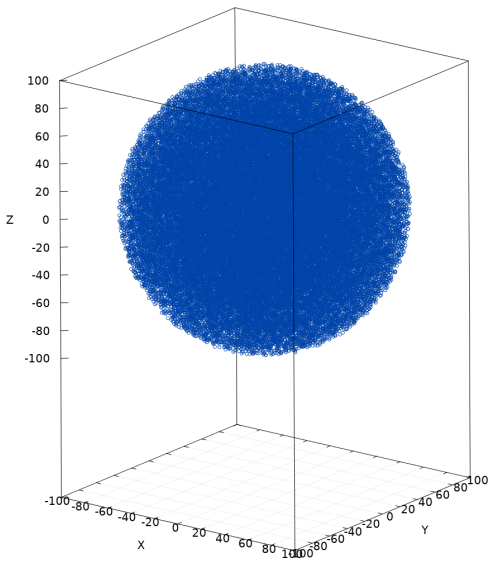

(a) Micela.

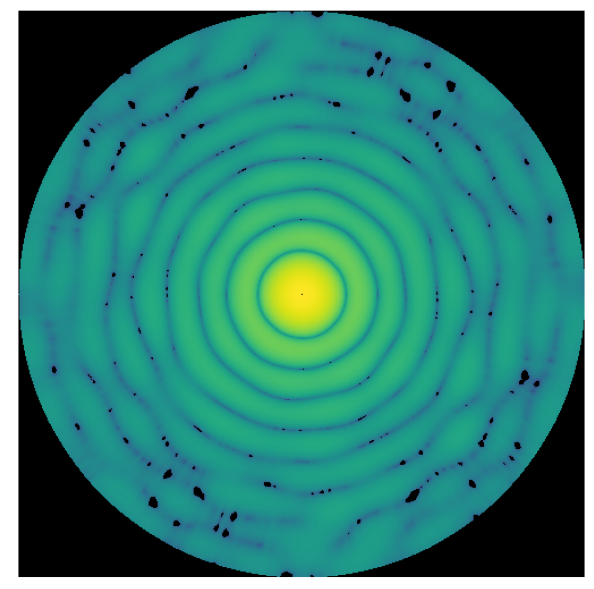

(b) Espalhamento

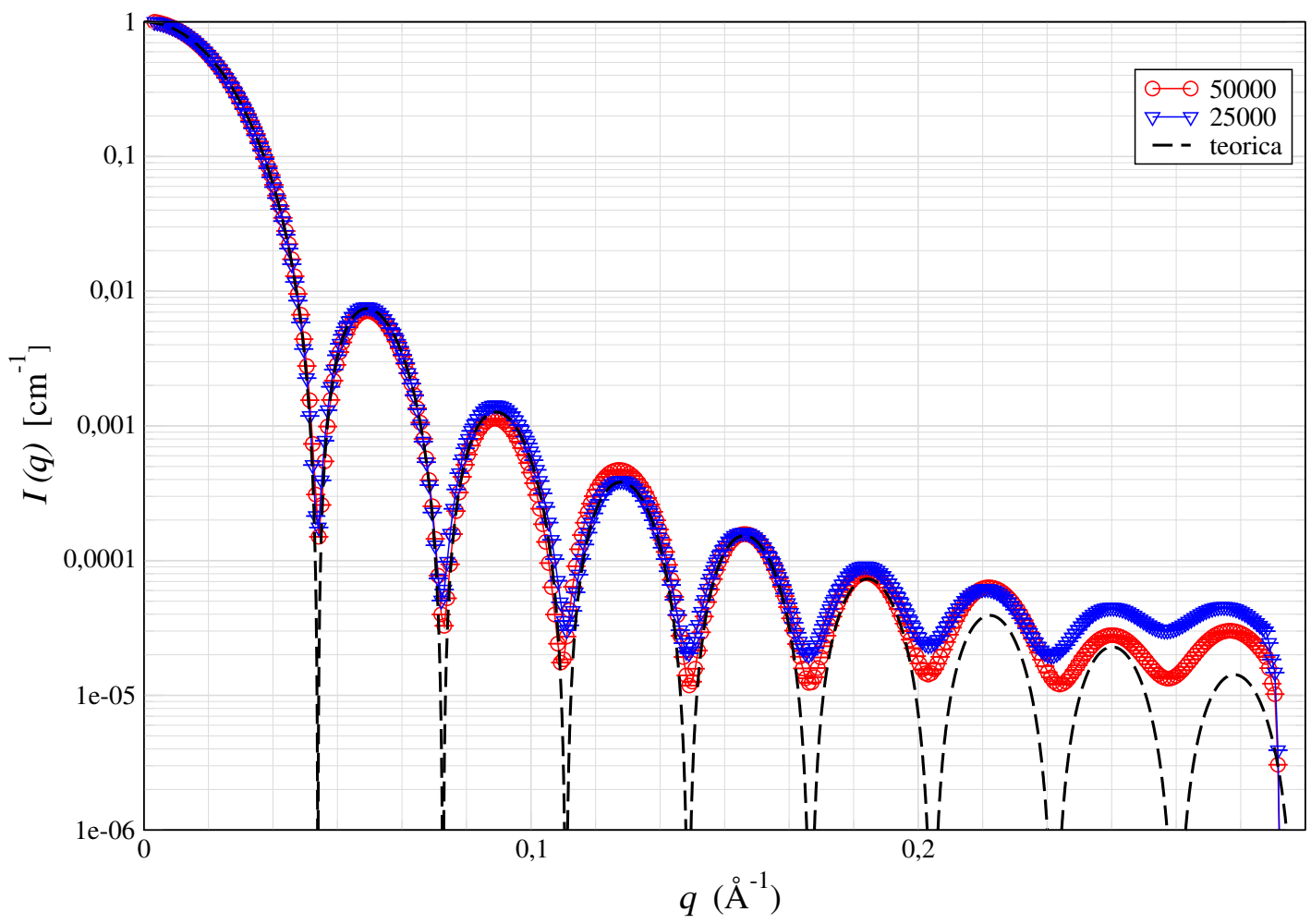

(c) Integrações em torno da horizontal $(\bigcirc)$ e da vertical $(\nabla)$.

Figura 4.11. Simulação de SAXS de micela esférica. São apresentados os resultados para simulações de micelas de raio $100.0 \AA$, com 25000 e 50000 pontos de espalhamento. A densidade de pontos é homogênea (não há shell). A distância entre amostra e detector é de $0.60 \mathrm{~m}$. O resultado é comparado com a curva de linha contínua, obtida a partir do cálculo analítico. 


\subsubsection{Micelas, $2 \times 1 \times 2$}

As figuras 4.12 e 4.14 mostram uma estrutura com $2 \times 2$ micelas uniaxiais (há apenas um eixo maior do que os demais) no plano $x z$. As curvas coincidem quando a dimensão maior do elipsoide se encontra na direção $y$, havendo simetria em no plano $x z$,do ponto de vista do feixe incidente (figura 4.12c). Quando o sistema é rotacionado de $90^{\circ} \mathrm{em}$ torno do eixo $z$, há assimetria do ponto de vista do feixe incidente, e os picos se deslocam, como mostra o gráfico 4.14c. O padrão observado é claramente quadriculado, como consequência da organização espacial do sistema. As posições dos picos, no entanto, é compatível com as dimensões impostas aos elipsoides.

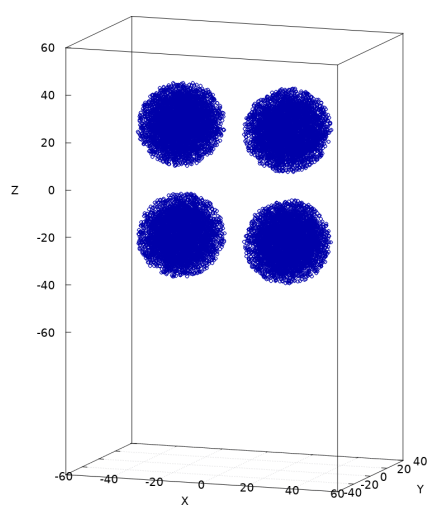

(a) Micelas

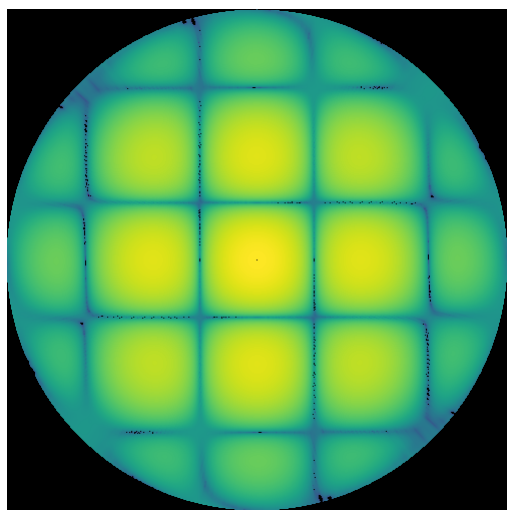

(b) Espalhamento

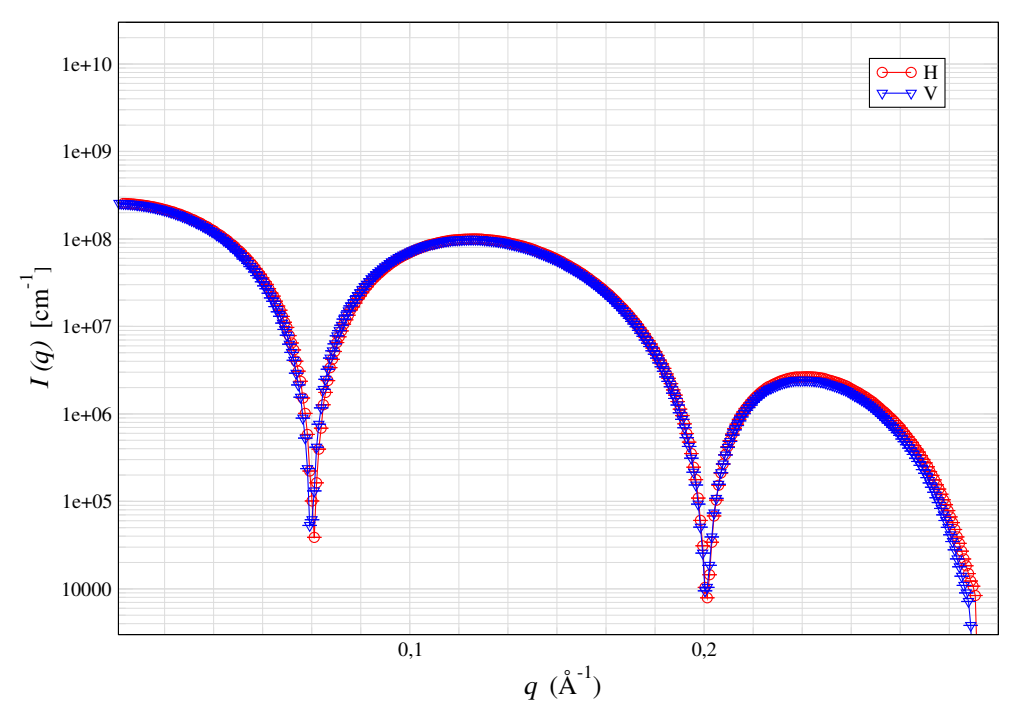

(c) Integrações em torno da horizontal $(\bigcirc)$ e da vertical $(\nabla)$.

Figura 4.12. Simulação de SAXS de um conjunto de $2 \times 1 \times 2$ estruturas micelares, em rede cúbica.

Cada micela tem 4000 pontos de espalhamento (16000 no total). O campo H encontra-se na direção paralela ao feixe de raios X incidente. Os eixos maiores das micelas têm $35.0 \AA \times 45.0 \AA \times 35.0 \AA$ (modelo uniaxial), simulando a fase $N c$, e a espessura da shell é de $4.10 \AA$. A camada de solvente tem, em média, 12.0Å. A distância entre amostra e detector é de $0.60 \mathrm{~m}$. 


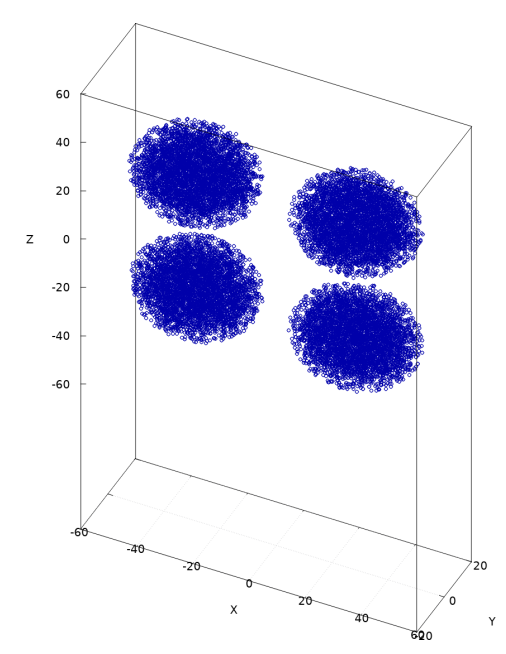

(a) Micelas.

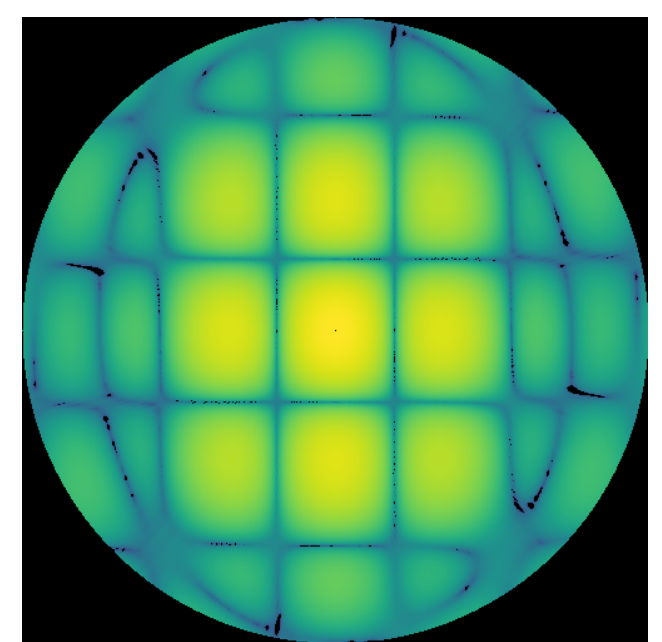

(b) Espalhamento.

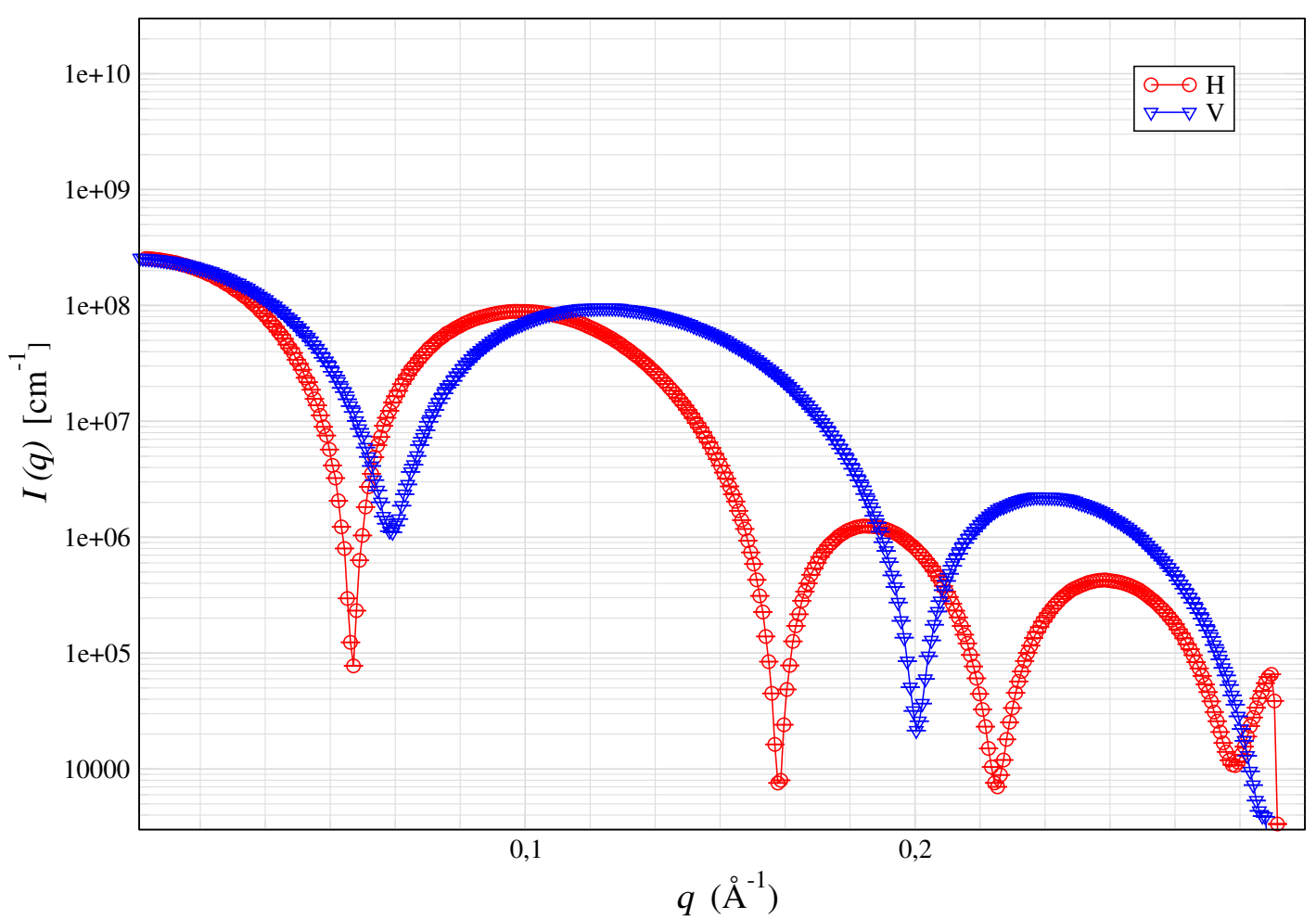

(c) Integrações em torno da horizontal $(\bigcirc)$ e da vertical $(\nabla)$.

Figura 4.13. Simulação de SAXS de um conjunto de $2 \times 1 \times 2$ estruturas micelares, em rede cúbica. Cada micela tem 4000 pontos de espalhamento (16000 no total). O campo $\mathrm{H}$ encontra-se $H$ na direção perpendicular ao feixe de raios X incidente. Os eixos maiores das micelas têm $45.0 \AA \times$ $35.0 \AA \times 35.0 \AA$ (modelo uniaxial), simulando a fase $N c$, e a espessura da shell é de $4.10 \AA$ A camada de solvente tem, em média, 12.0§. A distância entre amostra e detector é de $0.60 \mathrm{~m}$. 


\subsubsection{Micelas, $4 \times 1 \times 4$}

Na figura 4.14 a seguir, mostramos o resultado de simulações aumentando o número de micelas na estrutura quadrada, o que evidencia os efeitos de tamanho finito (finite size) do sistema. As considerações anteriores sobre os picos e as simetrias continuam válidas. Há, porém, um distanciamento entre o pico central da figura e os de primeira ordem, e a região intermediária entre ambos tem menor intensidade de espalhamento, o que é qualitativamente consistente com medidas experimentais, ainda que as ondulações permaneçam em função de interferências construtivas.

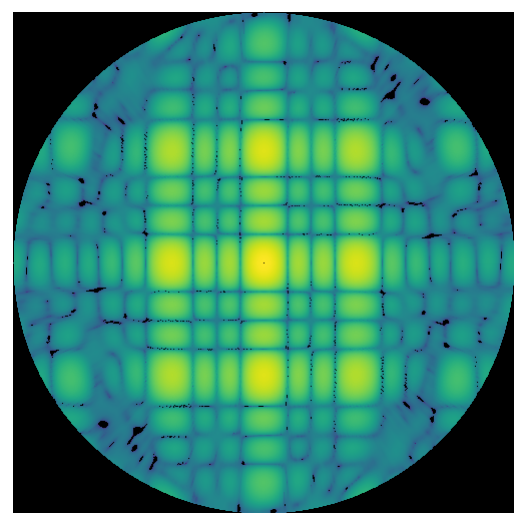

(a) Espalhamento.

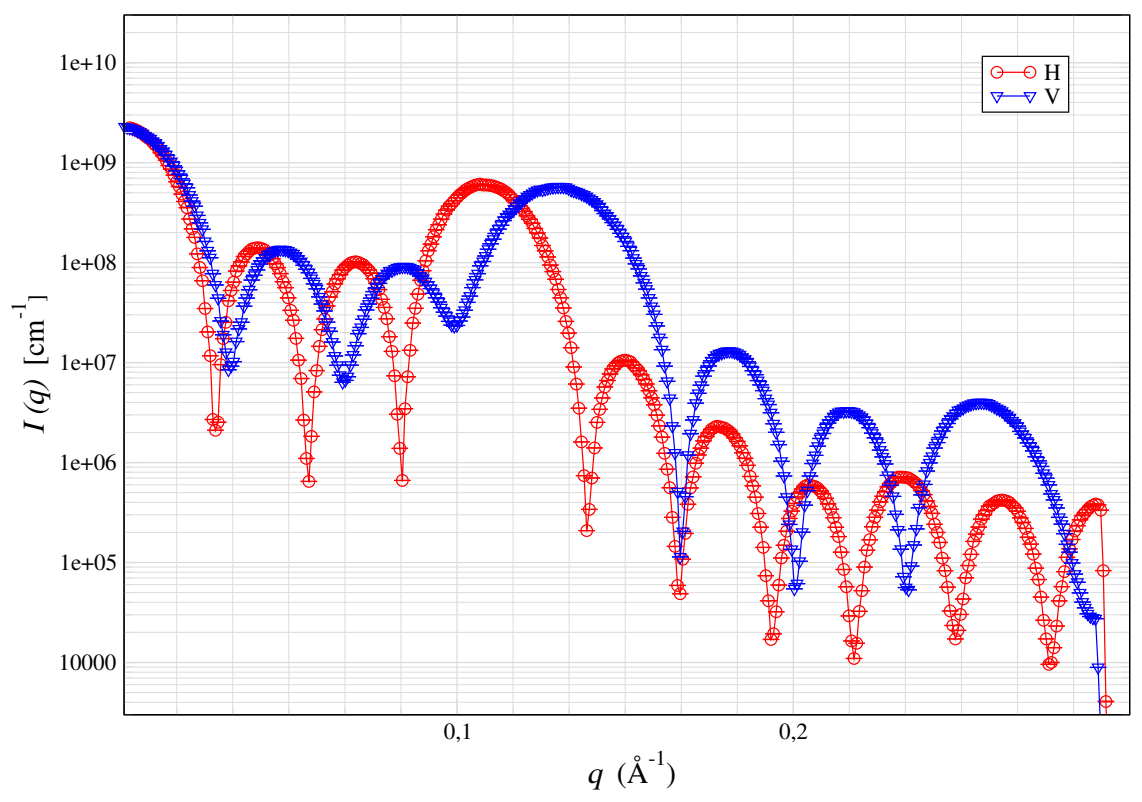

(b) Integrações em torno da horizontal $(\bigcirc)$ e da vertical $(\triangle)$.

Figura 4.14. Simulação de SAXS de um conjunto de $4 \times 1 \times 4$ estruturas micelares, em rede cúbica. Cada micela tem 3000 pontos de espalhamento (48000 no total). O campo H encontrase na direção perpendicular ao feixe de raios $\mathrm{X}$ incidente. Os eixos maiores das micelas têm $45.0 \AA \times 35.0 \AA \times 35.0 \AA$ (modelo uniaxial), simulando a fase $N c$, e a espessura da shell é de $4.10 \AA \AA$ camada de solvente tem, em média, $12.0 \AA$. A distância entre amostra e detector é de $0.60 \mathrm{~m}$. 


\subsubsection{Micelas, $4 \times 4 \times 4$}

Prosseguimos agora com uma série de testes de configurações geométricas da estrutura de um conjunto de $4 \times 4 \times 4$ micelas. Iniciamos por uma rede cúbica e acrescentamos progressivamente modificações no conjunto, conforme as descrições da seção 2.5.1.1.

\subsubsection{Rede cúbica}

Há semelhança entre este padrão e o apresentado na figura 4.14. Apenas as proporções entre os picos se reduziram um pouco na estrutura cúbica deste grupo, indicando mais interferências destrutivas. É interessante, porém, observar como o modelo IBM da figura 4.16 tem alteração no pico vertical em relação ao da figura 4.12. Os valores dos picos nesses casos ainda correspondem aos das dimensões das micelas somadas à espessura da camada de solvente, porque as rotações têm menos efeito do que a definição rígida das distâncias. A figura 4.15 apresenta várias vistas de uma configuração com rotações aleatórias aplicadas às micelas.

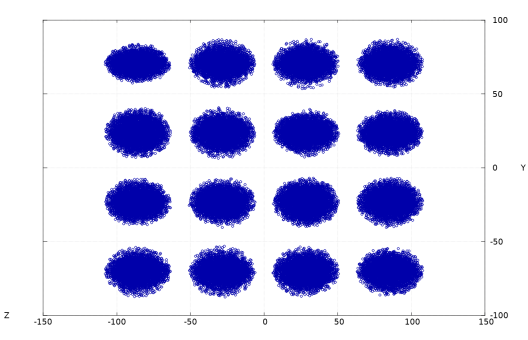

(a) Plano $x y$.

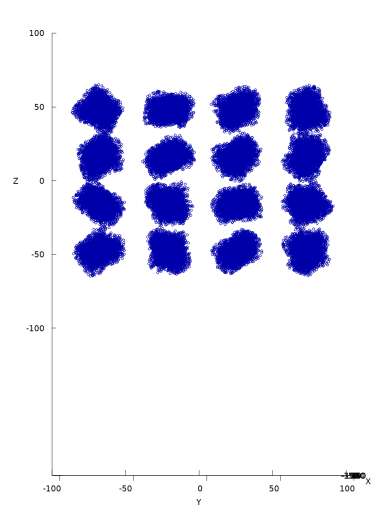

(c) Plano $y z$.

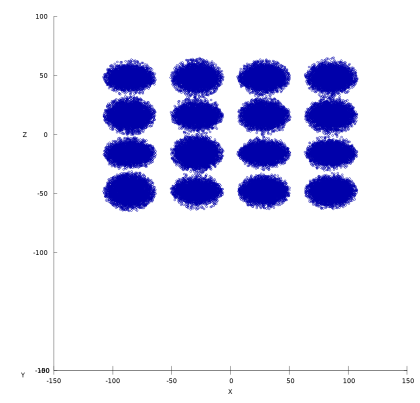

(b) Plano $x z$.

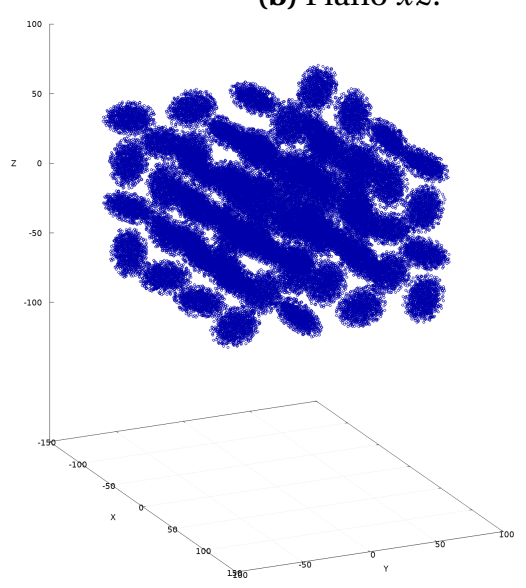

(d) Perspectiva.

Figura 4.15. Diversos pontos de vista das estruturas elipsoidais em configuração $4 \times 4 \times 4$. Foram aplicadas rotações aleatórias a cada micela em torno da direção do eixo $y$ (modelo IBM, fase $N c$ ). Cada micela tem 2000 pontos de espalhamento e seus eixos maiores têm $45.0 \AA \times 35.0 \AA \times 20.0 \AA$ (modelo IBM) e a espessura da shell é de $4.10 \AA$. A camada de solvente tem, em média, $12.0 \AA$. 


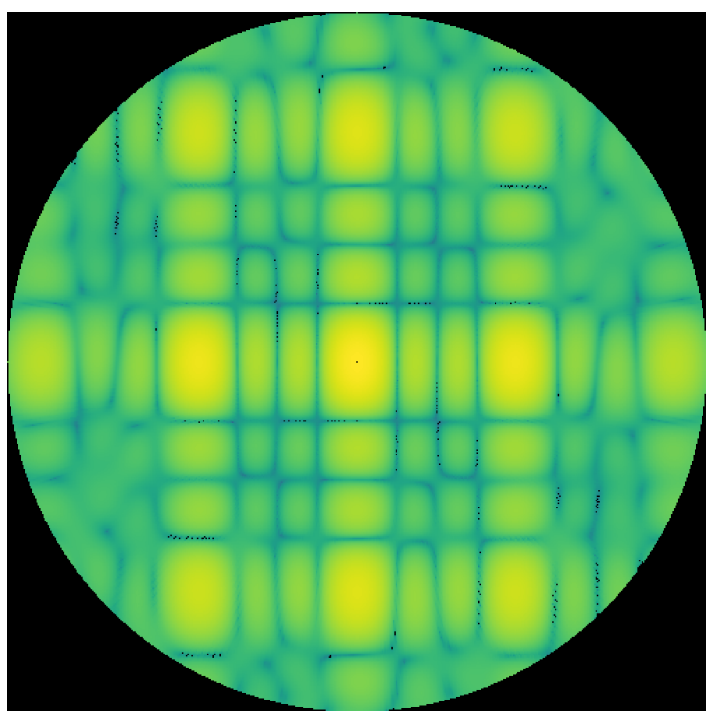

(a) Espalhamento.

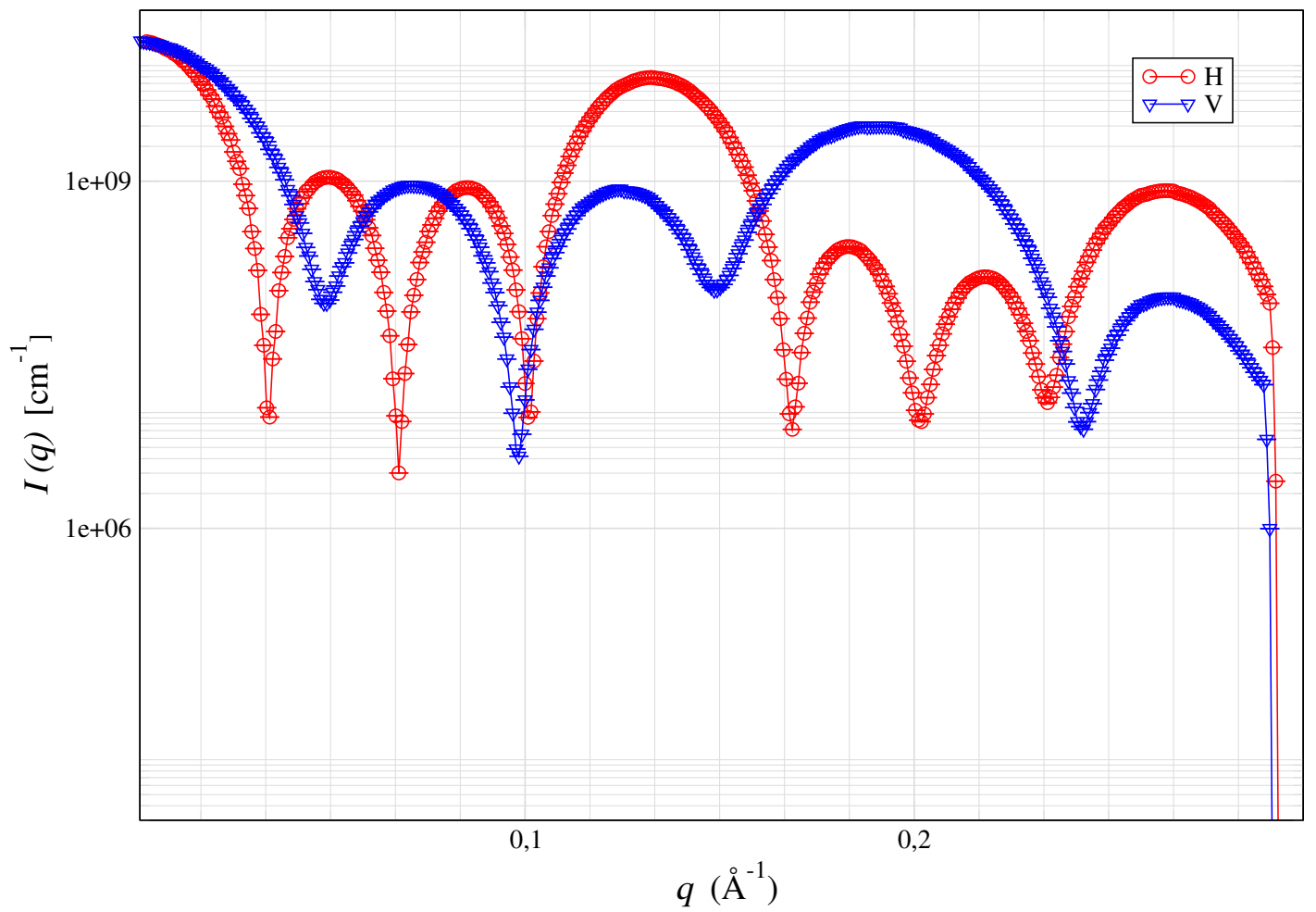

(b) Integrações em torno da horizontal $(\bigcirc)$ e da vertical $(\triangle)$.

Figura 4.16. Simulação de SAXS de um conjunto de $4 \times 4 \times 4$ estruturas micelares, em rede cúbica.

. Cada micela tem 2000 pontos de espalhamento (128000 no total). O campo H encontra-se na direção paralela ao feixe de raios $\mathrm{X}$ incidente. Os eixos maiores das micelas têm $35.0 \AA \times 45.0 \AA \times$ $20.0 \AA$ (modelo IBM), simulando a fase $N c$, e a espessura da shell é de $4.10 \AA$. A camada de solvente tem, em média, $12.0 \AA$. A distância entre amostra e detector é de $0.60 \mathrm{~m}$. 


\subsubsection{Rede cúbica com dispersões gaussianas}

Neste grupo de simulações foram efetuados pequenos deslocamentos gaussianos. Definemse como parâmetros as dispersões ( $\sigma$ de uma distribuição gaussiana normalizada) em cada direção, que são multiplicadas pelo valor da espessura da camada de solvente para se obter o deslocamento a ser tentado; caso haja "colisão", entre micelas, o deslocamento é descartado e tenta-se novamente até um número máximo de tentativas. A figura 4.17 apresenta quatro pontos de vista de uma configuração em que foram efetuados tais deslocamentos.

Vê-se aqui que o padrão quadriculado começa a se tornar difuso, pois perdem-se as interferências construtivas do sinal nas direções em que há maior deslocamento das micelas. Ainda são aproximadamente preservadas características da rede cúbica, principalmente nas direções de menores deslocamentos $(\sigma=0.5)$, o que é um indicativo do grau de ordem em cada direção. No caso IBM em que $H$ encontra-se paralelo ao feixe (figura A.10), as rotações das micelas causam picos mais difusos, e no entanto mais similares aos das imagens experimentais. É possível que haja uma distribuição de distâncias entre as micelas, que aqui seja em parte reproduzida. Como as distâncias entre as superfícies das micelas são tipicamente inferiores à espessura da camada de solvente, percebem-se os efeitos de interferência destrutiva a mais altos ângulos. 


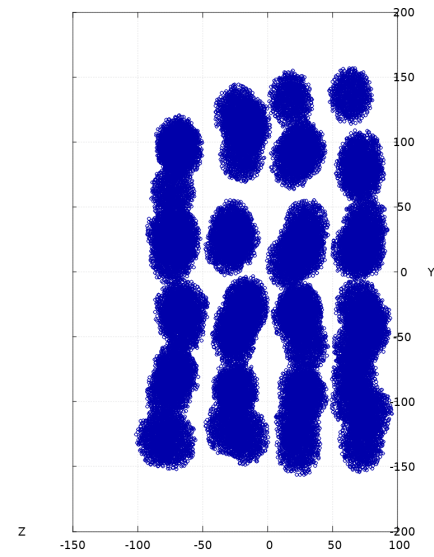

(a) Plano $x y$.

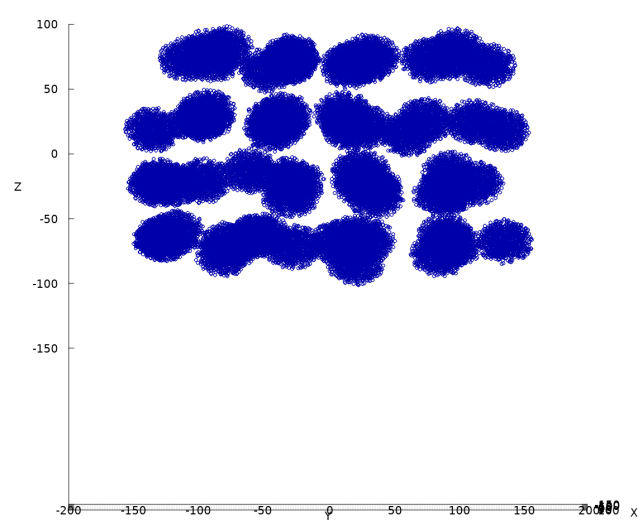

(c) Plano $y z$.

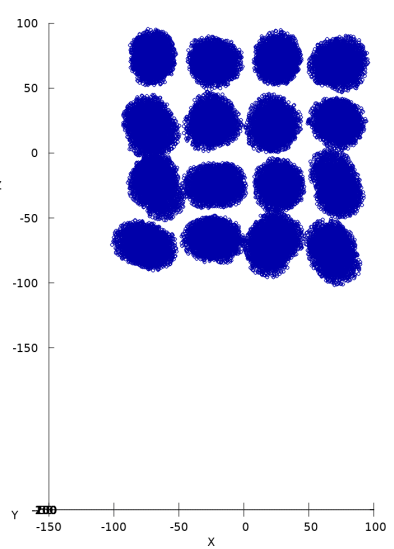

(b) Plano $x z$.

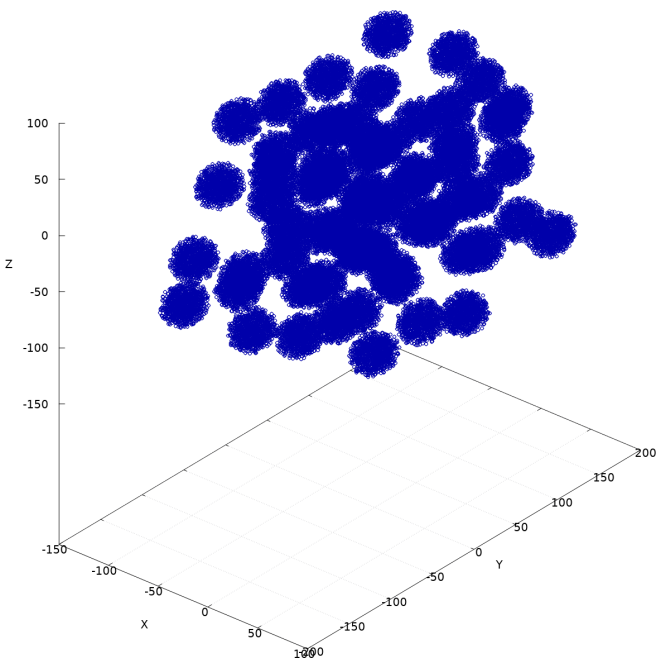

(d) Perspectiva.

Figura 4.17. Simulação de SAXS de um conjunto de $4 \times 4 \times 4$ estruturas micelares, em rede com pequenos deslocamentos gaussianos, predominantemente na direção $y\left(\sigma_{x}=0.5, \sigma_{y}=2.0, \sigma_{z}=\right.$ 0.5). Cada micela tem 1000 pontos de espalhamento (64000 no total). O campo $\mathrm{H}$ encontra-se na direção paralela ao feixe de raios X incidente. Os eixos maiores das micelas têm $35.0 \AA \times 45.0 \AA \times$ $35.0 \AA ̊$ (modelo uniaxial), simulando a fase $N c$, e a espessura da shell é de $4.10 \AA$ A camada de solvente tem, em média, 12.0Å. A distância entre amostra e detector é de $0.60 \mathrm{~m}$. 


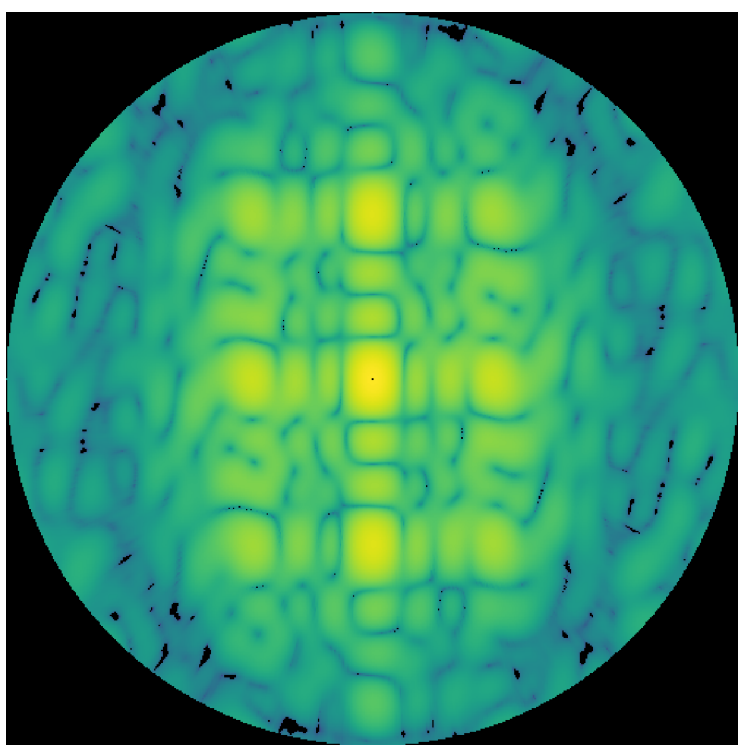

(a) Espalhamento.

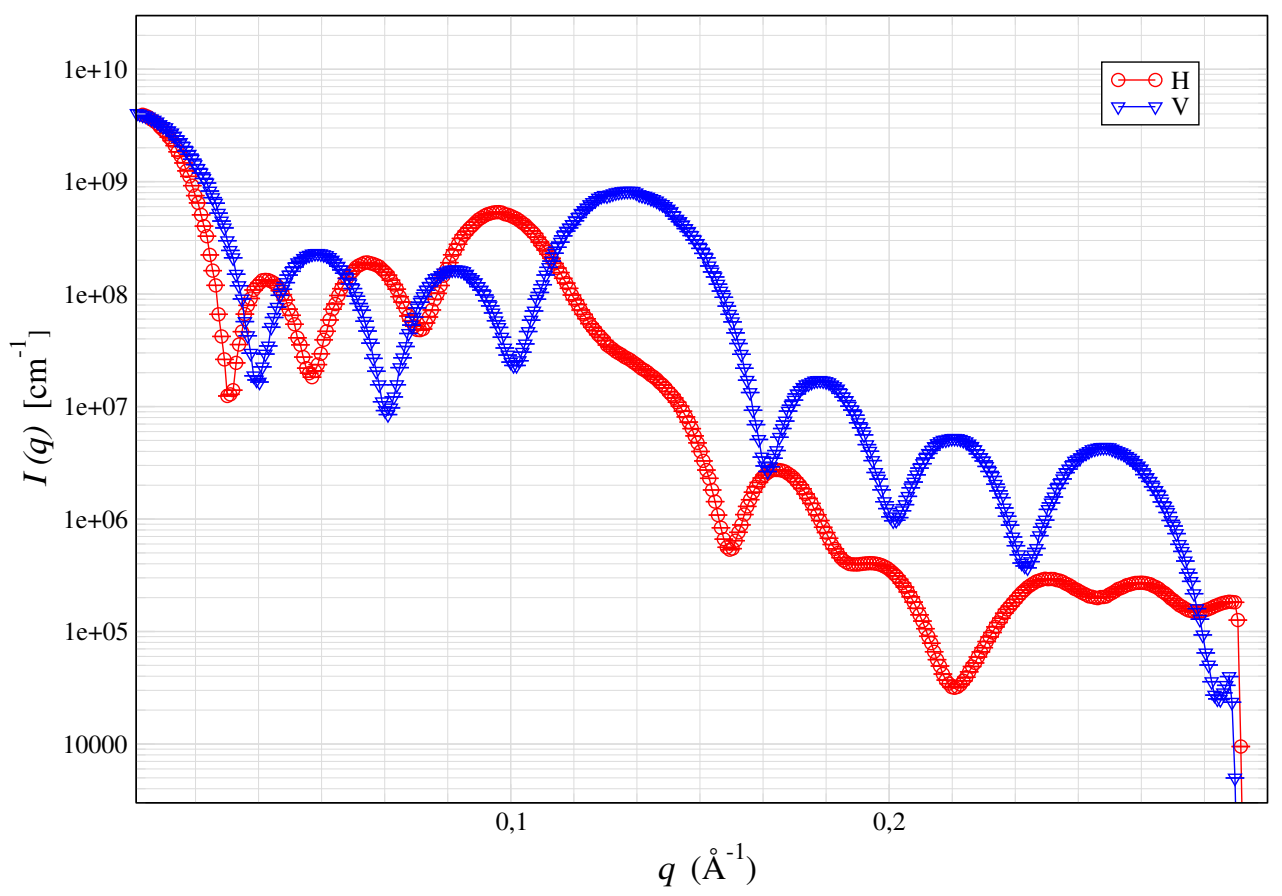

(b) Integrações em torno da horizontal $(\bigcirc)$ e da vertical $(\nabla)$.

Figura 4.18. Simulação de SAXS de um conjunto de $4 \times 4 \times 4$ estruturas micelares, em rede com pequenos deslocamentos gaussianos, predominantemente na direção $y\left(\sigma_{x}=2.0, \sigma_{y}=0.2, \sigma_{z}=\right.$ 0.2). Cada micela tem 1000 pontos de espalhamento (64000 no total). O campo H encontra-se na direção perpendicular ao feixe de raios X incidente. Os eixos maiores das micelas têm $45.0 \AA \times$ $35.0 \AA \times 35.0 \AA$ (modelo uniaxial), simulando a fase $N c$, e a espessura da shell é de $4.10 \AA$ A camada de solvente tem, em média, 12.0A. A distância entre amostra e detector é de $0.60 \mathrm{~m}$. 


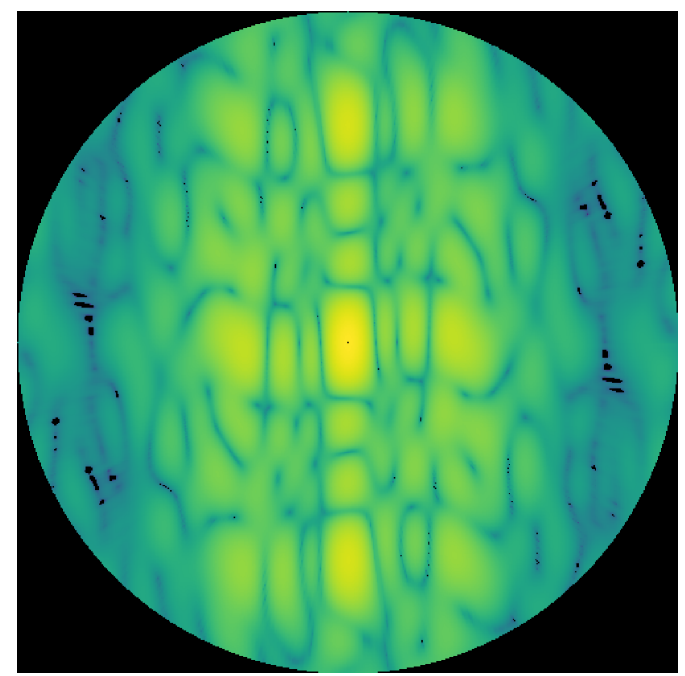

(a) Espalhamento.

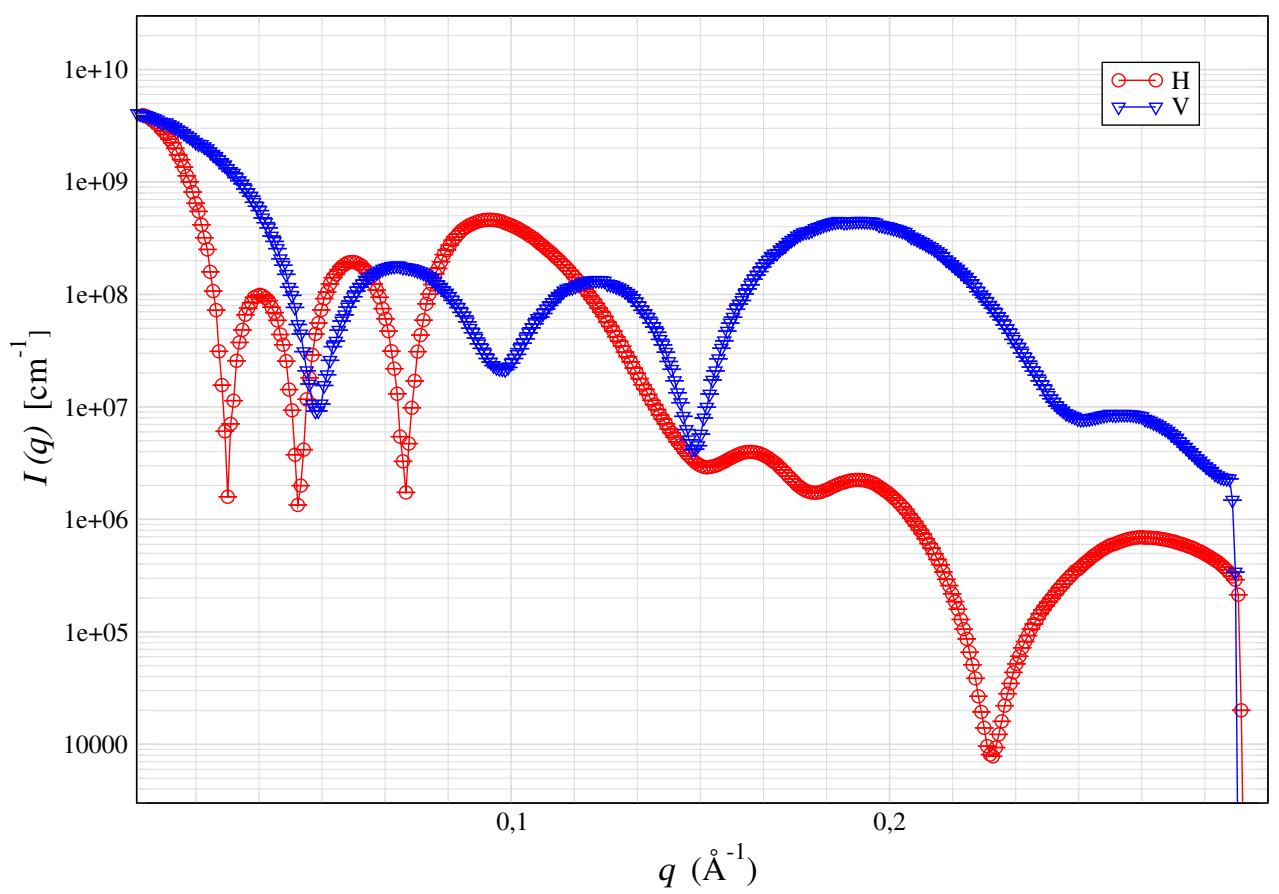

(b) Integrações em torno da horizontal $(\bigcirc)$ e da vertical $(\nabla)$.

Figura 4.19. Simulação de SAXS de um conjunto de $4 \times 4 \times 4$ estruturas micelares, em rede com pequenos deslocamentos gaussianos, predominantemente na direção y $\left(\sigma_{x}=2.0, \sigma_{y}=0.2, \sigma_{z}=\right.$ 0.2). Cada micela tem 1000 pontos de espalhamento (64000 no total). O campo H encontra-se na direção perpendicular ao feixe de raios X incidente. Os eixos maiores das micelas têm $45.0 \AA \times$ $35.0 \AA \times 20.0 \AA$ (modelo IBM), simulando a fase $N c$, e a espessura da shell é de $4.10 \AA$. A camada de solvente tem, em média, 12.0A. A distância entre amostra e detector é de $0.60 \mathrm{~m}$. 


\subsubsection{Rede cúbica, $20 \times 1 \times 20$, com e sem dispersões}

Aumentamos aqui o número de micelas, reduzindo bastante a quantidade de beads, e construindo a disposição quadrada em apenas uma camada. Na figura 4.20, vê-se que os efeitos de finite size ficam reduzidos, porém os picos de até segunda ordem são bastante nítidos, tanto na linha vertical quanto na horizontal. A aplicação de dispersões como na figura 4.21, na configuração de campo $H$ perpendicular ao feixe, reduz a intensidade do aspecto quadriculado nas laterais que correspondiam aos picos da linha horizontal, mas preserva nítidos os picos na vertical, porque foi imposta pequena dispersão na direção $z$. Uma configuração com dispersões, posicionada na direção de campo paralelo ao feixe (a ser efetuada), talvez produzisse um padrão ainda quadriculado, pois pequenas dispersões não parecem suficientes para quebrar essa regularidade, ao passo que maiores dispersões podem descaracterizar os picos da correspondente fase nemática. 


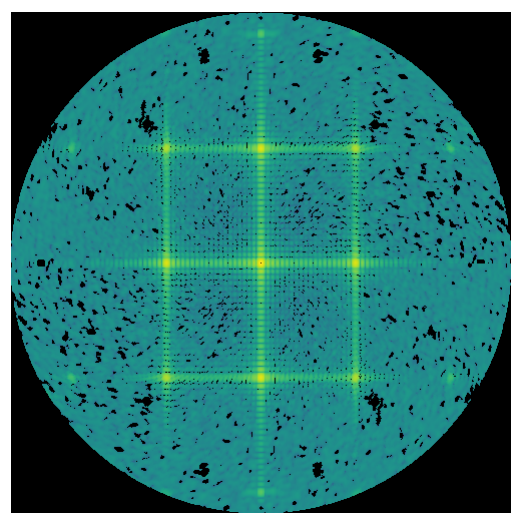

(a) Espalhamento.

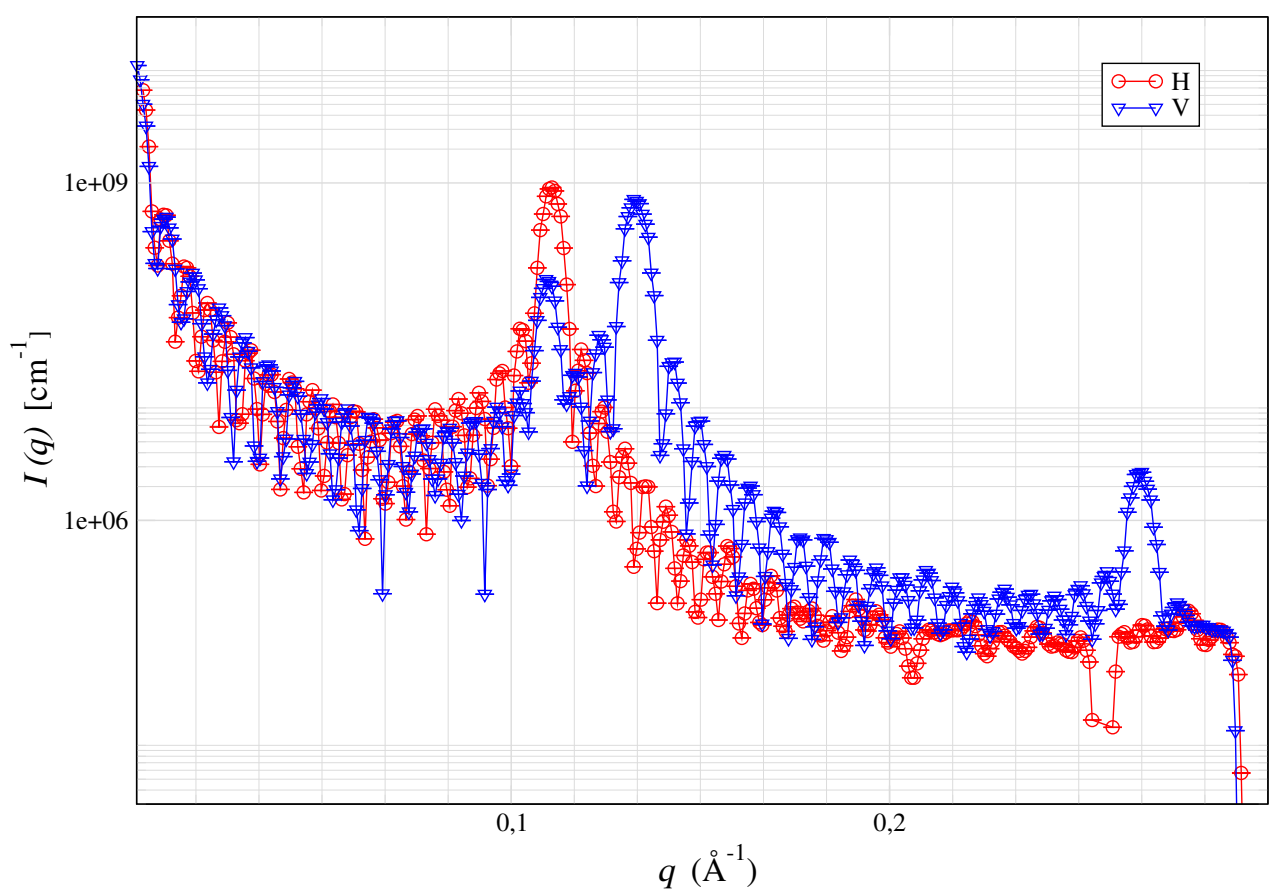

(b) Integrações em torno da horizontal $(\bigcirc)$ e da vertical $(\triangle)$.

Figura 4.20. Simulação de SAXS de um conjunto de $20 \times 1 \times 20$ estruturas micelares, em rede cúbica. Cada micela tem 300 pontos de espalhamento (120000 no total). O campo H encontrase na direção perpendicular ao feixe de raios $\mathrm{X}$ incidente. Os eixos maiores das micelas têm $45.0 \AA \times 35.0 \AA \times 35.0 \AA$ (modelo uniaxial), simulando a fase $N c$, e a espessura da shell é de $4.10 \AA$. A camada de solvente tem, em média, 12.0Å. A distância entre amostra e detector é de $0.60 \mathrm{~m}$. 


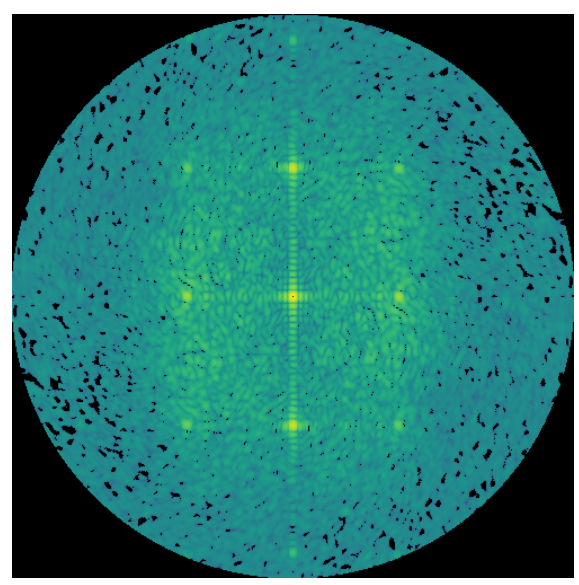

(a) Espalhamento.

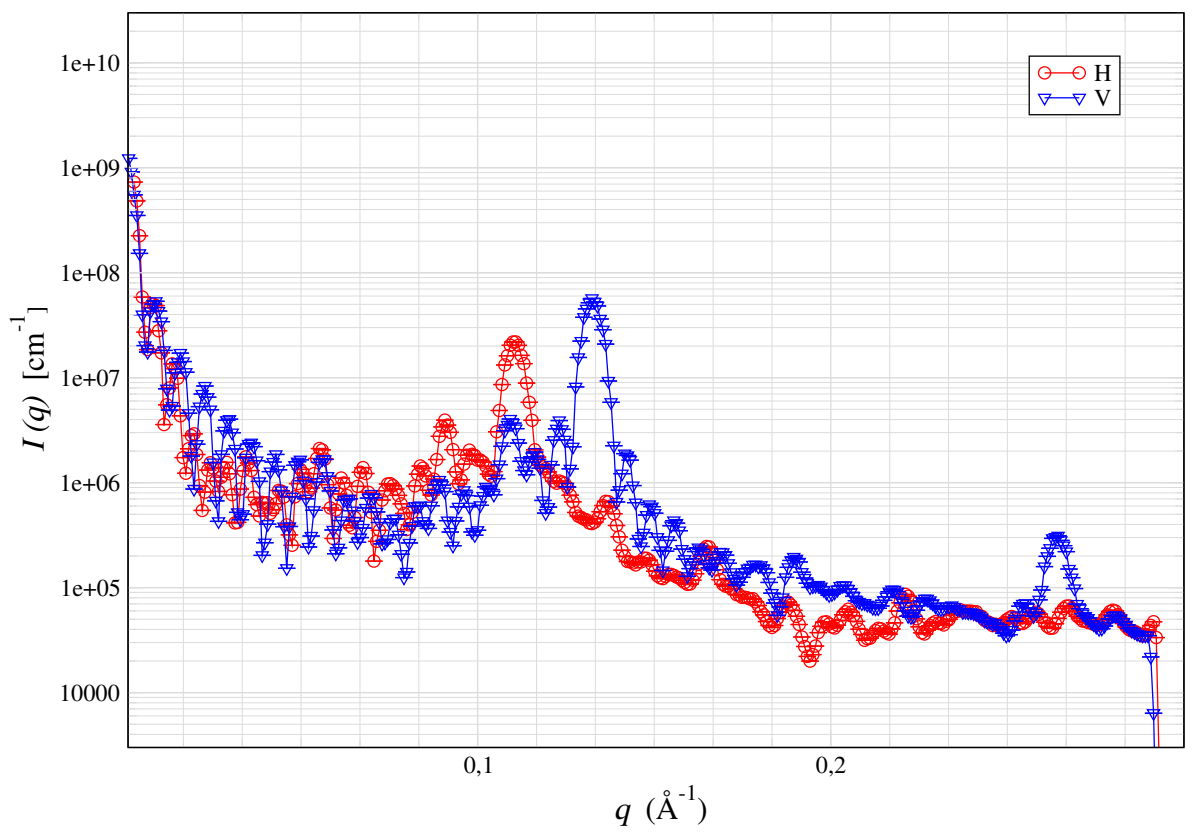

(b) Integrações em torno da horizontal $(\bigcirc)$ e da vertical $(\triangle)$.

Figura 4.21. Simulação de SAXS de um conjunto de $20 \times 1 \times 20$ estruturas micelares, em rede com pequenos deslocamentos gaussianos $\left(\sigma_{x}=3.0, \sigma_{y}=1.0, \sigma_{z}=0.25\right)$. Cada micela tem 200 pontos de espalhamento (80000 no total). O campo H encontra-se na direção perpendicular ao feixe de raios $\mathrm{X}$ incidente. Os eixos maiores das micelas têm $45.0 \AA \times 35.0 \AA \times 35.0 \AA$ (modelo uniaxial), simulando a fase $N c$, e a espessura da shell é de $4.10 \AA$ A camada de solvente tem, em média, 12.0Å. A distância entre amostra e detector é de $0.60 \mathrm{~m}$. 


\subsubsection{Dispersões rotacionais de aglomerados verticais}

As imagens a seguir são resultado das simulações de espalhamento por blocos de micelas dispersos. Seguindo a ideia de que as as micelas podem formar pequenos aglomerados [3, $47,46]$, criamos configurações a partir de blocos de micelas. As dimensões de cada bloco representam aproximadamente o comprimento de correlação entre elas em cada direção, isto é, 1 micela $\times 2$ micelas $\times 6$ micelas, cada uma com 300 pontos de espalhamento (beads). As simulações foram feitas com diferente número de blocos, dispostos em "camadas" na direção $x$, conforme as descrições abaixo. Cada bloco apresenta uma rotação aleatória em torno do eixo $y$, isto é, um tilt no ângulo azimutal de até $\pm 15^{\circ}$. A disposição dos blocos também teve pequena dispersão em relação a uma rede cúbica, ou seja, os blocos não foram colocados em posições pré-determinadas em cada camada.

A figura 4.22a representa uma configuração de $4 \times 2 \times 1=8$ blocos de micelas, ou 2 camadas ao longo do eixo $y$ de 4 blocos (de 12 micelas) ao longo do eixo $x$, com dispersões de posicionamento de cada bloco. A dimensão das micelas é $a \times b \times c=60 \AA \times 40 \AA \times 20 \AA$ (IBM); seu eixo maior foi alinhado ao eixo $x$, e foram efetuadas rotações aleatórias de cada micela ao longo do eixo $y$, simulando a fase $N_{C}$, com campo perpendicular à direção do feixe incidente.

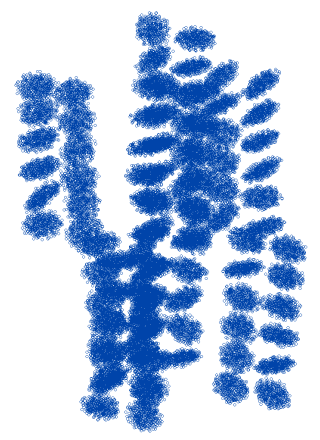

(a) $4 \times 2 \times 1$ blocos

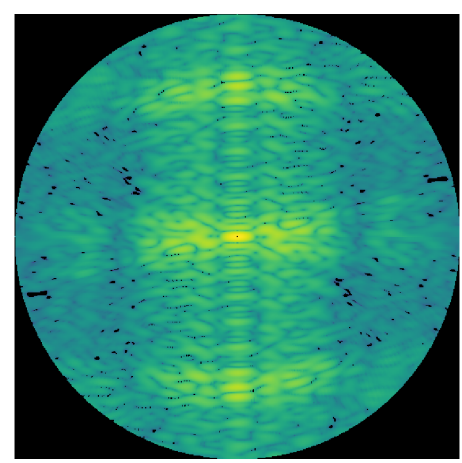

(b) $4 \times 2 \times 1$ blocos

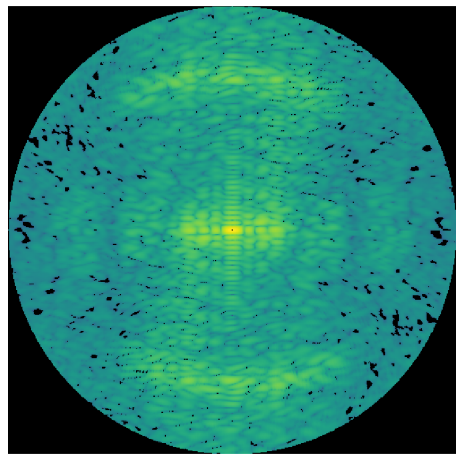

(c) $8 \times 1 \times 1$ blocos

Figura 4.22. A figura (a) é uma representação da disposição das micelas em blocos de $12\left(n_{x} \times n_{y} \times\right.$ $n_{z}=1 \times 2 \times 6$ ), por seu turno agrupados em camadas ao longo do eixo $y$. As figuras (b) e (c) são padrões de simulação de espalhamento. A figura (b) é resultado da disposição das micelas em 8 blocos, sendo 4 ao longo do eixo $x$, formando uma camada, e outra camada similar com 4 micelas foi adicionada, deslocada em $y$. A figura (c) corresponde a uma disposição de uma só camada de blocos de micelas em $x(8 \times 1 \times 1)$. O ângulo máximo da dispersão azimutal de cada bloco (tilt máximo) é de $\varphi_{\max }=15^{\circ}$.

Em todas as figuras foram verificadas a formação de arcos azimutais típicos dos padrões de espalhamento cruzando o eixo $z$, representando uma difusividade dos picos da rede cúbica (seção 4.2.4.1). Também se identificam picos ao longo do eixo $x(z=0)$, em função da 
disposição horizontal dos blocos; esses picos são difusos em função da dispersão aplicada aos blocos. A figura 4.23c é resultado da sobreposição de várias simulações de distintas configurações de blocos de micelas, como média de várias configurações num ensemble.

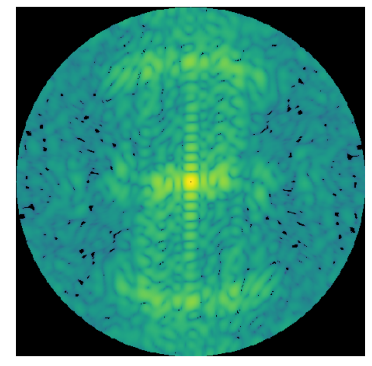

(a) $4 \times 3 \times 2$ blocos

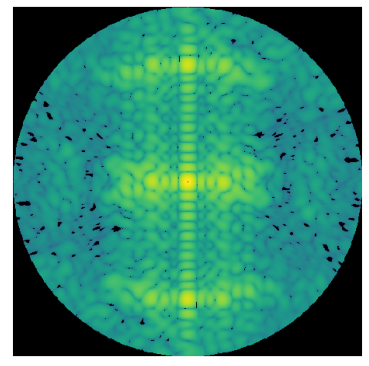

(b) $4 \times 5 \times 4$ blocos

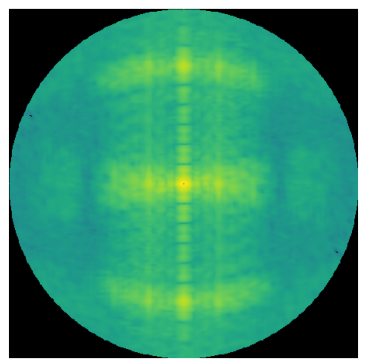

(c) Soma

Figura 4.23. Padrões de simulação de espalhamento por micelas agrupadas em blocos de 12 micelas $(1 \times 2 \times 6)$. A figura (a) é resultado da disposição das micelas em 24 blocos $(4 \times 3 \times 2)$, com dispersões. A figura (b) corresponde à disposição de 40 blocos de 12 micelas. A figura (c) é resultado da sobreposição (soma das intensidades) dos padrões produzidos por uma série de 8 simulações com 8, 16, 24 e 40 blocos de micelas.

Os resultados do cálculo do parâmetro de ordem para o ajuste da figura 4.24 são $\bar{P}_{2}=$ $0.787(0.001)$ e $\bar{P}_{4}=0.457$ (0.002). Estes valores do parâmetro de ordem são provenientes de um sistema bastante "regular", em comparação com as flutuações de um sistema experimental. Ou seja, ainda que haja picos pronunciados nas figuras 4.24 (a) e (b), elas são bastante simétricas, o que justifica os pequenos erros estimados, que são calculados pela média de quatro integrações da curva.

Tínhamos a princípio a hipótese de que o aumento da rede cúbica, pelo aumento do número de micelas, criaria padrões de espalhamento mais realistas, uma vez que se reduzem os efeitos de finite size. E, de fato, a figura 4.20 ( $m=20 \times 20$ micelas) dá a entender que é necessário algum processo de tomada ao limite de $m$ grande. As manipulações de uma rede menor, no entanto, já mostram haver caminhos complementares, cujos resultados vão ao encontro do que se conhece sobre nemáticos. As formas arredondadas, em arco, das regiões mais intensas de um padrão de espalhamento experimental sugerem que os picos de estruturas muito regulares como redes cúbicas têm de ser atenuados e espalhados, como o que se observa nas seção da 4.2.4.2. Na figura 4.21, em que os picos na direção vertical são claros, vê-se que é induzido um borramento (smearing) dos picos laterais pelas dispersões. As simulações desta seção, 4.2.6, mostram ainda que quando se levam em consideração os comprimentos de correlação, tem-se resultados mais próximos dos experimentais.

Encontrar os parâmetros que reproduzam totalmente as imagens de SAXS experimentais depende da compreensão da flutuação do diretor nemático do sistema, ou seja, do conhecimento da função $f(\beta)$. Avançamos um pouco nesse sentido por meio do cálculo dos 
parâmetros de ordem $\bar{P}_{2}$ e $\bar{P}_{4}$ dos dados experimentais. O próximo passo será introduzir restrições sobre o parâmetro de ordem nas simulações, que poderão fornecer resultados mais condizentes com os experimentos.

Os resultados apresentados neste capítulo demonstram o potencial da abordagem de simulação por elementos finitos. Hipóteses de configurações do sistema podem ser feitas, testadas e comparadas com resultados experimentais. Como demonstramos ao final, as imagens bidimensionais de espalhamento bidimensionais conseguem recuperar alguns dos detalhes que obtemos nos dados experimentais, ainda que aproximadamente. Este tipo

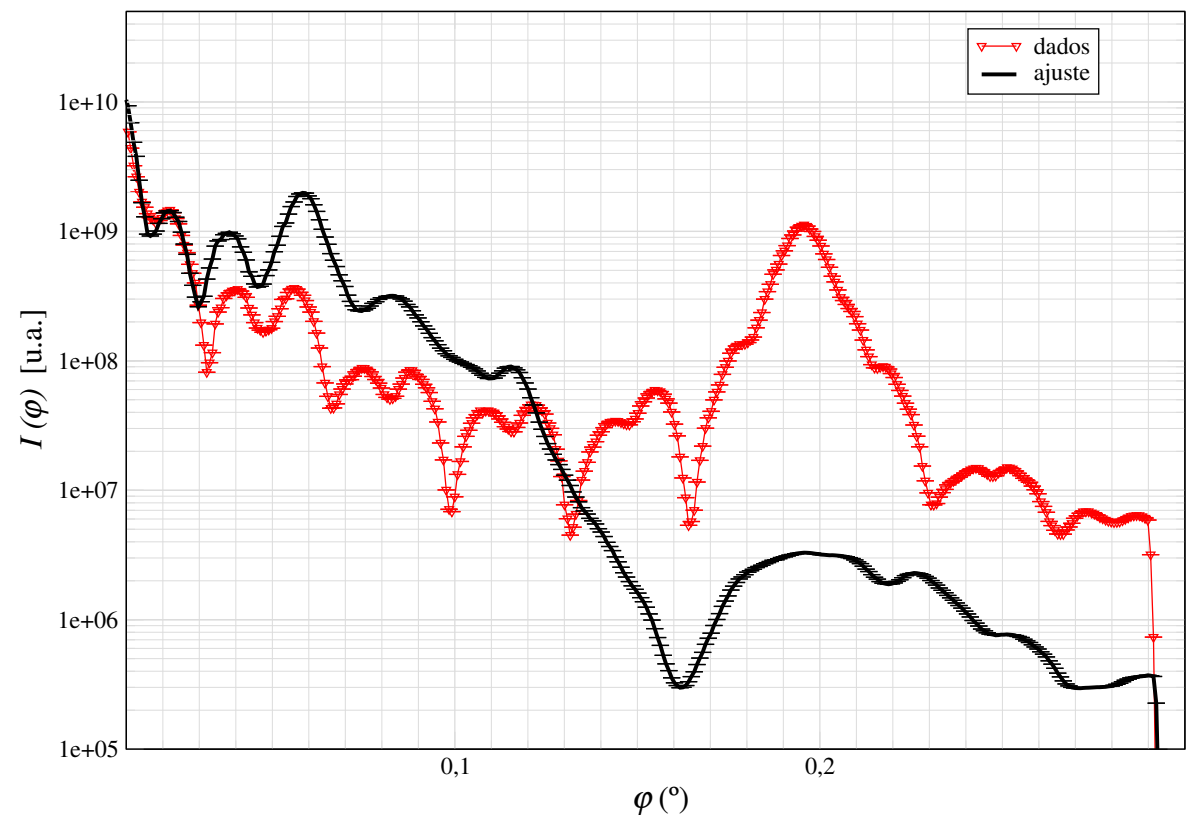

(a) Integração azimutal.

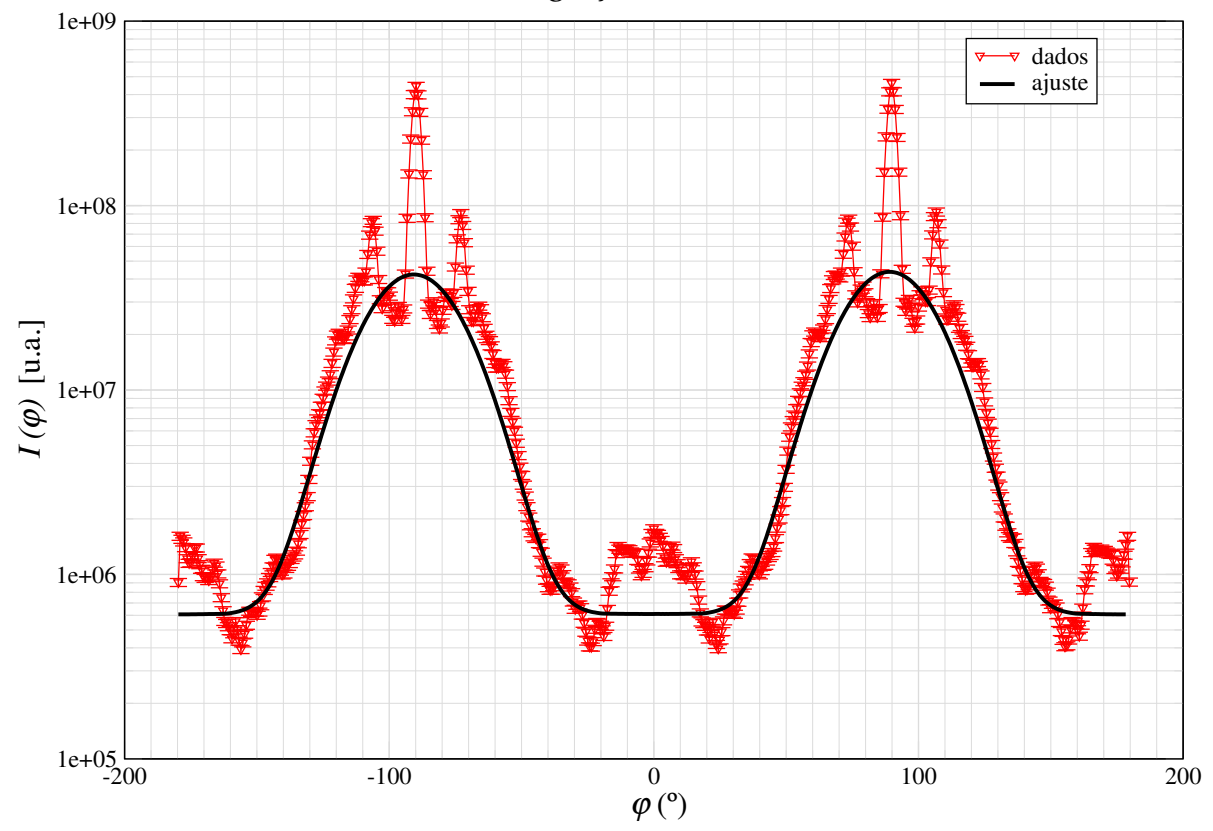

(b) Integração radial.

Figura 4.24. Resultados das integrações azimutal (a) e radial (b) da figura 4.23c. 
de abordagem não existe na literatura e permitirá uma compreensão detalhada da estrutura dos arranjos micelares em cristais líquidos.

\subsection{Análise das fases de uma mistura liotrópica}

Para avaliação da alegação de Amaral [30] (por continuidade a Quist [31]), de que haveria coexistência de fases $N_{C}$ e $N_{D}$, preparamos nos mesmos moldes do que foi indicado em seu artigo quatro amostras de SDS (Sigma-Aldrich, $\geq 99.0 \%$ ), 1-decanol (DeOH, SigmaAldrich, $\leq 99 \%$ ) e $\mathrm{D}_{2} \mathrm{O}$ (Sigma-Aldrich, 99,9\% de átomos de $\mathrm{D}$ ), com razões molares $M=$ $\left[\mathrm{D}_{2} \mathrm{O}\right] /[\mathrm{SDS}]=30,31,32,33$ e $M_{A}=[\mathrm{DeOH}] /[\mathrm{SDS}]=0,324$ ( $M$ será usado para identificar as amostras). Finalmente, as amostras foram dopadas com ferrofluido Ferrotec EMG 605 em baixa concentração (menos de $1 \mu \mathrm{L}$ por grama, o que corresponde a aproximadamente $10^{13}$ grãos de ferrofluido por $\mathrm{mL}$ ); esse procedimento aumenta a anisotropia da susceptibilidade magnética da amostra, facilitando seu alinhamento com o campo magnético [59]. Por consistência de verificação, foram preparadas também amostras sem ferrofluido, que apresentaram os mesmos resultados. Foram efetuadas medidas de microscopia de luz polarizada, conoscopia laser e SAXS.

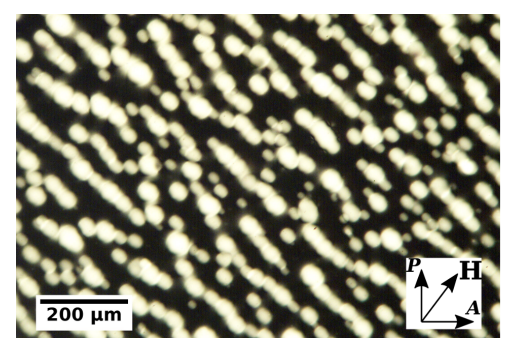

(a)

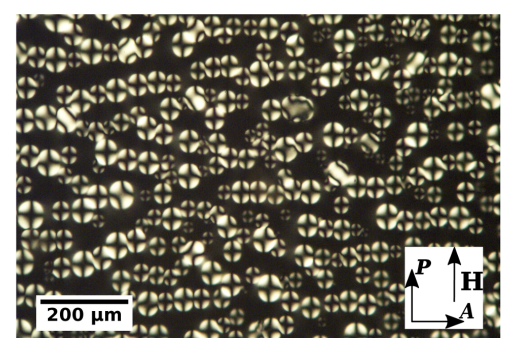

(b)

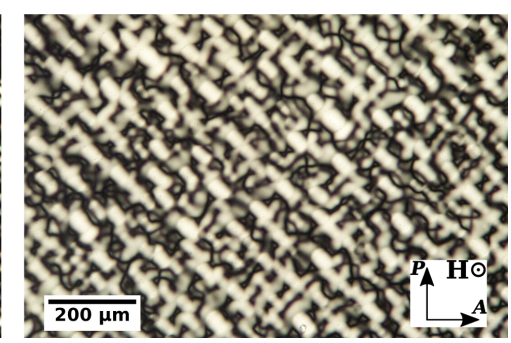

(c)

Figura 4.25. Texturas da mistura $M=30$ a $34^{\circ} \mathrm{C}$. As letras $P, A$ e $\mathbf{H}$ representam a direção do polarizador, do analisador e do campo magnético aplicado, respectivamente.

As texturas obtidas por MOLP (figura 4.25) mostram os padrões obtidos para a mistura $M=30$ à temperatura de $34^{\circ} \mathrm{C}$, representativa do intervalo em que se identificam as fases $N_{D}$ e lamelar. Observam-se na figura 4.25a regiões escuras e claras. A rotação da amostra, figura $4.25 \mathrm{~b}$, indica que a região escura assim permanece, mas em $4.25 \mathrm{c}$, com a mudança da direção do campo $\mathbf{H}$, confirma-se de que se trata de uma fase $N_{D}$. As regiões claras, por sua vez, não se alteram, dando indicação de uma fase lamelar, que não são influenciadas pelo campo magnético. A figura 4.27 corresponde ao resultado da conoscopia laser, que identifica a fase $N_{D}$ de $20^{\circ} \mathrm{C}$ até $29,3^{\circ} \mathrm{C}$ e então uma pequena região de fase $N_{B}$. Os pontos foram obtidos a partir dos padrões de interferência mostrados nas figuras 4.26 , em cada uma das fases. Acima de $32^{\circ} \mathrm{C}$, a figura de interferência da conoscopia é perdida, o que é um indicativo de coexistência de fases. Finalmente, a figura 4.28 apresenta os resultados de SAXS para a amostra $M=30$ em três diferentes temperaturas. As figuras (a) e (b) indicam a 
existência de fase $N_{D}$, com as bandas de primeira e segunda ordem na direção 3; o mesmo padrão é obtido com a rotação da amostra em $90^{\circ}$. Os picos das bandas encontram-se em $q_{1}=q_{2}=0.093 \pm 0.002 \AA^{-1}$ e $q_{3}=0.124 \pm 0.001 \AA$. Já em (c) e (d), identificam-se picos de Bragg, sobrepostos a um padrão de banda característico $N_{D}$. A fase que coexiste com $N_{D}$ é lamelar, pois os picos encontram-se em $q_{3 a}=0.127 \pm 0.001 \AA^{-1}$ e $q_{3 b}=0.255 \pm 0.002 \AA^{-1}$, $\operatorname{com} q_{3 b} / q_{3 a}=2,0$. Em temperaturas acima de $37^{\circ} \mathrm{C}$, correspondentes às figuras (e) e (f), perde-se a fase nemática e forma-se uma isotrópica, ainda coexistindo com a lamelar, em que $q_{3 a}=0.130 \pm 0.001 \AA^{-1}$ e $q_{3 b}=0.260 \pm 0.002 \AA^{-1}$, com razão 2,0 entre os picos.

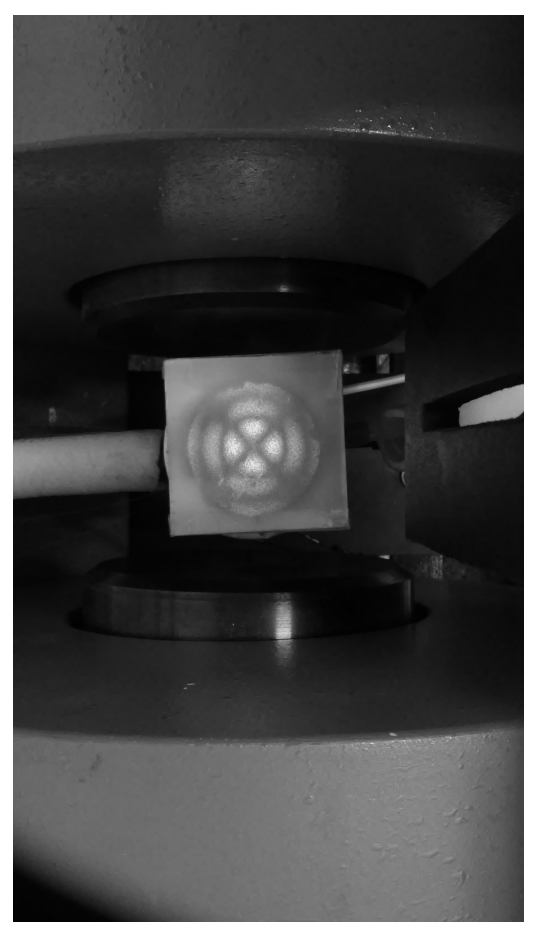

(a) $N_{D}, 25^{\circ} \mathrm{C}$

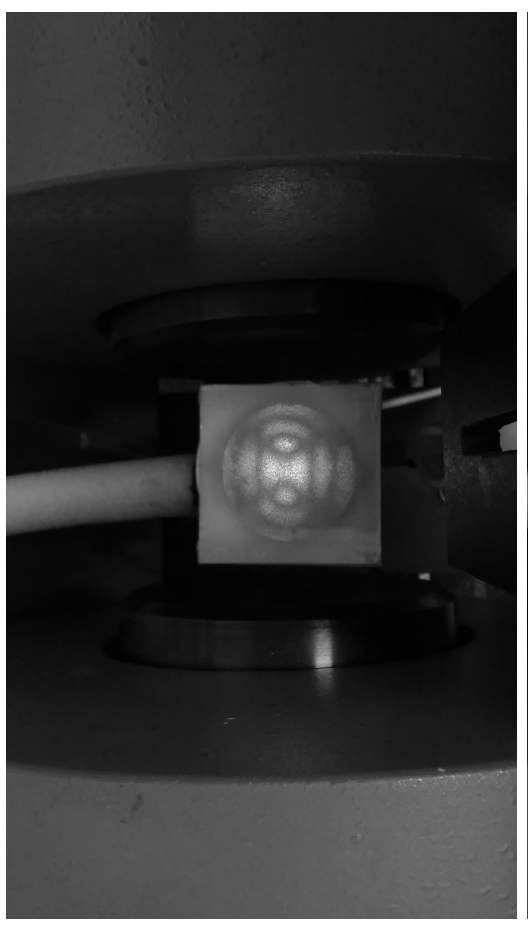

(b) $N_{B}, 23^{\circ} \mathrm{C}$

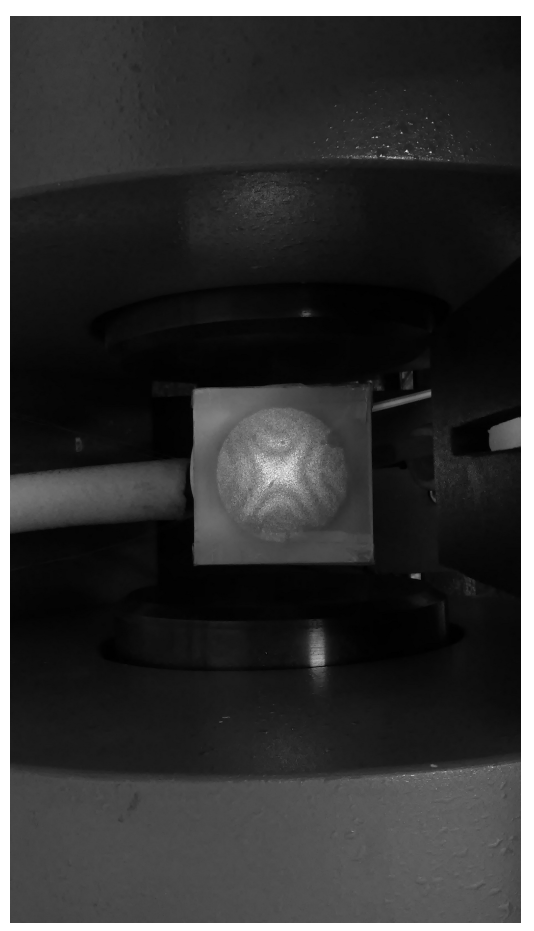

(c) $N_{C}, 10,5^{\circ} \mathrm{C}$

Figura 4.26. Padrões de conoscopia de uma amostra de SDS/1-decanol/ $\mathrm{D}_{2} \mathrm{O}$ nas fases $N_{D}, N_{B}$, e $N_{C}$. Cada padrão é visto projetado sobre um papel semitransparente que repousa sobre a célula com a amostra. Nas partes superior e inferior de cada figura, veem-se os polos do eletroímã, que gera sobre a amostra um campo de $\approx 1 \mathrm{kOe}$. A cânula na lateral sai de um compartimento de latão que contém a célula com a amostra e está ligada ao sistema de de banho térmico que controla a temperatura da amostra conjuntamente com um controlador auxiliar Neocera LTC-21.

Para os casos $M=31,32$ e 33, os padrões obtidos foram os mesmos em cada temperatura, isto é, a topologia do diagrama de fases é similar para cada uma das concentrações, logo as análise a seguir tomarão a mistura $M=32$ como exemplo. A figura 4.29 mostra as texturas da mistura $M=32$ a $30^{\circ} \mathrm{C}$, em que se pode ver regiões $N_{D}$ escurecidas; a mudança da direção do campo $\mathbf{H}$ altera por sua vez o diretor nemático (4.29c), o que confirma tratarse de uma fase nemática, e não meramente isotrópica. Abaixo de $27,5^{\circ} \mathrm{C}$, observou-se uma 


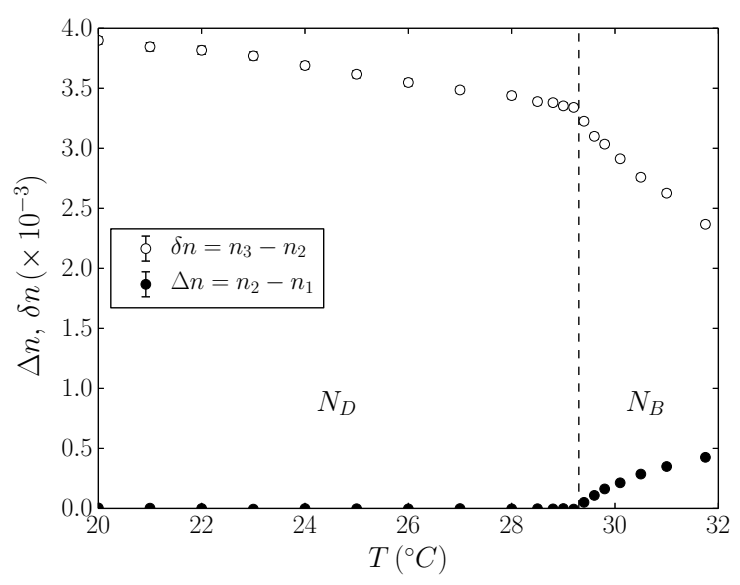

Figura 4.27. Birrefringências $\Delta n(\bullet)$ e $\delta n\left(\right.$ (o) da mistura $M=30$ em função da temperatura $T\left({ }^{\circ} \mathrm{C}\right)$, medidas com a conoscopia laser.

textura planar condizente com a fase $N_{B}$, o que foi confirmado pela conoscopia laser (figura 4.30); novamente, neste caso, perde-se o alinhamento acima dessa temperatura, indicando coexistência de fases.

A figura 4.31 apresenta também uma confirmação para a fase biaxial, $N_{B}$, no intervalo de temperaturas de $20,0^{\circ} \mathrm{C}$ a $27,5^{\circ} \mathrm{C}$, com picos das bandas em $q_{1}=0,092 \pm 0,003 \AA^{-1} \mathrm{e}$ $q_{3}=0,120 \pm 0,001 \AA^{-1}$. A figura 4.29 mostra os padrões de textura por MOLP obtidos a $30^{\circ} \mathrm{C}$. O mesmo tipo de comportamento anteriormente observado para a fase $N_{D}$ em coexistência com uma fase lamelar, isto é, as regiões escuras assim se mantêm conforme a amostra é rotacionada de $45^{\circ}$, mas a mudança de orientação do campo magnético altera o diretor nemático nessas regiões, porém não interferindo com as regiões claras (lamelares). Tais fases são confirmadas pelas medidas de SAXS apresentadas na figura 4.32, com as bandas orientadas $\left(N_{D}\right)$ sobrepostas aos picos de Bragg $q_{3 a}=0,123 \pm 0,001 \AA^{-1}$ e $q_{3 b}=0,247 \pm 0,003 \AA^{-1}$, com razão 2,00 entre si, que reforçam a existência da fase lamelar. Acima de $53,0^{\circ} \mathrm{C}$, a fase nemática é perdida e em seu lugar surge uma fase isotrópica.

Os resultados obtidos são resumidos pelo diagrama de fases apresentado na figura 4.33. Diferentemente dos resultados apresentados em [30, 31], não se observou nenhuma região de coexistência de fases nemáticas, o que é consistente com resultados experimentais anteriores obtidos para o parâmetro de ordem e com previsões teóricas [22, 23]. Não foi sequer observada fase calamítica $\left(N_{C}\right)$ nos intervalos de concentração e temperatura analisados. A adição de ferrofluido na mistura também não altera os resultados, como pudemos verificar em algumas amostras sem ferrofluido para as quais as medidas foram reproduzidas. Entendemos que a técnica principal utilizada em [30] para inferência desse resultado, conoscopia por microscopia óptica polarizada, não permite que se obtenha a precisão necessária à caracterização das fases, pois apenas se observam as regiões centrais do padrão. Com a conoscopia a laser, no entanto, são claramente vistos os padrões de raias que permitem calcular as birrefringências com precisão suficiente, como se observa nas figuras 4.26, obtidas para 
as amostras com SDS em questão. Em complemento, em todas medidas de fases obtidas historicamente no GFCx-IF-USP, com misturas de diversos tipos de surfactantes, nunca se observou textura ou padrão que indicasse tal coexistência.

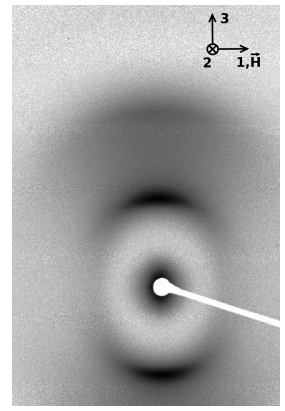

(a) $T=25^{\circ} \mathrm{C}$

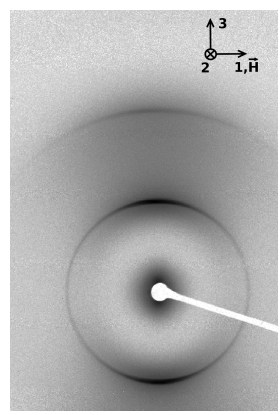

(c) $T=35^{\circ} \mathrm{C}$

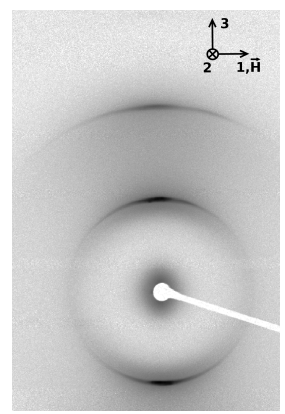

(e) $T=38^{\circ} \mathrm{C}$

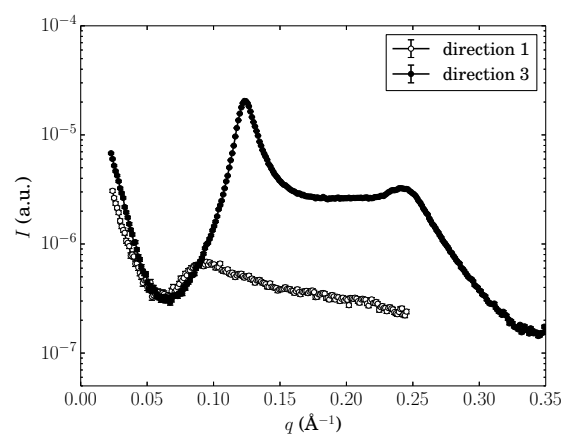

(b)

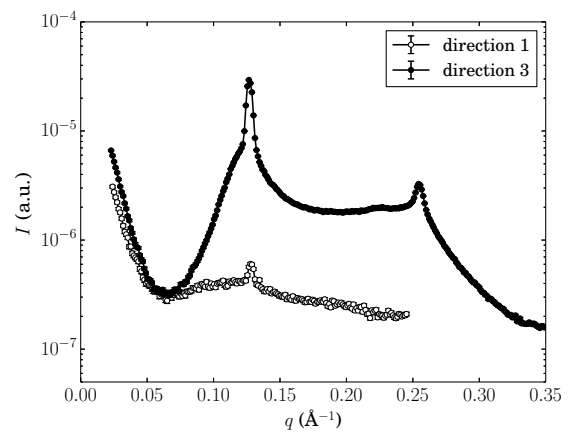

(d)

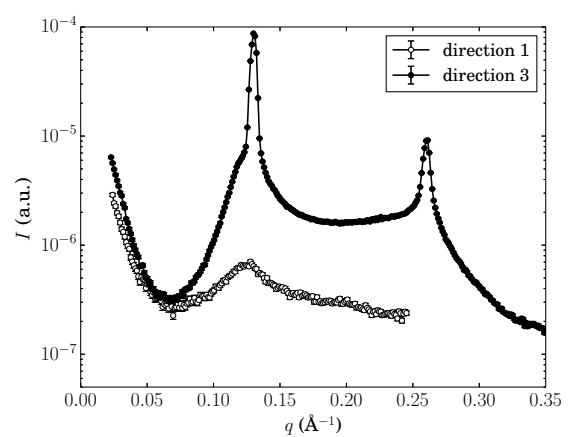

(f)

Figura 4.28. Resultados de SAXS da mistura $M=30$. As figuras, apresentadas duas a duas, correspondem ao padrão de espalhamento bidimensional (esquerda) e à curva de intensidade em função de $q$ nas direções 1 e 3 . As intensidades nas figuras à esquerda são representadas por uma escala logarítmica em tons de cinza (mais escuro, mais intenso). Em (a) e (b), a amostra se encontra na fase $N_{D}$ alinhada na direção 3, com $T=25^{\circ} \mathrm{C}$; em (c) e (d), a amostra tem uma coexistência de fase $N_{D}+$ lamelar, a $T=35^{\circ} \mathrm{C}$; em (e) e (f), exibe-se o padrão da amostra em fase isotrópica (ISO) + lamelar, a $T=38^{\circ} \mathrm{C}$. 


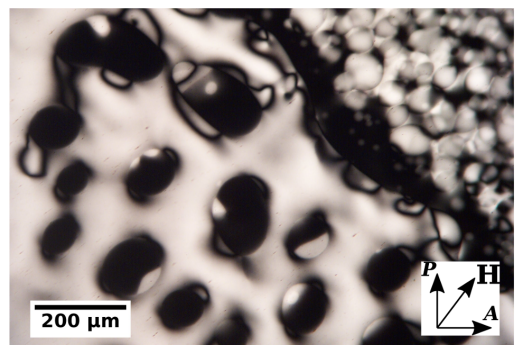

(a)

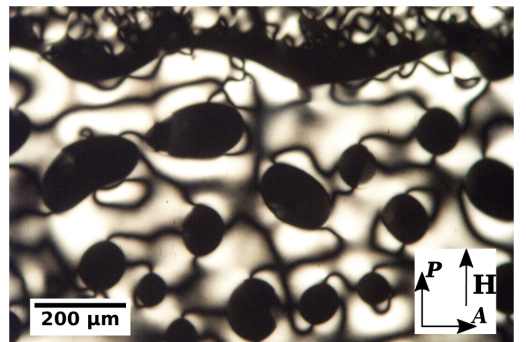

(b)

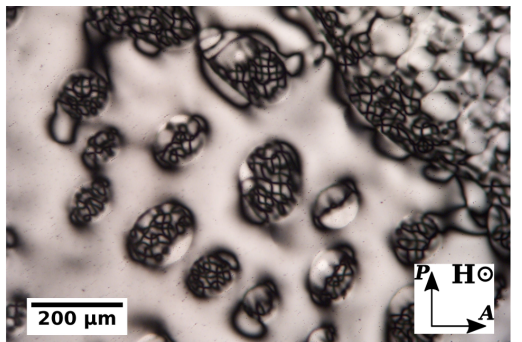

(c)

Figura 4.29. Texturas da mistura $M=32$ a $30^{\circ} \mathrm{C}$. As letras $P, A$ e $\mathbf{H}$ representam a direção do polarizador, do analisador e do campo magnético aplicado, respectivamente. Em (a) e (b), a maior dimensão é perpendicular a $\mathbf{H}$, no plano da figura.

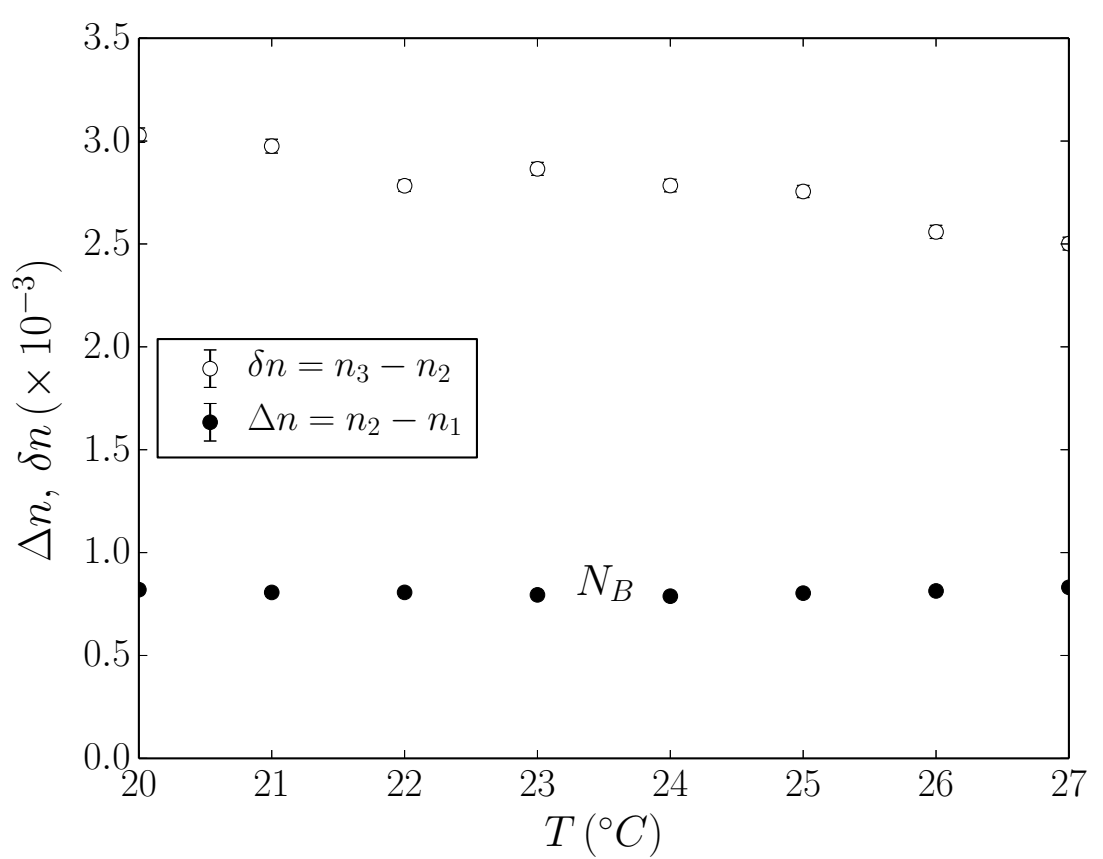

Figura 4.30. Birrefringências $\Delta n(\bullet)$ e $\delta n\left(\right.$ (o) da mistura $M=32$ em função da temperatura $T\left({ }^{\circ} \mathrm{C}\right)$, medidas com a conoscopia laser. 


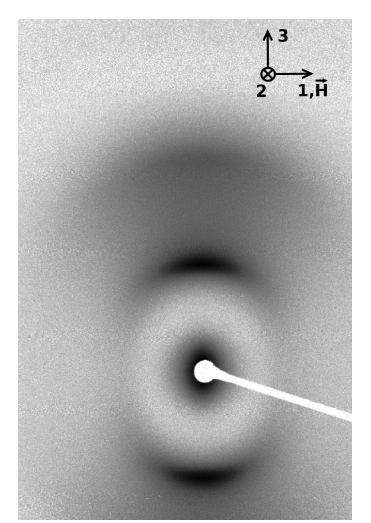

(a)

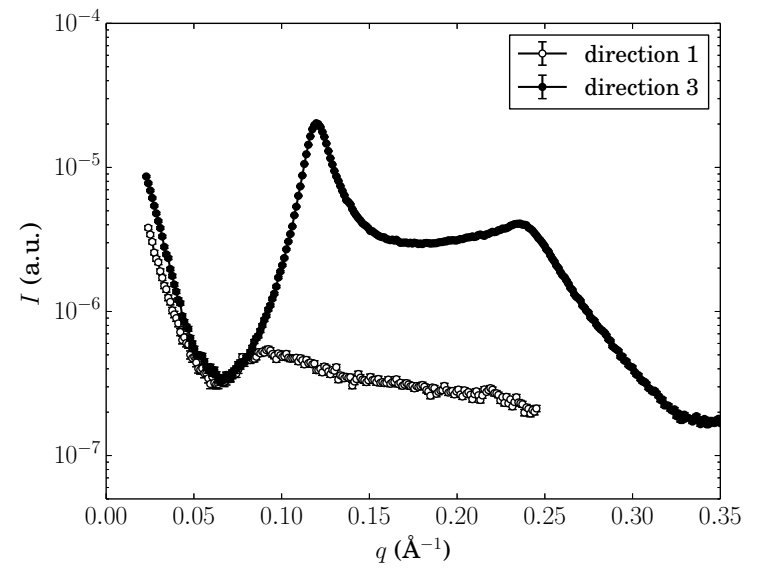

(b)

Figura 4.31. Resultados de SAXS para a mistura $M=32 \mathrm{em} T=25^{\circ} \mathrm{C}$. Em (a), vê-se o padrão de espalhamento 2D da amostra em fase $N_{B}$, com um diretor na direção 3 e outro na direção 1, paralelo a $\mathbf{H}$, em escala logarítmica de tons de cinza; em (b), as curvas de intensidade de espalhamento $I(q)$ nas direções 1 e 3.

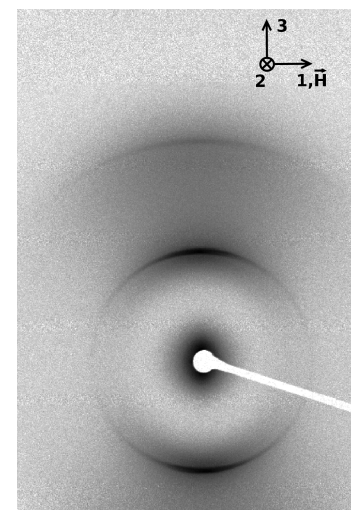

(a)

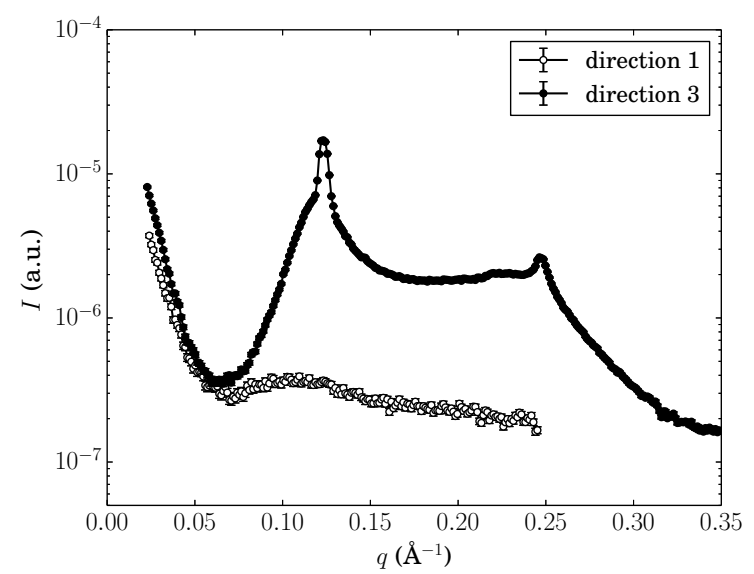

(b)

Figura 4.32. Resultados de SAXS para a mistura $M=32 \mathrm{em} T=35^{\circ} \mathrm{C}$. Em (a), tem-se o padrão de espalhamento bidimensional da amostra em coexistência de fase $N_{D}+$ lamelar (novamente, tons de cinza em escala logarítmica); em (b), $I(q)$ nas direções 1 e 3. 


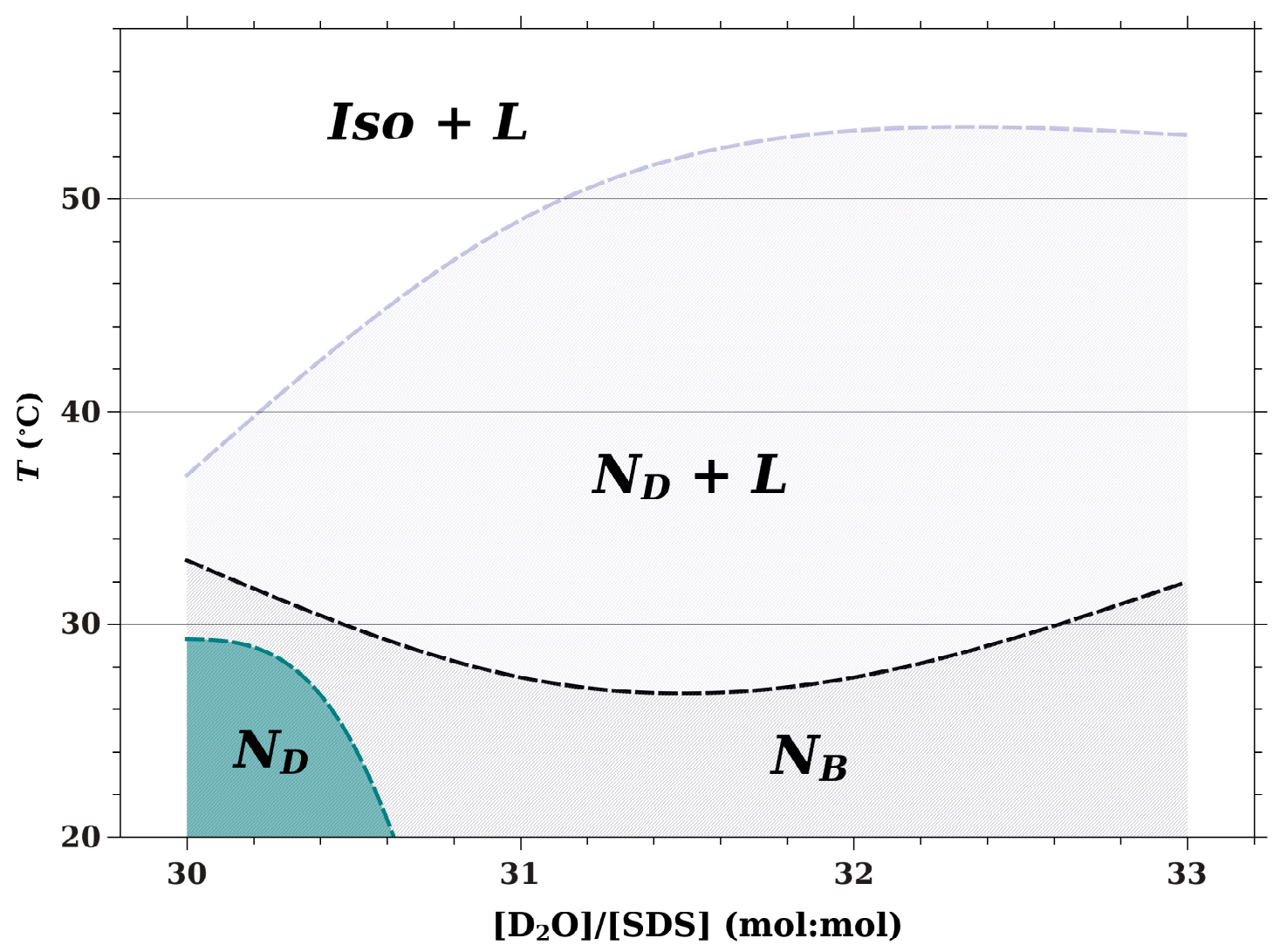

Figura 4.33. Diagrama de fase da mistura $\mathrm{SDS} / \mathrm{DeOH} / \mathrm{D}_{2} \mathrm{O}$ resultante das observações efetuadas com as técnicas de MOLP, conoscopia laser e SAXS. As abreviaturas são: $N_{D}$ (fase discótica), $N_{B}$ (fase biaxial), $L$ (fase lamelar), ISO (fase isotrópica) e o sinal de + indica a coexistência das fases. 


\subsection{Medidas de $D L S$}

Apresentamos aqui alguns dos resultados parciais obtidos neste trabalho, uma vez que as discussões sobre o significado físico dos resultados estão em andamento. A figura 4.34 mostra ajustes típicos da função de correlação, a título de exemplo, do que se obtêm os tempos típicos de relaxação dos modos bend (figura a) e splay e twist (figura b), na fase $N_{C}$; no caso da figura (b), são obtidos tempos de cada um dos modos por ajuste de uma soma de duas exponenciais.

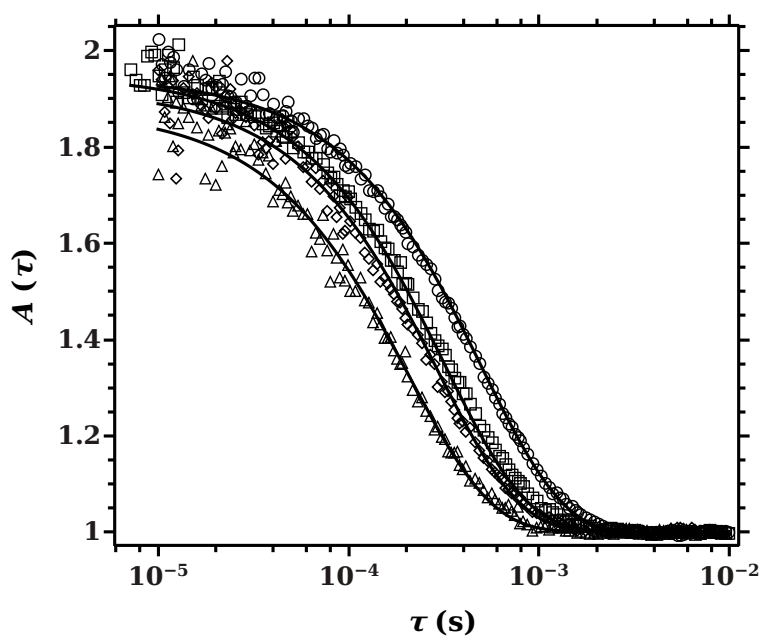

(a)

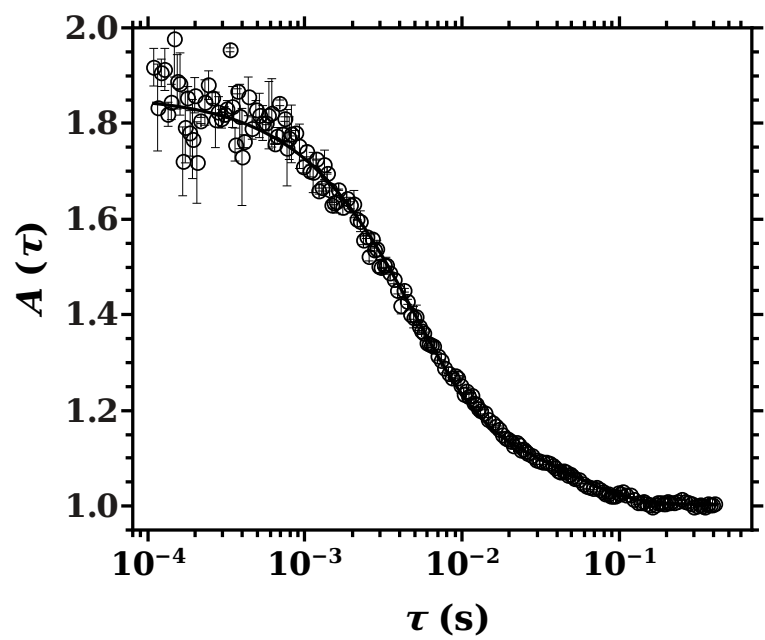

(b)

Figura 4.34. Ajuste típico de exponenciais a funções de correlação. Em (a), ajustes para a flutuação bend na fase $N_{C}$ sem ferrofluido para vários ângulos (externos) de espalhamento, de acordo com a geometria despolarizada. Os ângulos correspondentes aos símbolos da figura são $13^{\circ}(\bigcirc), 15^{\circ}(\square), 17^{\circ}(\diamond), 20^{\circ}(\triangle)$; as linhas contínuas são as exponenciais ajustadas. Em (b), ajustes para as flutuações splaye twist na fase $N_{C} \operatorname{com} 3,5 \times 10^{12}$ grãos de ferrofluido/mL, para um ângulo (externo) de espalhamento de $22^{\circ}$, de acordo com a geometria despolarizada. Cada exponencial ajustada fornece informação sobre a flutuação splay ou twist.

As figuras 4.35 e 4.36 mostram como as difusividades são obtidas por ajustes de retas (passando por zero) aos valores da frequência obtida em vários ângulos de espalhamento.

Em termos gerais, verificamos que há algumas alterações nas difusividades dos modos em função da concentração de ferrofluido, ainda que em concentrações muito baixas. Por exemplo, a difusividade da flutuação twist cai na fase $N_{D}$ (figura 4.38), o que pode ocorrer por alteração das constantes elásticas de cada modo (equação 3.9).

As medidas das flutuações do diretor foram efetuadas nas fases $N_{D}$ e $N_{C}$ (uniaxiais), para as quais dispomos de regras de seleção de espalhamento dos modos 3.15; estamos analisando a possibilidade de obter regras de seleção para a fase biaxial [73] e, em trabalho sobre adição de sais em liotrópicos, Akpinar et al. [53] conseguiram obter misturas com fase nemá- 
tica biaxial estável em um intervalo razoável de temperatura, o que suscita que este trabalho seja continuado futuramente também para essas fase. Há grande dificuldade em se definir exatamente a concentração de nanopartículas magnéticas, o que deve ser sanado em futuras investigações. As características do equipamento de que dispomos também influenciou na qualidade das medidas, o que nos levou a fazer uma série de aperfeiçoamentos, tanto na parte de óptica, como de acondicionamento das amostras e software. Esperamos retomar, com isso, as medidas de DLS de nemáticos e concluir essa etapa.

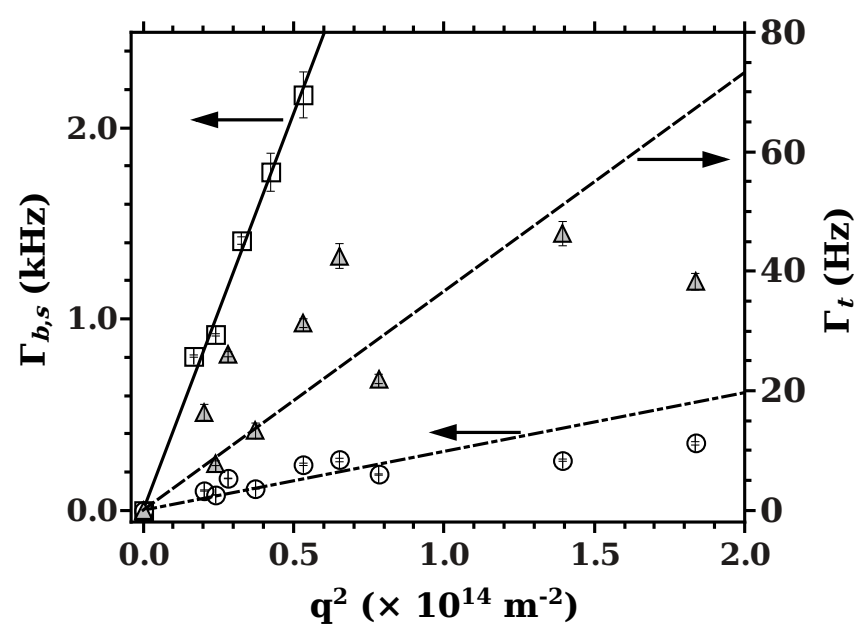

Figura 4.35. Dependência angular das frequências $\Gamma_{b}$ (bend), $\Gamma_{s}$ (splay) e $\Gamma_{t}$ (twist) na fase $N_{C}$ com uma dopagem de $3,5 \times 10^{12}$ grãos de ferrofluido $/ \mathrm{mL}$. Os dados de bend, splay e twist são representados por $\square$, $\bigcirc$, e $\triangle$, respectivamente.

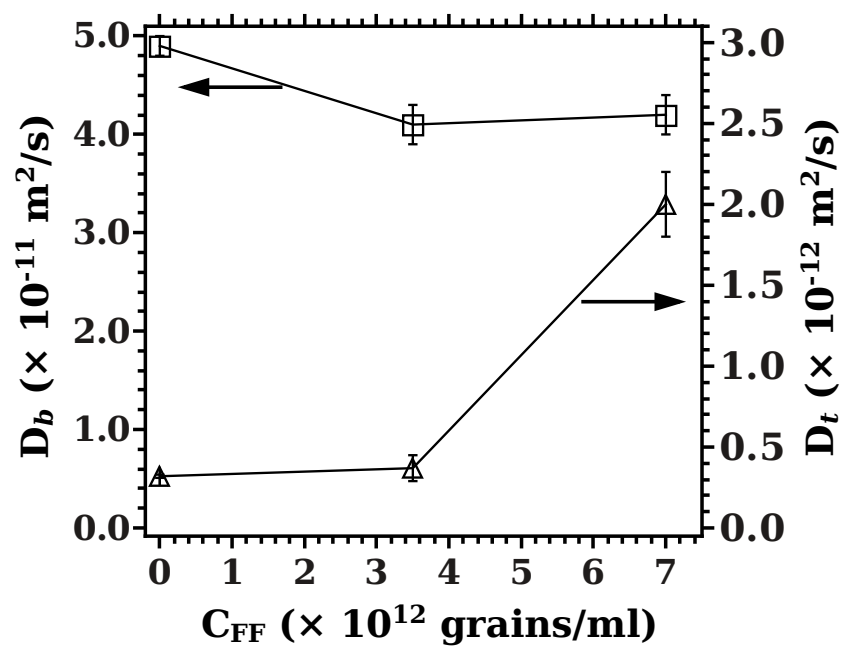

Figura 4.36. Difusividades $D_{b}$ (flutuação bend, $\square$ ) e $D_{t}$ (flutuação twist, $\Delta$ ) na fase $N_{C}$. 


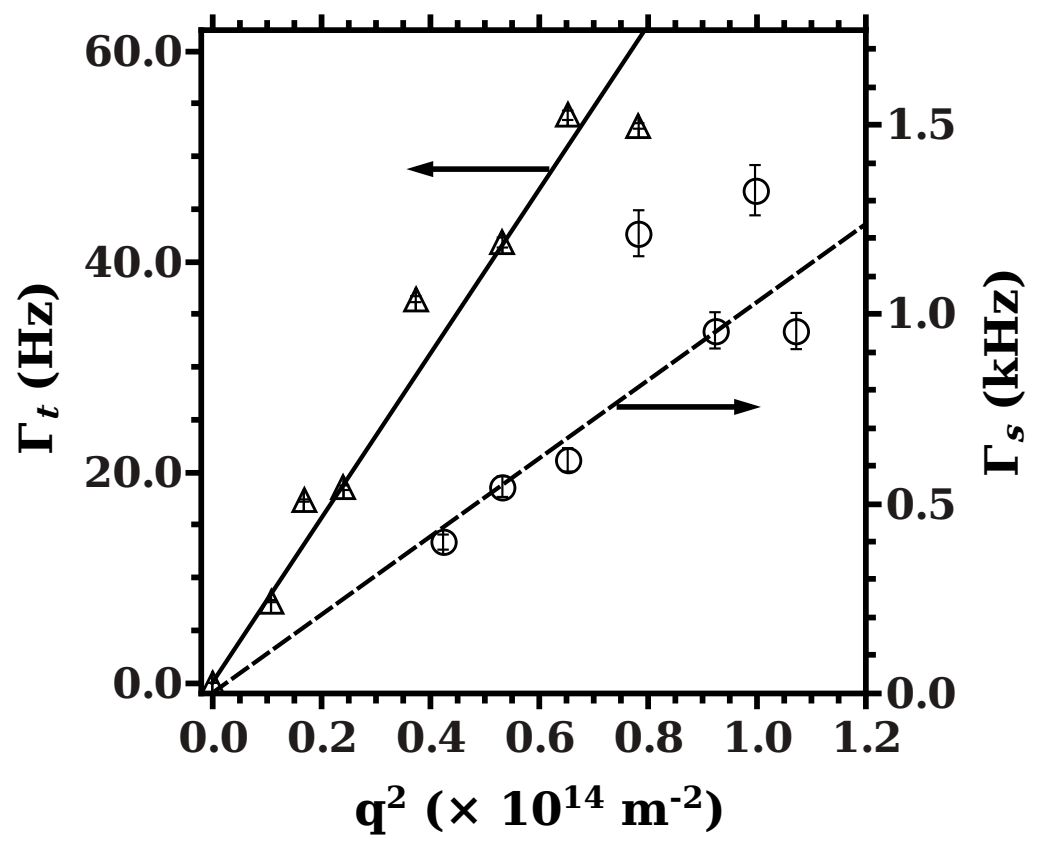

Figura 4.37. Dependência angular das frequências $\Gamma_{s}$ (splay, dados indicados por $\bigcirc$ ) e $\Gamma_{t}$ (twist, $\Delta$ ) na fase $N_{D}$ com uma dopagem de $3,5 \times 10^{12}$ grãos de ferrofluido/mL. O ajuste de uma reta fornece $D_{s, t}=\Gamma_{s, t} / q^{2}$.

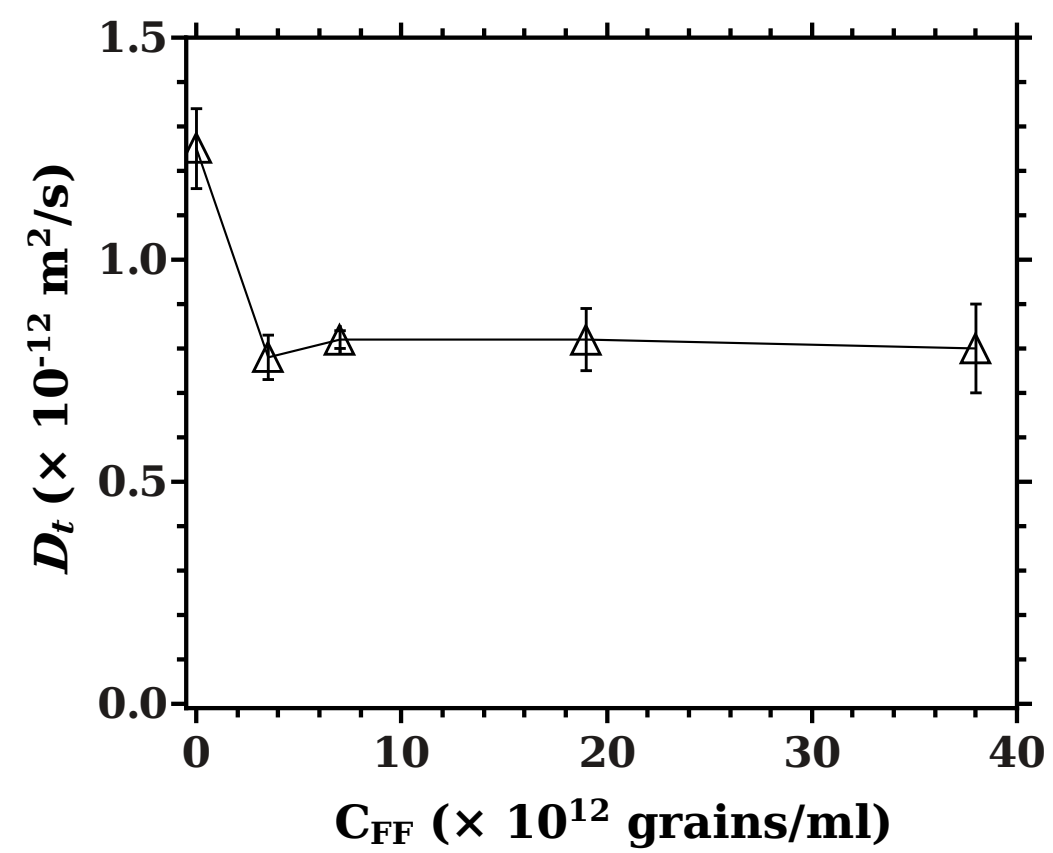

Figura 4.38. Difusividade da flutuação twist $D_{t}$ na fase $N_{D}$ em função da concentração de ferrofluido. 


\section{Capítulo 5}

\section{Conclusões}

Neste trabalho, abordamos uma série de propriedades de cristais líquidos liotrópicos por diversas técnicas de caracterização. Principalmente, desenvolvemos métodos de análise de sistemas orientados como os líquido cristalinos a partir de resultados de SAXS, baseados em modelagem e simulação computacional. Tomamos o problema da disposição das estruturas micelares em liotrópicos nemáticos [74, 1,2] como base para o desenvolvimento de um modelo quantitativo que leva em conta as características dos comportamentos coletivos dos agregados micelares, descrevendo sua ordem pseudolamelar. Não obstante o grande número de parâmetros do modelo, obtivemos resultados (apresentados na tabela 4.2) condizentes com conhecidos na literatura, como dimensões das estruturas pseudolamelares, raio médio da micela, excentricidade etc. O processo de ajuste exigiu restrição de intervalos válidos de cada parâmetro, com base em informações de outros procedimentos experimentais, uma vez que o software desenvolvido permite esse recurso. A perspectiva, à continuação do aperfeiçoamento desta técnica, é modelar toda a imagem produzida por SAXS, isto é, efetuar ajustes sobre toda a imagem. Podem ser definidos pequenos setores circulares e ajustados os parâmetros em várias direções, que devem ser consistentes entre si, e então fazer-se o ajuste concomitante das várias curvas.

Conjuntamente com o processo de modelagem, pretendemos estudar as configurações das estruturas micelares cujas simulações de espalhamento possam ser avaliadas pelo modelo de ajuste de curvas. E, no entanto, os resultados das simulações obtidos até então nos parecem promissores. A sequência de gráficos apresentados na seção 4.2 analisa os efeitos das diferentes disposições das micelas sobre o padrão de espalhamento. A forma do elipsoide é mais relevante pelo papel que tem na definição das distâncias entre micelas do que pelo seu próprio espalhamento, ou seja, por sua influência no fator de estrutura do que por seu próprio fator de forma (nos intervalos de $q$ considerados). As simulações em que as configurações emulam as correlações de mais longo alcance na direção do diretor nemático, com liberdade de flutuação nas demais direções, são as que mais se aproximam dos padrões de SAXS, pois mantêm-se os picos característicos das distâncias intermicelares e se 
reproduzem os arcos característicos da distribuição do parâmetro de ordem.

A manipulação da disposição geométrica do conjunto de micelas foi feita neste trabalho por transformações lineares cujos parâmetros são definidos a priori em cada arranjo. A escolha desses parâmetros tem base em dados da literatura e correção recursiva dos parâmetros, por tentativa e erro. Ainda há espaço de trabalho para que se consigam resultados ainda mais próximos aos experimentais por essa metodologia, como a implementação de polidispersidade e a execução de simulações com maior número de unidades em clusters de computadores alto desempenho. Em perspectiva, pode ser interessante implementar uma dinâmica no sistema, de modo que as translações e rotações sejam efetuadas por critérios físicos, de modo a produzir o empacotamento das micelas. Ou seja, é razoável desenvolver uma simulação de tipo Monte Carlo para que se encontrem configurações micelares em estado de equilíbrio termodinâmico e então se faça sobre esse sistema a simulação de SAXS.

No estudo de fases da mistura liotrópica à base de SDS, partimos da observação de sua textura, por microscopia óptica de luz polarizada, de sua birrefringência por conoscopia laser e dos padrões de espalhamento sobre estruturas lamelares ou coexistência de fases com a técnica de SAXS, chegamos ao diagrama de fases da figura 4.33, que contesta a hipótese de que seria possível a coexistência de fases nemáticas para essa mistura nas concentrações indicadas [30]. Esse resultado está em consonância com as perspectivas teóricas tradicionais sobre nemáticos.

Abordamos também o comportamento dinâmico de nemáticos, estudando as flutuações do diretor $\mathbf{n}_{0}$ (splay, twist, bend) por espalhamento de luz dinâmico (DLS) em função da presença de ferrofluido como dopante, variando as doses de sua concentração. Embora tenhamos observado algumas variações em alguns casos, obtivemos curvas que, até o momento, não nos permitem concluir um padrão claro de mudança das difusividades dos modos, que poderia estar associada a variações das constantes elásticas $K_{1,2,3}$ da energia de Frank (eq. 3.9), ou às suas correspondentes viscosidades.

As propostas abertas no decorrer das investigações desta tese são decerto mais amplas do que os resultados aqui apresentados, o que é uma animadora perspectiva científica. A abordagem multifatorial que propusemos nesta tese pode ser utilizada como toolbox para análises de outros tipos de sistemas compostos por cristais líquidos. Os métodos de análise e simulação de dados de espalhamento a baixo ângulo, tanto para curvas quanto para imagens bidimensionais são inovadoras e possuem um grande potencial para aprimoramento, fornecendo informações estruturais sobre os sistemas que não podem ser obtidos por outras técnicas experimentais. 


\section{Apêndice A}

\section{Resultados experimentais complementares}

\section{A.1 Medidas de SAXS}

Apresentamos aqui resultados complementares aos da seção 4.2, correspondentes a uma série de testes de configurações das estruturas micelares. Alguns dos testes são indicativos da tendência à convergência das curvas quando o número de micelas aumenta (seção A.1.1) e outros, ainda, de possibilidades de arranjos diversos, simulando possível quiralidade (seções A.1.6 e A.1.7)

\section{A.1.1 Micelas, $20 \times 1 \times 1$}

Para testar o efeito de finite size, foi efetuada uma simulação de uma cadeia linear de 20 micelas. Agora vê-se claramente um pico pronunciado e distinto dos demais (figura A.1c), com a redução clara de intensidade na região intermediária entre esse pico e o centro. Pode-se inferir portanto que o aumento do número de micelas tende a definir apenas alguns pontos de interferência construtiva que preservam informações sobre toda a estrutura. A intensidade da curva vertical é também apresentada. 


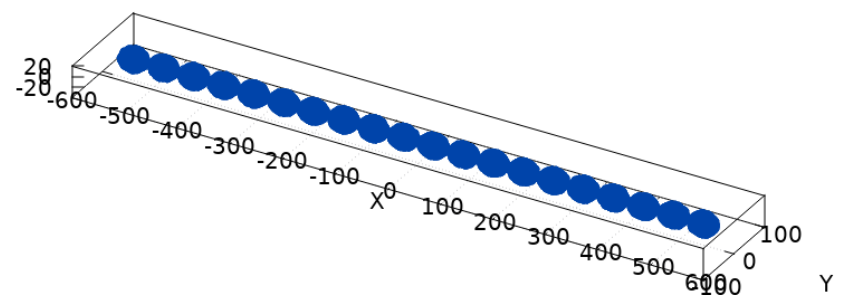

(a) Micelas.

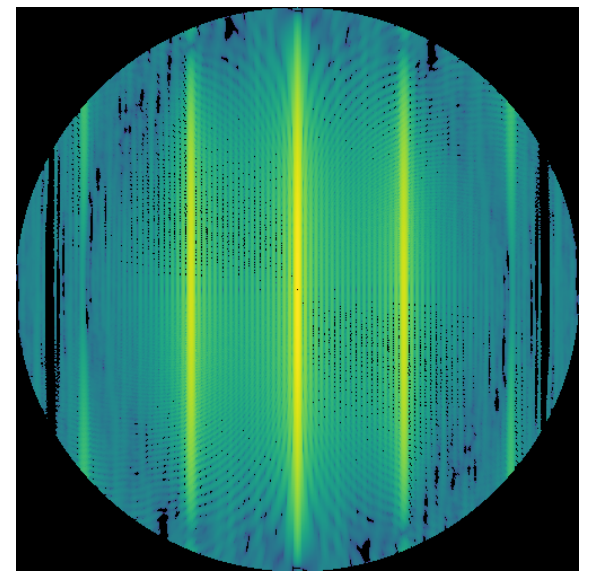

(b) Espalhamento.

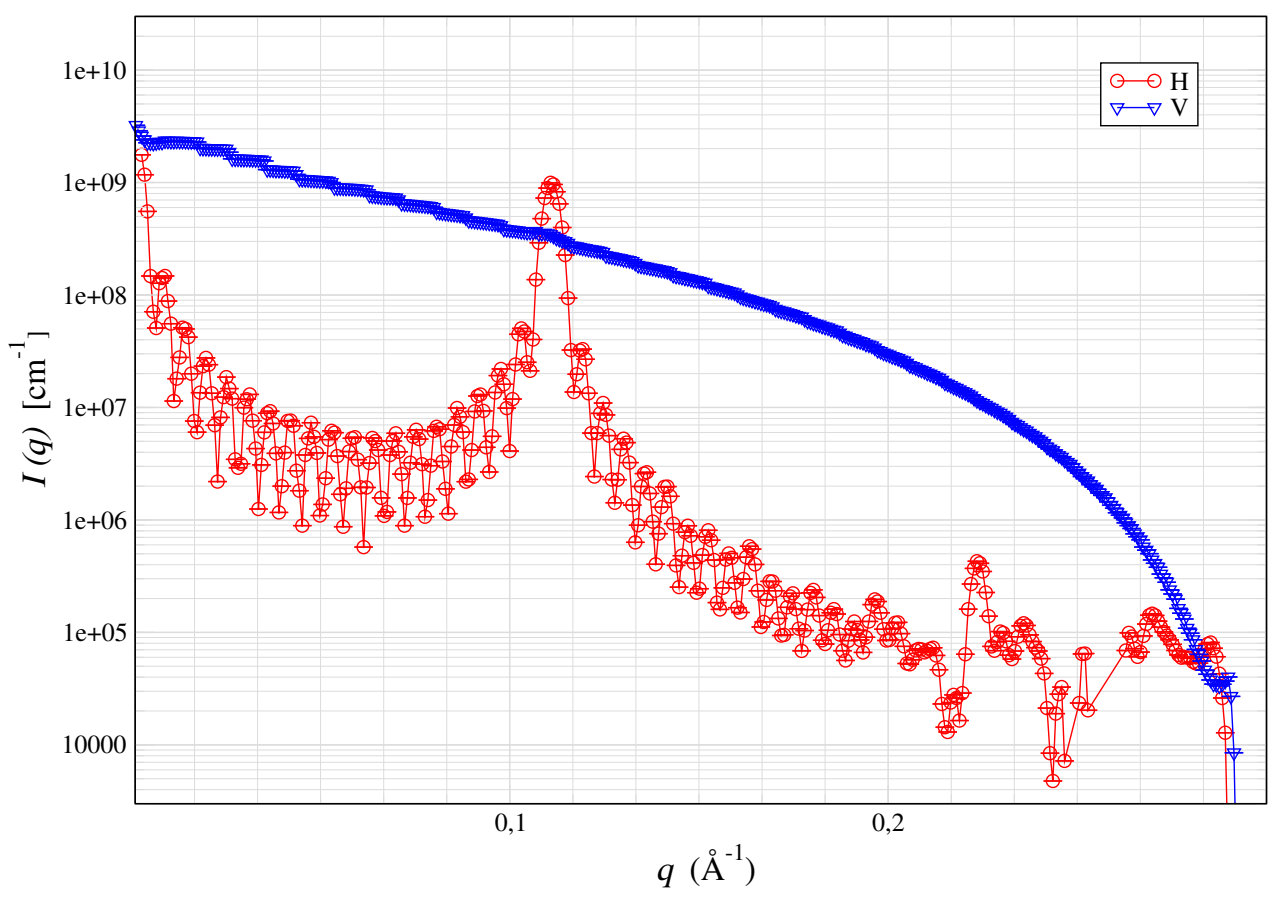

(c) Integrações em torno da horizontal $(\bigcirc)$ e da vertical $(\nabla)$.

Figura A.1. Simulação de SAXS de um conjunto de $20 \times 1 \times 1$ estruturas micelares, em rede cúbica.

. Cada micela tem 3000 pontos de espalhamento (60000 no total). O campo H encontra-se na direção perpendicular ao feixe de raios $\mathrm{X}$ incidente. Os eixos maiores das micelas têm $45.0 \AA \times$ $35.0 \AA \times 35.0 \AA$ (modelo uniaxial), simulando a fase $N c$, e a espessura da shell é de $4.10 \AA$. A camada

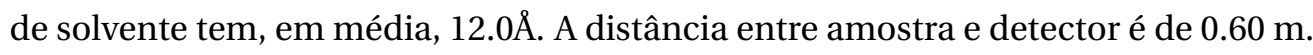




\section{A.1.2 Rede cúbica}

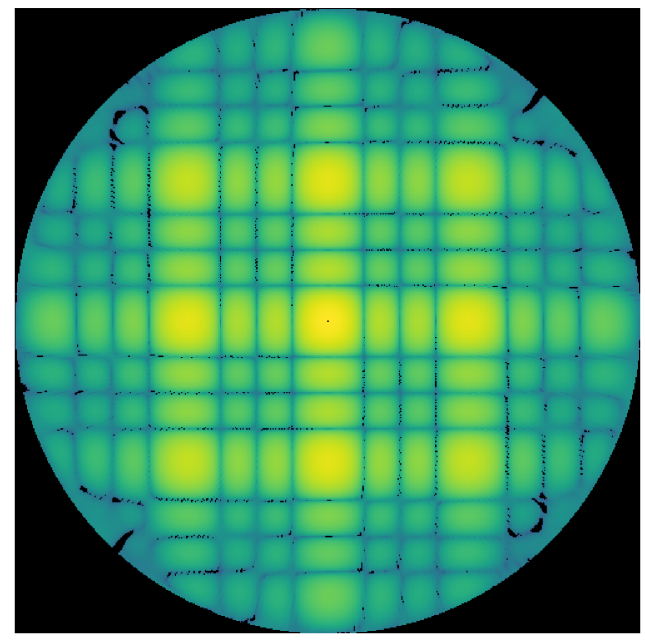

(a) Espalhamento.

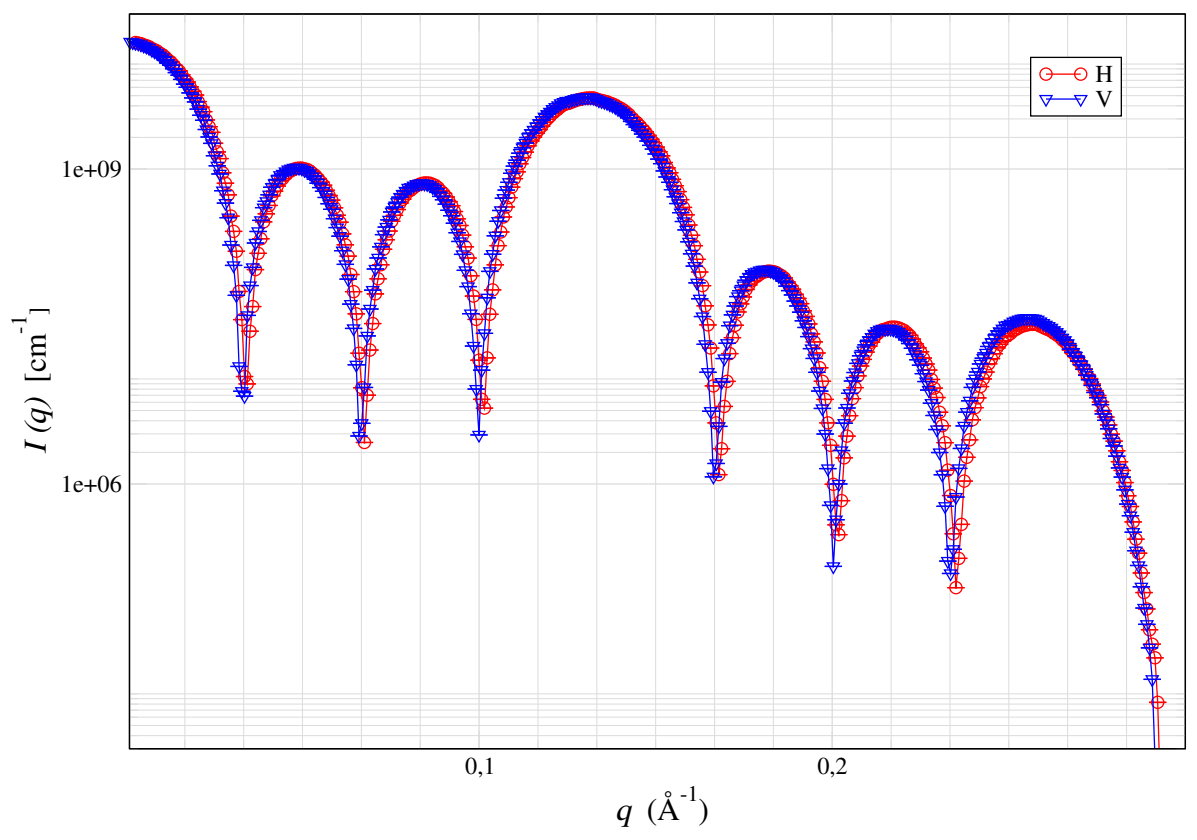

(b) Integrações em torno da horizontal $(\bigcirc)$ e da vertical $(\nabla)$.

Figura A.2. Simulação de SAXS de um conjunto de $4 \times 4 \times 4$ estruturas micelares, em rede cúbica. Cada micela tem 2000 pontos de espalhamento (128000 no total). O campo H encontra-se na direção paralela ao feixe de raios X incidente. Os eixos maiores das micelas têm $35.0 \AA \times 45.0 \AA \times$ $35.0 \AA$ (modelo uniaxial), simulando a fase $N c$, e a espessura da shell é de $4.10 \AA$. A camada de solvente tem, em média, 12.0Å. A distância entre amostra e detector é de $0.60 \mathrm{~m}$. 


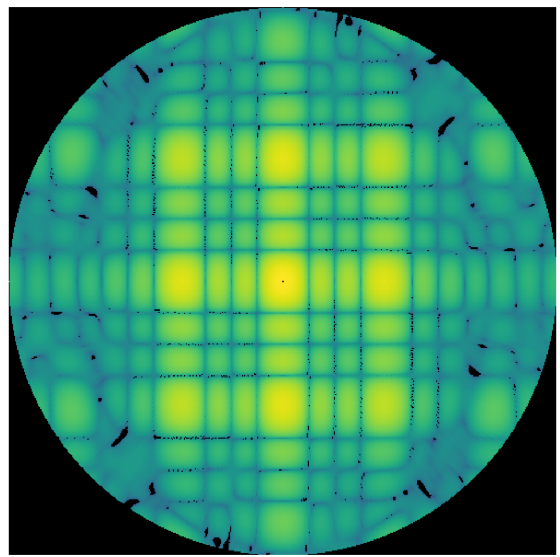

(a) Espalhamento.

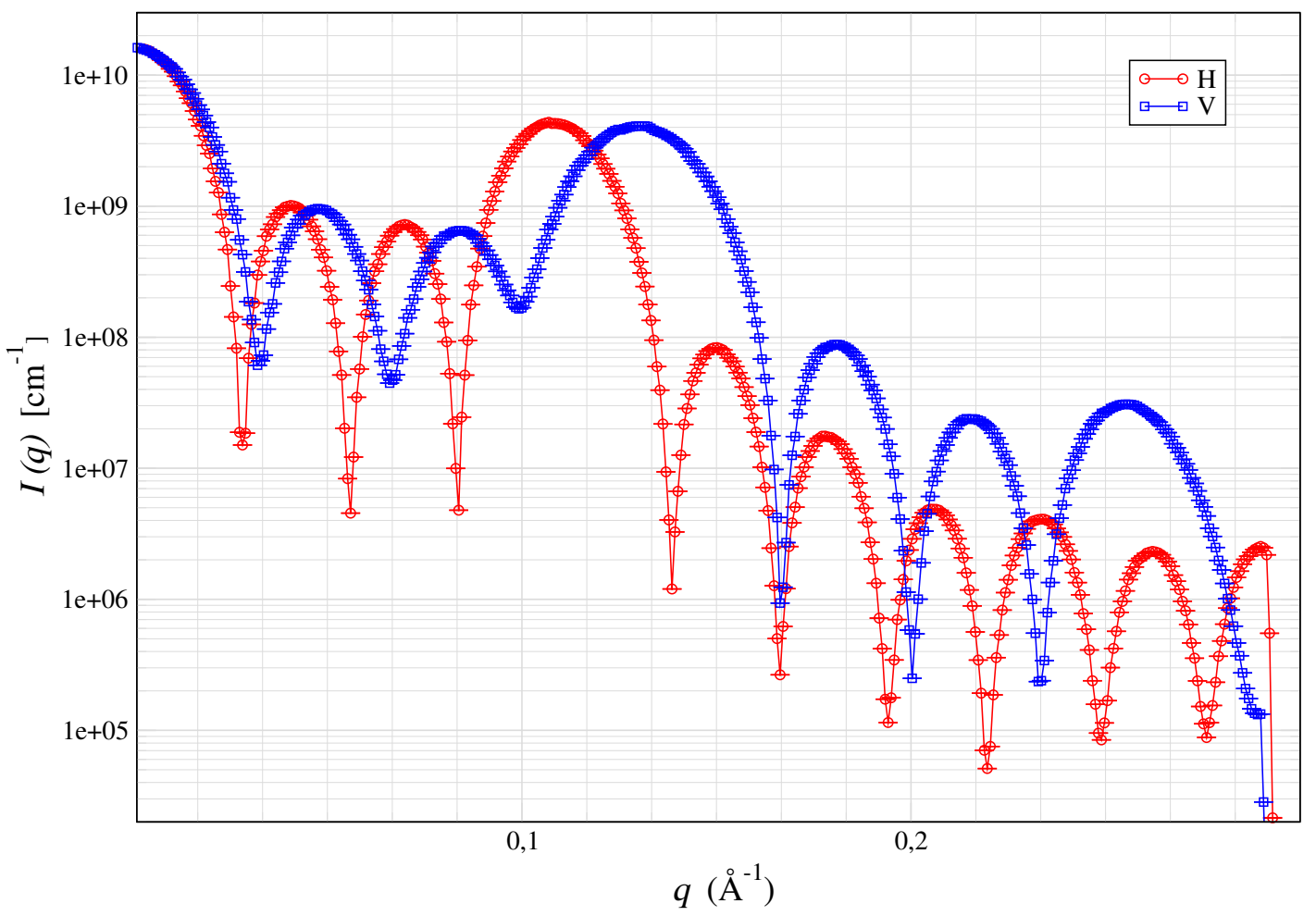

(b) Integrações em torno da horizontal $(\bigcirc)$ e da vertical $(\triangle)$.

Figura A.3. Simulação de SAXS de um conjunto de $4 \times 4 \times 4$ estruturas micelares, em rede cúbica. Cada micela tem 2000 pontos de espalhamento (128000 no total). O campo H encontra-se na direção perpendicular ao feixe de raios X incidente. Os eixos maiores das micelas têm $45.0 \AA \times$ $35.0 \AA \times 35.0 \AA$ (modelo uniaxial), simulando a fase $N c$, e a espessura da shell é de $4.10 \AA$. A camada de solvente tem, em média, 12.0A. A distância entre amostra e detector é de $0.60 \mathrm{~m}$. 


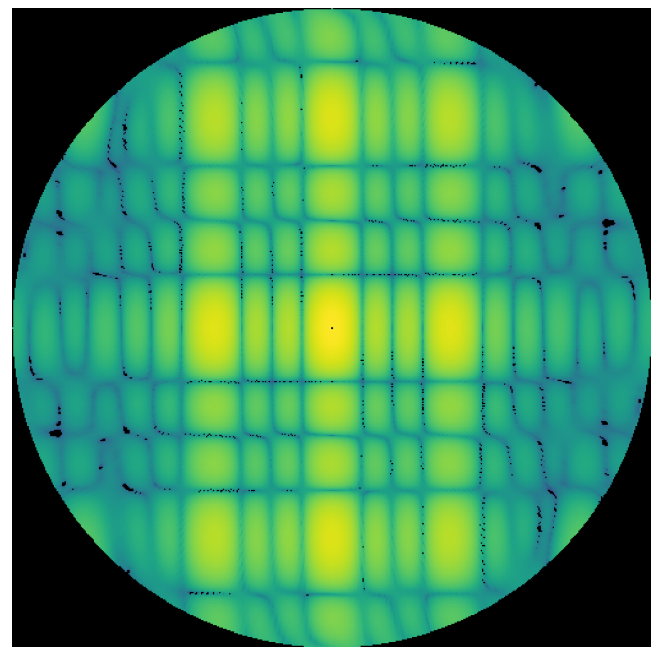

(a) Espalhamento.

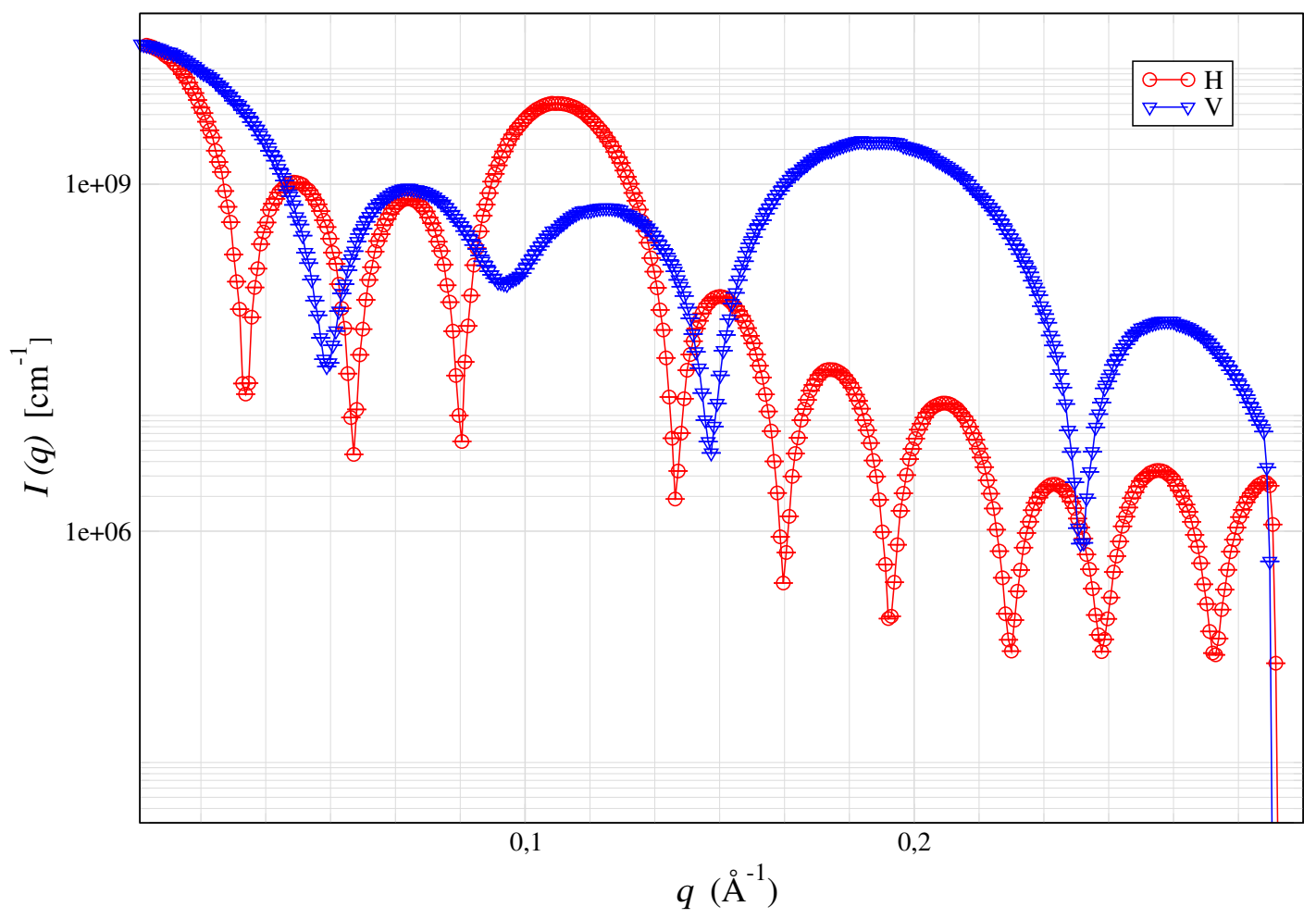

(b) Integrações em torno da horizontal $(\bigcirc)$ e da vertical $(\triangle)$.

Figura A.4. Simulação de SAXS de um conjunto de $4 \times 4 \times 4$ estruturas micelares, em rede cúbica. Cada micela tem 2000 pontos de espalhamento (128000 no total). O campo H encontra-se na direção perpendicular ao feixe de raios $X$ incidente. Os eixos maiores das micelas têm $45.0 \AA \times$ $35.0 \AA \times 20.0 \AA$ (modelo IBM), simulando a fase $N c$, e a espessura da shell é de $4.10 \AA$. A camada de solvente tem, em média, $12.0 \AA$. A distância entre amostra e detector é de $0.60 \mathrm{~m}$. 


\section{A.1.3 Rede cúbica de corpo centrado}

No caso de camadas deslocadas para formação uma rede de corpo centrado, vê-se o desdobramento do pico e a atenuação constante da intensidade em função de $q$. Aparentemente, o empacotamento nesse tipo de estrutura descaracteriza os picos da fase nemática, embora haja suavização dos perfis das curvas. Observa-se ainda uma deformação em relação ao padrão quadrado (figura A.5)no caso IBM com $H$ paralelo ao feixe (figura A.7), mantendose as características gerais dos picos. De fato, as alterações nas orientações das micelas, mantendo-se seus centros na rede, implicam pequenas variações arbitrárias das distâncias entre as superfícies de micelas vizinhas, o que torna a imagem mais difusa; o último pico horizontal da figura A.7b é mais pronunciado, e seu valor corresponde a distância de aproximadamente $2 \pi / 0.267 \approx 23.5 \AA$, pouco mais do que o menor eixo da micela, o que significa que as rotações reduziram o tamanho efetivo da camada de solvente, uma vez que não foi implementada uma dinâmica de acomodação das micelas após translações e rotações. 


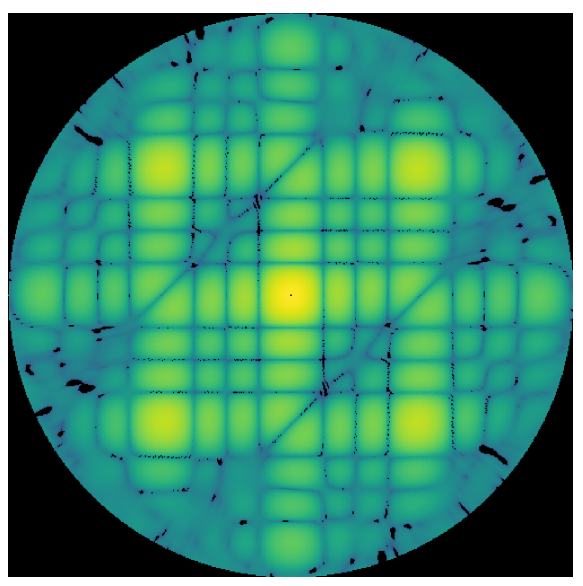

(a) Espalhamento.

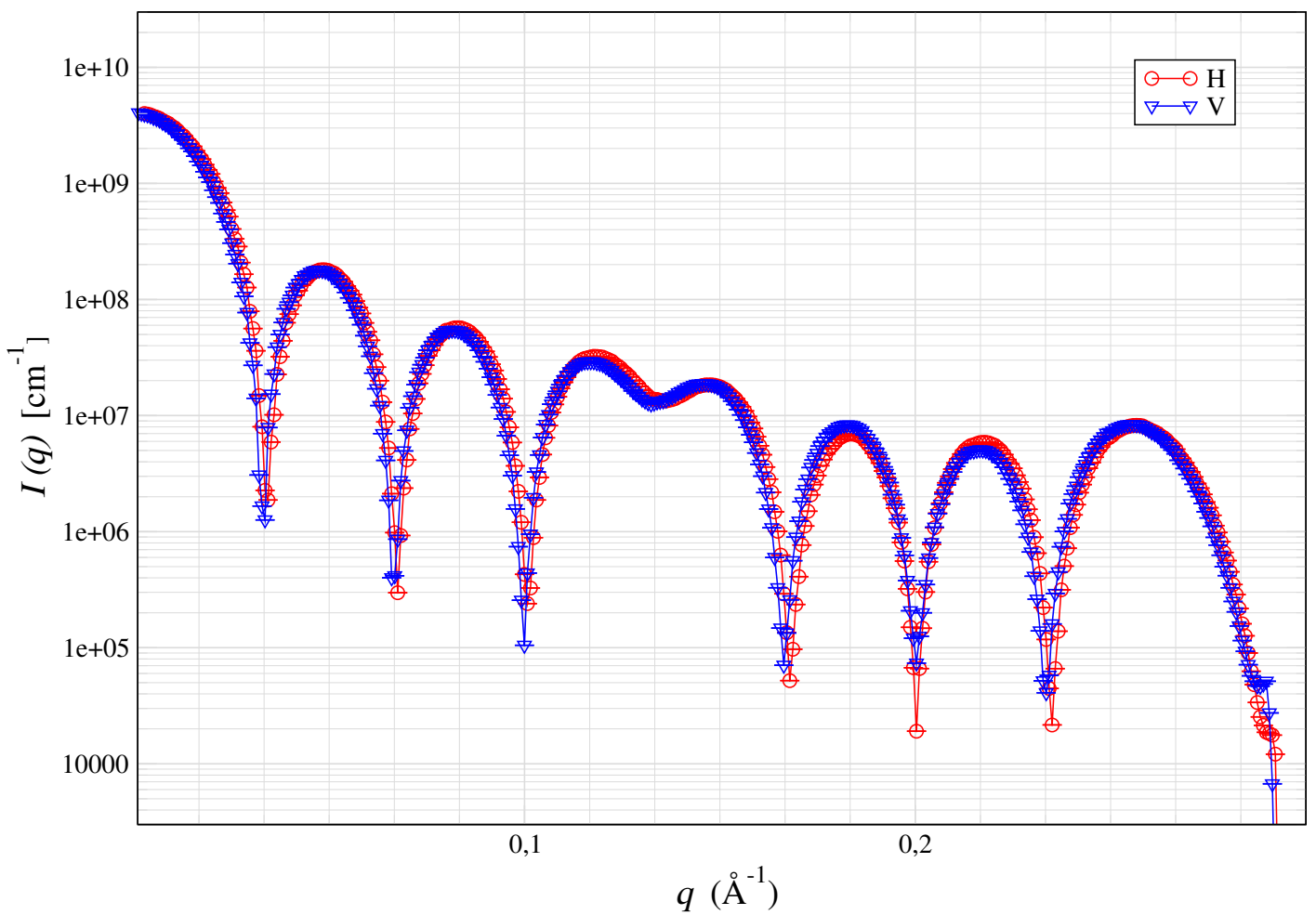

(b) Integrações em torno da horizontal $(\bigcirc)$ e da vertical $(\nabla)$.

Figura A.5. Simulação de SAXS de um conjunto de $4 \times 4 \times 4$ estruturas micelares, em rede cúbica de corpo centrado . Cada micela tem 1000 pontos de espalhamento (64000 no total). O campo H encontra-se na direção paralela ao feixe de raios $\mathrm{X}$ incidente. Os eixos maiores das micelas têm $35.0 \AA \times 45.0 \AA \times 35.0 \AA$ (modelo uniaxial), simulando a fase $N c$, e a espessura da shell é de $4.10 \AA$. A camada de solvente tem, em média, 12.0Å. A distância entre amostra e detector é de $0.60 \mathrm{~m}$. 


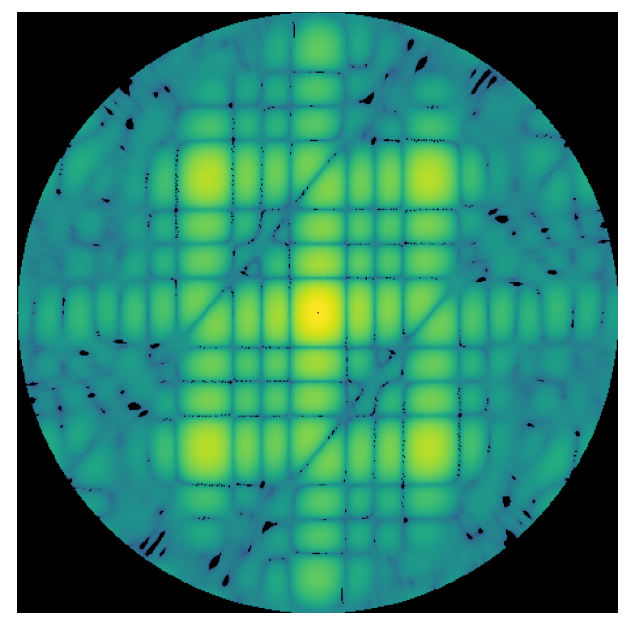

(a) Espalhamento.

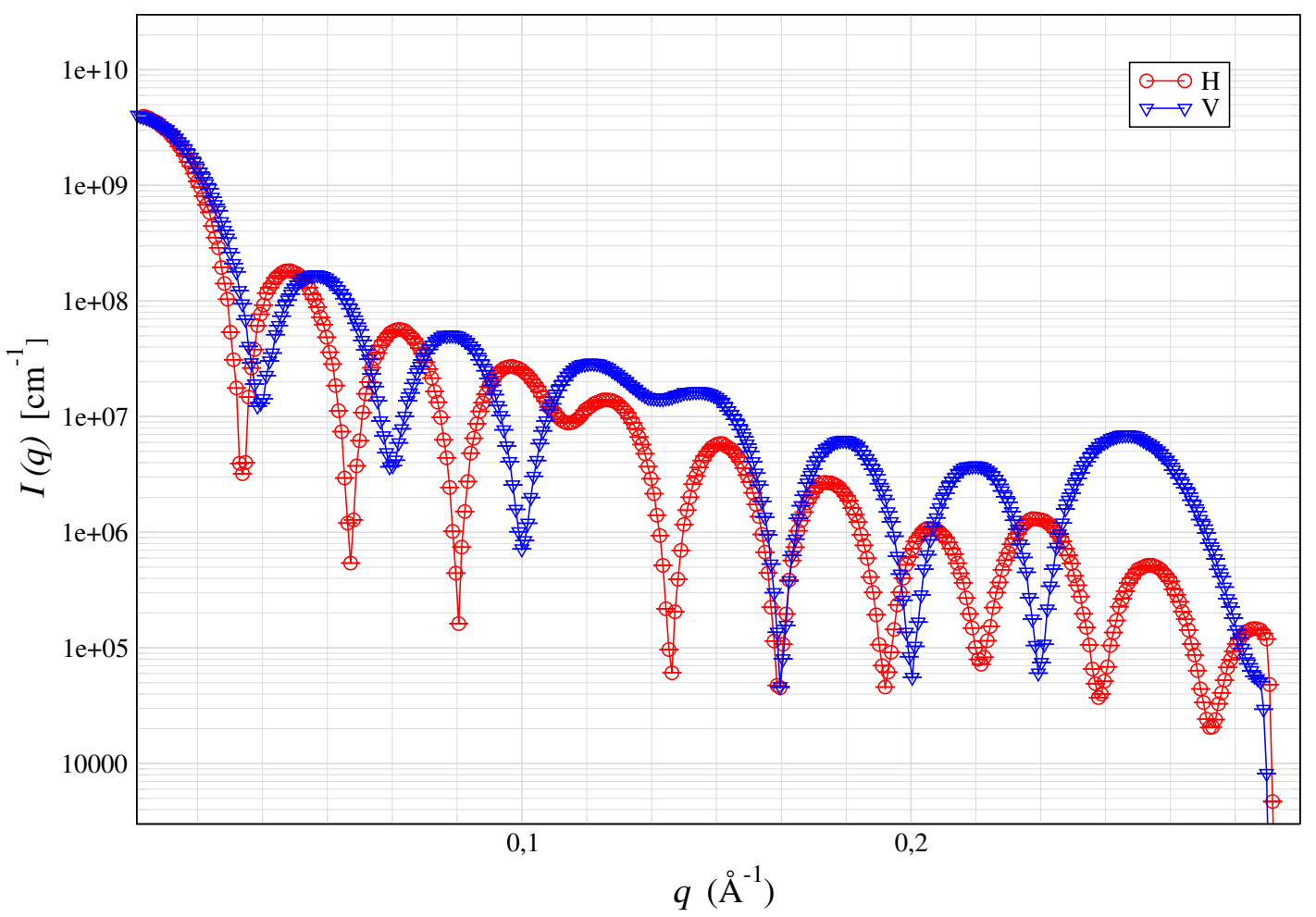

(b) Integrações em torno da horizontal $(\bigcirc)$ e da vertical $(\triangle)$.

Figura A.6. Simulação de SAXS de um conjunto de $4 \times 4 \times 4$ estruturas micelares, em rede cúbica de corpo centrado . Cada micela tem 1000 pontos de espalhamento (64000 no total). O campo H encontra-se na direção perpendicular ao feixe de raios X incidente. Os eixos maiores das micelas têm $45.0 \AA \times 35.0 \AA \times 35.0 \AA$ (modelo uniaxial), simulando a fase $N c$, e a espessura da shell é de

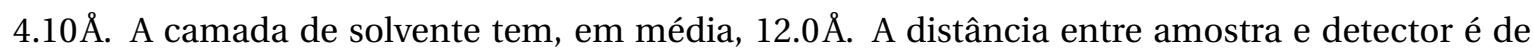
$0.60 \mathrm{~m}$. 


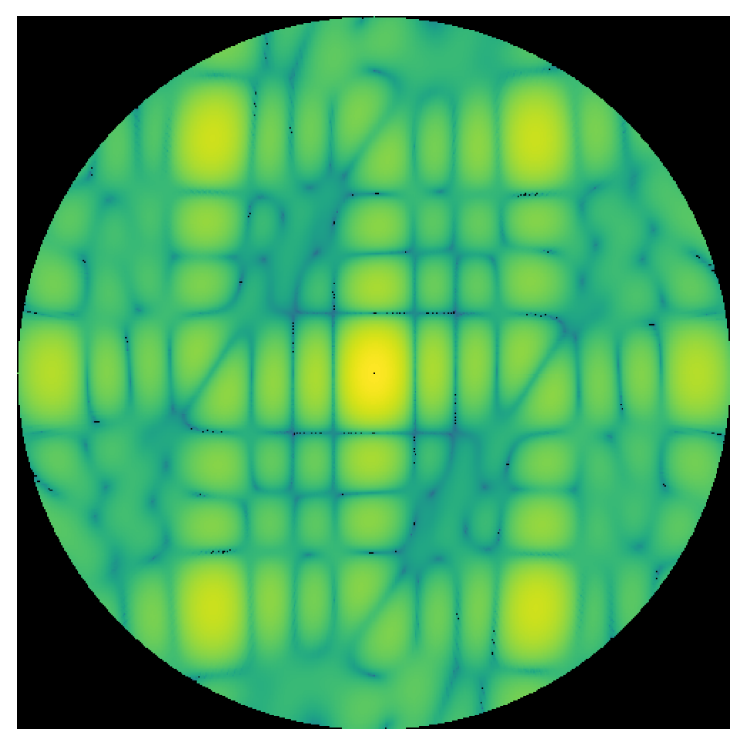

(a) Espalhamento.

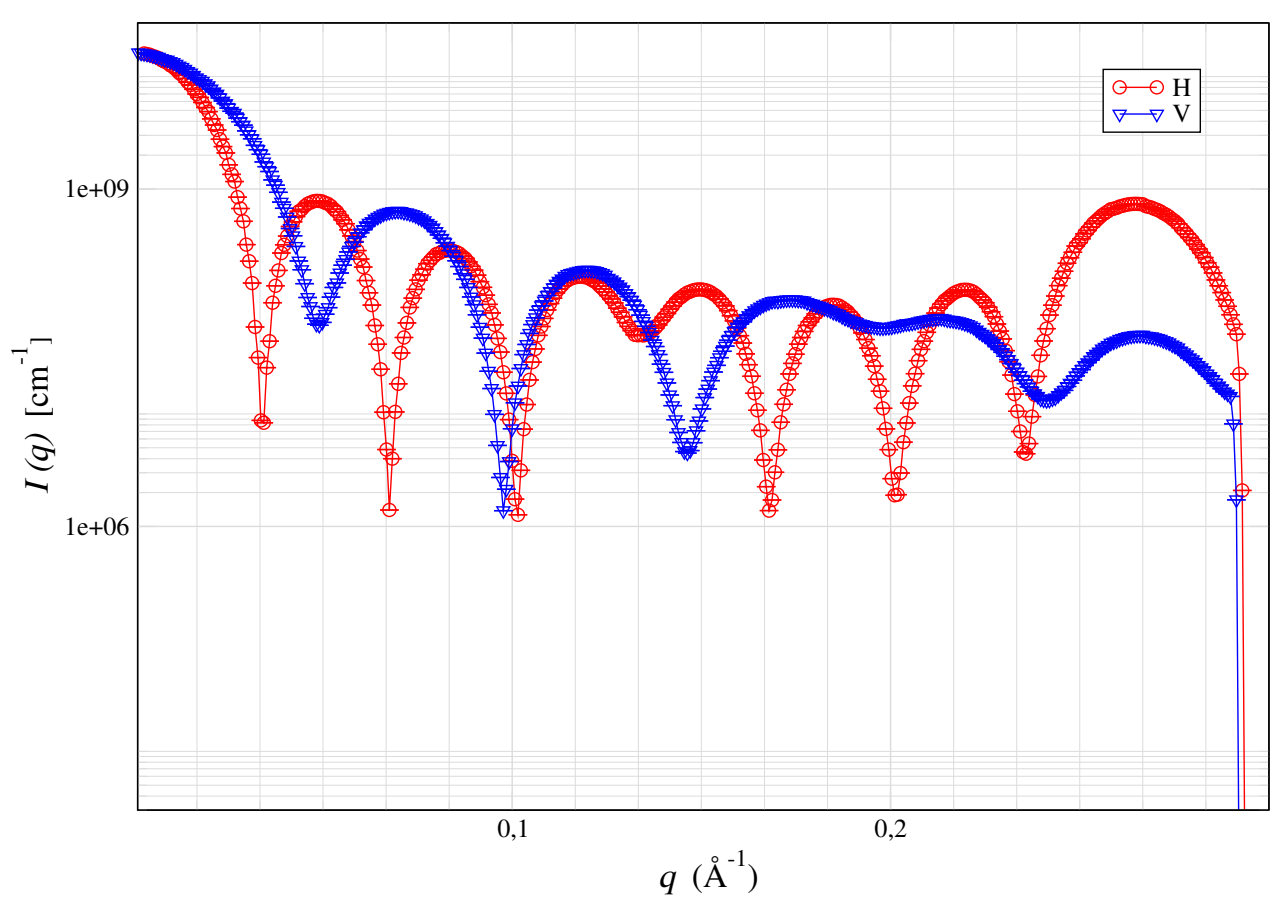

(b) Integrações em torno da horizontal $(\bigcirc)$ e da vertical $(\nabla)$.

Figura A.7. Simulação de SAXS de um conjunto de $4 \times 4 \times 4$ estruturas micelares, em rede cúbica de corpo centrado . Cada micela tem 2000 pontos de espalhamento (128000 no total). O campo $\mathrm{H}$ encontra-se na direção paralela ao feixe de raios $\mathrm{X}$ incidente. Os eixos maiores das micelas têm $35.0 \AA \times 45.0 \AA \times 20.0 \AA$ (modelo IBM), simulando a fase $N c$, e a espessura da shell é de $4.10 \AA$. A camada de solvente tem, em média, $12.0 \AA$. A distância entre amostra e detector é de $0.60 \mathrm{~m}$. 


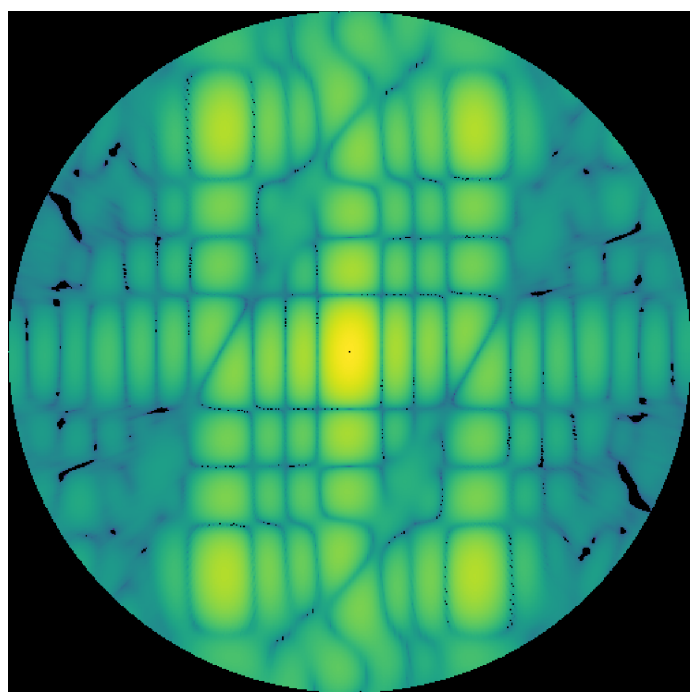

(a) Espalhamento.

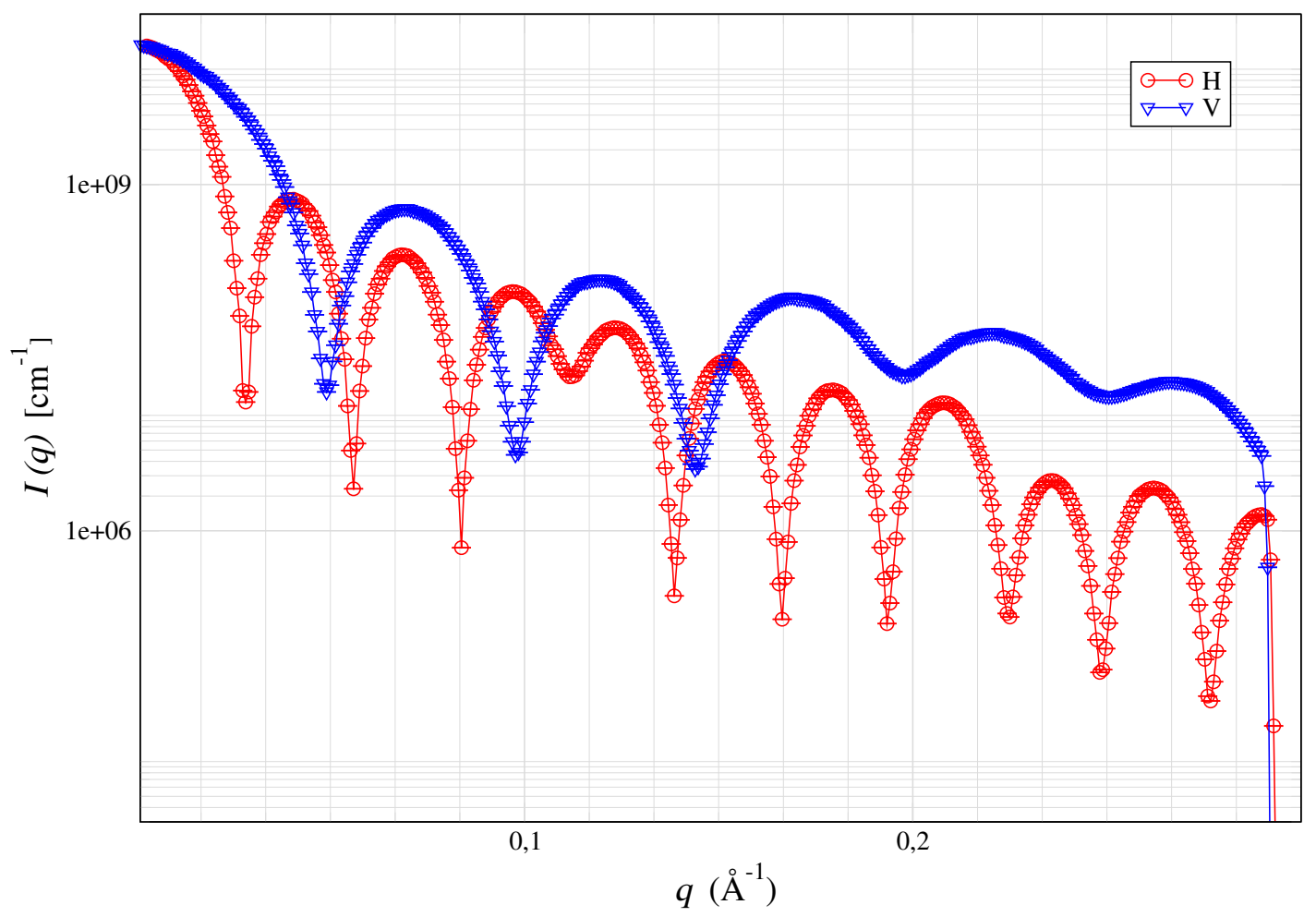

(b) Integrações em torno da horizontal $(\bigcirc)$ e da vertical $(\triangle)$.

Figura A.8. Simulação de SAXS de um conjunto de $4 \times 4 \times 4$ estruturas micelares, em rede cúbica de corpo centrado. Cada micela tem 2000 pontos de espalhamento (128000 no total). O campo H encontra-se na direção perpendicular ao feixe de raios X incidente. Os eixos maiores das micelas têm $45.0 \AA \times 35.0 \AA \times 20.0 \AA$ (modelo IBM), simulando a fase $N c$, e a espessura da shell é de $4.10 \AA$. A camada de solvente tem, em média, $12.0 \AA$. A distância entre amostra e detector é de $0.60 \mathrm{~m}$. 


\section{A.1.4 Rede cúbica de corpo centrado com dispersões gaussianas}

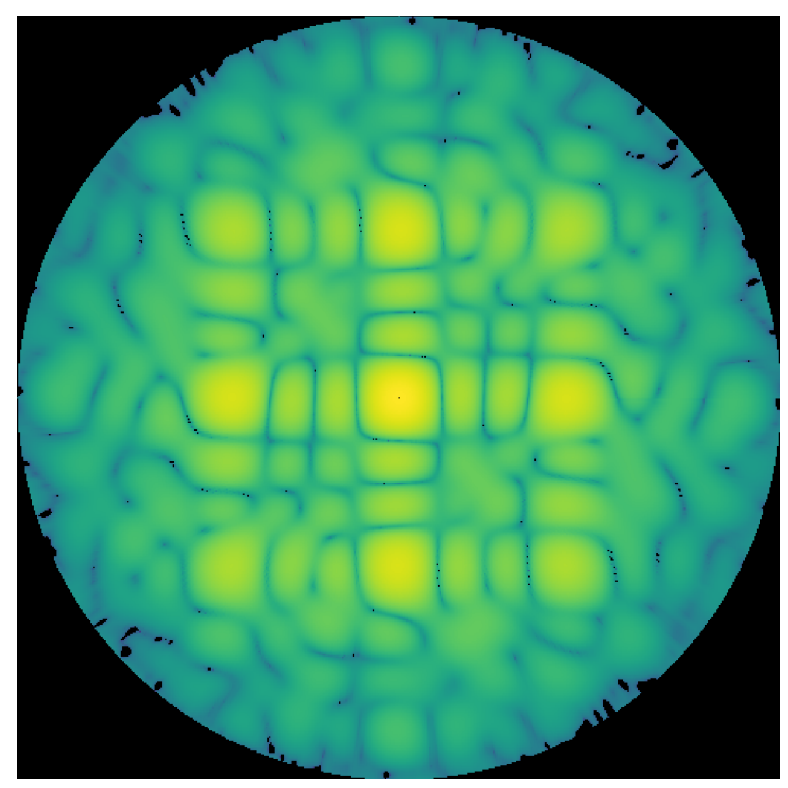

(a) Espalhamento.

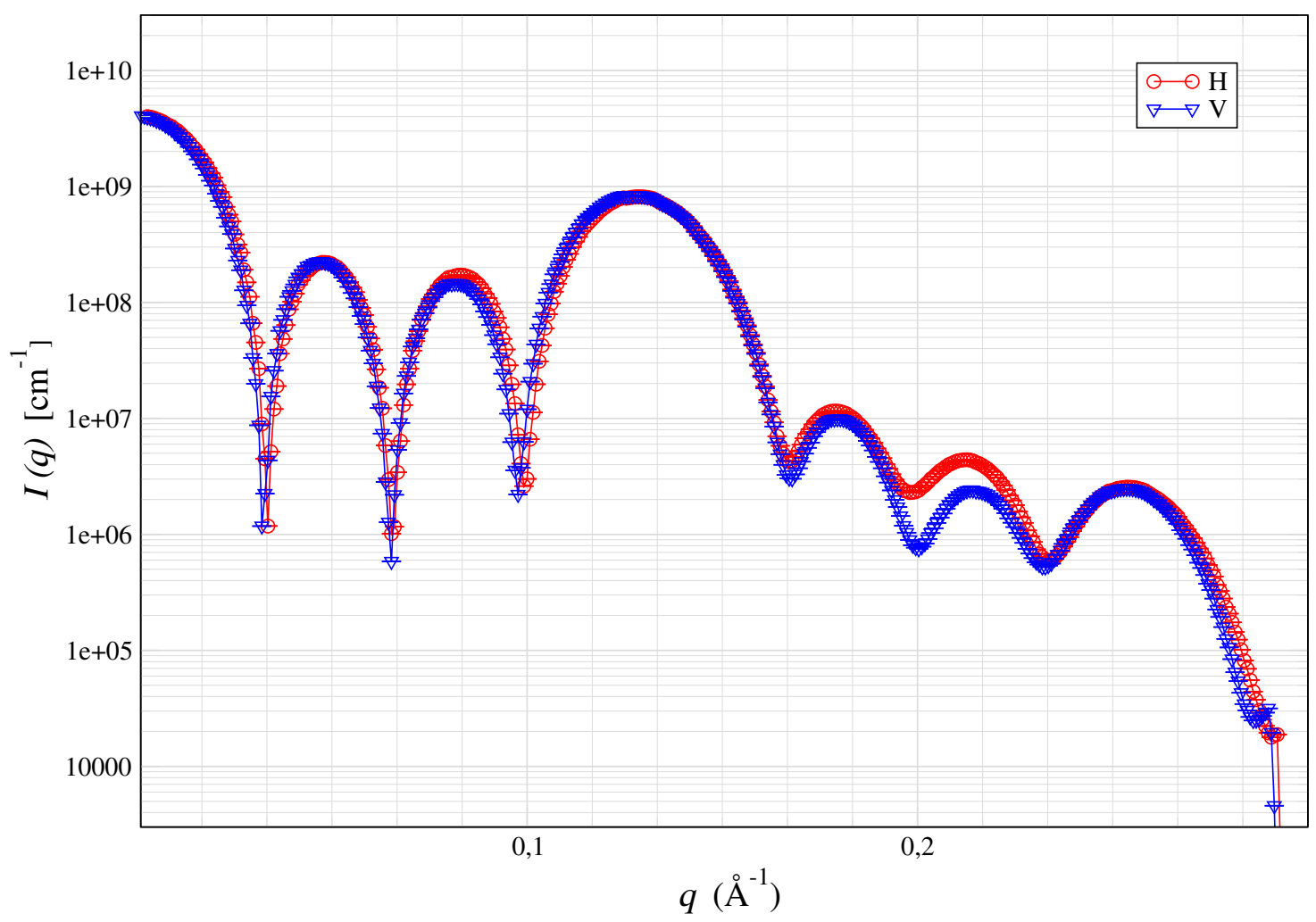

(b) Integrações em torno da horizontal $(\bigcirc)$ e da vertical $(\nabla)$.

Figura A.9. Espalhamento das estruturas da figura 4.17 e integração azimutal da imagem em ângulos de $30^{\circ}$ em torno da horizontal e da vertical. 


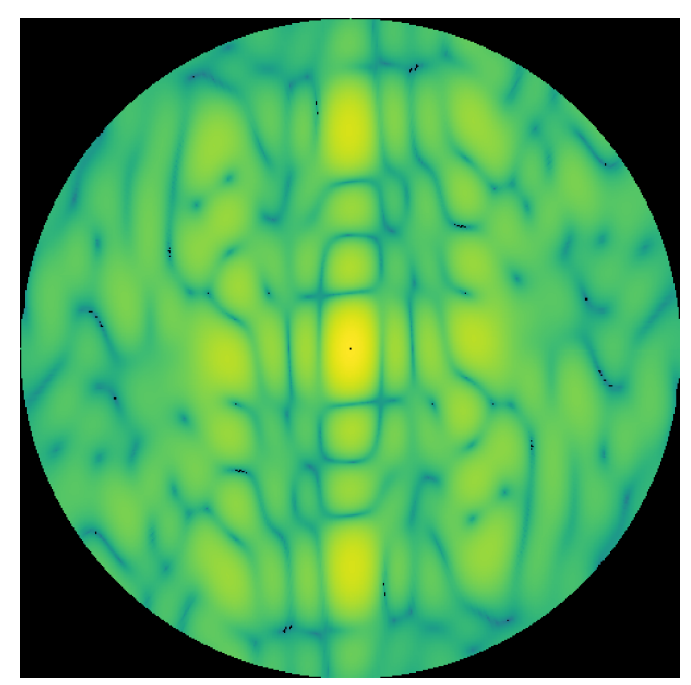

(a) Espalhamento.

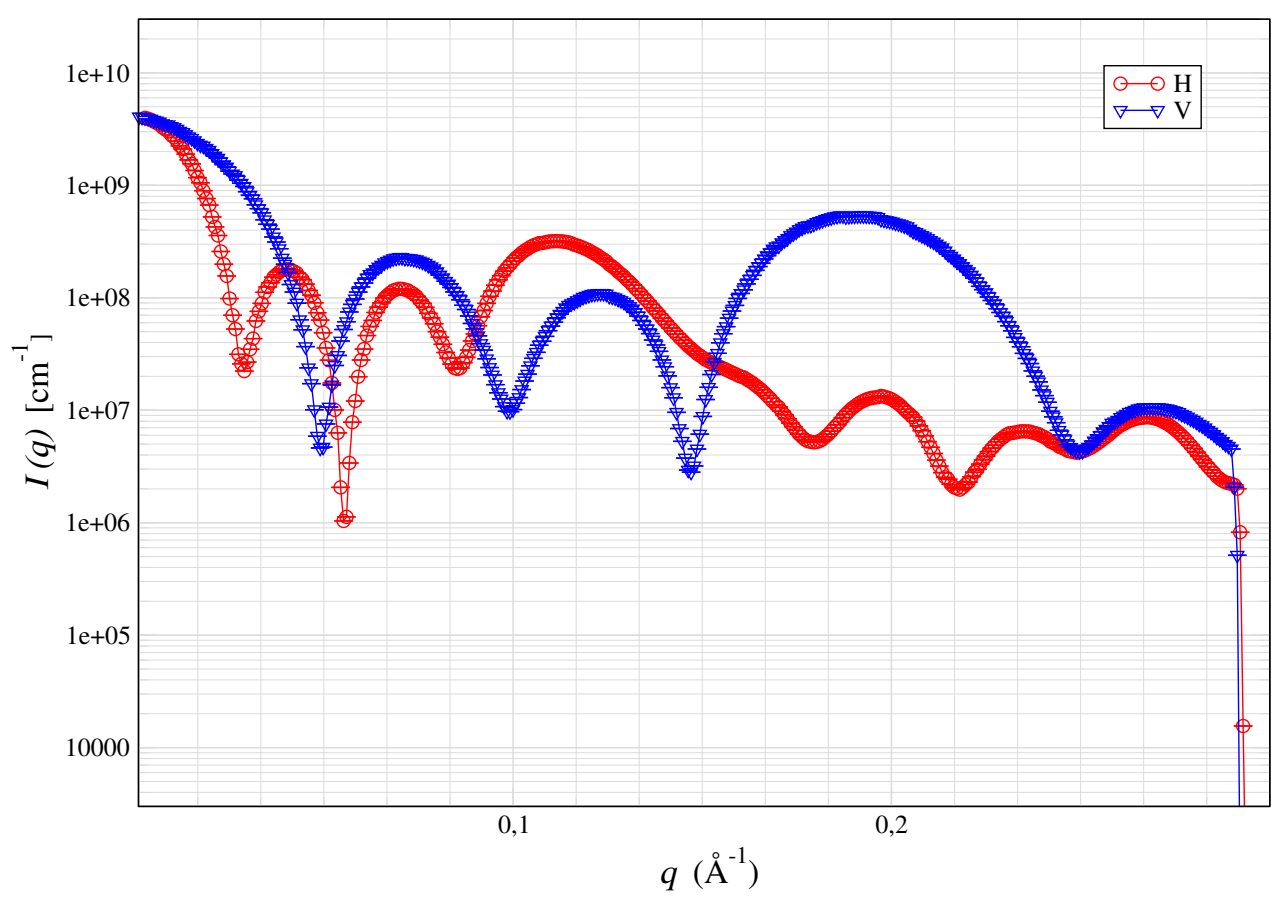

(b) Integrações em torno da horizontal $(\bigcirc)$ e da vertical $(\nabla)$.

Figura A.10. Simulação de SAXS de um conjunto de $4 \times 4 \times 4$ estruturas micelares, em rede com pequenos deslocamentos gaussianos, predominantemente na direção y $\left(\sigma_{x}=0.2, \sigma_{y}=2.0, \sigma_{z}=\right.$ 0.2). Cada micela tem 1000 pontos de espalhamento (64000 no total). O campo $\mathrm{H}$ encontra-se na direção paralela ao feixe de raios X incidente. Os eixos maiores das micelas têm $35.0 \AA \times 45.0 \AA \times$ $20.0 \AA$ (modelo IBM), simulando a fase $N c$, e a espessura da shell é de $4.10 \AA$. A camada de solvente tem, em média, 12.0Å. A distância entre amostra e detector é de $0.60 \mathrm{~m}$.

\section{A.1.5 Rede cúbica de corpo centrado com dispersões gaussianas}

Neste grupo, parece haver uma imposição muito incisiva das dispersões, de modo a se descaracterizar a ordem orientacional. Alguns picos são preservados na diagonal, acompa- 
nhando a mudança na estrutura geral da geometria.

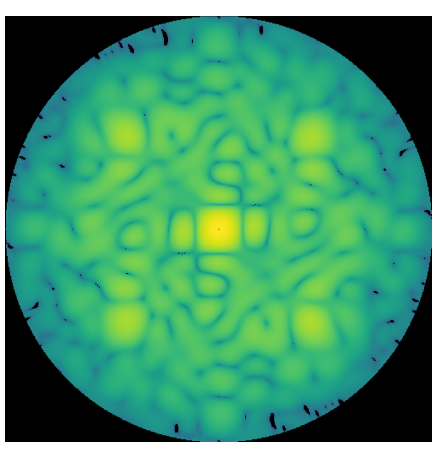

(a) Espalhamento.

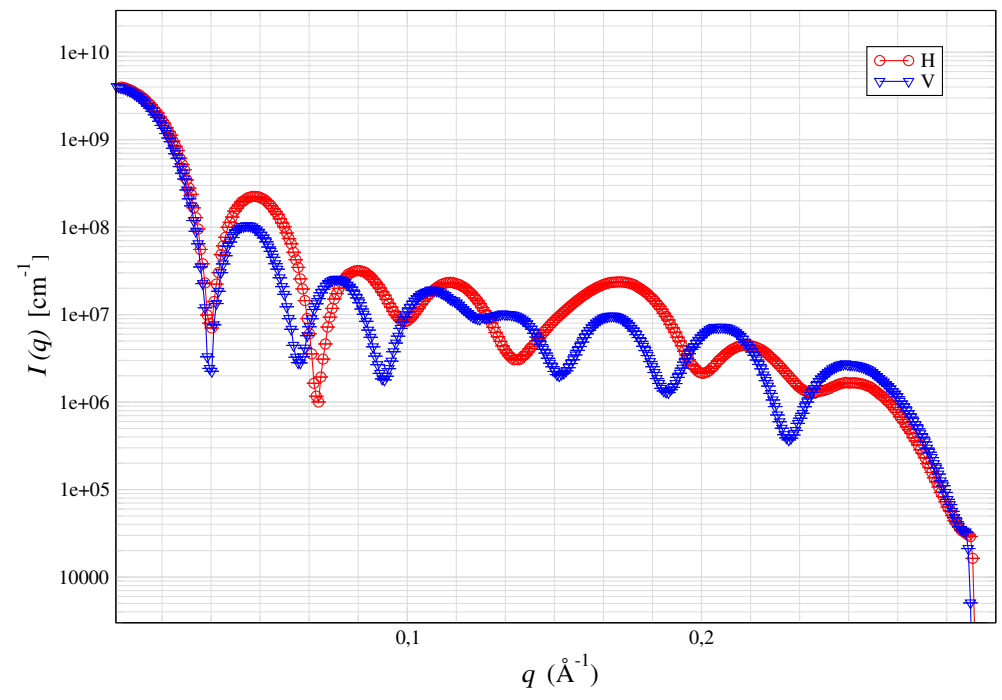

(b) Integrações em torno da horizontal $(\bigcirc)$ e da vertical $(\triangle)$.

Figura A.11. Simulação de SAXS de um conjunto de $4 \times 4 \times 4$ estruturas micelares, em rede cúbica de corpo centrado com pequenos deslocamentos gaussianos $\left(\sigma_{x}=0.5, \sigma_{y}=2.0, \sigma_{z}=0.5\right)$. Cada micela tem 1000 pontos de espalhamento (64000 no total). O campo H encontra-se na direção paralela ao feixe de raios X incidente. Os eixos maiores das micelas têm $35.0 \AA \times 45.0 \AA \times 35.0 \AA$ (modelo uniaxial), simulando a fase $N c$, e a espessura da shell é de $4.10 \AA$. A camada de solvente tem, em média, 12.0Å. A distância entre amostra e detector é de $0.60 \mathrm{~m}$. 


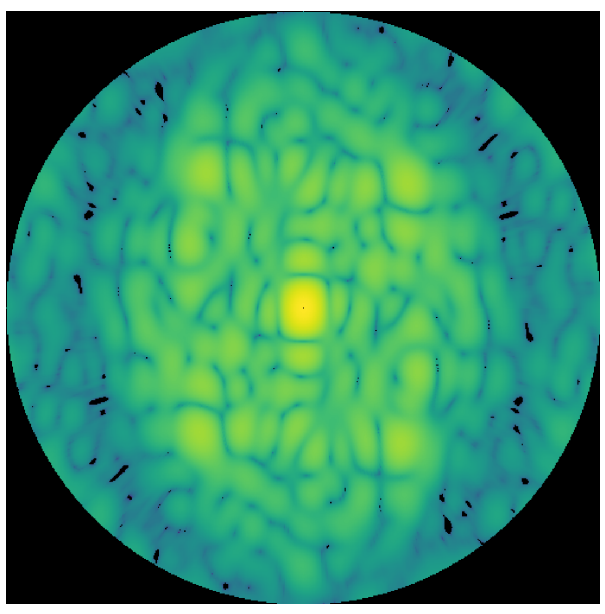

(a) Espalhamento.

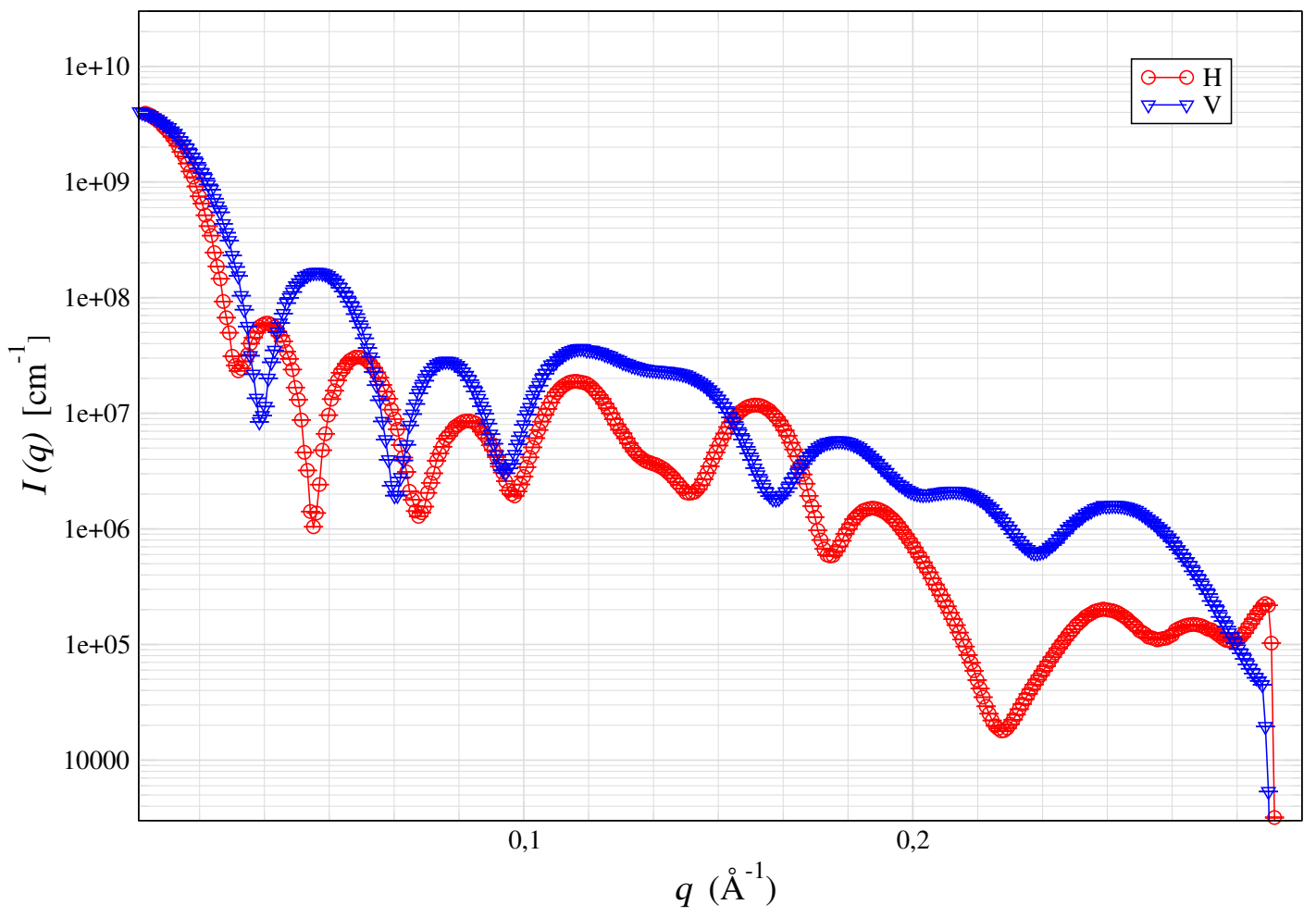

(b) Integrações em torno da horizontal $(\bigcirc)$ e da vertical $(\nabla)$.

Figura A.12. Simulação de SAXS de um conjunto de $4 \times 4 \times 4$ estruturas micelares, em rede cúbica de corpo centrado com pequenos deslocamentos gaussianos $\left(\sigma_{x}=2.0, \sigma_{y}=0.5, \sigma_{z}=0.5\right)$. Cada micela tem 1000 pontos de espalhamento (64000 no total). O campo H encontra-se na direção perpendicular ao feixe de raios $\mathrm{X}$ incidente. Os eixos maiores das micelas têm $45.0 \AA \times 35.0 \AA \times$ $35.0 \AA$ (modelo uniaxial), simulando a fase $N c$, e a espessura da shell é de $4.10 \AA$. A camada de solvente tem, em média, $12.0 \AA$. A distância entre amostra e detector é de $0.60 \mathrm{~m}$. 


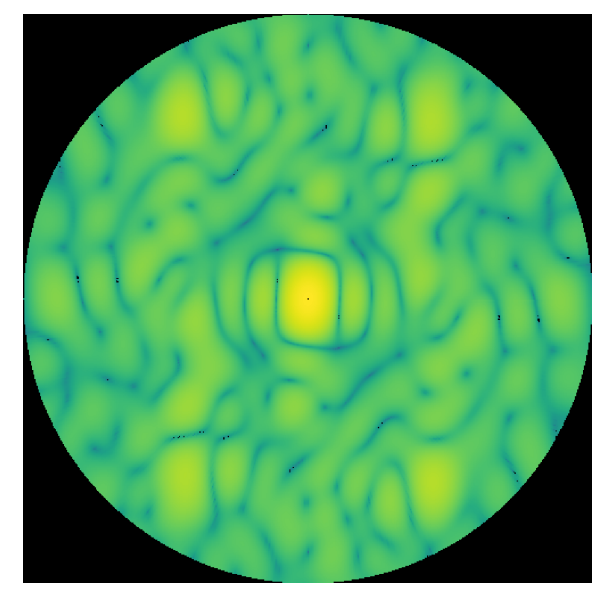

(a) Espalhamento.

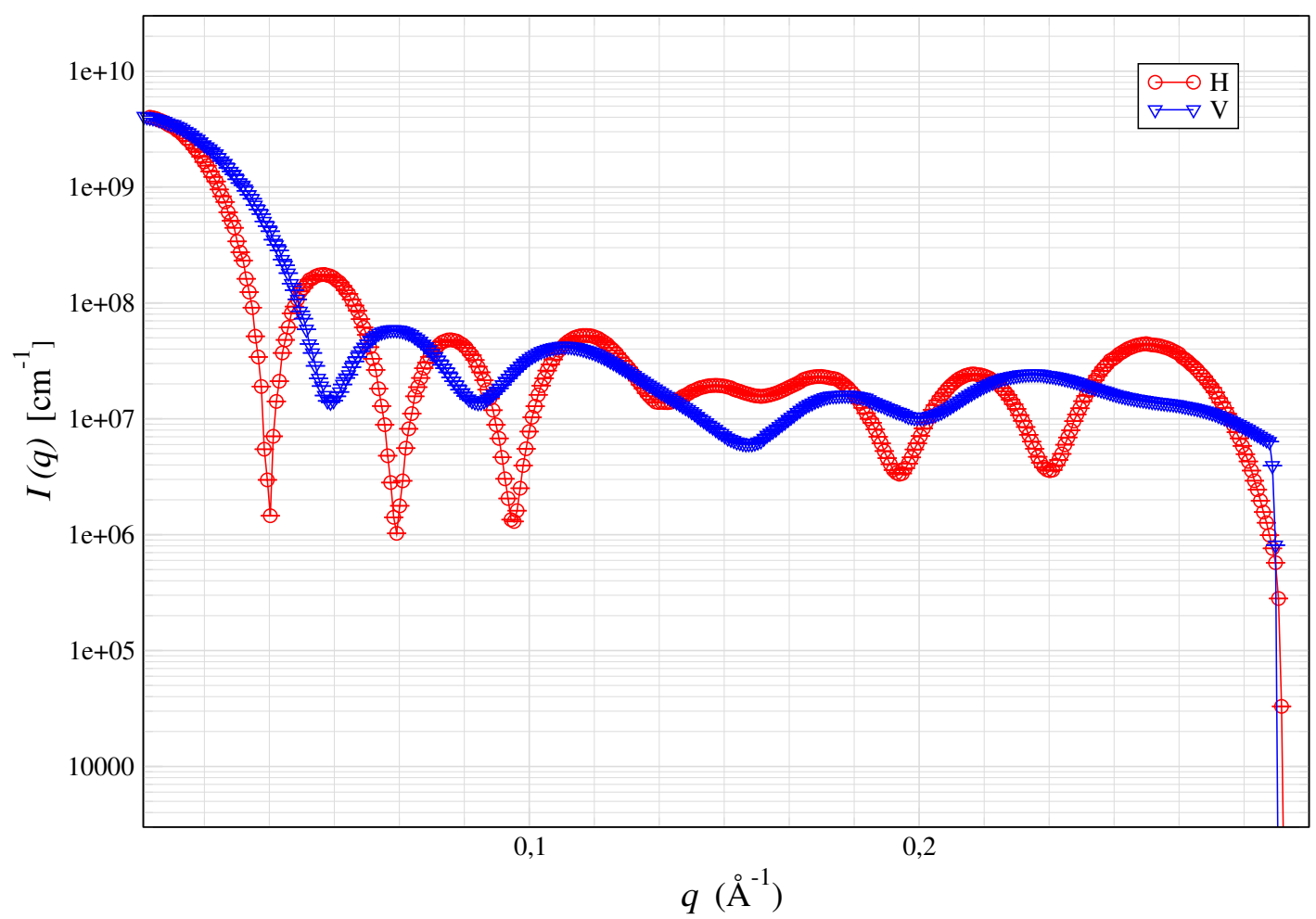

(b) Integrações em torno da horizontal $(\bigcirc)$ e da vertical $(\triangle)$.

Figura A.13. Simulação de SAXS de um conjunto de $4 \times 4 \times 4$ estruturas micelares, em rede cúbica de corpo centrado com pequenos deslocamentos gaussianos $\left(\sigma_{x}=0.5, \sigma_{y}=2.0, \sigma_{z}=0.5\right)$. Cada micela tem 1000 pontos de espalhamento (64000 no total). O campo H encontra-se na direção paralela ao feixe de raios $X$ incidente. Os eixos maiores das micelas têm $35.0 \AA \times 45.0 \AA \times 20.0 \AA$ (modelo IBM), simulando a fase $N c$, e a espessura da shell é de $4.10 \AA$. A camada de solvente tem, em média, 12.0^. A distância entre amostra e detector é de $0.60 \mathrm{~m}$. 


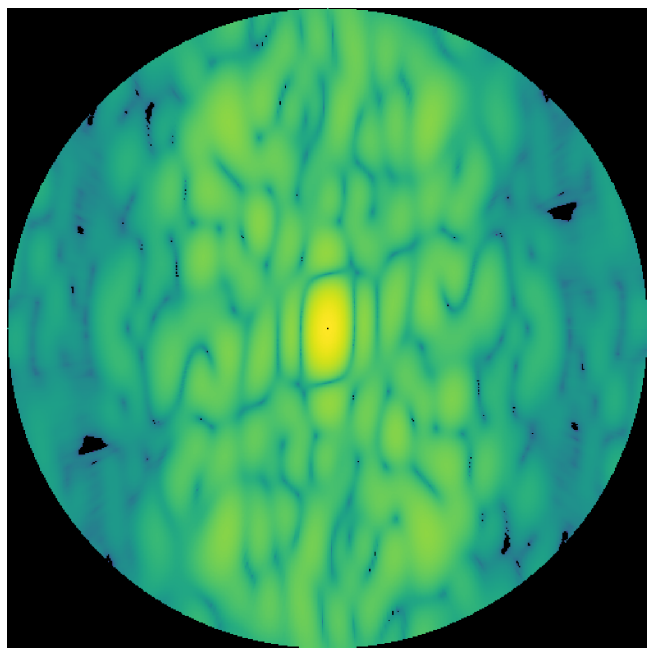

(a) Espalhamento.

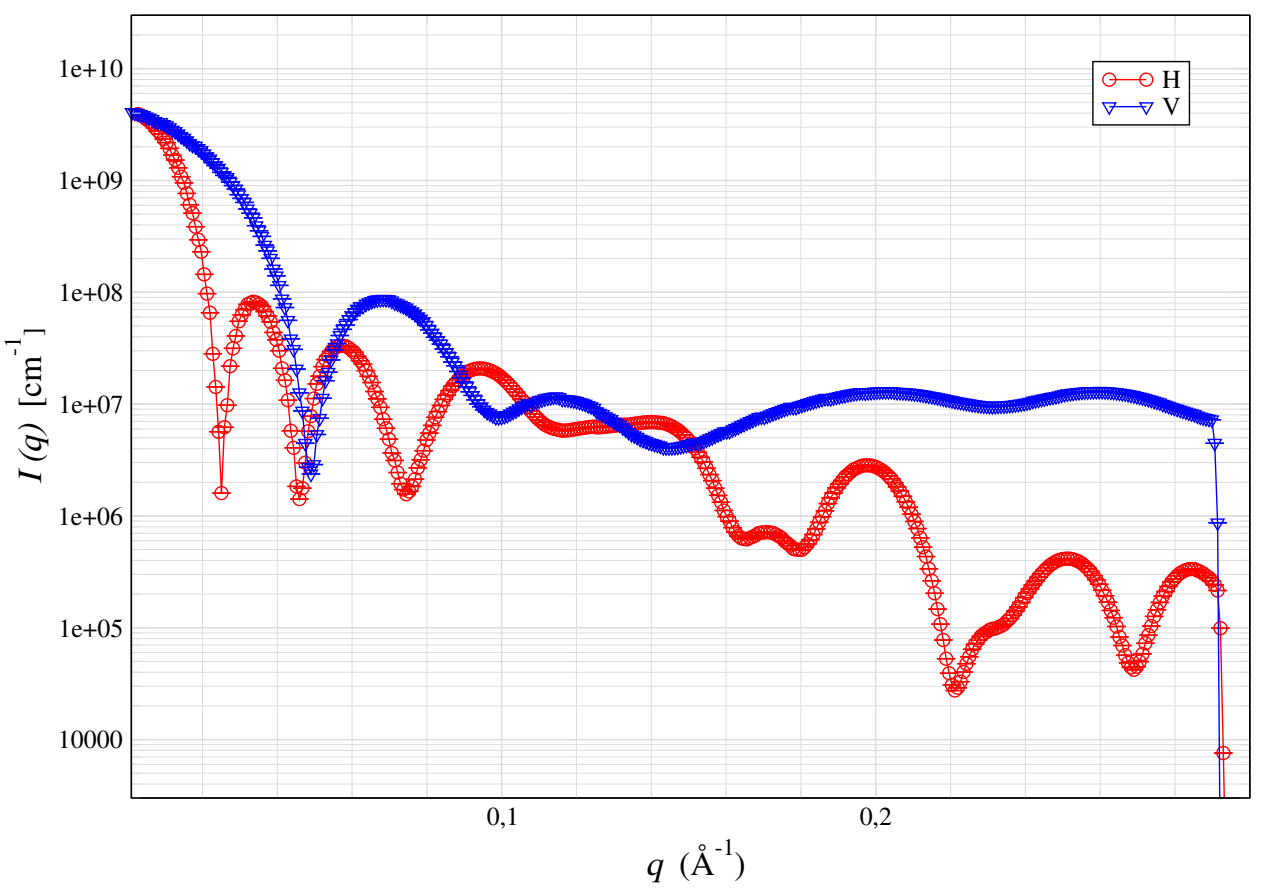

(b) Integrações em torno da horizontal $(\bigcirc)$ e da vertical $(\nabla)$.

Figura A.14. Simulação de SAXS de um conjunto de $4 \times 4 \times 4$ estruturas micelares, em rede cúbica de corpo centrado com pequenos deslocamentos gaussianos $\left(\sigma_{x}=2.0, \sigma_{y}=0.5, \sigma_{z}=0.5\right)$. Cada micela tem 1000 pontos de espalhamento (64000 no total). O campo H encontra-se na direção perpendicular ao feixe de raios $\mathrm{X}$ incidente. Os eixos maiores das micelas têm $45.0 \AA \times 35.0 \AA \times$ $20.0 \AA$ (modelo IBM), simulando a fase $N c$, e a espessura da shell é de $4.10 \AA$. A camada de solvente tem, em média, $12.0 \AA$ A A distância entre amostra e detector é de $0.60 \mathrm{~m}$. 


\section{A.1.6 Camadas rotacionadas em torno do eixo $y$}

Aqui implementou-se um método alternativo, em que a construção do conjunto de micelas se deu por camadas. Assim, tomou-se um grupo quadrado $(4 \times 4)$ de micelas e se aplicou uma rotação rígida no conjunto de um ângulo dado $\psi$ em torno do eixo $y$, ao mesmo tempo que se rotacionou cada micela no sentido contrário, $-\psi$, de modo a preservar-se a orientação da micela. O mesmo processo é repetido para camada ao longo do eixo $y$ (seção 2.5.1.1). Aqui, mais uma vez, a tentativa de se dar mais graus de liberdade às micelas implicou grande perda de ordem. Um exame mais detido da configuração das estruturas mostra que as rotações efetuadas acabavam por criar distâncias arbitrárias entre as fileiras de micelas de camadas distintas, o que implica interferências destrutivas arbitrárias. E, no entanto, em alguns casos passa-se a ter o padrão de imagem de redes quadradas rotacionadas e superpostas. É possível que em uma rede com mais micelas se consiga um padrão mais simétrico, como esperado no caso do espalhamento na direção paralela ao campo na fase $N_{C}$. 


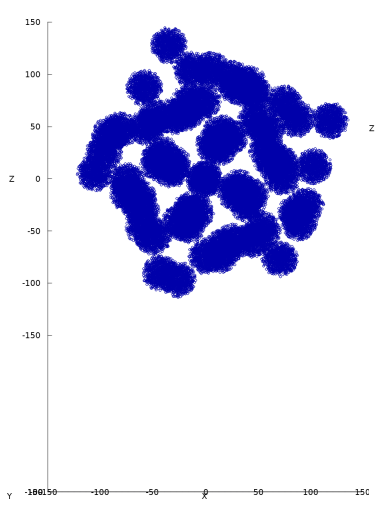

(a) Plano $x z$ e perspectiva.

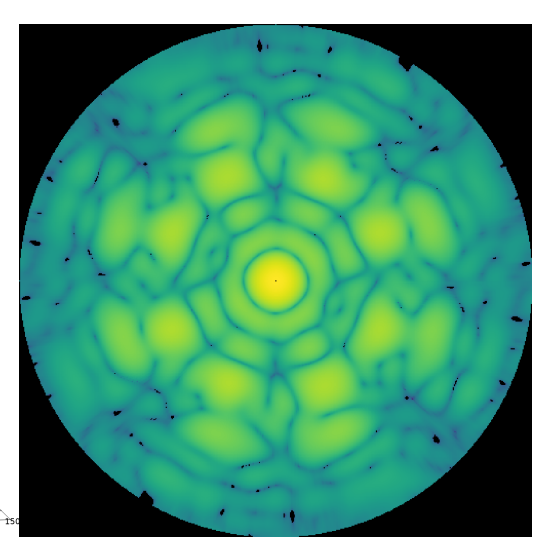

(b) Espalhamento.

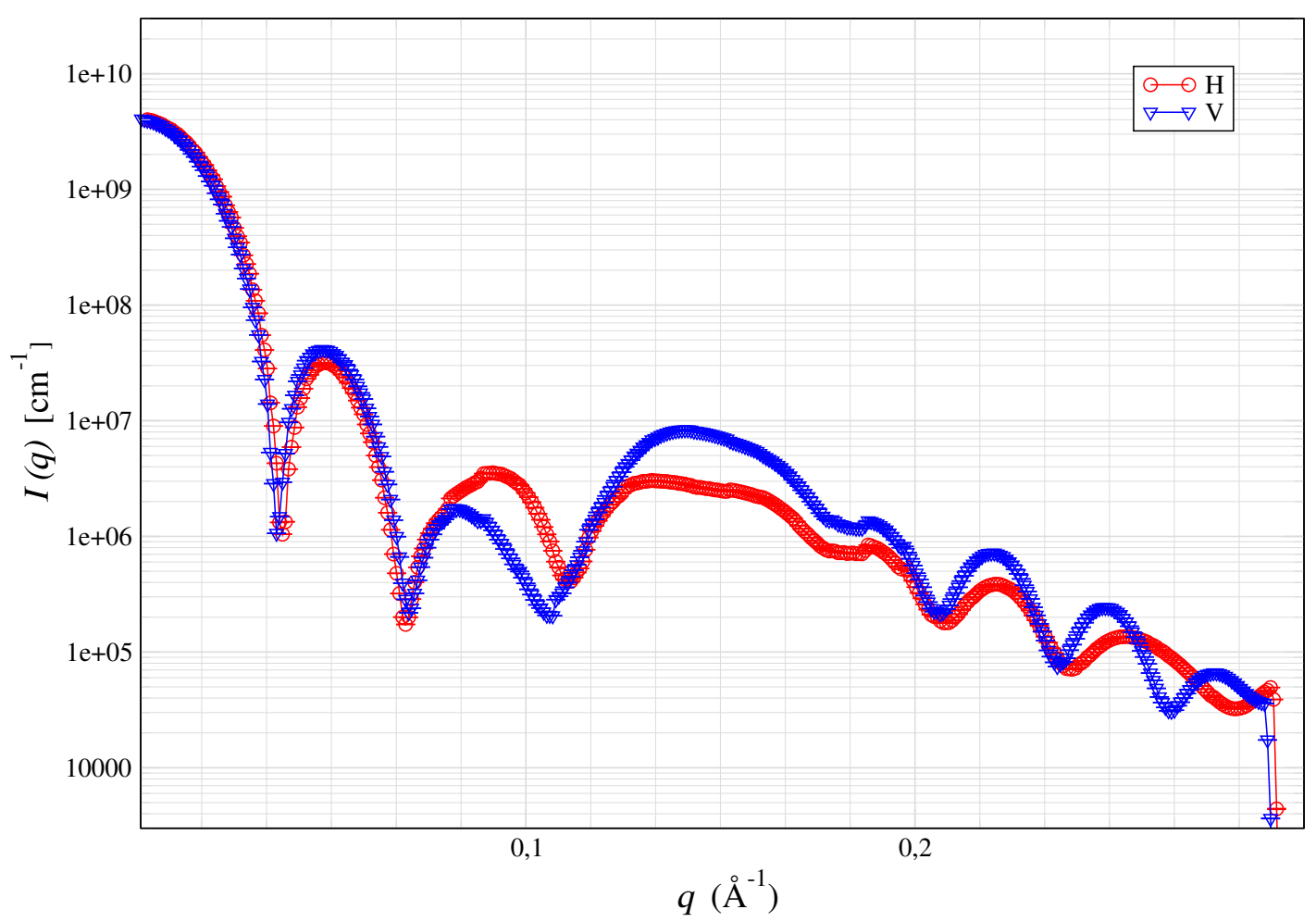

(c) Integrações em torno da horizontal $(\bigcirc)$ e da vertical $(\triangle)$.

Figura A.15. Simulação de SAXS de um conjunto de $4 \times 4 \times 4$ estruturas micelares, em rede. Cada micela tem 1000 pontos de espalhamento (64000 no total). O campo H encontra-se na direção paralela ao feixe de raios X incidente. Os eixos maiores das micelas têm $35.0 \AA \times 45.0 \AA \times 35.0 \AA$ (modelo uniaxial), simulando a fase $N c$, e a espessura da shell é de $4.10 \AA$. A camada de solvente tem, em média, 12.0A. Foram efetuadas rotações sucessivas de $40^{\circ}$ em torno do eixo $y$ em cada camada $x z$ das micelas. A distância entre amostra e detector é de $0.60 \mathrm{~m}$. 


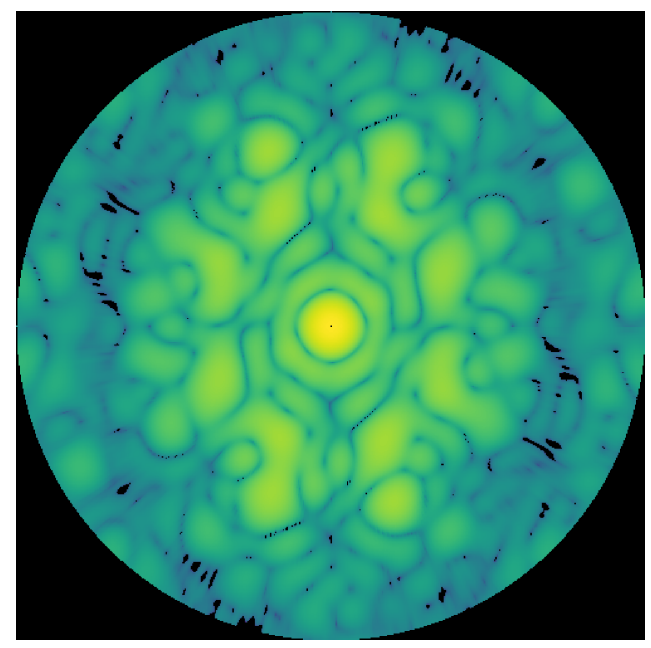

(a) Espalhamento.

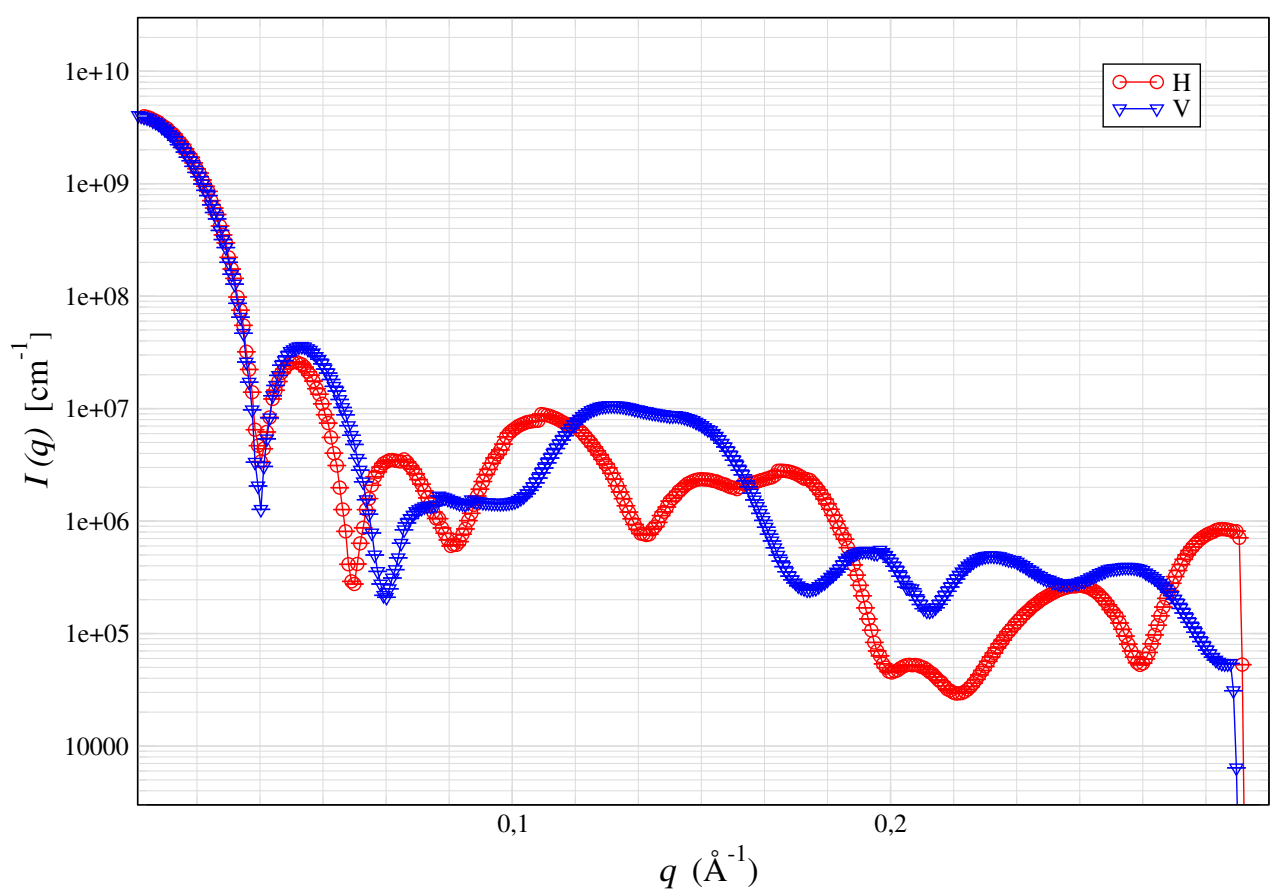

(b) Integrações em torno da horizontal $(\bigcirc)$ e da vertical $(\nabla)$.

Figura A.16. Simulação de SAXS de um conjunto de $4 \times 4 \times 4$ estruturas micelares, em rede . Cada micela tem 1000 pontos de espalhamento (64000 no total). O campo H encontra-se na direção perpendicular ao feixe de raios X incidente. Os eixos maiores das micelas têm $45.0 \AA \times 35.0 \AA \times$ $35.0 \AA$ (modelo uniaxial), simulando a fase $N c$, e a espessura da shell é de $4.10 \AA$. A camada de solvente tem, em média, 12.0A. Foram efetuadas rotações sucessivas de $40^{\circ}$ em torno do eixo $y$ em cada camada $x z$ das micelas. A distância entre amostra e detector é de $0.60 \mathrm{~m}$. 


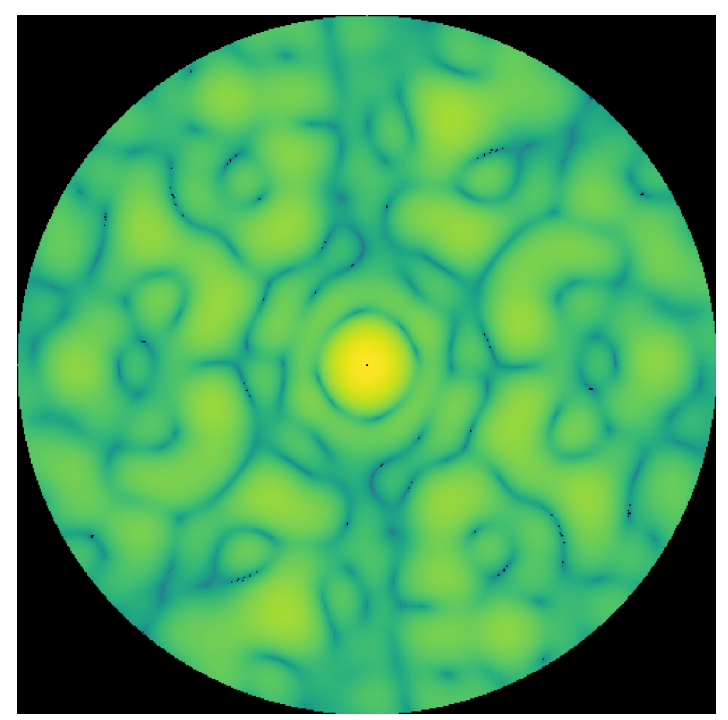

(a) Espalhamento.

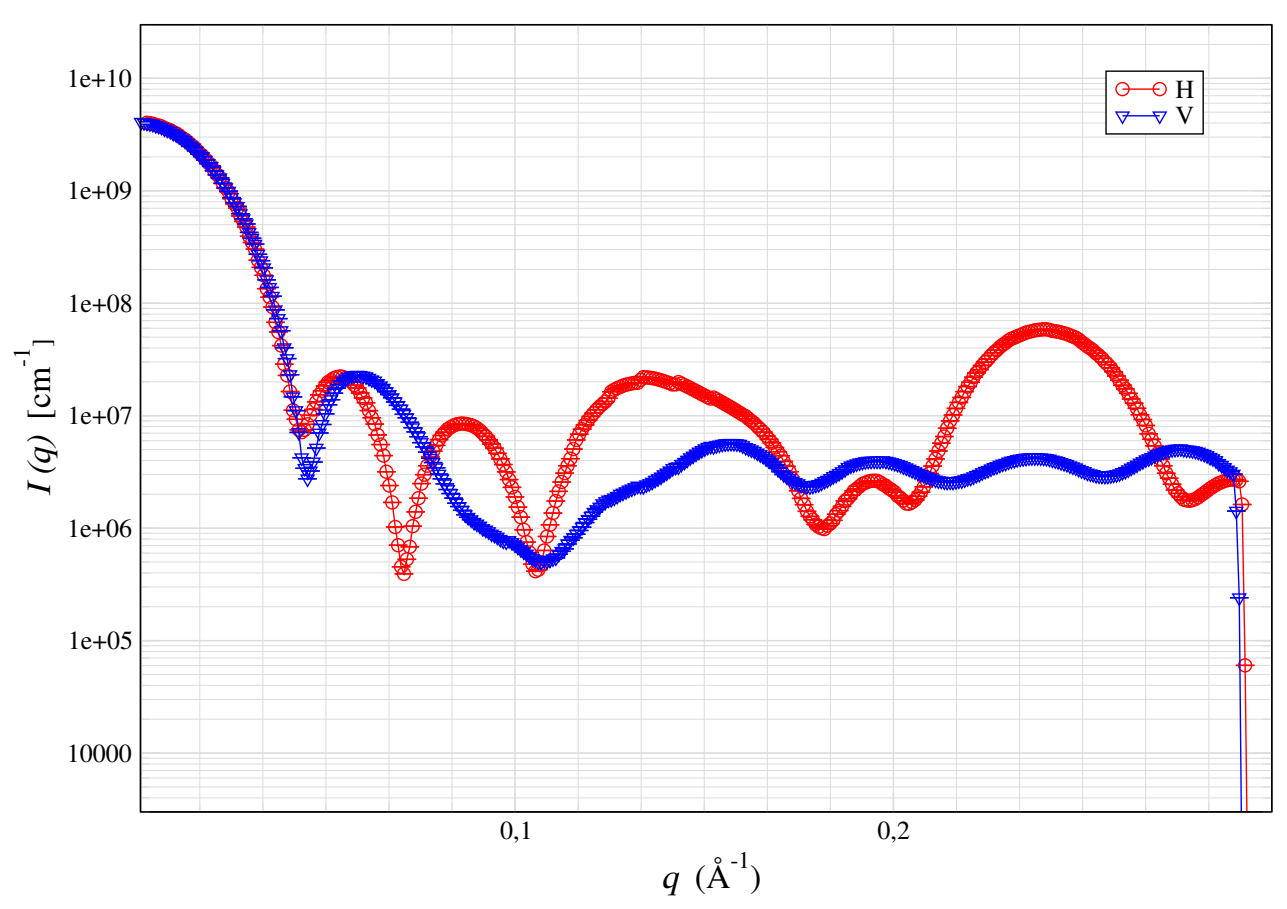

(b) Integrações em torno da horizontal $(\bigcirc)$ e da vertical $(\triangle)$.

Figura A.17. Simulação de SAXS de um conjunto de $4 \times 4 \times 4$ estruturas micelares, em rede . Cada micela tem 1000 pontos de espalhamento (64000 no total). O campo H encontra-se na direção paralela ao feixe de raios $X$ incidente. Os eixos maiores das micelas têm $35.0 \AA \times 45.0 \AA \times 20.0 \AA$ (modelo IBM), simulando a fase $N c$, e a espessura da shell é de $4.10 \AA$. A camada de solvente tem, em média, 12.0A. Foram efetuadas rotações sucessivas de $40^{\circ} \mathrm{em}$ torno do eixo $y$ em cada camada $x z$ das micelas. A distância entre amostra e detector é de $0.60 \mathrm{~m}$. 


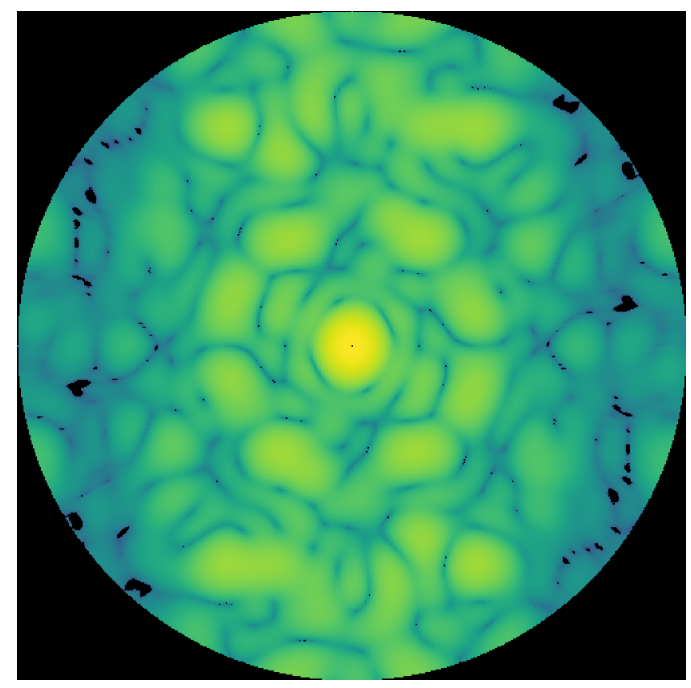

(a) Espalhamento.

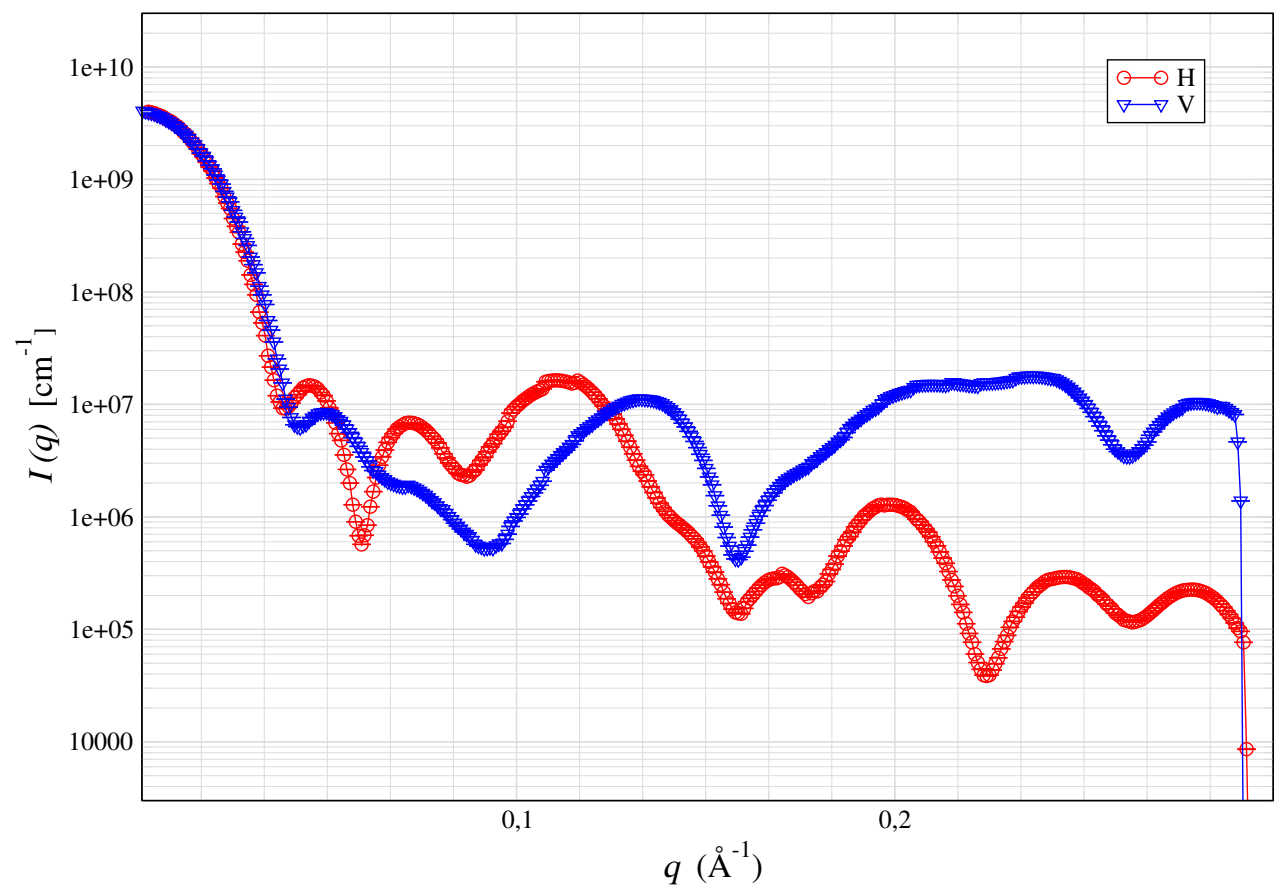

(b) Integrações em torno da horizontal $(\bigcirc)$ e da vertical $(\nabla)$.

Figura A.18. Simulação de SAXS de um conjunto de $4 \times 4 \times 4$ estruturas micelares, em rede . Cada micela tem 1000 pontos de espalhamento (64000 no total). O campo H encontra-se na direção perpendicular ao feixe de raios $\mathrm{X}$ incidente. Os eixos maiores das micelas têm $45.0 \AA \times 35.0 \AA \times$ $20.0 \AA$ (modelo IBM), simulando a fase $N c$, e a espessura da shell é de $4.10 \AA$. A camada de solvente tem, em média, 12.0Å. Foram efetuadas rotações sucessivas de $40^{\circ} \mathrm{em}$ torno do eixo $y$ em cada camada $x z$ das micelas. A distância entre amostra e detector é de $0.60 \mathrm{~m}$. 


\section{A.1.7 Camadas rotacionadas em torno do eixo $y$, com dispersões}

Este caso intensifica os efeitos obtidos na seção anterior. Os padrões de interferência são difusos e tendem a aplainar as curvas. Deve procurar-se uma configuração que não seja tão destrutiva e preserve alguma regularidade na direção em que se espera ordem.

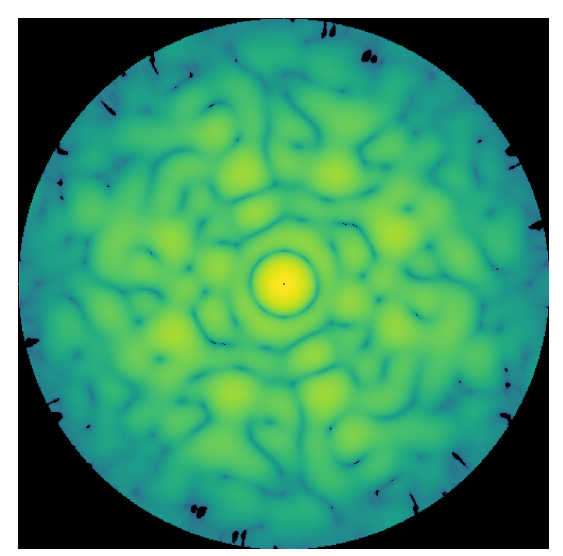

(a) Espalhamento.

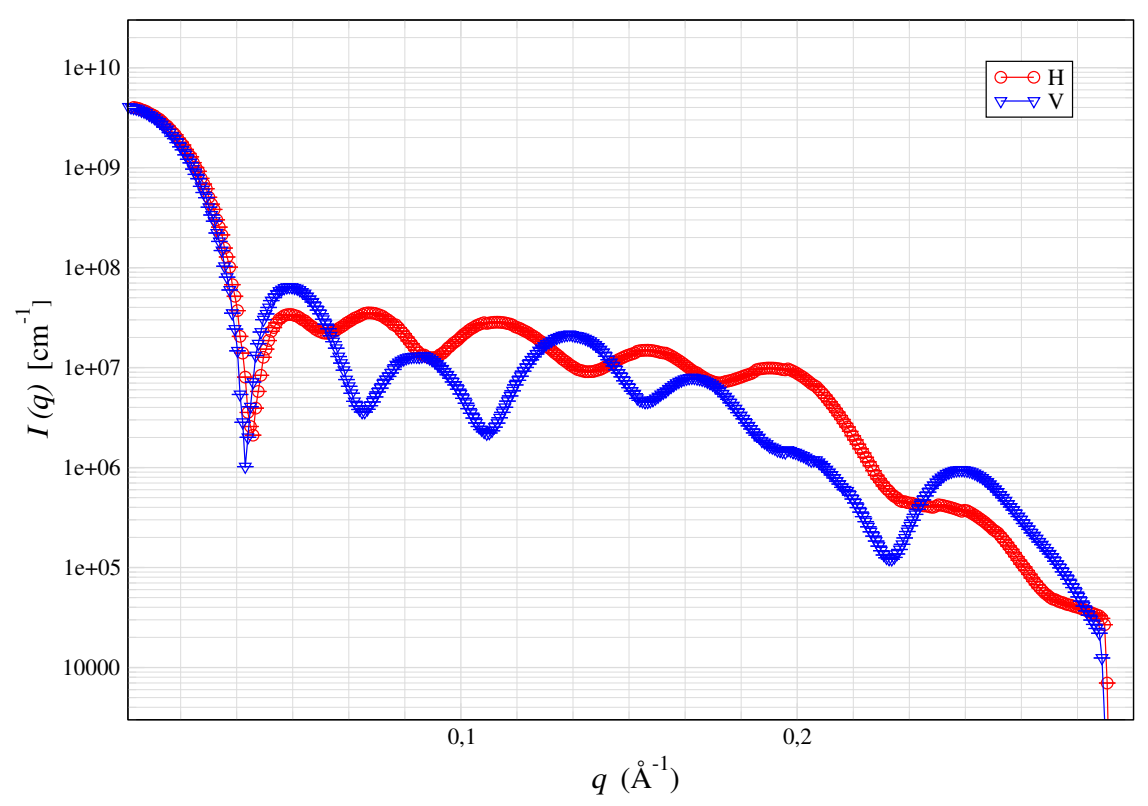

(b) Integrações em torno da horizontal $(\bigcirc)$ e da vertical $(\nabla)$.

Figura A.19. Simulação de SAXS de um conjunto de $4 \times 4 \times 4$ estruturas micelares, em rede com pequenos deslocamentos gaussianos. Cada micela tem 1000 pontos de espalhamento (64000 beads no total). O campo $\mathrm{H}$ encontra-se na direção paralela ao feixe de raios $\mathrm{X}$ incidente. Os eixos maiores das micelas têm $35.0 \AA \times 45.0 \AA \times 35.0 \AA$ (modelo uniaxial), simulando a fase $N c$, e a espessura da shell é de $4.10 \AA$. A camada de solvente tem, em média, $12.0 \AA$. Foram efetuadas rotações sucessivas de $40^{\circ} \mathrm{em}$ torno do eixo $y$ em cada camada $x z$ das micelas. A distância entre amostra e detector é de $0.60 \mathrm{~m}$. 


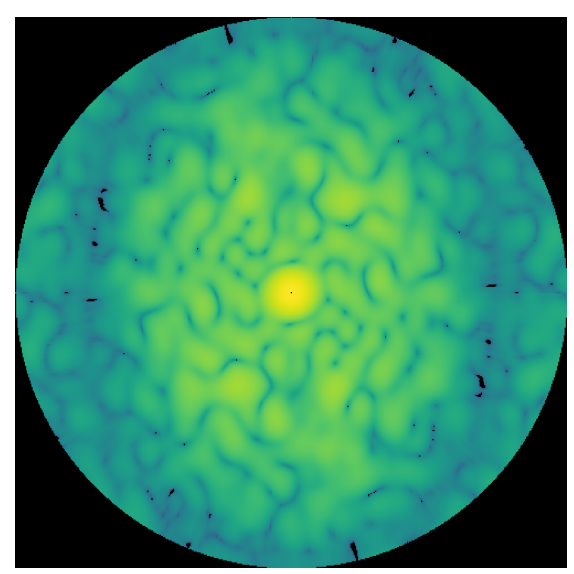

(a) Espalhamento.

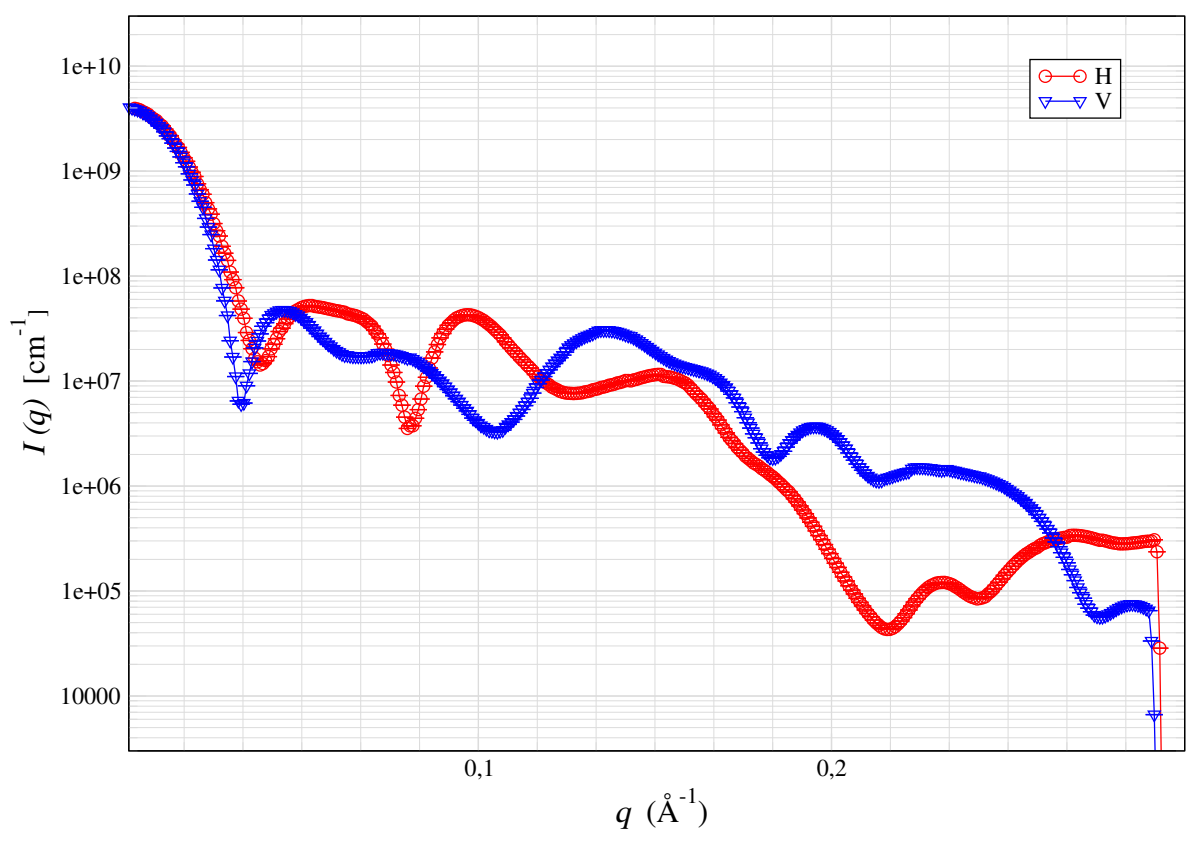

(b) Integrações em torno da horizontal $(\bigcirc)$ e da vertical $(\nabla)$.

Figura A.20. Simulação de SAXS de um conjunto de $4 \times 4 \times 4$ estruturas micelares, em rede com pequenos deslocamentos gaussianos. Cada micela tem 1000 pontos de espalhamento (64000 no total). O campo $\mathrm{H}$ encontra-se na direção perpendicular ao feixe de raios $\mathrm{X}$ incidente. Os eixos maiores das micelas têm $45.0 \AA \times 35.0 \AA \times 35.0 \AA$ (modelo uniaxial), simulando a fase $N c$, e a espessura da shell é de $4.10 \AA$. A camada de solvente tem, em média, 12.0^. Foram efetuadas rotações sucessivas de $40^{\circ}$ em torno do eixo $y$ em cada camada $x z$ das micelas. A distância entre amostra e detector é de $0.60 \mathrm{~m}$. 


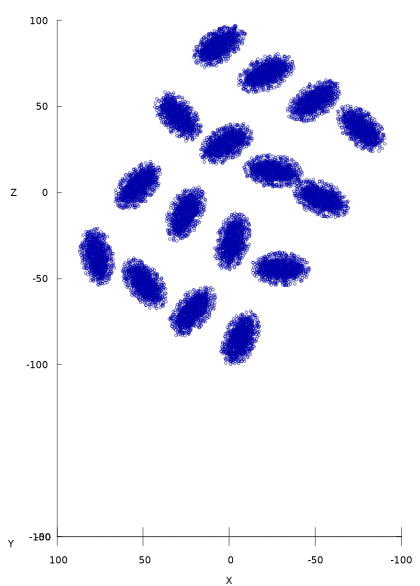

(a) Uma camada de micelas.

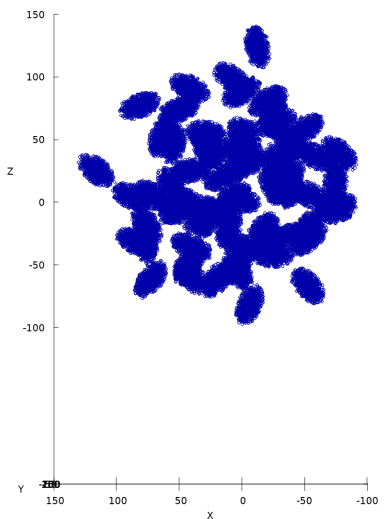

(b) Micelas dispersas, plano $x z$.

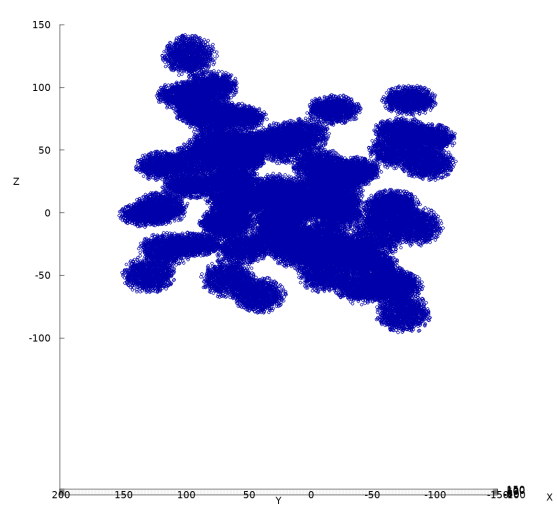

(c) Micelas, plano $y z$.

Figura A.21. Conjunto de $4 \times 4 \times 4$ estruturas micelares, em rede cúbica. Foram efetuados pequenas translações gaussianas e rotações arbitrárias, também gaussianas, em torno do eixo $y$. Cada micela tem 1000 pontos de espalhamento (64000 no total). O campo H encontra-se na direção paralela ao feixe de raios $\mathrm{X}$ incidente. Os eixos maiores das micelas têm $35.0 \AA \times 45.0 \AA \times 20.0 \AA$ (modelo IBM), simulando a fase $N c$, e a espessura da shell é de $4.10 \AA$. A camada de solvente tem, em média, 12.0Å. Foram efetuadas rotações sucessivas de $30^{\circ}$ em torno do eixo $y$ em cada camada $x z$ das micelas. 


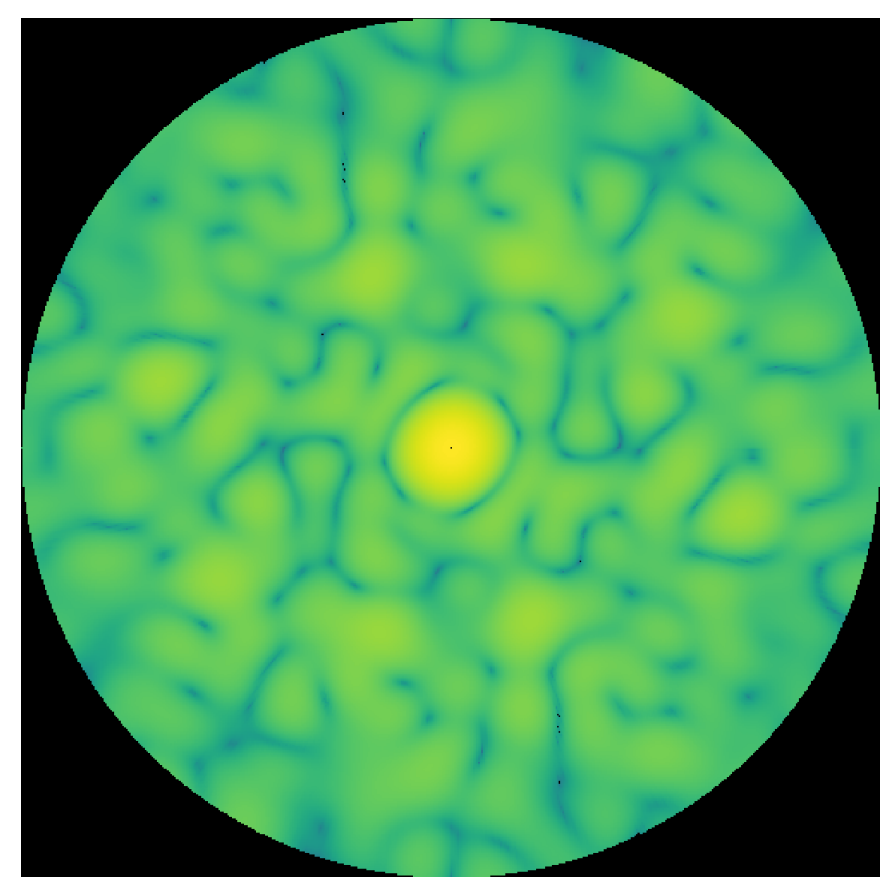

(a)

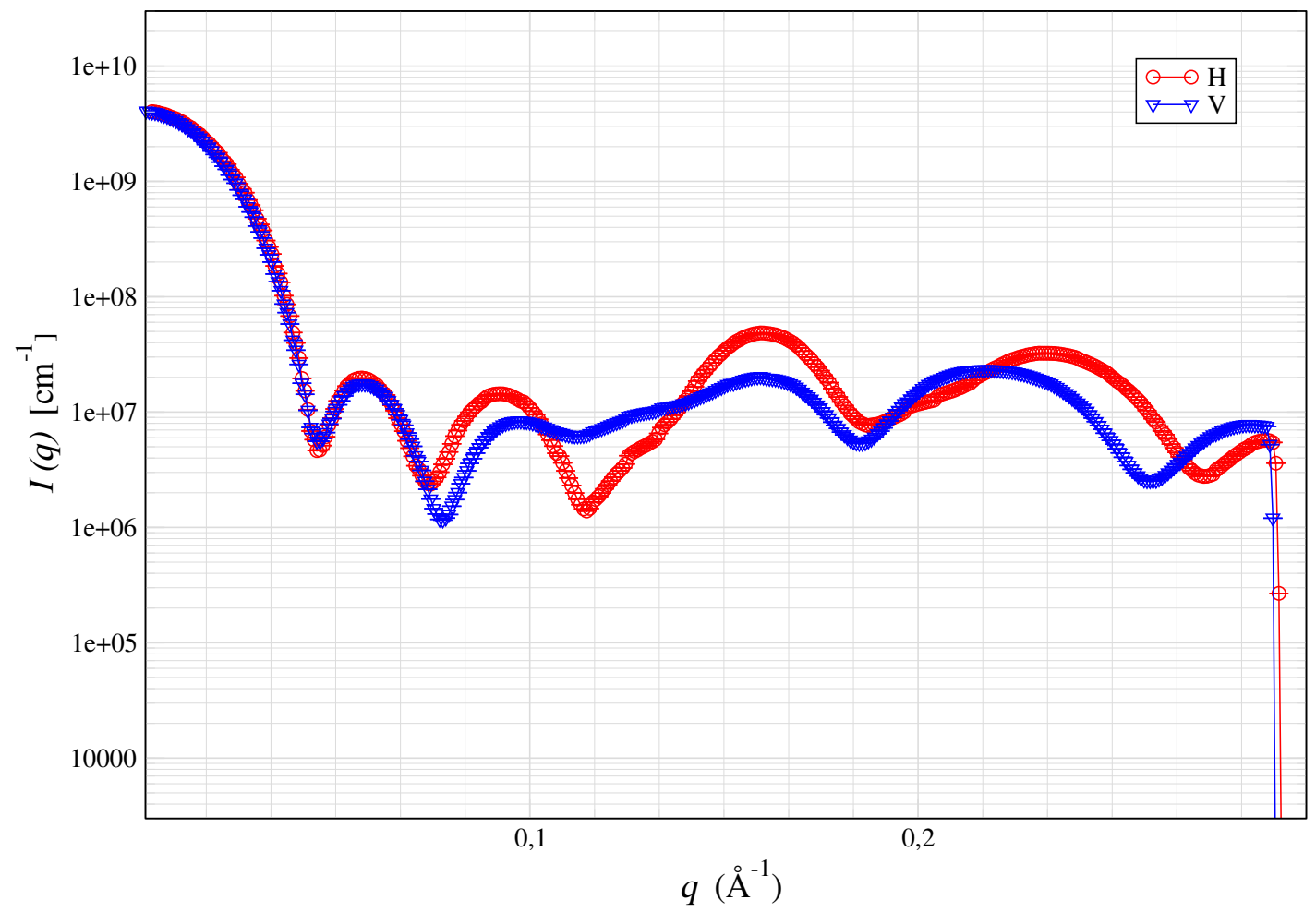

(b) Integrações em torno da horizontal $(\bigcirc)$ e da vertical $(\triangle)$.

Figura A.22. Simulação de SAXS do conjunto de micelas da figura A.21. A distância entre amostra e detector é de $0.60 \mathrm{~m}$. 


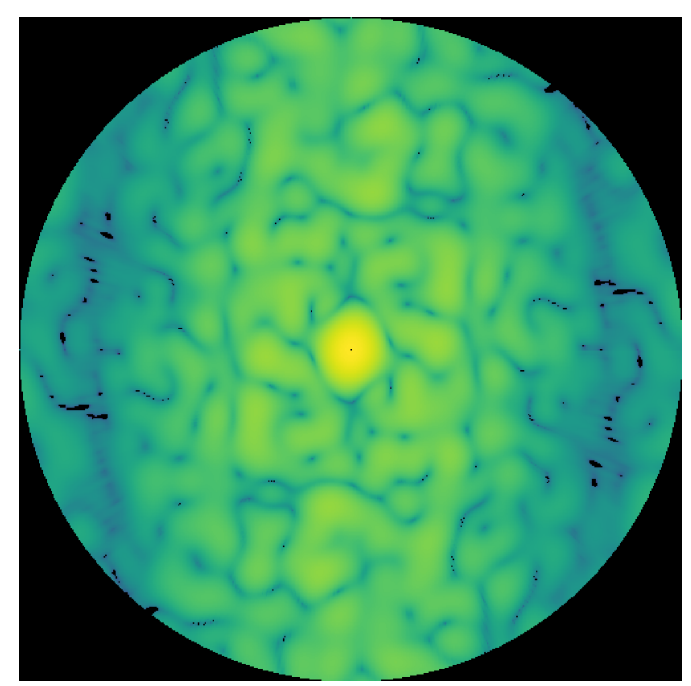

(a) Espalhamento.

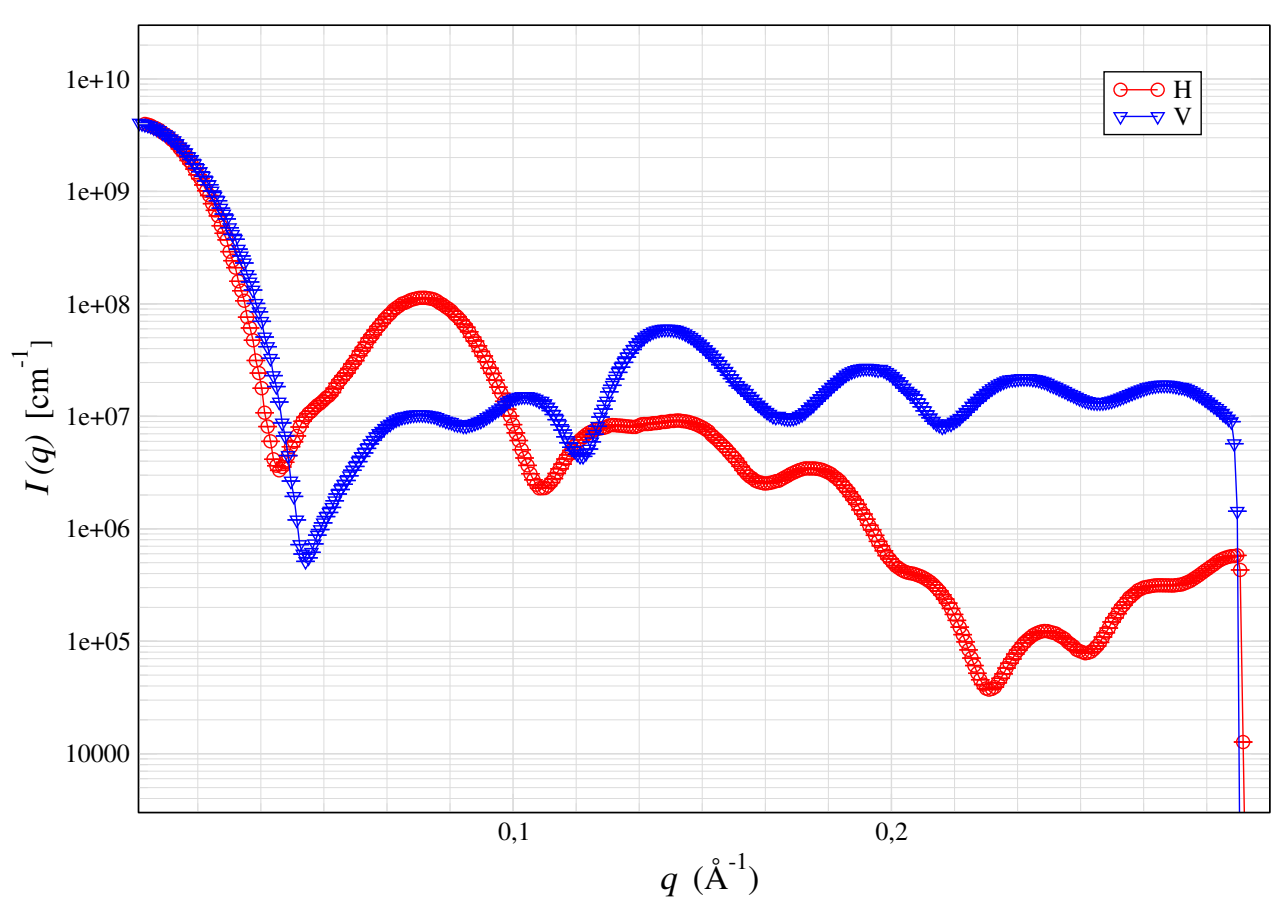

(b) Integrações em torno da horizontal $(\bigcirc)$ e da vertical $(\triangle)$.

Figura A.23. Simulação de SAXS de um conjunto de $4 \times 4 \times 4$ estruturas micelares, em rede com pequenos deslocamentos gaussianos. Cada micela tem 1000 pontos de espalhamento (64000 no total). O campo $\mathrm{H}$ encontra-se na direção perpendicular ao feixe de raios $\mathrm{X}$ incidente. Os eixos maiores das micelas têm $45.0 \AA \times 35.0 \AA \times 20.0 \AA$ (modelo IBM), simulando a fase $N c$, e a espessura da shell é de $4.10 \AA$. A camada de solvente tem, em média, 12.0 . Foram efetuadas rotações sucessivas de $40^{\circ} \mathrm{em}$ torno do eixo $y$ em cada camada $x z$ das micelas. A distância entre amostra e detector é de $0.60 \mathrm{~m}$. 


\section{Referências Bibliográficas}

[1] AM Figueiredo Neto, Y Galerne, AM Levelut, and L Liebert. Pseudo-lamellar ordering in uniaxial and biaxial lyotropic nematics : a synchrotron x-ray diffraction experiment. $J$. Phys. Lett.-Paris, 46(11):499-505, 1985.

[2] AM Figueiredo Neto and SRA Salinas. The Physics of Lyotropic Liquid Crystals. Oxford University Press, 2005.

[3] Y Galerne, AM Figueiredo-Neto, and L Liébert. Microscopical structure of the uniaxial and biaxial lyotropic nematics. J Chem Phys, 97(3):1851-1856, 1987.

[4] A Guinier and G Fournet. Small Angle Scattering of X-rays. John Wiley \& Sons, 1955.

[5] O Glatter. X-ray small angle scattering of molecules composed of subunits. Acta Phys. Aust., 36(4):307-315, 1972.

[6] O Glatter and O Kratky, editors. Small angle x-ray scattering. Academic Press, London; New York, 1982.

[7] P Lindner and Th Zemb, editors. Neutrons, X-rays and light: scattering methods applied to soft condensed matter. Nort-Holland, 2002.

[8] EB Priestley, PJ Wojtowicz, and P Sheng. Introduction to Liquid Crystals. Plenum Press, 1974.

[9] RL Jones. Soft Condensed Matter. Oxford University Press, 2002.

[10] WC Preston. Some correlating principles of detergent action. The Journal of Physical and Colloid Chemistry, 52(1):84-97, 1948.

[11] JN Israelachvili. Intermolecular and surface forces, chapter 17, pages 375-377. Academic Press, 2 edition, 1992.

[12] C Tanford. The hidrophobic effect: formation of micelles and biological membranes. Wiley, 1980.

[13] J Charvolin, AM Levelut, and ET Samulski. Lyotropic nematics : molecular aggregation and susceptibilities. J. Phys. Lett.-Paris, 40(22):587-592, 1979. 
[14] F Fujiwara, LW Reeves, M Suzuki, and JA Vanin. Solution Chemistry of Surfactants, pages 63-77. Plenum Press, 1979.

[15] K Radley, LW Reeves, and AS Tracey. Effect of counterion substitution on the type and nature of nematic lyotropic phases from nuclear magnetic resonance studies. J. Phys. Chem., 80(2):174-182, 1976.

[16] LJ Yu and A Saupe. Observation of a biaxial nematic phase in potassium laurate-1decanol-water mixtures. Phys. Rev. Lett., 45(1000), 1980.

[17] KD Lawson and TJ Flautt. Magnetically oriented lyotropic liquid crystalline phases. Journal of the American Chemical Society, 89(21):5489-5491, 1967.

[18] P Tolédano and AM Figueiredo-Neto. Phase transitions in complex fluids. World Scientific, 1998.

[19] Y Galerne and JP Marcerou. Temperature behaviour of the order-paramenter invariants in the uniaxial and biaxial nematic phases of a lyotropic liquid crystal. Phys. Rev. Lett., 51(23):2109-2111, 1983.

[20] Y Galerne and JP Marcerou. Temperature-concentration behaviour of the order parameter in the nematic phases of a lyotropic liquid crystal. J. Phys. France, 46(4):589-594, 1985.

[21] MB Lacerda Santos, Y Galerne, and G Durand. Critical slowing down of biaxiality fluctuations at the uniaxial-to-biaxial phase transition in a lyotropic disklike nematic liquid crystal. Phys. Rev. Lett., 53(8):787-790, 1984.

[22] R Alben. Phase transitions in a fluid of biaxial particles. Phys. Rev. Lett., 30(778), 1973.

[23] MJ Freiser. Ordered states of a nematic liquid. Phys. Rev. Lett., 24(1041), 1970.

[24] PG deGennes and J Prost. The Physics of Liquid Crystals. Oxford University Press, 1993.

[25] EF Henriques, VB Henriques, and PR Krebs. Bimodal form distribution from modelling biaxial lyotropic liquid crystal solutions through a polydisperse maier-saupe model. $\mathrm{Li}$ quid Crystals, 44(3):510-525, 2017.

[26] E doCarmo, DB Liarte, and SR Salinas. Statistical models of mixtures with a biaxial nematic phase. Phys. Rev. E, 81, 2010.

[27] E doCarmo, AP Vieira, and SR Salinas. Phase diagram of a model for a binary mixture of nematic molecules on a bethe lattice. Physical Review E, 83(1), 2011.

[28] C Alves, JS Pedersen, and CLP Oliveira. Modelling of high-symmetry nanoscale particles by small-angle scattering. Journal of Applied Crystallography, 47(1):84-94, 22014. 
[29] C Alves, JS Pedersen, and CLP Oliveira. Calculation of two-dimensional scattering patterns for oriented systems. J. Appl. Crystallogr., 50, 2017.

[30] LQ Amaral, OR Santos, WS Braga, NM Kimura, and AJ Palangana. Biaxial phase and coexistence of the two uniaxial nematic phases in the system sodium dodecyl sulphatedecanol-d2o. Liq. Cryst., 42(2):240-247, 2015.

[31] PO Quist. First order transitions to a lyotropic biaxial nematic. Liq. Cryst., 18(4):623629, 1995.

[32] AG Oliveira-Filho, E Akpinar, D Reis, and AM Figueiredo Neto. A survey on the phase diagram of the system sodium dodecyl sulphate/1-decanol / 2 2o concerning an eventual coexistence of uniaxial nematic phases. Liquid Crystals, 2017.

[33] R Mahe. GeniX-3D - Installation and operation manual. Xenocs, 2014.

[34] BD Cullity. Elements of X-ray diffraction. Addison-Wesley, 1956.

[35] P Debye. Light scattering in solutions. Journal of Applied Physics, 15(4):338-342, 1944.

[36] P Debye and AM Bueche. Scattering by an inhomogeneous solid. J. Appl. Phys., 20, 518., 1949.

[37] P Debye. Zerstreuung von röntgenstrahlen. Annalen der Physik, 351(6):809-823, 1915.

[38] S Förster, A Timmann, M Konrad, C Schellbach, A Meyer, SS Funari, P Mulvaney, and Knott R. Scattering curves of ordered mesoscopic materials. J Phys Chem B, 109(4):1347-60, 2005.

[39] Freiberger $\mathrm{N}$ and Glatter O. Small-angle scattering from hexagonal liquid crystals. $J$. Phys. Chem. B, 110(30), 2006.

[40] RT Zhang, RM Suter, and JF Nagle. Theory of the structure factor of lipid bilayers. Phys. Rev. E, 50:5047-5060, 121994.

[41] K Huang. Statistical Mechanics. John Wiley \& Sons, 1987.

[42] L Landau and E Lifchitz. Physique Statistique, volume V of Physique Thérorique. Éditions Mir, 1967.

[43] VW Maier and A Saupe. Eine einfache molekulare theorie des nematischen kristallingflüssingen zustandes. Zeitschrift für Naturforschung A, 13A:564-566, 1958.

[44] PG deGennes. Short range order effect in the isotropic phase of nematics and cholesterics. Mol Cryst Liq Cryst, 12:193, 1971. 
[45] G Vertogen and WH deJeu. Thermotropic liquid crystals, fundamentals. Springer-Verlag, 1988.

[46] M Deutsch. Orientational order determination in liquid crystals by x-ray diffraction. Phys. Rev. A, 44:8264-8270, Dec 1991.

[47] AJ Leadbetter and EK Norris. Distribution functions in three liquid crystals from x-ray diffraction measurements. Mol. Phys., 38(3):669-686, 1979.

[48] B Bhattacharjee, S Paul, and R Paul. Orientational distribution function and order parameters of two 4'-alkoxy-4-cyanobiphenyls in mesomorphic phase. Molecular Crystals and Liquid Crystals, 89(1-4):181-192, 1982.

[49] BK Vainshtein. Diffraction of X-rays by chain molecules. Elsevier Publishing Company, 1966.

[50] BC McAlister and BP Grady. Simulation of small-angle x-ray scattering from singleparticle systems. J. Appl. Crystallogr., 31:594-599, 1998.

[51] BC McAlister and BP Grady. The use of monte-carlo simulations to calculate smallangle scattering patterns. Macromol. Symp., 190:117-129, 2002.

[52] H Goldstein. Classical Mechanics. Addison-Wesley, 2 edition, 1980.

[53] E Akpinar, D Reis, and AM Figueiredo Neto. Lyotropic mixture made of potassium laurate/1-undecanol/k2so4/water presenting high birefringences and large biaxial nematic phase domain: a laser conoscopy study. Eur. Phys. J. E, 35(50), 2012.

[54] Malik WU and Jain AK. Electrometric determination of critical micelle concentration of soap solutions. J. Electroanal. Chem., 14:37-41, 1967.

[55] Sidhardhan et al. Physico-chemical characterization and synthesis of potassium laurate as herbicides against moss. Int. J. Res. Chem. Environ., 2(4):306-309, 2012.

[56] E Akpinar, D Reis, and AM Figueiredo Neto. Effect of alkyl chain length of alcohols on nematic uniaxial-to-biaxial phase transitions in a potassium laurate/alcohol/k2so4/water lyotropic mixture. Liq. Cryst., 39(7):881-888, 2012.

[57] E Akpinar, M Turkmen, C Canioz, and AM Figueiredo Neto. Role of kosmotropechaotrope interactions at micelle surfaces on the stabilization of lyotropic nematic phases. Eur. Phys. J. E, 39(11):107, 2016.

[58] E Akpinar, C Canioz, M Turkmen, D Reis, and AM Figueiredo Neto. Effect of the surfactant alkyl chain length on the stabilization of lyotropic nematic phases. Liq. Cryst., 0:1-11, 2017. 
[59] F Brochard and PG deGennes. Theory of magnetic suspensions in liquid crystals. J. Phys. (France), 31:691-708, 1970.

[60] T Kroin, AJ Palangana, and AM Figueiredo Neto. Determination of the bend elastic constant and the anisotropy of diamagnetic susceptibility of lyotropic nematic calamitic liquid crystals. Phys. Rev. A, 1989.

[61] D Reis. Efeito do comprimento da cadeia do alcool nas transicoes de fase colestericacolesterica em cristais liliquidos liotropicos. Master's thesis, Instituto de Física - Universidade de São Paulo, 2013.

[62] AM Figueiredo-Neto. Estrutura e ordem local em cristais líquidos liotrópicos nemáticos uniaxiais e biaxial colestéricos. (Tese de livre docência.). PhD thesis, IF-USP, 1988.

[63] M Born and E Wolf. Optics of crystals. In Principles of Optics: Electromagnetic Theory of Propagation, Interference and Diffraction of Light, pages 790-852. Cambridge University Press, Cambridge, 101999.

[64] Erol Akpinar, Dennys Reis, Muhammet Yildirim, and Antônio Martins Figueiredo Neto. New Lyotropic Mixtures with Non-Chiral N-Acylamino Acid Surfactants Presenting the Biaxial Nematic Phase Investigated by Laser Conoscopy, Polarized Optical Microscopy and X-ray Diffraction. Materials, 7(6):4132-4147, June 2014.

[65] CLP Oliveira, T Vorup, CBF Aandersen, GR Andersen, and JS Pedersen. Applications of Synchrotron Light to Scattering and Diffraction in Materials and Life Sciences, chapter Discovering New Features of Protein Complexes Structures by Small-Angle X-Ray Scattering - Chap. 11, pages 231-44. Springer, 2009.

[66] J Kieffer and G Ashiotis. Pyfai: a python library for high performance azimuthal integration on gpu. ArXiv, 2014.

[67] EB Knudsen, HO Sørensen, JP Wright, G Goret, and J Kieffer. Fabio: easy access to two-dimensional x-ray detector images in python. Journal of Applied Crystallography, 46(2):537-539, Apr 2013.

[68] BJ Berne and R Pecora. Dynamic Light Scattering. Dover, 2000.

[69] Orsay Liquid Crystal Group. Dynamics of fluctuations in nematic liquid crystals. J. Chem. Phys., 51(2):816, 1969.

[70] WH DeJeu. Physical properties of liquid crystalline materials. Gordon and Breach, 1980.

[71] MB Lacerda Santos and G Durand. Order and micellar density fluctuations in the biaxial, uniaxial (nc and nd), and isotropic phases of a lyotropic nematic liquid crystal studied by light beating spectroscopy. J. Phys., 47(3):529-547, 1986. 
[72] E Akpinar, G Topcu, D Reis, and AM Figueiredo-Neto. Effect of the anionic azo dye sunset yellow in lyotropic mixtures with uniaxial and biaxial nematic phases. Journal of Molecular Liquids, 318, 2020.

[73] ZH Wang and PH Keyes. Critical and multicritical fluctuations of nematic liquid crystals. Physical Review E, 54(5):5249-5262, 1996.

[74] LQ Amaral. Micelles forming biaxial lyotropic nematic phases. Liquid Crystals, 37(67):627-640, 2010. 